DOE/MC/21023--3142

DE93 000230

\title{
Second-Generation Pressurized Fluidized Bed Combustion -- Small Gas Turbine Industrial Plant Study
}

\author{
Topical Report
}

\author{
J. Shenker \\ R. Garland \\ D. Horazak \\ F. Seifert \\ R. Wenglarz
}

Work Performed Under Contract No.: DE-AC21-86MC21023

\author{
For \\ U.S. Department of Energy \\ Ofince of Fossil Energy \\ Morgantown Energ Technology Center \\ P.0. Box 880 \\ Morgantown, West Virginia 26507-0880
Bj
Foster Wheeler Development Corporation
12 Peach Tree Hill Road
Livingston, New Jersey 07039

July 1992 


\section{ABSTRACT}

Second-Generation Pressurized Fluidized Bed Combustion (PFBC) plants provide a coal-fired, high-efficiency, combined-cycle system for the generation of electricity and steam. The plants use lime-based sorbents in PFB combustors to meet environmental air standards without back-end gas desulfurization equipment. The second-generation system is an improvement over earlier PFBC concepts because it can achieve gas temperatures of $2100^{\circ} \mathrm{F}$ and higher for improved cycle efficiency while maintaining the fluidized beds at $1600^{\circ} \mathrm{F}$ for enhanced sulfur capture and minimum alkali release.

Second-generation PFBC systems are capable of supplying the electric and steam process needs of industrial plants. The basic second-generation system can be applied in different ways to meet a variety of process steam and electrical requirements. To evaluate the potential of these systems in the industrial market, conceptual designs have been developed for six second-generation PFBC plants. These plants cover a range of electrical outputs from 6.3 to 41.5 inle and steam flows from 46,067 to $442,337 \mathrm{lb} / \mathrm{h}$.

Capital and operating costs have been estimated for these six plants and for equivalent (in size) conventional, coal-fired atmospheric fluidized bed combustion cogeneration plants. Economic analyses were conducted to compare the cost of steam for both the second-generation plants and the conventional plants. 


\section{ACKNOWLEDGMENTS}

This work was performed by Foster Wheeler Development Corporation (FWDC) as part of U.S. DOE Contract DE-AC21-86MC21023. Donald Bonk is the Contracting Officer's Technical Representative and Archie Robertson is the Program Manager for FWDC.

The work presented in this report was a combined effort of FWDC and three companies working under subcontracts to FWDC. The team member companies, their responsibilities, and key personnel are:

- Foster Wheeler Development Corporation-Overall direct of this task; conceptual design and cost estimating of the plant carbonizers, pressurized fluidized bed combustors, fluidized bed heat exchangers, gas cleanup equipment, and associated auxiliaries:

Jack Shenker, Principal Investigator James Van Hook

S. F. Wu

- Allison Gas Turbine Division-General Motors Corporation-Conceptual design and cost estimating of the gas turbines and topping combustors for the small plants:

Richard Wenglarz, Principal Investigator

Colin Wilkes

- Gilbert/Commonwealth. Inc.-Conceptual design and cost estimating of balance-of-plant-type components; overall plant layout, performance, design, and cost estimates of comparison plants; and economic analysis:

Dennis Horazak, Principal Investigator

Thomas Buchanan

Lynn Rubow

Frank Seifert

- Westinghouse Power Generation Business Unit-Conceptual design and cost estimating of the gas turbines and the topping combustors for the large plants.

Richard Garland, Principal Investigator editor.

The preparation of this report was coordinated by FWDC with Jean Rabe as

We thank them for their work on the project and their contribution to this report. 
Section

EXECUTIVE SUMMARY 1

Introduction 1

General Conclusions 2

Process Description 3

Plant Arrangements 4

Plant Design 5

Plant Costs and Economics 12

Section 1 INTRODUCTION 17

1.1 Study Objectives 17

1.2 Second-Generation PFB Combustion Technology 17

1.3 Industrial Market 18

1.4 Cases Studied 22

1.5 References 23

Section 2 PLANT SUBSYSTEMS AND ARRANGEMENTS 25

$2.1 \quad$ Process Description 25

2.2 Plant Arrangements 27

2.2.1 Possible Plant Arrangements 27

2.2.2 Plant Arrangements and Design Parameters 30

2.3 Feedstock Preparation and Feeding 46

2.3.1 Coal Handling System 46

2.3.2 Dolomite Handling System 50

2.3.3 Slurry System $\quad 54$

2.4 Carbonizer/PFBC Is and 50

2.4.1 Carbonizer Subsystem 54

2.4.2 PFBC Subsystem With CPFBC/FBHE Arrangement 61

2.4.3 PFBC Subsystem With Bubbling Bed Arrangement 69

2.5 Hot Gas Cleanup and Piping 79

2.5.1 Hot Gas Cleanup 79

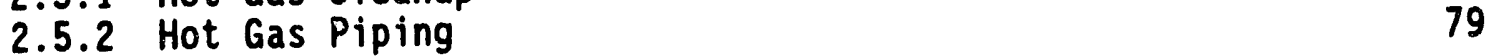


2.6 Westinghouse 151 Gas Turbine and Topping Combustor

2.6.1 Introduction

2.6.2 Development Path of the Model 151 Combustion Turbine

2.6.3 The Model 151 Adapted to Second-Generation PFBC

2.6.4 Conceptual Design and General Description of the MASB

2.6.5 Fuel System

2.6.6 Pressurized Fluidized Bed Combustor Bypass System

2.6.7 Installation of Model 151 With Topping Combustion

2.7 Allison 501 Gas Turbine and Topping Combustor . 101

2.7.1 Combustor and Turbine Skids 101

2.7.2 Topping Combustor

2.7.3 Gas Turbines

$\begin{array}{lll}2.8 & \text { Balance of Plant } & 115\end{array}$

2.8.1 Steam and Feedwater System 115

2.8.2 Make o Water System 117

2.8.3 Industrial Waste Treatment System 123

2.8.4 Ash and Spent Sorbent Removal System 125

2.8.5 Plant Electrical Equipment 127

2.9 References $\quad 135$

Section 3 PLANT COSTING BASIS 137

$\begin{array}{lll}3.1 & \text { Costing Parameters } & 137\end{array}$

$\begin{array}{lll}3.2 & \text { Capital Cost } & 138\end{array}$

3.2.1 Bare Erected Cost 138

3.2.2 Total Plant Cost 142

3.2.3 Capital Cost Estimate Exclusions 143

$3.3 \quad$ Operating Costs and Expenses 143

3.3.1 Operating Labor $\quad 144$

3.3.2 Maintenance 144

3.3.3 Consumables 145

3.4 References $\quad 146$

Section 4 INDUSTRIAL SECOND-gEMERATION PFBC PLANTS 147

4.1 Case 1: $353,000 \mathrm{lb} / \mathrm{h}$ Steam and $40 \mathrm{MW} \quad 148$

4.1.1 Plant Description 148

4.1.2 Plant Performance 152

4.1.3 Plant Capital Cost 157

4.1.4 Plant Operating Costs 157 
4.2 Case 2: $442,000 \mathrm{lb} / \mathrm{h}$ Steam and 20 MW 162

4.2.1 Plant Description 162

4.2.2 Plant Performance 166

4.2.3 Plant Capital Cost 171

4.2.4 Plant Operating Costs 171

4.3 Case 3: 46,000 1b/h Steam and 6 MW 176

4.3.1 Plant Description 176

4.3.2 Plant Performance 180

4.3.3 Plant Capital Cost 185

4.3.4 Plant Operating Costs. 185

4.4 Case 4: 75,000 lb/h Steam and $9 \mathrm{MW} \quad 190$

4.4.1 Plant Description 190

4.4.2 Plant Performance 194

4.4.3 Plant Capital Cost 199

4.4.4 Plant Operating Costs 199

4.5 Case 5: 86,000 $\mathrm{lb} / \mathrm{h}$ Steam and $7 \mathrm{MW} 204$

4.5.1 Plant Description 204

4.5.2 Plant Performance 208

4.5.3 Plant Capital Cost 213

4.5.4 Plant Operating Costs 213

4.6 Case 6: 73,000 7b/h Steam and 9 MW 218

4.6.1 Plant Description 218

4.6.2 Plant Performance 222

4.6.3 Plant Capital Cost 227

4.6.4 Plant Operating Costs 227

Section 5 COMPARISON CASES 233

5.1 Comparison: Large AFBC 234

5.1.1 Plant Description 234

5.1.2 Plant Performance 235

5.1.3 Plant Capital and Operating Costs 237

5.2 Comparison: Large AFBC--Cogeneration 240

5.2.1 Plant Description $\quad 240$

5.2.2 Plant Performance 241

5.2.3 Plant Capital and Operating Costs 243 
Section

5.3 Comparison: Large Gas Turbine Cogeneration

5.3.1 Plant Description

5.3.2 Plant Performance

5.3.3 Plant Capital and Operating Costs

5.4 Comparison: Small AFBC

5.4.1 Plant Description

5.4.2 Plant Performance

5.4.3 Plant Capital and Operating Costs

5.5 Comparison: Small AFBC Cogeneration 256

5.5.1 Plant Description $\quad 256$

5.5.2 Plant Performance $\quad 256$

5.5.3 Plant Capital and Operating Costs 250

5.6 Comparison: Small Gas Turbine Cogeneration 260

5.6.1 Plant Description 260

5.6.2 Plant Performance 260

5.6.3 Plant Capital and Operating Costs 260

5.7 References $\quad 264$

Section 6 COMPARISON OF ALTERHATIVE CASE ECONOMICS 265

6.1 General Assumptions 265

$6.2 \quad$ Capital Costs $\quad 266$

6.3 Operating Expenses 266

6.3.1 Operating and Maintenance Expenses 2.66

6.3.2 Purchased Power Costs 267

6.3.3 Income Tax Effects 268

6.4 Evaluations, Comparisons, and Sensitivity Analyses 268

6.4.1 Evaluations and Comparisons

6.4.2 Sensitivity Analyses

Section 7 RESEARCH AND DEVELOPNENT ISSUES 289

Section 8 CONCLUSIONS 295

Appendix A EMISSIONS A-1

A.1 Sulfur $\quad A-1$

A.2 NO $\quad A-2$

A.3 References $\quad$ A-3 
1 Summary of Plant Parameters $\quad 6$

2 Summary of Results $\quad 15$

$3 \quad$ Plant Operating Parameters 31

4 Steam Generator Pressure Parts-Case 1 71

$5 \quad$ PFBC Steam Generator Pressure Parts--Case $4 \quad 78$

6 Cross-Flow Filter Design Data $\quad 80$

7 Carbonizer Hot Gas Piping $\quad 81$

8 CPFBC Hot Gas Piping $\quad 82$

9 Initial W251 Engine Configuration $\quad 84$

10 Model 151 Performance at ISO Conditions $\quad 85$

11 Power Skid Equipment 109

12 Plant Nitrogen Requirements 123

13 Motor Voltage Rating and Power Supply Service 133

14 Code of Direct Accounts Summary 140

15 Plant Summary Performance Data--Case 1

16 Auxiliary Summary--Case 1

17 Heat Exchanger Performance--Case 1 154

18 Heat and Material Balance--Case 1

19 Total Plant Cost Summary--Case 1

20 Annual Operating Costs--Case $1 \quad 161$

21 Plant Summary Performance Data--Case $2 \quad 167$

22 Auxiliary Summary--Case $2 \quad 167$

23 Heat Exchanger Performance--Case 2

24 Heat and Material Balance--Case $2 \quad 169$

25 Total Plant Cost Summary--Case 2

26 Annual Operating Costs--Case 2

27 Plant Summary Performance Data--Case $3 \quad 181$

28 Auxiliary Summary--Case $3 \quad 181$

29 Heat Exchanger Performance--Case 3

30 Heat and Material Balance--Case $3 \quad 183$

31 Total Plant Cost Summary--Case $3 \quad 187$

32 Annual Operating Costs--Case $3 \quad 189$

33 Plant Summary Performance Data--Case 4

34 Auxiliary Summary--Case 4 
Tables (Cont)

Number

Page

35 Heat Exchanger Performance--Case 4

36 Heat and Material Balance--Case 4

37 Total Plant Cost Summary--Case 4

38 Annual Operating Costs--Case 4

39 Plant Sumnary Performance Data--Case 5

40 Auxiliary Summary--Case $5 \quad 209$

41 Heat Exchanger Performance--Case $5 \quad 210$

42 Heat and Material Balance--Case 5

43 Total Plant Cost Summary--Case 5

44 Annual Operating Costs--Case 5

45 Plant Summary Performance Data--Case 6

46 Auxiliary Summary--Case $6 \quad 223$

47 Heat Exchanger Performance--Case $6 \quad 224$

48 Heat and Material Balance--Case $6 \quad 225$

49 Total Plant Cost Summary--Case 6

50 Annual Operating Costs--Case 6

51 Installed Capital Costs--Comparison Cases 233

52 Summary Performance Data--Large AFBC 236

53 Auxiliary Summary--Large AFBC 236

54 Installed Capital Cost--Large AFBC 238

55 Annual Operating Costs--Large AFBC 239

56 Summary Performance Data--Large AFBC Cogeneration 242

57 Auxiliary Summary--Large AFBC Cogeneration 242

58 Installed Capital Cost--Large AFBC Cogeneration 244

59 Annual Operating Costs--Large AFBC Cogeneration 245

60 Summary Performance Data--Large Gas Turbine Cogeneration 248

61 Installed Capital Cost--Large Gas Turbine Cogeneration 249

62 Annual Operating Costs--Large Gas Turbine Cogeneration 250

63 Summary Performance Data--Small AFBC 252

64 Auxiliary Summary--Small AFBC 252

65 Installed Capital Cost--Small AFBC 254

66 Annual Operating Costs--Small AFBC Boiler 255

67 Summary Performance Data--Small AFBC Cogeneration 257

68 Auxiliary Summary--Small AFBC Cogeneration 257

69 Installed Capital Cost--Small AFBC Cogeneration 258 
70 Annual Operating Costs--Small AFBC Cogeneration

71 Summary Performance Data--Small Gas Turbine Cogeneration

72 Installed Capital Cost--Small Gas Turbine Cogeneration 262

73 Annual Operating Costs--Small Gas Turbine Cogeneration 263

74 Baseline Assumptions 265

75 Summary of Capital Costs for Study Cases 266

76 Operating Expense Criteria $\quad 266$

77 Components of Typical Rate Schedules 267

$78 \quad$ Large Plant Input Assumptions and First Year 0\&M Expenses 269

79 Small Plant Input Assumptions and First Year 0\&M Expenses 271

80 Large Plant Comparative Costs 273

81 Small Plant Comparative Costs $\quad 275$

82 Summary of Results 278

83 Unit Cost of Steam With Income Tax Effect 279

84 Unit Cost of Steam Without Income Tax Effect 280

85 Summary of Results Under Various Purchased Power Rate 284

86 Capital Cost Reductions Required To Achieve Equivalent Steam Costs

87 Second-Generation PFBC R\&D Needs 291

A.1 Plant Sulfur Emissions A-1

A.2 PFB Combustor $\mathrm{NO}_{x}$ Emissions A-3

A.3 Topping Combustor $\mathrm{NO}_{\mathrm{x}}$ Emissions A-3 
1 Second-Generation PFBC System Process Flow Diagram

2 Heat and Material Balance--Case 1

3 Case 1 Plant--Elevation View 9

4 CPFBC/FBHE/Cyclone/Barrier Filter--Elevation View 11

5 Case 4 Plant--Elevation View 13

6 Basic Second-Generation PFB Combustion System--Process Flow Diagram

7 Electrical Demand vs. Steam Demand--Paper, Chemical, and Petroleum Plants

8 Fossil-Fuel-Fired Nonutility Generating Projects 21

9 Foster Wheeler Smaller Boiler Sales 22

10 Carbonizer Mass Flow Balance 26

11 Arrangement With Additional Coal Firing in PFBC 28

12 Arrangement With Adiabatic Bed 29

13 Arrangement With Air Bypassing Around PFBC 29

14 Arrangement With Natural-Gas Firing in Topping Combustor 30

15 Site Plan $\quad 35$

16 Site Plan at Grade and Operating Floor 37

17 Section A-A--Elevation View 41

18 Section B-B--Elevation View 43

19 Coal Yard Flow Diagram 48

20 Coal Preparation System $\quad 49$

21 Coal Handling System--Cases 3, 4, 5, and 6

22. Dolomite Handling System 53

23 Slurry System Schematic $\quad 55$

24 Carbonizer Subsystem--Plan and Elevation Views 57

25 Carbonizer Dimensions $\quad 58$

26 Carbonizer Cyclone $\quad 59$

27 Carbonizer Collecting Hopper--Cases 1, 2, and $3 \quad 60$

28 Carbonizer Collecting Hopper--Cases 4 and $5 \quad 62$

29 CPFBC/FBHE Arrangement $\quad 63$

30 Circulating PFB Combustor Vessel--Cases 1 anó 2

31 CPFBC Cyclone--Cases 1 and $2 \quad 66$

$\begin{array}{lll}32 & \text { FBHE--Case } 1 & 67\end{array}$ 
Figures (Cont)

Number

Page

33 Solids Flow Through FRHE 69

34 Steam Circuitry--Case $4 \quad 70$

35 PFBC--Case $3 \quad 73$

36 PFBC--Case $4 \quad 75$

37 Steam Circuitry--Case 4

38 Model 151 With External Combustion System Adapted to Blast Furnace Operation $\quad 86$

39 Model 151 With External Topping Combustion System Adapted to Second-Generation PFBC 87

40 Airflow Patterns Within the MASB 88

41 Velocity Cnaracteristic of Free and Forced Vortex Flow 91

42 Conceptual Layout of MASB $\quad 91$

43 MASB Mechanical Design and Installation 96

44 Fuel Gas System Schematic $\quad 97$

45 Conceptual Arrangement--PFBC Bypass System 98

46 Schematic Arrangement--PFBC Bypass System 98

Conceptual Layout--Model 151 With External Topping Combustor
and PFBC Valving

48 Conceptual Leyout--Model 151 Combustion Turbine Generator 105

49 Power System/Combustion System Skids 107

$50 \mathrm{RQL}$ Lean-Zone Enissions From Coal/Water Slurry--CO vs. $\mathrm{NO}_{x}$ Corrected to 15-Percent Exhaust $\mathrm{O}_{2}$

111

51 RQL Topping Combustor for Smaller Second.Generation PFBC Cogeneration Systems

52 Schematic of Flows to Rich, Quench, Lean, and Dilution Zones of Topping Combustor

53 RQL Topping Combustor--Cross Section 113

54 Model 510 KM Turbine 114

55 Internal Duct in Center Section of Model 501 KM Turbine 114

56 Demineralized Water System 119

57 Compressed Air System 121

58 Ash Handling System 126

59 One-Line Electrical Diagram 129

60 Components of Capital Costs 139

61 Heat and Material Balance--Case $1 \quad 149$

62 Heat and Material Balance--Case 2 
Figures (Cont)

Number

63 Heat and Material Balance--Case 3

64 Heat and Material Balance--Case 4

65 Heat and Material Balance--Case 5

66 Heat and Material Balance--Case 6

67 Process Flow Diagram--Large AFBC 234

68 Process Flow Diagram--Large AFB Cogeneration 240

69 Process Flow Diagram--Large Gas Turbine Cogeneration 246

70 Cost of Steam From Alternative Sources At Various Plant Operating Factors--Large Plants

71 Cost of Steam From Alternative Sources At Various Plant Operating Facters--Small Plants

282

72 Cost of Steam From Alternative Sources With Purchased Power Costs Calculated Under Three Alternative Utility Rate Structures 285

73 Cost of Steam From Alternative Sources at Various Coal cost Levels--Large Plants

74 Cost of Steam From Alternative Sources at Various Coal cost Leveis--Small Plants 


$\begin{array}{ll}\text { ANSI } & \text { American National Standards Institute } \\ \text { A/E } & \text { Architect/Engineer } \\ \text { AFBC } & \text { Atmospheric Fluidized Bed Combustor } \\ \text { CF } & \text { Capacity Factor } \\ \text { CPFBC } & \text { Circulating Pressurized Fluidized Bed Combustor } \\ \text { FBHE } & \text { Fluidized Bed Heat Exchanger } \\ \text { FBN } & \text { Fuel-Bound Nitrogen } \\ \text { FWDC } & \text { Foster Wheeler Development Corporation } \\ \text { HGCU } & \text { Hot Gas Cleanup } \\ \text { HRSG } & \text { Heat-Recovery Steam Generator } \\ \text { LHV } & \text { Lower Heating Value } \\ \text { MASB } & \text { Multiannular Swirl Burnel } \\ \text { NSPS } & \text { New Source Performance Standards } \\ \text { OJ } & \text { Operating Jobs } \\ \text { OLC } & \text { Operating Labor Charge } \\ \text { PFB } & \text { Pressurized Fluidized Bed } \\ \text { PFBC } & \text { PFB Combustor } \\ \text { RPD } & \text { Restricted Pipe Discharge } \\ \text { RQL } & \text { Rich-Quench-Lean } \\ \text { TAG } & \text { EPRI Technical Assessment Guide } \\ \text { TEFC } & \text { Totally Enclosed, Fan Cooled } \\ \text { TENC } & \text { Totally Enclosed, Noncooled } \\ \text { TPC } & \text { Total Plant Cost }\end{array}$




\section{INTRODUCTION}

In this study, part of U.S. DOE Contract DE-AC21-86MC21023, Foster wheeler Development Corporation (FWDC) and subcontractors are conducting the research and development necessary to commercialize the second-generation Pressurized Fluidized Bed (PFB) Combustion system. It is a totally coal-fired system that can achieve state-of-the-art gas turbine inlet temperatures while maintaining the fluidized beds at the lower temperatures required for efficient sulfur capture. Tilis result is accomplished by pyrolyzing part or all of the coal to form fuel gas and char. The char, and sometimes additional coal, is then burned in a separate fluidized bed. The fuel gas and the products of char and coal combustion are then combined in a topping combustor, where the gas temperature is raised to the gas turbine inlet conditions. A conceptual design study of a utility-size second-generation system ( 450 MWe) has been part of this contract, and the economics of a system of this size have been determined favorable. The objectives of this study were to determine:

- The technical feasibility of applying the second-generation PFB combustion system to smaller gas turbine sizes in industrial cogeneration plants

- The economic feasibility of the second-generation PFB combustion system for these plants

- The technological gaps that would impede the implementation of secondgeneration PFB combustion systems for these industrial plants.

The approach was to develop conceptual designs for several industrial-size second-generation PFB combustion plants and to prepare an economic enalysis of these plaits relative to conventional cod- and gas-fired cngeneration systems. Six cases were selected for study. Two of the cases, referred to as the large plants, were based on a 21-me Westinghouse 151 gas turbine. These plants would be built for a large industrial user, and they were designed for maximum steam generation. The four remaining plants were based on two, parallel, 3.5-MWe Allison 501 gas turbines. These plants, referred to as the small plants, were designed for minimum physical size, minimum capital cost, and simple operation. One of the small plants is a $1-1 / 2$ generation plant that uses natural gas in the topping combustor instead of generating fuel gas from the coal. When the six cases are referred to collectively, the term "secondgeneration systems" is used, even thoug'n one case is actually a 1-1/2 generation system.

\footnotetext{
A. Robertson, et al., "Second-Generation Pressurized Fluidized Bed Combustion Plant: Conceptual Design and Optimization of a Second-Generation PFB Combustion Plant," Phase 1 Task 1 report to the DOE (Contract Di-AC21-86MC21023), September 1989.
} 
The analysis has shown that it is possible to extend the second-generation system to the 7-MWe size for industrial cogeneration. Most of the technological concerns for these industrial-size plants are the same as those determined for the utility size plant--the subject of research and development efforts now under way. There are some areas of design not covered by the current research that would be of concern to industrial users. Although not critical to the technical success of the plant, these concerns would affect acceptance by users in the industrial sector because of cost and operating considerations. For example:

- Industrial users would be less likely than utilities to have long-term fuel contracts; therefore, the effects of coal variation on plant operation are important and would require research beyond that currently planned in this area.

- The smaller plants in the present study were designed with bubbling bed PF8 combustors (PFBCs) instead of the circulating beds used in the larger plants and in the utility study. This choice was made to reduce costs and plant height requirements. Research would be desirable to determine certain design parameters for a char-fired bubbling bed. The parameters would include the number of feed points and the bed geometry required for complete combustion of the char.

- Slurry feed systems for the coal and sorbent have the potential for reducing capital and operating costs. Although the feasibility of feeding coal and sorbent to a PFBC has been demonstrated, long-term reliability of this feeding method needs to be demonstrated.

- Turrodown in indusirial plants has an added dimension over utility plants in that demand varies for both eiectricity and process steam. The investigation of various turndown schemes would be of interest to industrial users. This work would prebably best be accomplished with computer models of the systews that would give quantitative information on inputs and outputs at partial-load operation.

An economic analysis compared the plants developed in this study with conventional cogeneration systems that have comparable steam outputs. The following assumptions were made:

- All the electricity generated by the various systems could be uset within the facility.

- Differences between the electrical outputs of the different systems would have to be satisfied with purchased power.

Assuming a 20-year plant life and costs typical of an Ohio Valley location, the resultant cost of steam was calculated for the study cases and the comparison plants.

Under the base-case cost assumptions, the lowest cost of steam in the larger plant category was the Atmospheric Fluidized Bed Combustor (AFBC) cogeneration comparison plant. The lowest cost of steam in the smaller plants would be achieved with a conventional natural-gas-fired gas turbine cogeneration system. However, higher electric rates for purchased power lower the cost of steam for the second-generation system relative to the other options; how the effects of income tax are considered in the economic analysis also affect the 
relative cost of steam between ire second-generation plants and the comparison plants. With other electric utility rate structures in the Ohio area and different treatment of the effect of income tax, the second-generation system becomes the option with the lowest cost of steam in the larger plant sizes. In the smaller plant sizes, the conventional gas turbine cogeneration system remains the lowest cost of steam option--even at the higher electric rates used in this study.

An increase in the size of the plants will tend to benefit the economics of the second-generation system vs. the alternative systems because the secondgeneration systems have higher capital costs than alternative cogeneration systems. As the size of the plants increases, capital costs do not increase as much as the output of electricity and steam. For example, the cost of such systems as coal handling and slurry feeding decreases on a pound-of-coal basis as the plant coal flow increases. The effect on other capital equipment is similar.

The larger plants in this study appear to be a borderline size where the second-generation system may or may not be the best option, depending on the specific costs of a user. As the size increases, the cost scenarios under which the second-generation system results in the lowest cost of steam will become more numerous. There are certainiy electric rates in different parts of the country that are as high or higher than $7.60 \mathrm{t} / \mathrm{kWh}$. At these rates the second-generation system would be of benefit even at the 41 -MWe size.

\section{PROCESS DESCRIPTION}

A process flow diagram showing the basic arrangement of the second-generation PFBC system is shown in Figure 1. Although this arrangement can be modified to achieve different objectives, the most general arrangement is shown in the figure. Crushed coal and sorbent are mixed with water to form a slurry with 70-percent solids and 30-percent water. This fuei/sorbent slurry is fed to the carbonizer subsystem. In this subsystem, the coal is pyrolyzed into lowBtu fuel gas and char. Pyrolysis is accomplished in a jetting, adiabatic fluidized bed that is maintained at $1600^{\circ} \mathrm{F}$. The fuel gas leaving the carbonizer is cleaned of particulates by passing it through a cyclone and then a barrier filter. The solids from the carbonizer, including char, sorbent, and ash, are fed to the PFBC.

The combustor can be either a Circulating Pressurized Fluidized Bed Combustor (CPFBC) with a Fluidized Bed Heat Exchanger (FBHE), as shown in Figure 1, or a bubbling bed with or without heat-transfer surface in the bed. Char is burned in the CPFBC shown in Figure 1. Coal can also be fired in the CPFBC, along with the char from the carbonizer, if more steam generation is required. The CPFBC is maintained at $1600^{\circ} \mathrm{F}$ by transferring heat to the steam cycle in the FBHE. The flue gas from the CPFBC is cleaned of particulates in a cyclone and barrier filter before it enters the topping combustor.

Fuel gas from the carbonizer and flue gas from the CPFBC combine in the topping combustor, where combustion of the fuel gas takes place and the gas temperature is raised to the gas turbine inlet temperature. The gas turbine iniet temperature for the larger plants in this study is $1950 \circ$. The smaller plants have an inlet temperature of $1977^{\circ} \mathrm{F}$. The gas leaves the gas turbine through a Heat Recovery Steam Generator (HRSG), where additional heat is transferred to the steam cycle. 


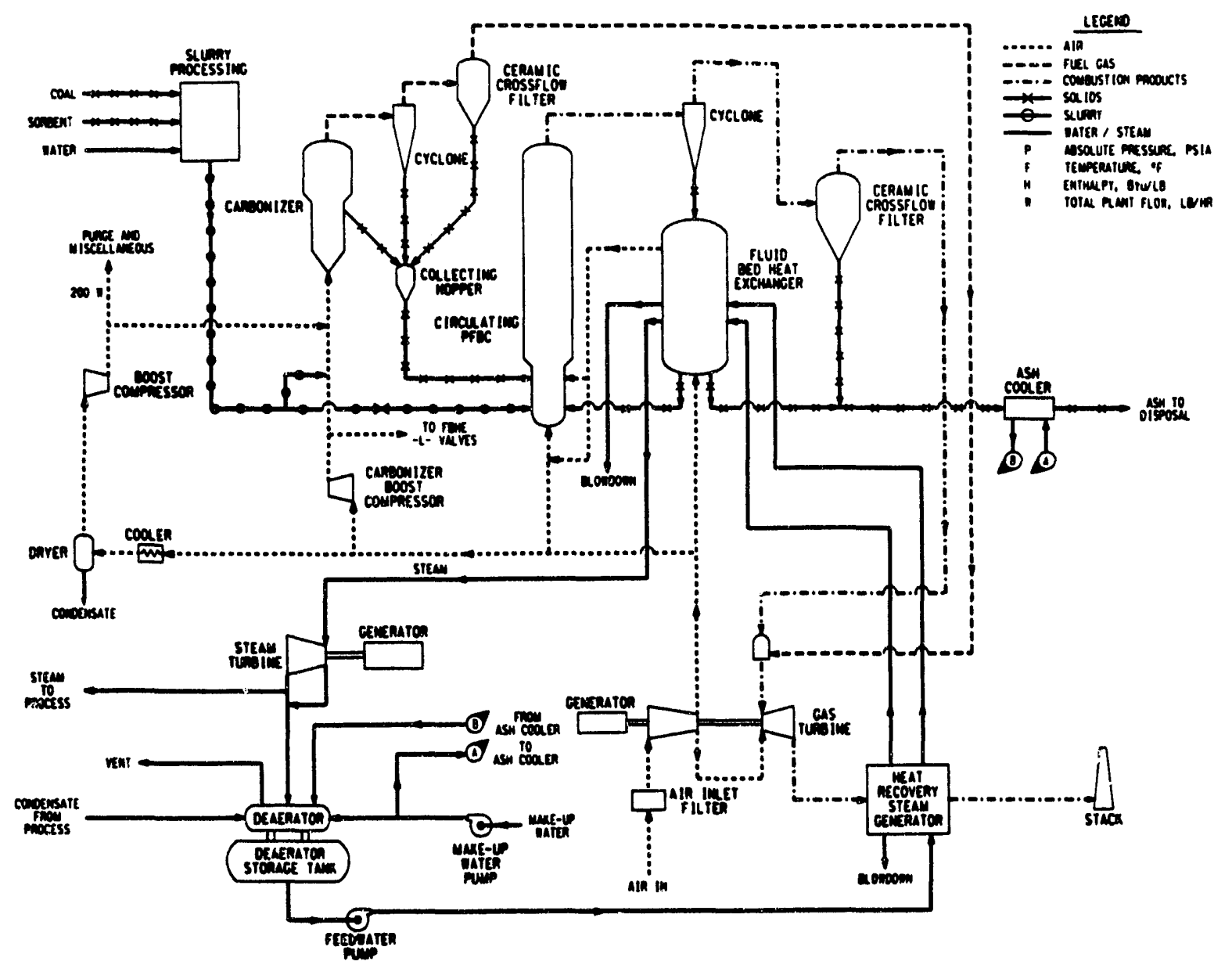

Figure 1 Second-Generation PFBC System Process Flow Diagram

\section{PLAN ARPAKGEMHFITS}

The basic arrangement shown in Figure 1 can be mindified to achieve specific objectives, as was done for the different study cases. Case 1 uses the system as it is shiown in Figure 1 . It is based on a Westinghouse 151 gas turbine generating 21 MWe. This case uses maximum firing of coal in the CPFBC to achieve the greatest steam generation. Steam generated at $1200 \mathrm{psig} / 950^{\circ} \mathrm{F}$ drives a back-pressure turbine before going to the process at $150 \mathrm{psig.} \mathrm{The}$ combined electrical generation of this plant is 41.5 mWe, and it ger.arates $353,477 \mathrm{lb} / \mathrm{h}$ process steam.

Case 2 is basically the same as Case 1, except there is no steam turbine. All the steam is generated at the process condition of 150 psig saturated. The electrical power generation in Case 2 is 21.2 MWe, and the process steam flow is $442,337 \mathrm{lb} / \mathrm{h}$.

Cases 3, 4, 5, and 6 are based on two Allison 501 gas turbines operating in paralle1. Case 3 has a jetting, adiabatic PFB combustor instead of the CPFBC and FBHE. In this case, no heat is transferred to the steam cycle in the combustor. Sufficient excess air in the combustor maintains a $1600^{\circ} \mathrm{F}$ bed temperature without heat-transfer surface in the bed. Only char is fired in the PFB combustor. Process steam at 150 psig is generated in an HRSG. By arranging the plant in this manner, the capital cost of the PFBC is lowered, and its operation is simplified. The electrical power generated in Case 3 is 6.3 MWe, and the process steam flow is $46,067 \mathrm{lb} / \mathrm{h}$. 
Case 4 uses a bubbling bed PFBC with heat-transfer surface in the bed. Only char is fired in the PFBC. Air is bypassed around the PFBC and fed directly to the topping combustor. This arrangement reduces the size of the hot gas cleanup equipment for the PFBC and generates more steam than in Case 3 Steam is generated at $700 \mathrm{psig} / 750^{\circ} \mathrm{F}$, and the steam drives a back-pressure $t$ irbine before becoming process steam at $150 \mathrm{psig.} \mathrm{The} \mathrm{electrical} \mathrm{power} \mathrm{generation}$ with this arrangement is 9.0 MWe, and the process steam flow is $74,819 \mathrm{lb} / \mathrm{h}$.

Case 5 is the same as Case 4 except that the steam is generated at the process conditions of 150 psig saturated. The resultant electrical power generation is 7.1 MWe, and the steam flow is $86,018 \mathrm{lb} / \mathrm{h}$.

Case 6 is a 1-1/2 generation system. There is no carbonizer in this arrangement. Instead, natural gas is fired in the topping combustor to raise the gas temperature to the gas turbine inlet temperature. Coal is fired in a bubbling bed PFBC, and steam is generated in the bed. Air is al so bypassed around the PFBC in this arrangement to reduce the size of the PFBC hot gas cleanup equipment. Steam is generated at $700 \mathrm{psig} / 750^{\circ} \mathrm{F}$, and the steam drives a backpressure turbine before becoming process steam at 150 psig. The electrical power generation is 8.8 MWe, and the process steam flow is $72,863 \mathrm{lb} / \mathrm{h}$.

The major operating parameters for the different study cases are listed in Table 1. Process flow, including flow stream information for the Case I system, is iliustrated in Figure 2. This diagram shows and quantifies all the flow streams.

\section{PLANT DESIGN}

The plants were designed to be additions to existing industrial plants, which themselves were designed to be typical of a large industrial facility such as a pulp and paper mili, steel mill, chemical process plant, or refinery. Some of the key assumptions in the development and analysis of the secondgeneration systems and the comparison systems are:

- The new steam plant is necessary because of additional process steam requirements.

- The new plant adds less than 20 percent to the existing steam generating capacity.

- The power generated will be used within the plant.

An elevation view of the Case 1 second-generation system is shown in Figure 3. This figure illustrates the relative size and arrangement of the various components. The CPFBC, FBHE, cyclone, and barrier filter are shown with dimensions in Figure 4. Final fabrication of the FBHE and barrier filter vessels will be done in the field for the Case 1 system. The steam pressure parts of the FBHE will be fabricated in a shop and shipped to the field as a completed unit. The FBHE pressure vessel sections will then be assembled in the field.

"These diagrams are provided for all the cases in Section 5 of the main report. 


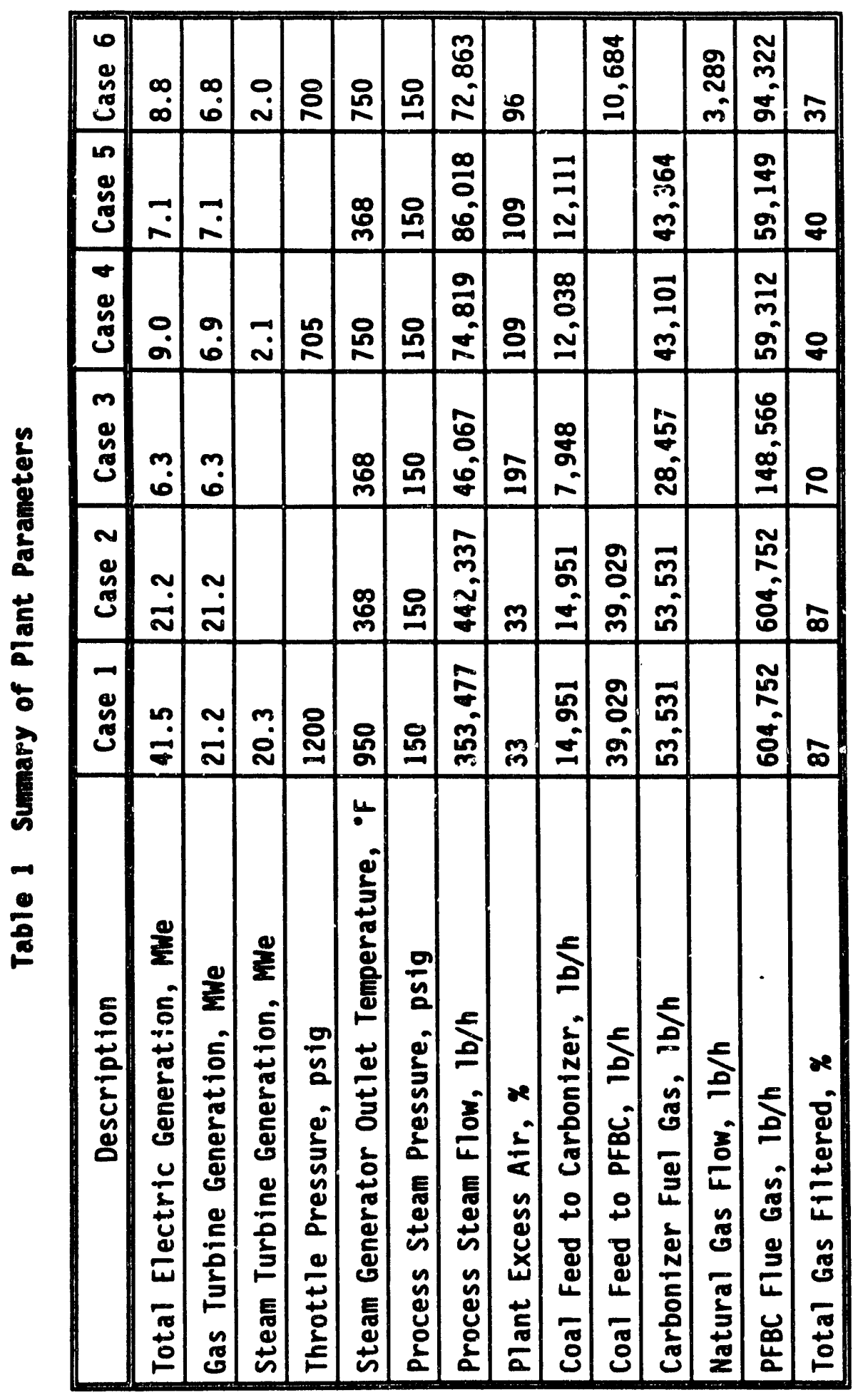




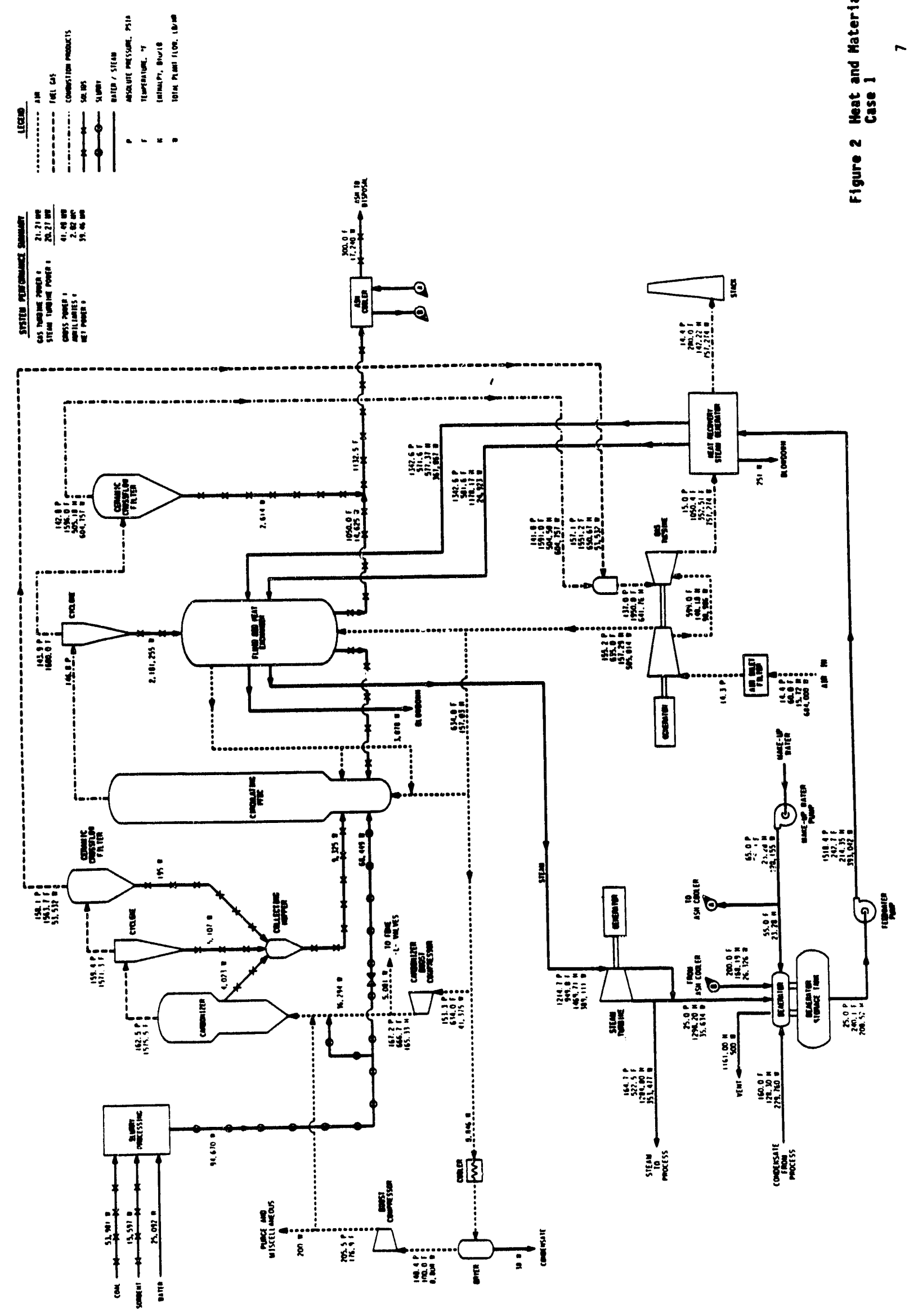




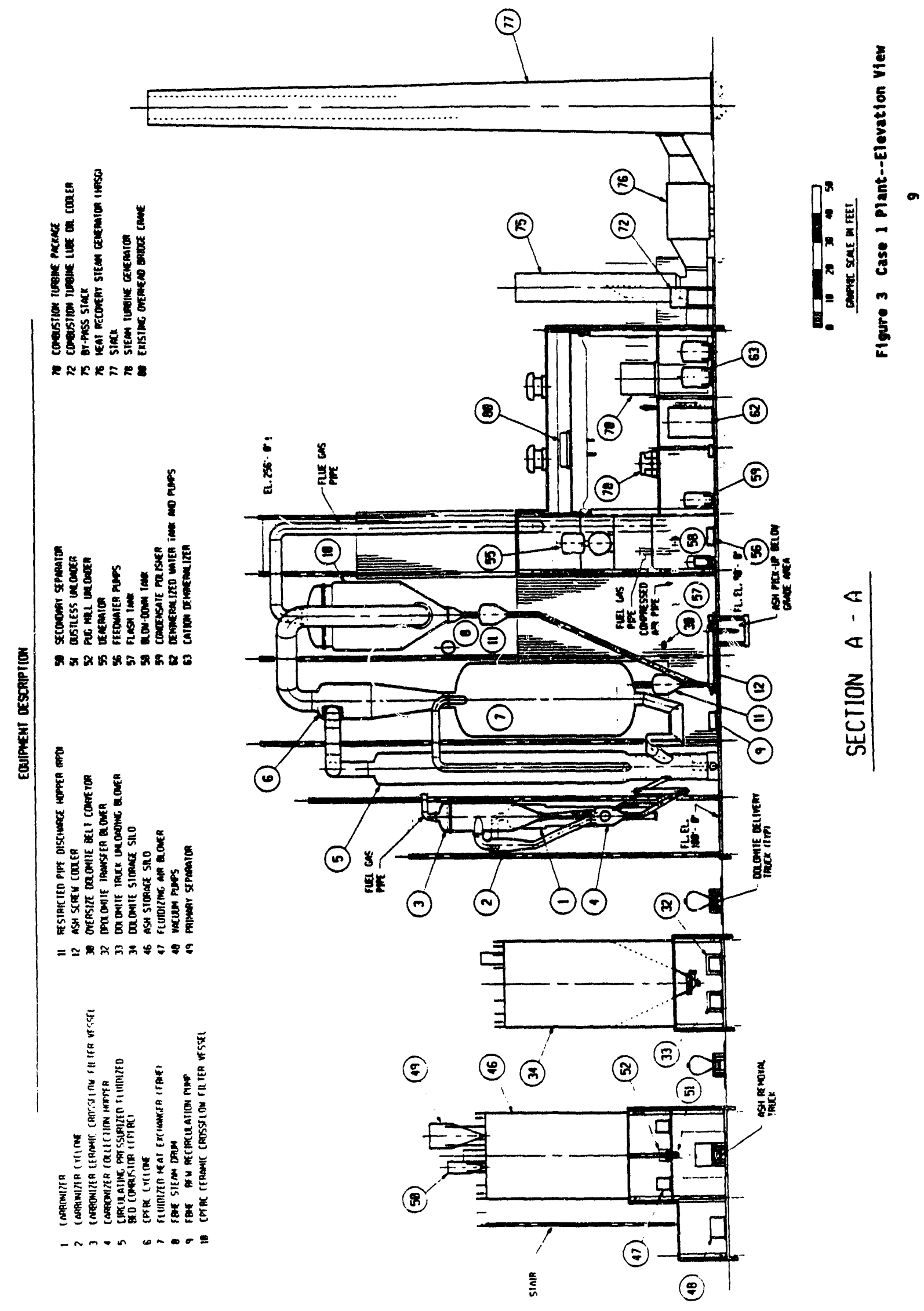




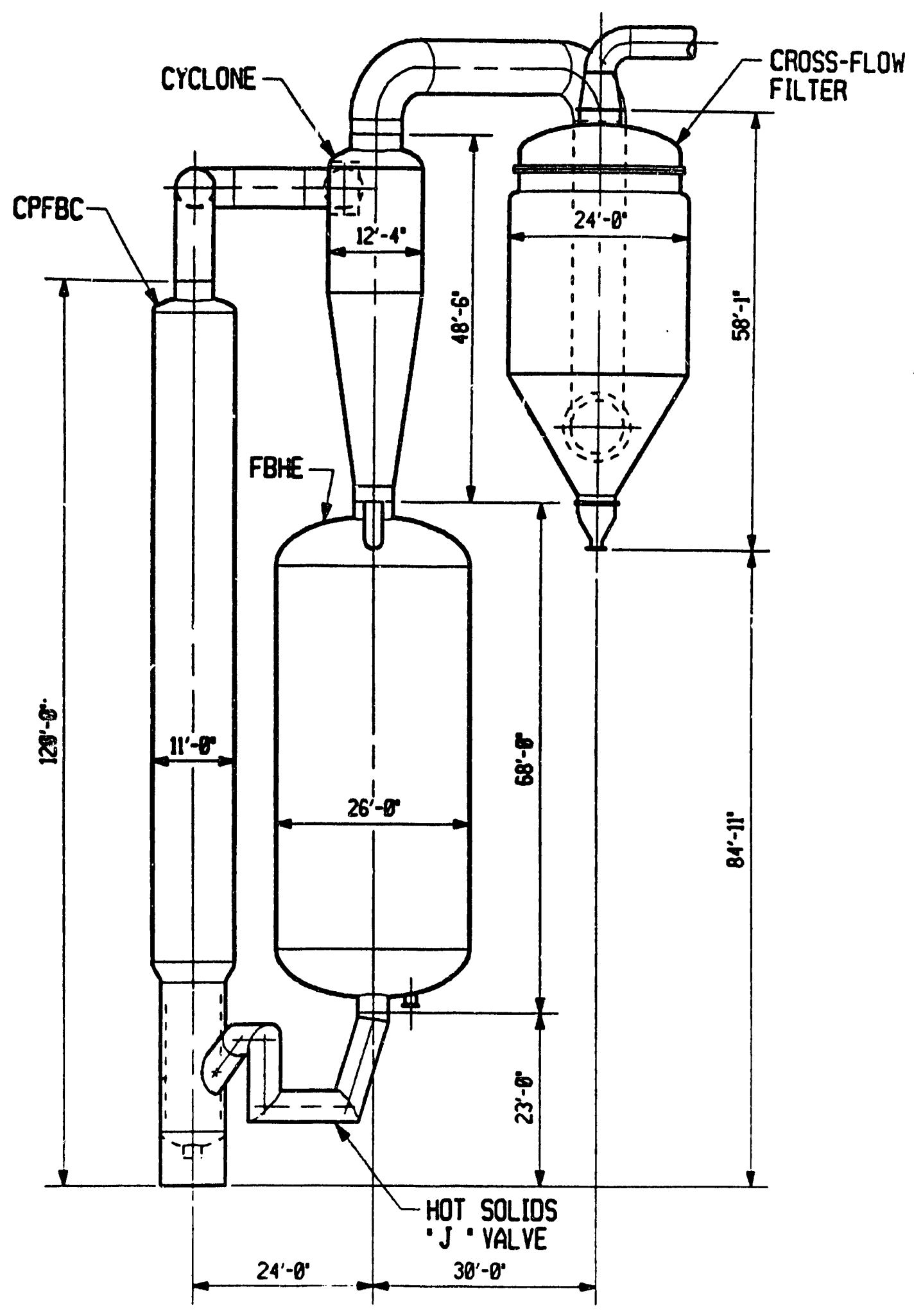

Figure 4 CPFBC/FBHE/Cyclone/Barrier Filter--Elevation View 
An elevation view of the Case 4 system is shown in Figure 5 . The components included in this system are mostly the same as for Case 1, but the sizes of the components and their relative sizes are different. The change in relative size of the components results from the differences in the way the secondgeneration system was configured. In the Case 1 arrangement, all the vitiated air goes through the CPFBC, and coal is fired along with the char. Case 4 uses a bypass arrangement, where a large proportion of the air goes directly from the turbine compressor to the topping combustor. No coal is fired in the Case 4 PFBC, but carbonizer fuel and char output are a greater portion of the plant thermal output. The lower airflows in the Case 4 PFBC make a bubbling bed more suitable than a CPFBC and greatly reduce the size of the PFBC hot gas cleanup equipment. The carbonizer and its hot gas cleanup equipment are relatively larger in the Case 4 system than in the Case 1 system.

\section{PLANT COSTS AND ECONOMICS}

Capital and operating costs were developed for the six second-generation systems studied. Comparison case designs were cost estimated and analyzed in the same manner as for the secund-generation cases. The comparison cases were an AFBC boiler system with no electric power generation, an AFBC cogeneration system, and a gas turbine cogeneration system fired with natural gas. Two sets of comparison plant designs were devaloped. One set has approximately the same steam output as the smaller plants, and the other set has steam outputs approximately the same as in the larger plants.

Because the characteristics of the various second-generation plants and comparison plants differ, the electrical outputs of the plants vary considerably. The electrical outputs of the Case 1 and Case 4 second-generation systems were assumed to be the required electrical outputs for the large and smali plants respectively. Plants that do not produce as much electric power as these plants have an expense for purchased power equivalent to the difference between their electric output and the output of Case 1 or Case 4.

The economic comparison of the various plants was done on the basis of the cost of steam. The cost of steam for each of the plants was determined by calculating the levelized cost of the capital investment, fixed costs, and operating expenses. The total of these three costs represents the total levelized operating expenses for each of the plants--the combined cost of electricity and steam. The purchased cost of the total electric requirement was then subtracted from this cost to determine the total cost of steam. The total cost of steam divided by the steam flow rate for the plant yielded the unit cost of steam. The results of the economic comparison are summarized in Table 2 for the base-case cost assumptions. The cost per thousand pounds of steam is listed in this table, both with and without an income tax effect. Because of the different capital costs and electrical outputs of the various plants, the proportion of the costs depreciated and expended varies considerably among the plants. For example, the second-generation plants produce more electricity, but their capital cost is greater. These differences can lead to differences in the taxes paid by a company. The treatment of the tax liability is not totally clear cut because the tax would be determined by overall company operations, not just the power plant. For this reason, the cost of steam has been calculated with and without the tax effect. 


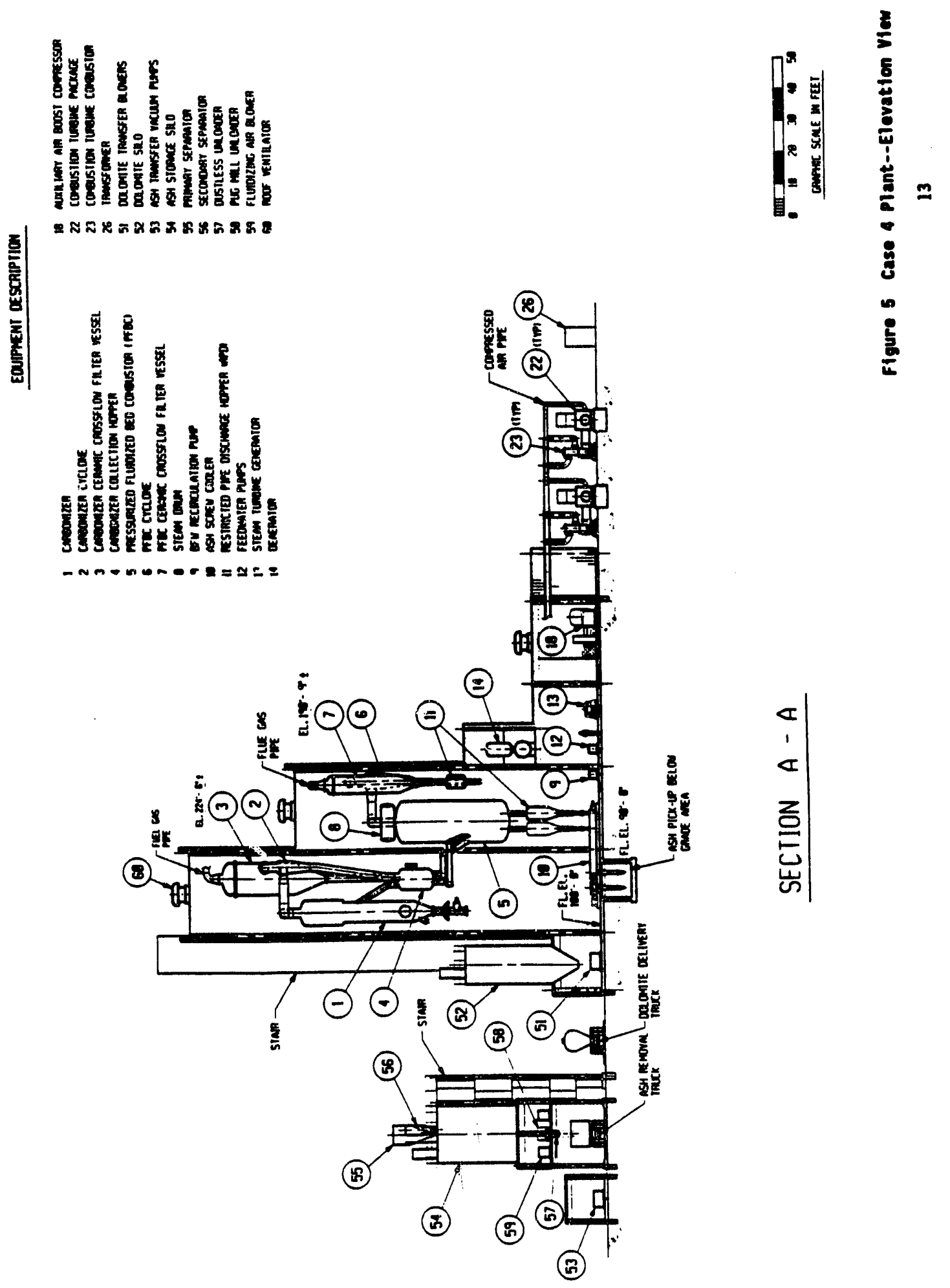




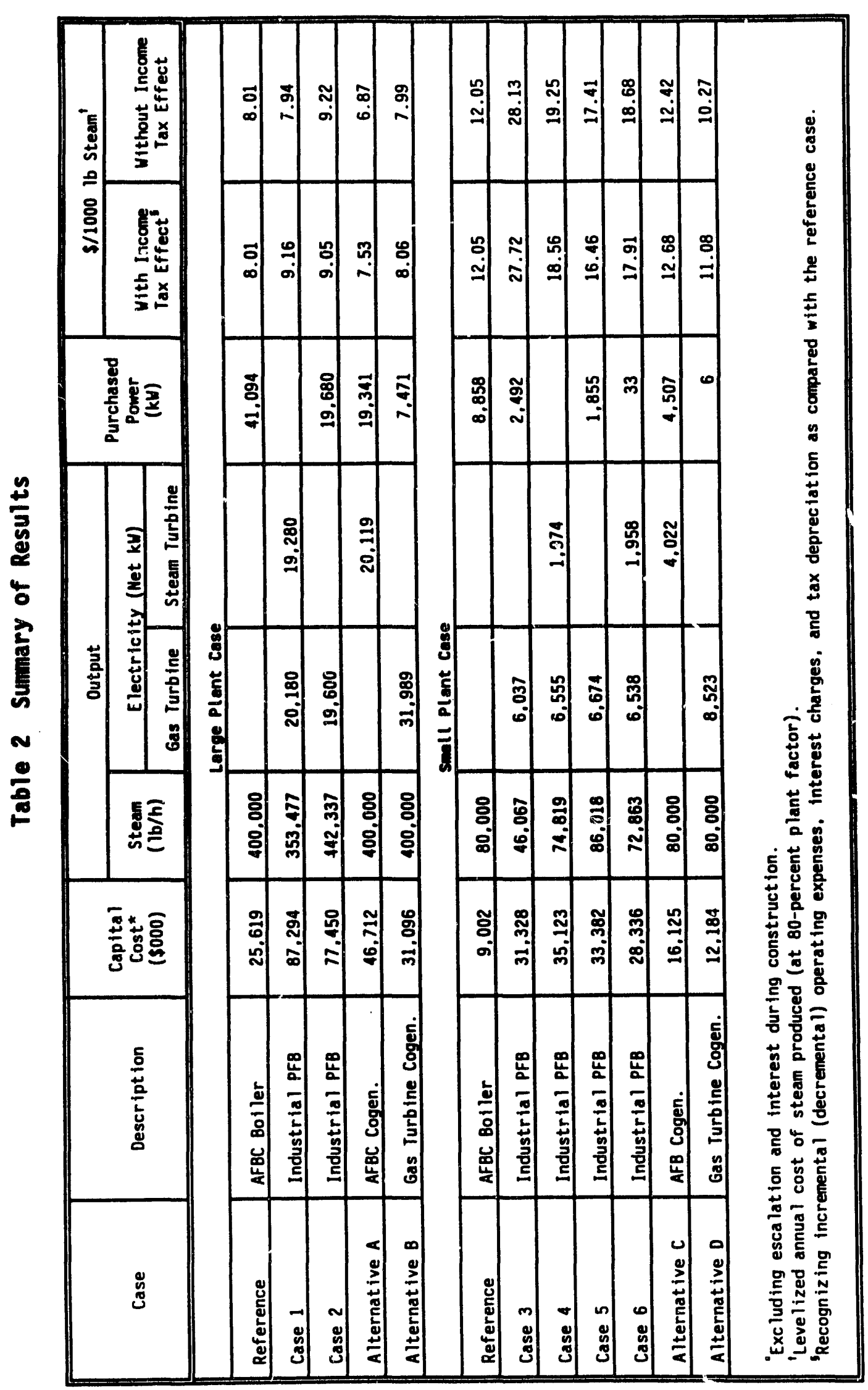


As Table 2 shows, AFBC cogeneration has the lowest cost of steam for the large plants, and the natural gas-fired gas turbine cogeneration has the lowest cost of electricity for the small plants. The economic analysis in Table 2 is based on an electric rate structure of a specific electric utility in the Ohio Valley area. This rate structure results in an average purchased power cost of approximately $50.0648 / \mathrm{kWh}$. Other major utilities within the assumed plant region have higher electric rates. One utility has a rate structure that yields a purchased power cost of approximately $\$ 0.0760 / \mathrm{kWh}$. Using this rate and assuming no standby electric charges or income tax effects, the Case 1 plant yields the lowest cost of steam. 
Section 1

IKTRODUCTION

\subsection{STUDY OBJECTIYES}

This study was performed as a part of U.S. DOE Contract DE-AC2186mC21023. Under this contract, Foster Wheeler Development Corporation (FWDC) and subcontractors are conducting the necessary research and development to comercialize the second-generation PFB combustion system. A utility-size second-generation system has been conceptually designed as part of this contract; the economics of a system of this size are favorable [1]. The objectives of the present study were to determine:

- The technical feasibility of applying the second-generation PFB combustion system to smaller gas turbine sizes in industrial cogeneration plants

- The economic feasibility of the second-generation PFB combustion system for these plants

- Any technological gaps that would impede the implementation of secondgeneration PFB combustion systems for these industrial plants.

The approach to this study was to develop conceptual designs for several second-generation PFB combustion plants and analyze the economics of these plants relative to conventional cogeneration systems. An in-depth analysis of the industrial market requirements was beyond the scope of this study, but a limited investigation was made to establish plant sizes and arrangements. With the wide variety of industrial applications, a "typical" plant probably does not exist in the strict sense, but the cases were chosen to have reasonable outputs and equipment designs that could be applied to a variety of industries. An attempt was also made to have the different case studies reflect as many arrangements of the system as possible so as to explore the implications of the different arrangements regarding design, costs, and development requirements. Throughout the report, when the six cases are referred to collectively, the term "second-generation systems" is used, even though one case is actualiy a 1-1/2 generation system.

\subsection{SECOWD-GENERATIOH PFB COMBUSTIOH TECYNOLOGY}

The second-generation PFB combustion plant differs from the firstgeneration plants in that it is capable of gas turbine inlet temperatures in excess of $2100^{\circ} \mathrm{F}$. These gas turbine inlet temperatures are accomplished in an environmentally acceptable manner using coal as the only fuel. The firstgeneration PFB combustion plants are limited to gas turbine inlet temperatures of approximately $1600^{\circ} \mathrm{F}$ because of sulfur-removal considerations in the fluidized bed. By using a carbonizer (pyrolyzer) and a topping combustor in

\footnotetext{
'References are listed at the end of each section.
} 
conjunction with the pressurized fluidized bed combustor (PFBC), the secondgeneration PFB combustion system overcomes the gas temperature limit of the first-generation systems. A simplified process diagram illustrates the process (Figure 6). Coal fed to the carbonizer is converted into low-Btu gas and char. The char is then fed to the PFBC, where it is burned. The flue gas from the PFBC and the fuel gas from the carbonizer are combined in the topping combustor, where combustion raises the temperature to the gas turbine inlet temperature. Gas turbine inlet temperatures of over $2100^{\circ} \mathrm{F}$ are achievable with the second-generation system.

Both the carbonizer and the PFBC are fluidized beds that operate at approximately $1600^{\circ} \mathrm{F}$. The sorbent in these beds removes sulfur. The carbonizer is always kept at temperature by maintaining the proper air, fuel, and sorbent flows to achieve this temperature without transferring heat from the bed. The PFBC can also be operated in this manner, but it generally contains heat-transfer surface to generate steam. The choice of bubbling or circulating fluidized beds for the carbonizer and PFBC is not dictated by the secondgeneration process. The assumption has been made that either type of bed can be used if properly designed.

\subsection{MOUSTRIAL MARKE}

The industrial market is quite diverse in its demand for electricity and steam. This diversity is reflected in the Dun and Bradstreet data shown in Figure 7. These data are the averaged use of steam and electricity for specific industrial plants. As the figure shows, steam and electrical demands cover a wide range of capacities and thermal-to-electric ratios. Because of the wide and uniform spread of the data, this information is not very helpful for choosing plant sizes, but it is interesting to note that the secondgeneration PFB combustion system is capable of steam and electric outputs within this map that are not achievable with conventional cogeneration systems.

Regions where the different cogeneration technologies could provide systems that exactly match the steam and electrical demands of the plants are delineated in Figure 7. Because stean and electric production are interrelated in any cogeneration system, there are limits to the relative outputs of stean and electricity that can be achieved with each type of system. The figure shows that, for many plants, the second-generation system would be a better match of the steam and electric requirements than conventiona? cogeneration systems.

Figure 8 shows the number of plants being purchased in different electrical power size ranges. The basis of this graph is the September 1989 Power Engineering list of nonutility projects in the construction or design stage. Most of the projects are under 50 MWe, and there are peaks in the ranges 0-10, 20-30, and 40-50 MWe. 


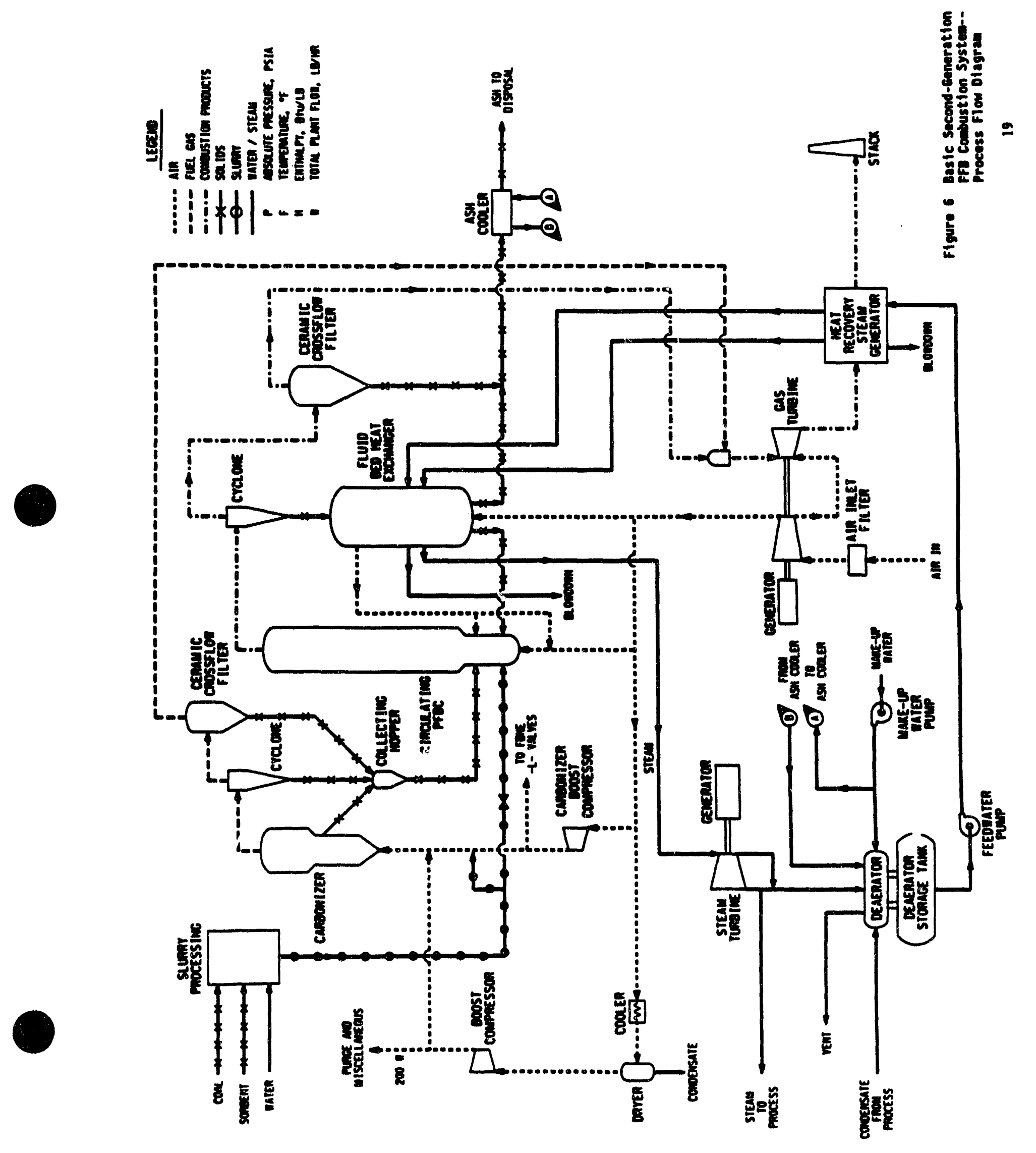




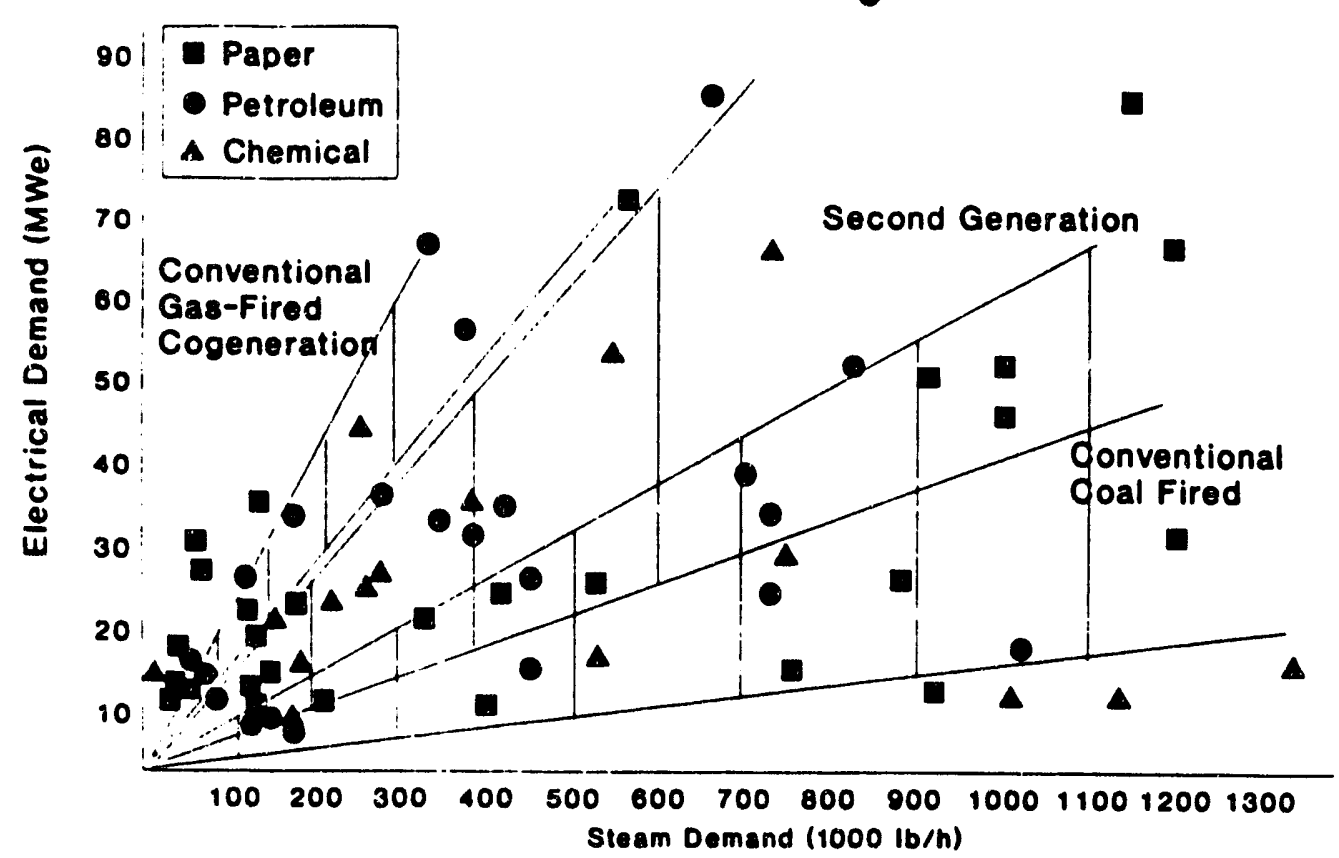

Figure 7 Electrical Demand vs. Steam Demand--Paper, Chemical, and Petroleum Plants (Source: Dun and Bradstreet 1985 Data Base)

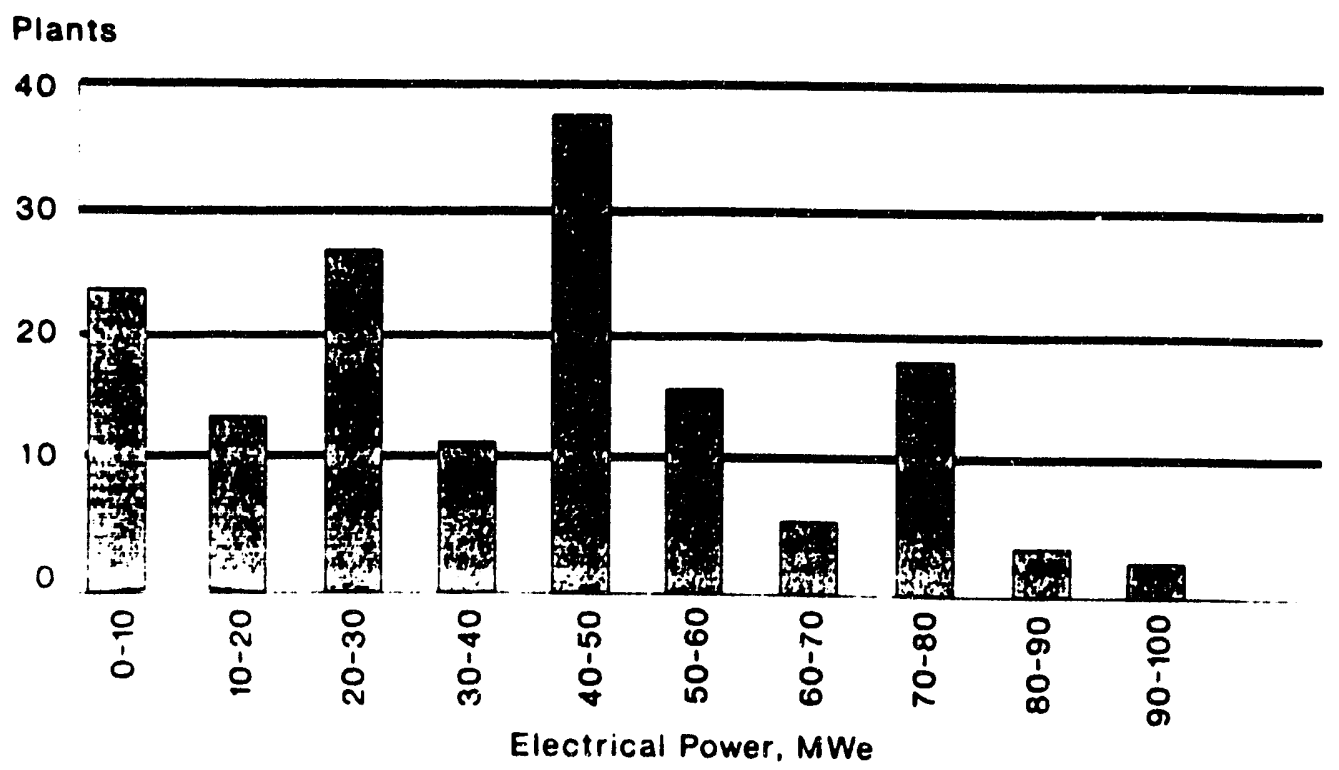

Figure 8 Fossil-Fuel-Fired Nonutility Generating Projects (Source: Power . Engineering, September 1989) 
Foster Wheeler's sales records were reviewed to obtain an indication of the steam capacity and steam conditions of boilers being purchased by industrial users. The steam pressures of boilers purchased from 1973 to 1988 are plotted against steam flow rates in Figure 9. As the plot shows, there is a tendency for the boilers purchased by different industries to group according to steam pressure and flow. The manufacturing companies have the lowest pressures and flows, and the paper companies tend to have the highest pressures and flows.

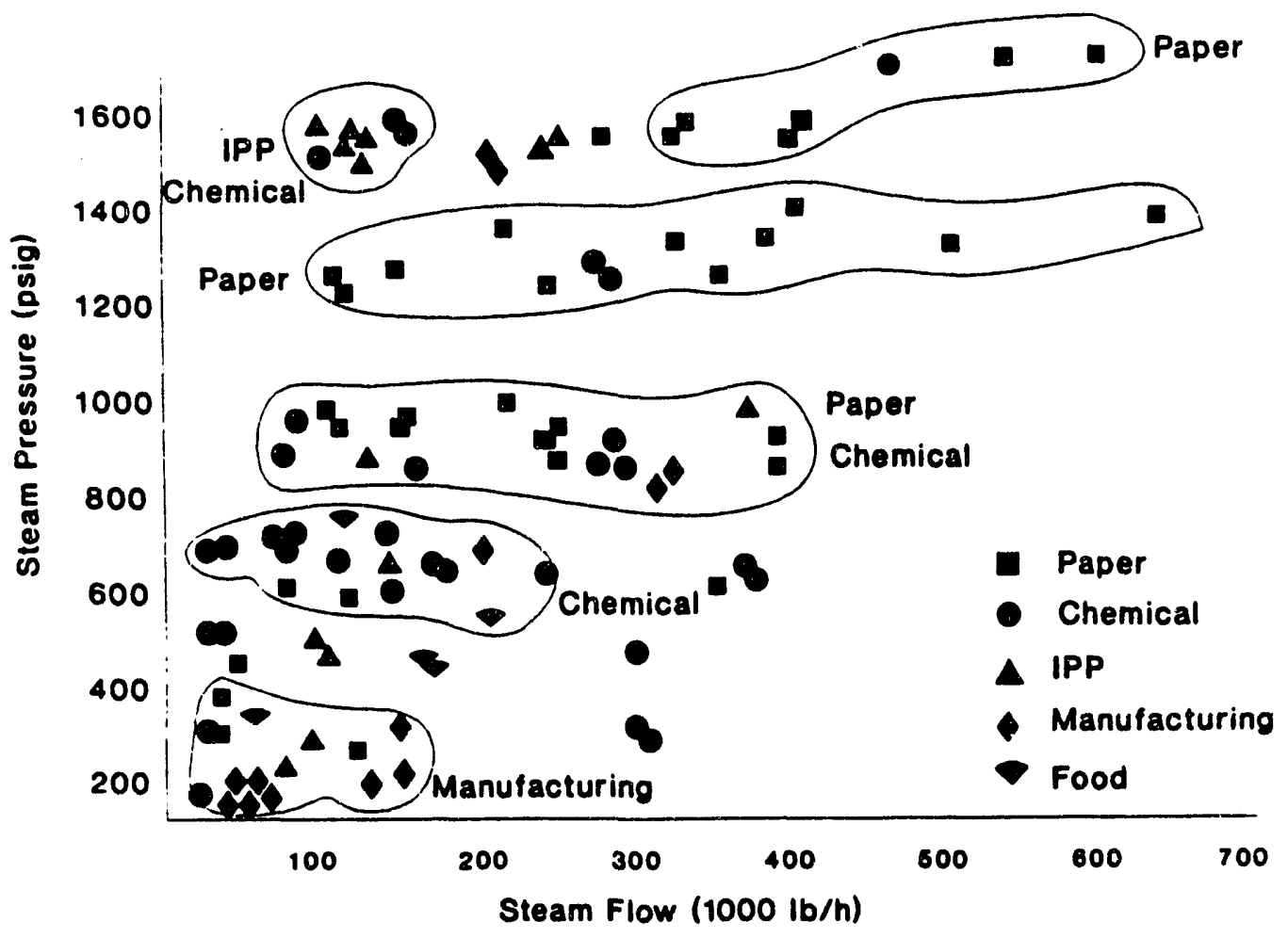

Figure 9 Foster Wheeler Smaller Boiler Sales (1973 - 1988)

\subsection{CASES STUDIED}

Based on the objectives of the study and the limited analysis of the industrial market, study cases were selected for two gas turbine systems. Two plants were designed based on a 21-MWe Westinghouse 151 Gas turbine, and three plants were designed based on two 3.5-MWe Allison 501 gas turbines. In addition to the five second-generation plants, a sixth case was evaluated. This case was a "1-1/2 generation" system without a carbonizer. In this system, coal would be fired in the PFBC, and natural gas would be fired in the topping combustor to bring the gas temperature up to gas turbine inlet conditions. The 1-1/2 generation system is also based on two 3.5-MWe Allison gas turbines.

The relatively large plants based on the Westinghouse 21-PWe gas turbine were designed to give maximum steam production. This approach was taken for two reasons. First, a run of the economic analysis program developed by Westinghouse for the utility plants indicated that the maximum steam production plant would probably give the best internal rate of return for this size industrial system. Second, this plant would be for a large industrial user, probably in the paper or chemical industries, where steam demand would be high. The high relative output of steam is achieved by firing additional coal along with the char in the PFBC. 
The smaller plants based on the two Allison 3.5-MWe gas turbines were designed to minimize capital costs, plant size, and system complexity. Systems of this size would probably be used in small chemical or manufacturing plants. These users tend to have lower steam demands. Also, manufacturing plants in particular are sensitive to system space requirements and operating complexity. These objectives are pursued in different ways in the different small system cases. Case 3 uses an adiabatic PFBC. This type of design eliminates steam production equipment upstream of the gas turbine and simplifies plant operation. In Cases 4 and 5, air beyond that required for combustion is bypassed arcund the PFBC. This type of design reduces the size of the PFBC and the hot gas cleanup equipment for the PFBC. Case 6 is designed for bypass of air around the PFBC and the use of natural gas in the topping combustor. This arrangement eliminates the carbonizer and its related hot gas cleanup equipment.

\subsection{REFERENCES}

1. A. Robertson, et al., "Second-Generation Pressurized Fluidized Bed Combustion Plant: Conceptual Design and Optimization of a Second-Generation PFB Combustion Plant," Phase 1 Task 1 report to the Department of Energy under Contract DE-AC21-86MC21023, September 1989. 


\section{PLANT SUBSYSTEMS AND ARRANGEMENTS}

\subsection{PROCESS DESCRIPTION}

A basic process flow diagram for the second-generation PFB combustion system is shown in Figure 6 . First, the coal and 1 ime-based sorbent are crushed and pressurized for injection into the system. The basic pressurizing can be accomplished either with a dry lock-hopper arrangement followed by pneumatic transport or with a slurry system. With a dry lock-hopper system, incoming coal must be dried before it is fed to the lock hoppers. In the utility conceptual design study, the coal drying system turned out to be a major cost item and safety concern. Since slurry feeding is less capital intensive and should require less attention during operation, it was selected for the plants in this study. Tests at the Grimethorpe PFB combustion facility in the United Kingdom have indicated the feasibility of this type of feeding [1]. The plants in this study have been based on a combined coal/sorbent/water slurry feed. The mixture is 70 wt\% solids and 30 wt\% water.

The coal/sorbent slurry is fed to the carbonizer and, when greater steam generation is desired, to the PFBC also. The carbonizer is a jetting fluidized bed operating at a superficial gas velocity of $3 \mathrm{ft} / \mathrm{s}$. There is no heat-transfer surface in the carbonizer, but the air-to-coal feed ratio is adjusted to maintain bed temperature at $1600^{\circ} \mathrm{F}$. The mass flow balance for the carbonizer is shown in Figure 10. This mass balance is for Pittsburgh No. 8 coal and Plum Run dolomite with the carbonizer operating at $11 \mathrm{~atm} / 1600^{\circ} \mathrm{F}$.

The fuel gas generated in the carbonizer goes through a hot gas cleanup system, consisting of a cyclone and a cross-flow barrier filter, before being burned in the topping combustor. The char/sorbent residue from the carbonizer and the particulates collected by the fuel gas hot cleanup system are injected into the PFBC. Coal/sorbent siurry can also be fed to the PFBC when a greater steam output is desired.

The operation and design of the PFBC can vary depending upon the requirements of the plant. The combustor can be a circulating PFBC (CPFBC) with a heat exchanger in the solids flow loop or a bubbling bed with or without heat-transfer surface. There are trade-offs in the selection of PFBC type. CPFBC systems are preferred from a performance standpoint. The stagad combustion in these systems can minimize $\mathrm{NO}_{\mathrm{x}}$ production. There is also evidence that CPFBC systems can increase combustion efficiency and sorbent utilization. However, the CPFBC systems require an extra pressure vessel and a significantly greater height. These requirements raise capital costs and limit acceptance in certain industries. CPFBCs would definitely be chosen for the larger plants, but bubbling beds would have benefits for the smaller plants. Excess air levels in the PFBC and the means for obtaining these levels affect plant outputs and design. These variations are discussed in detail in Section 2.2.

Flue gas from the PFBC goes through a cyclone and a cross-flow filter before combining with the fuel gas in the topping combustor. Combustion of the fuel gas is accomplished with the heat and excess air from the PFBC flue gas. The combined high-temperature gas is expanded through the gas turbine. A heat-recovery steam generator (HRSG) downstream of the gas turbine generates steam for the steam cycle. 


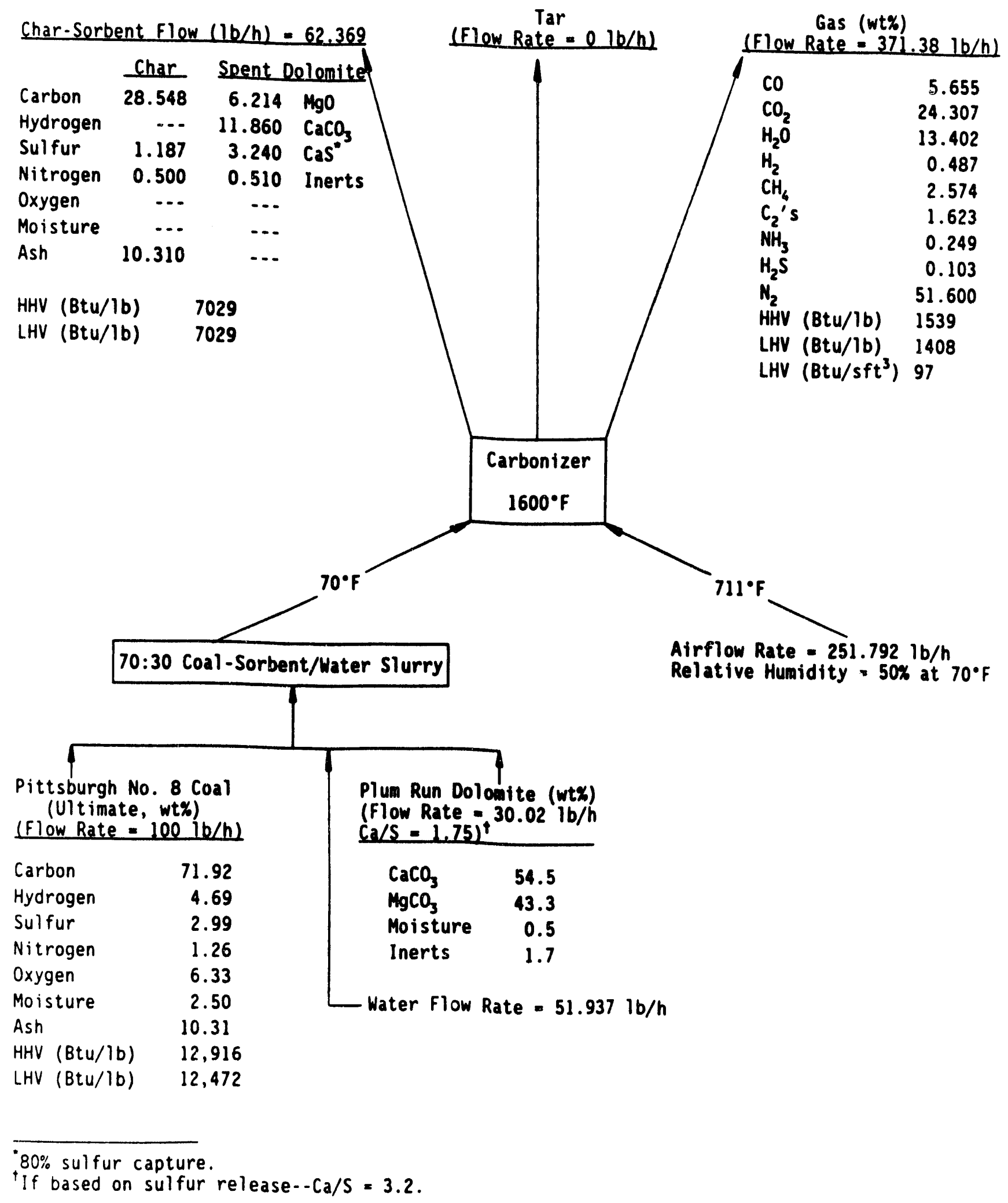

Figure 10 Carbonizer Mass Flow Balance 
Additional heat load for steam generation can also be obtained from heattransfer surface in the PFBC portion of the process. Depending on plant requirements, the steam can drive a back-pressure turbine or extraction turbine or it can be generated at process steam conditions.

The emissions for the second-generation PFB combustion plants will be well within New Source Performance Standards (NSPS) allowable limits. Emissions leveis are discussed in Appendix $A$.

\subsection{PLANT ARRANGEMENTS}

\subsubsection{Possible Plant Arrangements}

The basic plant arrangement in Figure 6 can be applied differently to achieve various objectives. Some variations can be obtained by using different proportions of coal feed between the carbonizer and the CPFBC and different excess air levels in the CPFBC itself. Other variations involve minor process modifications. By changing the manner in which the second-generation system is applied, different thermal-to-electrical ratios can be achieved, and the relative size and expense of some components can be changed.

Figures 11 through 14 show four different arrangements of the secondgeneration system in block diagram form. The arrangement in Figure 6 is the one most applicable for utility power generation. The greatest cycle efficiency in terms of electrical output and fuel heat input can be achieved with this arrangement if the proper excess-air level is chosen for the fuel being fired [2]. Typically, the maximum cycle efficiency will be achieved at an excess-air level in the CPFBC of 180 to 220 percent, depending on the fuel, carbonizer temperature, and operating parameters of the gas and steam turbines. The maximum cycle efficiency occurs at a high excess-air level because this type of operation shifts a greater proportion of the power generation from the steam turbine to the more efficient gas turbine cycle. Operation in this mode would not necessarily be desirable for an industrial user. In industrial cogeneration applications, a large portion of the energy in the steam leaving the steam turbine is used in the process; therefore, the cycle efficiency in terms of electrical output vs. fuel heat input is not as important. With the process application shown in Figure 6 , coal is fired in the CPFBC along with the char from the carbonizer. The amount of coal that can be fired in the CPFBC ranges from zero to a level that will result in 30 -percent excess air in the combustor.

By firing more coal in the CPFBC (Figure 11), more steam can be generated. The outlet temperature of the CPFBC is 1 imited to $1600^{\circ} \mathrm{F}$ to control the level of alkali entering the gas turbine and thereby minimize the risk of gas turbine corrosion. Any additional heat generated by the higher levels of coal being fired is removed by heat exchanger surface in the CPFBC. Coal can be fired in the CPFBC to the point where the excess air in this part of the process is about 30 percent. This flexibility provides a wide range of thermal-to-electrical ratios. Operation in this mode at the lowest excess-air point will also result in the maximum possible steam production for the gas turbine operating parameters.

A unique operating condition can be achieved that will eliminate the need for heat exchanger surface in the PFBC. At a particular level of excess air (typically about 400 percent), the bed in the PFBC can be maintained at $1600^{\circ} \mathrm{F}$ without steam generation. Referred to as "operating with an adiabatic bed," this condition results at an excess-air level where the heat in the flue 


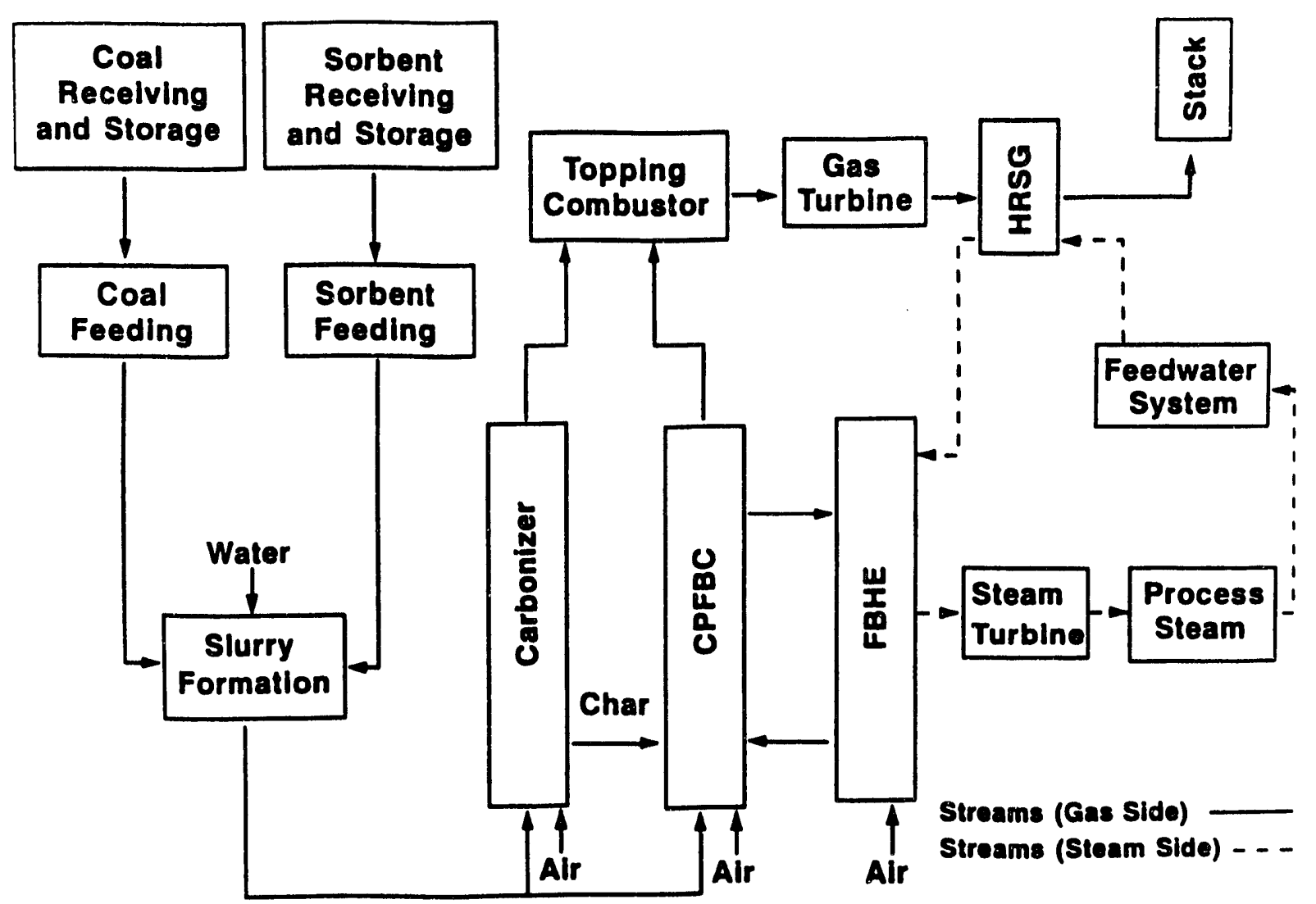

Figure 11 Arrangement With Additional Coal Firing in PFBC

gas from the PFBC at the operating temperature balances with the heat input from the char. Steam is still generated by the HRSG downstream of the gas turbine, but this mode of operation eliminates the need for heat exchanger surface in the PFBC and thereby lowers its cost. A drawback to this plant arrangement is that the range of operation is more restricted. Figure 12 shows the adiabatic bed plant in block diagram form.

Lower excess-air levels can be achieved in the PFBC by bypassing air around it instead of, or in addition to, firing more coal in the PFBC. The p) ant arrangement for this mode of operation is shown in Figure 13. The benefit from bypassing the air is a smaller PFBC and smaller gas cleanur equipment for it. However, this arrangement results in a larger carbonizer and associated hot gas cleanup equipment. Even if no additional coal is fired in the PFBC, more steam is generated in the PFBC than would be the case if air were not bypassed. With PFBC air bypass, relatively cold air is delivered to the topping combustor. The colder air increases the fuel gas flow requirement, raising coal flow to the carbonizer and resulting in greater char flow to the PFBC. This increased char flow generates more steam in the PFBC than would be generated without the bypassed air.

Figure 14 shows another possible plant arrangement, where natural gas is fired in the topping combustor instead of fuel gas generated from the coal. This system is referred to as a 1-1/2 generation system. Capital costs are lower because the carbonizer and its related equipment are eliminated. Air bypassing around the PFBC can also be used with the 1-1/2 generation system to reduce the size of the PFBC hot gas cleanup equipment. 


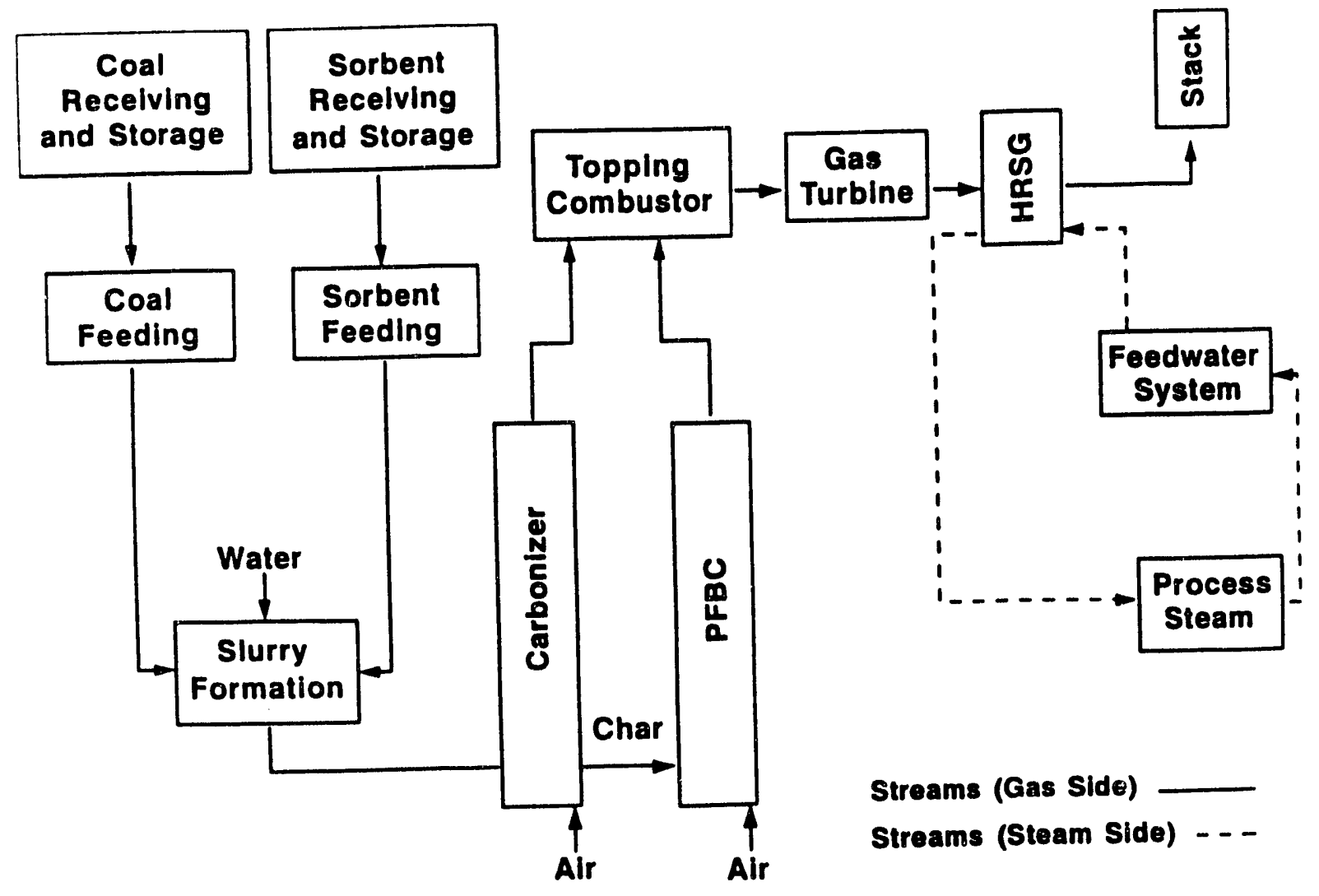

Figure 12 Arrangement With Adiabatic Bed

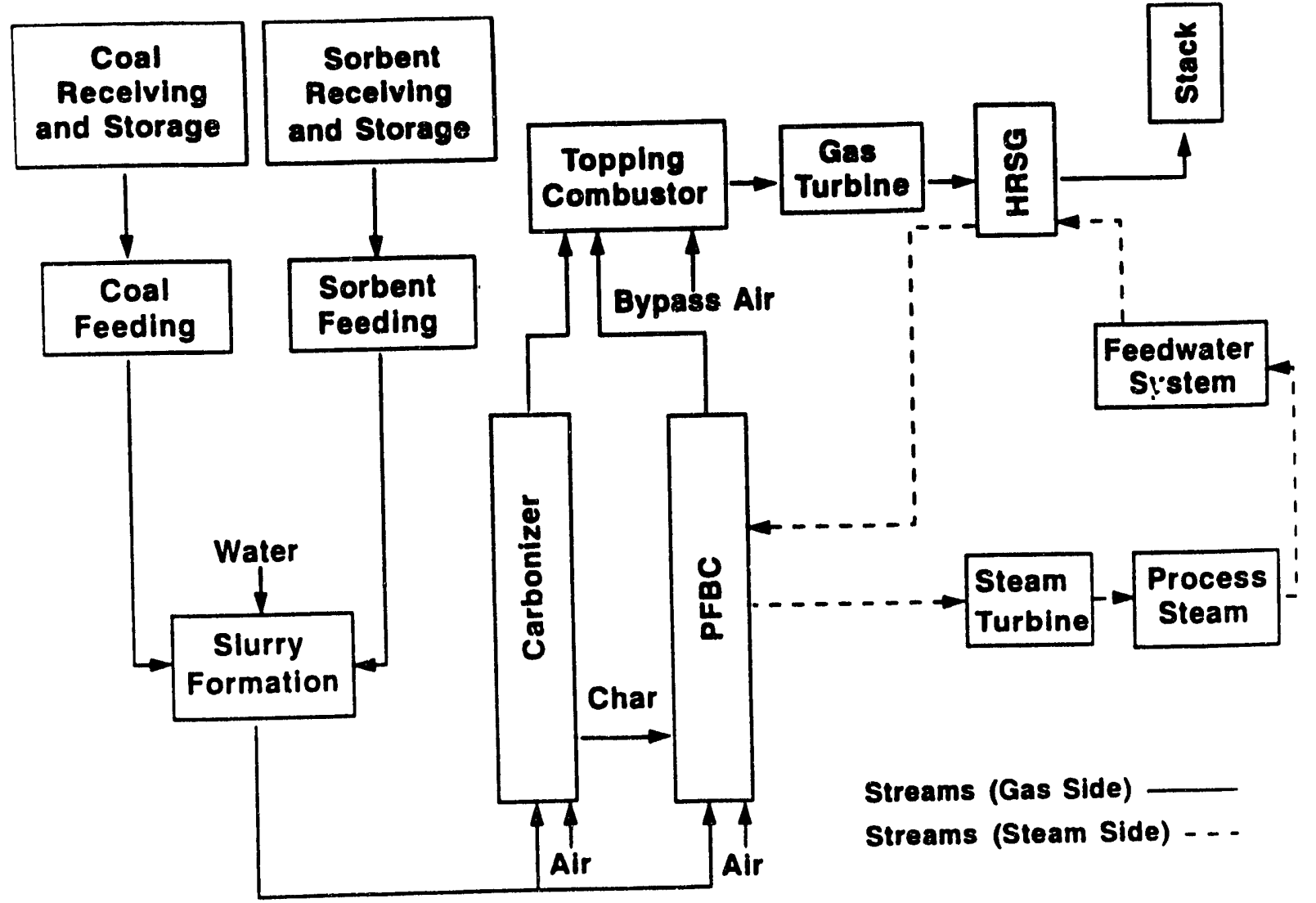

Figure 13 Arrangement With Air Bypassing Around PFBC 


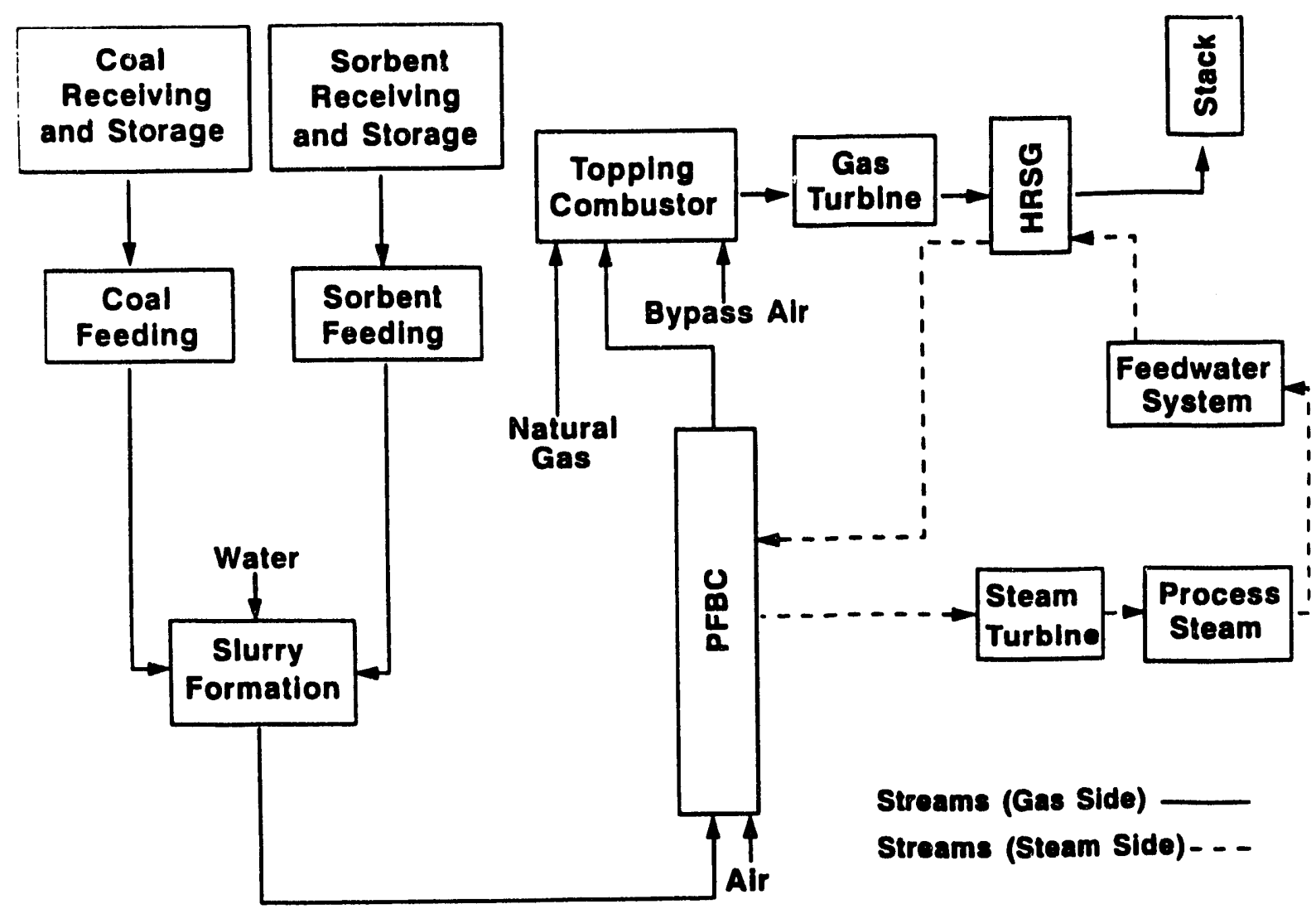

Figure 14 Arrangement With Matural-Gas Firing in Topping Combustor

\subsubsection{Plant Arrangements and Design Parameters}

The plant arrangement variations discussed in Section 2.2.1 have been used as the basis for five conceptual plants. Operating parameters for the plants are summarized in Table 3 . All of the plants are cogeneration facilities supplying 150-psig process steam, 65 percent of which is assumed to be returned to the cycle as condensate.

Cases 1 and 2 correspond to the plant arrangement in Figure 11. These plants would be selected by a large industrial user with high steam and electrical demands. They are based on a modified Westinghouse Model 151 gas turbine operating at $11 \mathrm{~atm}$ with a $1950^{\circ} \mathrm{F}$ topping combustor outlet temperature. This gas turbine provides approximately 21 -MWe gross electrical outp.it. For Case 1 , the combined gross electrical output of the gas and steam turbine sets is 41 MWe, and the process steam flow is $353,477 \mathrm{lb} / \mathrm{h}$. The thermal-toelectrical ratio for this plant is 3.1 . Case 2 is basically the same plant as Case 1 , except there is no steam turbine. All the steam in Case 2 is generated at process conditions. The gross electrical output of Case 2 is 21 MWe, with a $442,337 \mathrm{lb} / \mathrm{h}$ process steam flow. The thermal-to-electrical ratio for this plant is 7.2. In both Cases 1 and 2, coal is fired in the CPFBC in addition to the char from the carbonizer. "The resultant excess air in the CPFBC is 30 percent.

Case 3 (Figure 12) is a smaller plant based on two Allison 501 gas turbines operating at 11 atm with a $1977^{\circ} \mathrm{F}$ topping combustor outlet temperature. An adiabatic bed in the PFBC provides the simplest plant arrangement. The resultant excess air in the combustor is 414 percent. No steam turbine is used in this case, and the outputs are 6.3 MWe and 46,067 lb/h steam flow. The thermal-to-electrical ratio for this plant is 2.4 . 
Table 3 Plant Operating Parameters

\begin{tabular}{|c|c|c|c|c|c|c|}
\hline Description & Case 1 & Case 2 & Case 3 & Case 4 & Case 5 & Case 6 \\
\hline Total Electric Generation, MWe & 41.5 & 21.2 & 6.3 & 9.0 & 7.1 & 8.8 \\
\hline Gas Turbine Generation, MWe & 21.2 & 21.2 & 6.3 & 6.9 & 7.1 & 6.8 \\
\hline Steam Turbine Generation. MWe & 20.3 & & & 2.1 & & 2.0 \\
\hline Throttle Pressure, psig & 1200 & & & 705 & & 700 \\
\hline Steam Generator Out let Temperature, $F$ & 950 & 368 & 368 & 750 & 368 & 750 \\
\hline Process Steam Pressure, psig & 150 & 150 & 150 & 150 & 150 & 150 \\
\hline Process Steam Flow, $\mathrm{lb} / \mathrm{h}$ & 353.477 & 442.337 & 46.067 & 74,819 & 86,018 & 72,863 \\
\hline Plant Excess Air, $X$ & 33 & 33 & 197 & 109 & 109 & 96 \\
\hline Coai Feed to Carbonizer, $\mathrm{lb} / \mathrm{h}$ & 14.951 & 14.951 & 7.948 & 12,038 & 12,111 & \\
\hline Coal Feed to PFBC, $\mathrm{lb} / \mathrm{h}$ & 39,029 & 39.029 & & & & 10.684 \\
\hline Carbonizer Fuel Gas. $\mathrm{lb} / \mathrm{h}$ & 53.531 & 53,531 & 28,457 & 43,101 & 43.364 & \\
\hline Natural Gas Flow, $\mathrm{lb} / \mathrm{h}$ & & & & & & 3.289 \\
\hline PFBC Flue Gas, $\mathrm{lb} / \mathrm{h}$ & 604,752 & 604.752 & 148.566 & 59,312 & 59,149 & 94.322 \\
\hline Total Gas Filtered, $x$ & 87 & 87 & 70 & 40 & 40 & 37 \\
\hline
\end{tabular}

Cases 4 and 5 (Figure 13) incorporate air bypass around the PFBC to generate additional steam. These plants are also based on two Allison 501 gas turbines. The excess air level is 40 percent in the PFBC. Case 5 is analogous to Case 3--there is no steam turbine and the electrical output is 7.0 MWe. The low excess-air operation of Case 5, however, results in a steam output of $86,018 \mathrm{lb} / \mathrm{h}$, which is almost twice that of the adiabatic operation in Case 3. The Case 5 thermal-to-electrical ratio is 3.8 . Case 4 has a steam turbine and will generate 9.0 MWe from the combined cycle. The steam flow in this case is $74,819 \mathrm{lb} / \mathrm{h}$, which results in a thermal-to-electrical ratio of 2.3 .

Case 6 (Figure 14) is a 1-1/2 generation system that uses natural-gas firing in the combustor and the bypass of air around the PFBC. A steam turbine is used in this case, and the electrical output is 8.8 MWe with $72,863 \mathrm{lb} / \mathrm{h}$ process steam flow. The thermal-to-electric ratio is 2.6 .

Each of the six plants studied was based on certain site assuniptions and conditions. The Plant Site is assumed to be in the Ohio River Valley of Southwestern Pennsylvania/Eastern Ohio, serving an existing industrial facility. The new steam plant is instalied to provide additional process steam to the existing facility. Even though the existing facility is not identified, the process steam and power requirements are typical of a large industrial facility such as pulp and paper mill, steel mill, chemical process plant, or refinery. The following assumptions were made in the development of the new steam plant:

- The new steam plant is installed at a large existing industrial facility.

- The new steam plant is necessary because of the additional process steam required. 
- The new plant adds less than 20 percent steam to the existing steamgenerating capacity.

- Seasonal steam load requirements are accommodated by the existing boilers.

- Power generated will be used in the plant (i.e., no power sale to the utility).

- Sufficient space is available for the new plant adjacent to the existing power house.

- The existing facility is burning low-sulfur coal. The new steam plant will burn high sulfur ( 3 percent) coal.

- Space is available for the new coal pile (or silo) close to the existing coal pile (or silo).

- Coal is delivered to site by rail for Cases 1 and 2 and by truck for Cases 3, 4, and 5 .

- Sized dolomite $(1 / 8$ in. $\times 0)$ is delivered to the site by truck.

- Ash is removed from the site by truck.

- The existing makeup pretreatment system has enough capacity to provide boiler makeup water for the new system.

- Existing cooling towers have enough capacity to accomodate the cooling water requirements of the new system.

- Stean (65 percent of it) is returned as condensate.

- An additional water treatment system for boiler makeup is required.

- A new wastewater treatment system must be added to treat effluent from the new plant.

- These systems or equipment are extended to serve the new steam plant:

- Plant Air

- Fire Protection

- Building HVAC and Sanitary Sewer
- Turbine Crane

- Miscellaneous Drains

- Control Room

In addition, the following criteria/constraints were made part of the development of the overall plant arrangement:

- Good relationship among systems/equipment shared by the new steam plant and the existing facility.

- Access to components/systems for maintenance.

- Convenient access to plant where needed, such as ash and dolomite transport truck routes.

- Most components located above grade. 
- Enclosure of only those components requiring frequent attendance, in-place service, or protection from the weather.

Equipment and systems were laid out using these criteria. The arrangement drawings prepared for Case 1 are also applicable to Case 2, with some minor modifications.

Overall site Plan. The overall site plan for Case 1 is depicted in Figure 15. Site plans for the other cases would be similar. The new steam plant is adjacent to the existing steam plant. The new coal pile is near the existing coal pile, but it is separate from the existing coal pile because the new plants will use high-sulifur coal. Coal is delivered to the site by rail and conveyed to the storage pile by the existing belt conveyor (29) and stackout conveyor (11).

Coal from the coal pile $(10)$ is reclaimed and delivered to new bunkers inside the boiler house by the new and existing belt conveyors. Sized dolomite is delivered to the site by truck and stored in a silo (8). From the storage silo, dolcmite is conveyed pneumatically to the dolomite surge bin inside the boiler house.

Ash from the CPFBC is collected and pneumatically transported to an ash silo (9). Ash is removed from the site by truck and is taken to the outside landfili for final disposal.

The CPFBC equipment (1) is west of the existing boiler house (20). The steam turbine and gas turbine are located in the new turbine building (4) which is west of the existing turbine building (22) and south of the CPFBC island. HRSG, stack, and transformer/switch gear are outside, south of the new turbine building.

The overall site plan also shows the existing coal pile, existing power house complex, and buildings adjacent to the power house.

Plan at Grade (F], 100') and at operating floop (FI, 120'). The plan at grade drawing (Figure 16) provides additional detail and depicts equipment located at grade. Cation and anion demineralizers (63) and (64), condensate polisher (59), caustic and acid storage tanks and pumps (66) and (65), and demineralized water and condensate storage tanks and pumps (62) and (61) are in the turbine building below the turbine operating floor. Acid and caustic tanks at the west end of the turbine building are accessible for truck delivery of acid and caustic. Two feedwater pumps (56), a blow-down tank (58), and a flash tank (57) are in the PFBC island under the deaerator. Coal/water mixture tanks (20) and slurry pumps are inside the boiler house building under the coal and dolomite surge bins. A single-story structure housing the carbonizer air booster (16), auxiliary air booster (17), and instrument air compressors sits directiy north of the coal preparation equipment.

The bypass stack (75), HRSG (76), and main stack (77) are outdoors, south of the turbine building. The electrical equipment room is in the southeast corner of the turbine building.

The plan at $120 \mathrm{ft}$ (operating floor), also presented in Figure 16, shows gas and steam turbine, dolomite surge bin, and CPFBC equipment. The turbine building is next to the existing steam turbine building and south of the PFBC equipment island. The turbine building size is based on the overall gas turbine size. An existing bridge crane is extended to the new turbine building for both steam and gas turbine maintenance. The steam turbine is in 


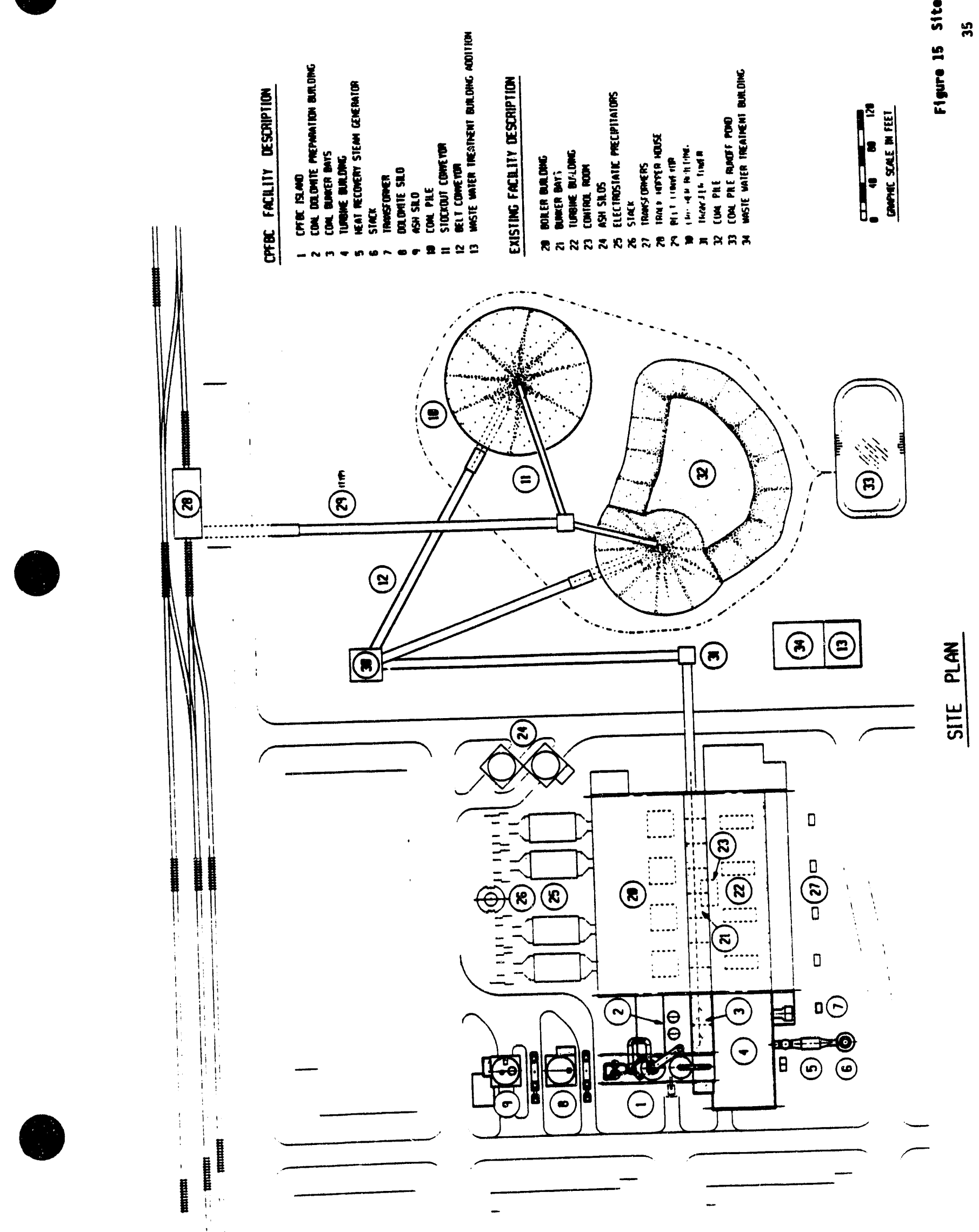



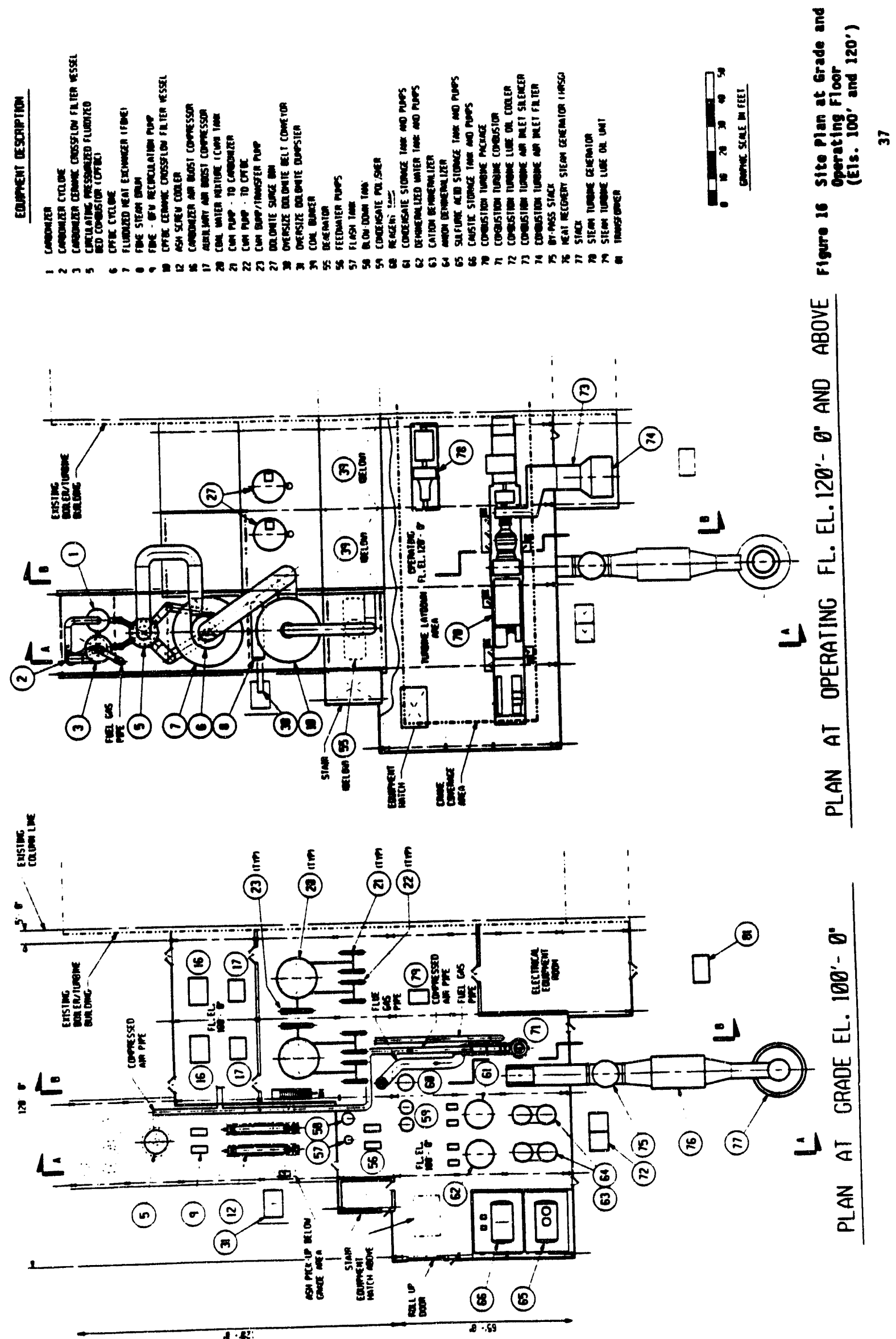
the northeast corner of the turbine building. The deaerator and coal bunkers are north of the turbine building, but at the higher elevation.

The CPFBC island, with all CPFBC equipment, is outside (no building enclosure), in the northwest corner. It includes the carbonizer, carbonizer cyclone, CPFBC, FBHE, CPFBC cyclone, and CPFBC and carbonizer cross-flow filters. This arrangement was selected to facilitate the maintenance of all equipment and to minimize the capital costs for the expensive ductwork and piping.

Elevation Sections $A-A$ and $B-B$. Section $A-A$ (Figure 17) and Section B-B (Figure 18), looking east, illustrate the elevation differences and relative positions of major equipment. The elevation differences between the turbine building, the coal bunker area, and the compressor building are shown in Section B-B. Elevation of the existing boiler house is shown in the background.

The plant arrangement for Case 2 is the same as for Case 1 except for the following major differences:

- The steam turbine is eliminated.

- Makeup water treatment includes Zeolite softeners instead of demineralizers.

- Feedwater pumps are single-stage low-pressure pumps instead of multistage high-pressure pumps.

The plants for Cases 3, 4, and 5 are smaller than the plants for Cases 1 and 2. Like Case 1, Case 4 includes a steam turbine, demineralizers, and multistage high-pressure feedwater pumps. Like Case 2, Cases 3 and 5 omit these items.

Civil. Architectural, and Structural plant Aspects. Building structures enclose the following plant components:

- Steam turbine

- Gas turbines

- Coal preparation equipment

- Selected areas of the steam generation module housing compressors and critical equipment.

- Makeup water treatment equipment

- Wastewater treatment equipment. 


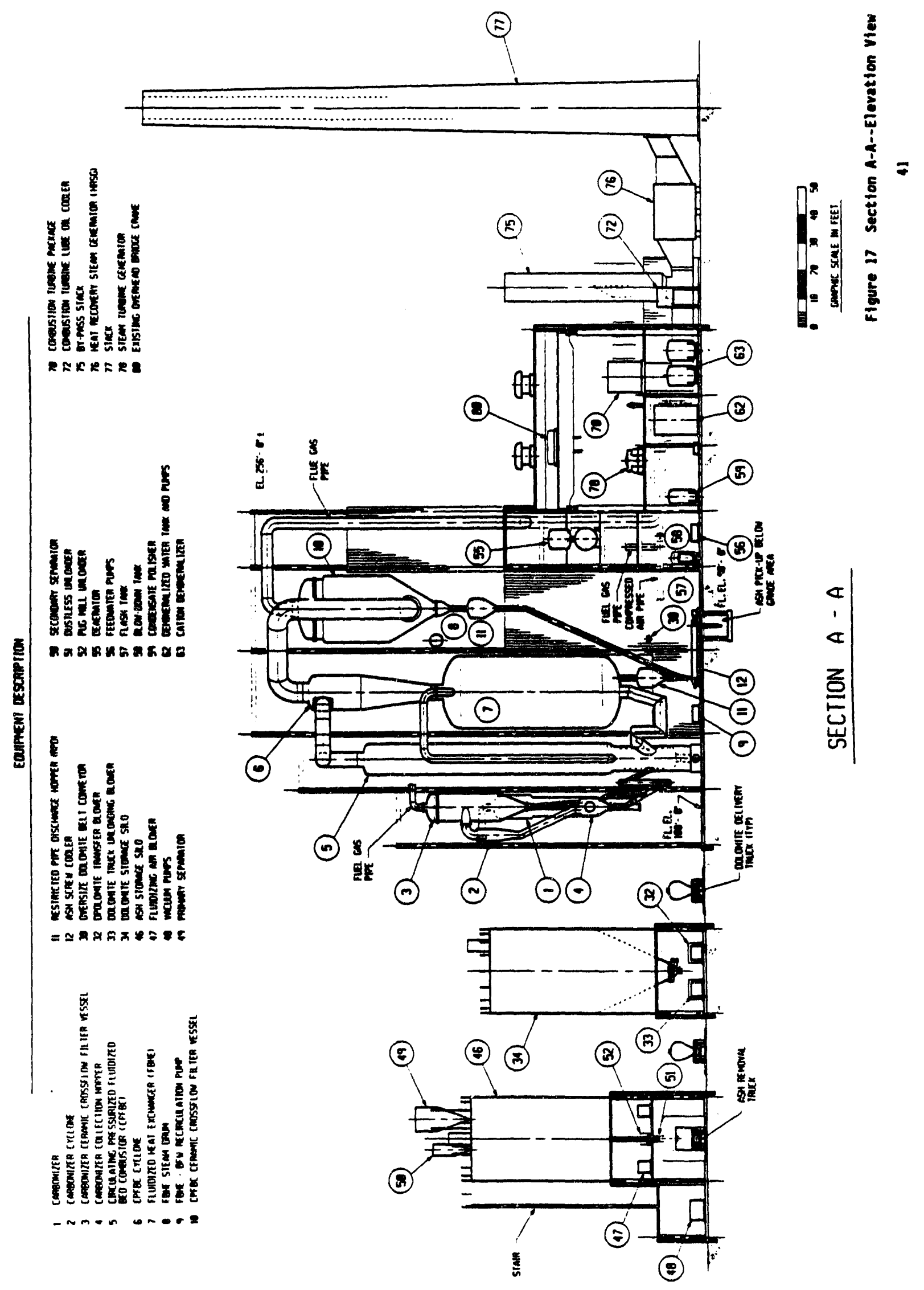



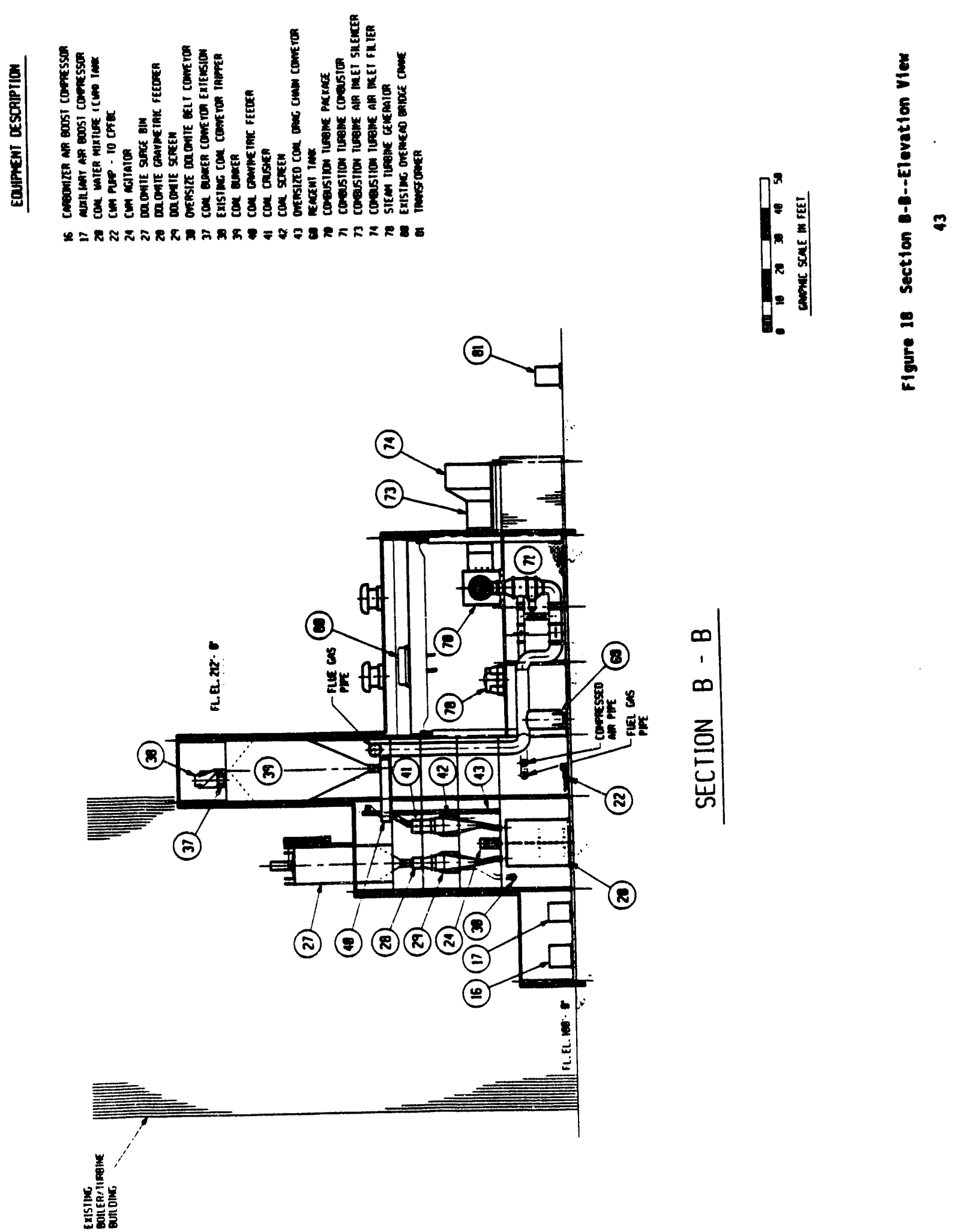
Codes and Standards. The following are applicable in establishing structural engineering design criteria and steel and concrete construction requirements:

- The BOCA Basic Building Code, or a comparable governing code, based on plant location.

- American National Standards Institute, "Minimum Design Loads for Buildings and Other Structures," ANSI A58.1.

- Local building codes, as applicable.

- American Concrete Institute

- ACI 301, "Specification for Structural Concrete for Buildings"

- ACI 318, "Building Code Requirements for Reinforced Concrete"

- ACI 307, "Specification for the Design and Construction of Reinforced Concrete Chimneys"

- American Institute of Steel Construction

- AISC, "Specification for the Design, Fabrication, and Erection of Structural Steel for Buildings"

- AISC, "Code of Standard Practice for Steel Buildings and Bridges."

Building/Structure Description. Listed in this section are descriptions of structures, surface design, and materials of construction.

- Structures

- Building structures and equipment supports are steel framed, AISC Type 2 construction, with bracing for transfer of lateral forces.

- Building foundations are anticipated to be spread footings and mats, based on the assumption that rock will be found near the ground surface. Should the subsurface exploratory program and geotechnical evaluation conducted for the specific site prove differently, the most economical, deep foundations would be selected at that time. Caissons, steel piles, cast-in-place or precast piles, and composite piles are possible alternatives if shallow foundations prove unfeasible.

\section{- Surface Desion}

- The site is conceptually designed to conform, where feasible, with the existing facility.

- The final earth grade adjacent to equipment and buildings will be at least 6 in. below the finished floor slab, with a minimum slope away from the building to normal grade of 0.5 percent.

- The additional plant roads are all two lanes with a paved shoulder, with the pavement type and thickness selected based on the soil-bearing value of the subgrade and the anticipated vehicular axle loads. iload cross sections are crowned to achieve positive drainage; they slope away from the crown at a slope of at least 2 percent. 
- The material storage area [coal storage (Cases 1 and 2)] and the associated runoff pond are designed to conform to all state and Federal regulations. The coal pile and the coal pile runoff pond are lined with a 30-mil PVC 1iner.

- Materials of Construction

- Structural Steel--ASTM A36, unless otherwise dictated by design requirements.

- Exterior Halls--Insulated metal siding.

- Interior Partitions.

-- Metal studs with two layers of gypsum board on each face

-- Concrete masonry units (normal weight) where required for fire barriers, stairwells, lavatories, and other selected locations.

- Elevated Floors--Metal floor deck and reinforced concrete slab.

- Roof--Metal deck, rigid insulation, and single-ply membrane roofing.

- Stairs--Open grating.

\subsection{EEEDSTOCK PREPARATIOH AND FEEDING}

A slurry system pressurizes and feeds the coal and sorbent. Its capital and energy costs are lower than a lock-hopper system costs. Tests done at the Grimethorpe PFBC facility in the United Kingdom have indicated the feasibility of this type of feeding [1]. The Grimethorpe tests used Pittsburgh No. 8 coal and Plum Run dolomite combined in slurries with from 25 to 28 wt\% water. These slurries were successfully mixed, pressurized, transported, and fired. Although more research will be needed to address specific design and long-term operating aspects of a slurry system, the feasibility of this type of system for industrial-size plants has been demonstrated.

The feedstock preparation and feeding systems for all of the cases are basically the same except that the larger plants (Cases 1 and 2) have two completely redundant systems so that repairs can be made while the unit is on line. Because of the lower feed rates of the smaller plants (Cases 3, 4, and 5 ), it is feasible to use the slurry mixing tank as a buffer for on-line maintenance. These systems are redundant downstream of the mixing tank, but not upstream of the mixing tank. The mixing tank is sized so that 16 hours of slurry would be available at full load, allowing time to perform maintenance on the crusher, feeder, or other upstream equipment.

\subsubsection{Coal Handling System}

jor functions:

System Functions. The coal handling system provides the following ma-

- Unloads coal from the unit train for Cases 1 and 2 and from trucks for Cases $3,4,5$, and 6

- Stores coal at the site 
- Reclaims coal from the storage pile and conveys it to bunkers inside the boiler house.

The existing coal handling system conveys the low-sulfur coal (sulfur $<2$ percent) for use in the existing boilers. Along with additional new equipment, it conveys the high-sulfur coal ( 3 percent) to the new coal bunkers for the new steam plant. The coal handling system is the same for Case 1 and Case 2.

For Cases $3,4,5$, and 6 , a new coal handling system conveys the highsulfur coal ( 3 percent) to the new coal bunkers for the new steam plant.

Desion criteria. The coar handing system is based on the following design criteria:

\begin{tabular}{|c|c|c|}
\hline & Cases 1 and 2 & Cases $3,4,5,6$ \\
\hline $\begin{array}{l}\text { Assumed existing coal handling } \\
\text { system capacity, } t / h\end{array}$ & 250 & None \\
\hline $\begin{array}{l}\text { New coal handling system } \\
\text { capacity, } t / h\end{array}$ & 250 & 50 \\
\hline $\begin{array}{l}\text { New coal pile storage requirements, } \\
\text { days }\end{array}$ & $\begin{array}{l}3 \text { plus unit train } \\
\text { unloading }\end{array}$ & 4 \\
\hline Coal storage & $\begin{array}{l}\text { Outside, close to } \\
\text { steam plant }\end{array}$ & Enclosed silo \\
\hline Coal bunker storage requirements, $h$ & 16 & 16 \\
\hline Coal density, $1 \mathrm{~b} / \mathrm{ft}^{3}$ & 50 & 50 \\
\hline Coal size (as received), in. & $2 \times 0$ run of mine & $3 / 4 \times 0$ \\
\hline Design use rate, $t / h$ & 27 & 6 \\
\hline
\end{tabular}

System Description. The coal handling system for Cases 1 and 2 is shown schematically in Figures 19 and 20 . The existing system is modified to allow receipt and storage of the new high-sulfur coal. A new gravity diverter gate in the stacker house allows the coal to be diverted to a new stacker conveyor. The new stacker conveyor, with a telescoping discharge chute, transfers coal from the railroad unloading conveyor to the new coal storage pile, which has a capacity for storing the coal delivered in one unit train plus 3 days' storage (12,000 tons total). One unit train delivery is required every other week. New insertable dust collectors at the tail and head ends of the new stacker conveyor control dust. The existing coal handling system is used for unloading railroad cars and for conveying the coal from the unloading area to the stacker house.

The new coal pile has one reclaim hopper with a vibratory feeder which feeds a new 30 -in. reclaim belt conveyor. The new reclaim conveyor transfers coal from the new coal pile to the existing crusher house. The crusher building is modified to allow the new reclaim belt conveyor to feed onto the belt feeding the crushing equipment. A new insertable-type dust collector at the discharge of the new reclaim conveyor controls dust. The existing facility is used for crushing the coal and for conveying the coal to the tripper conveyor. 


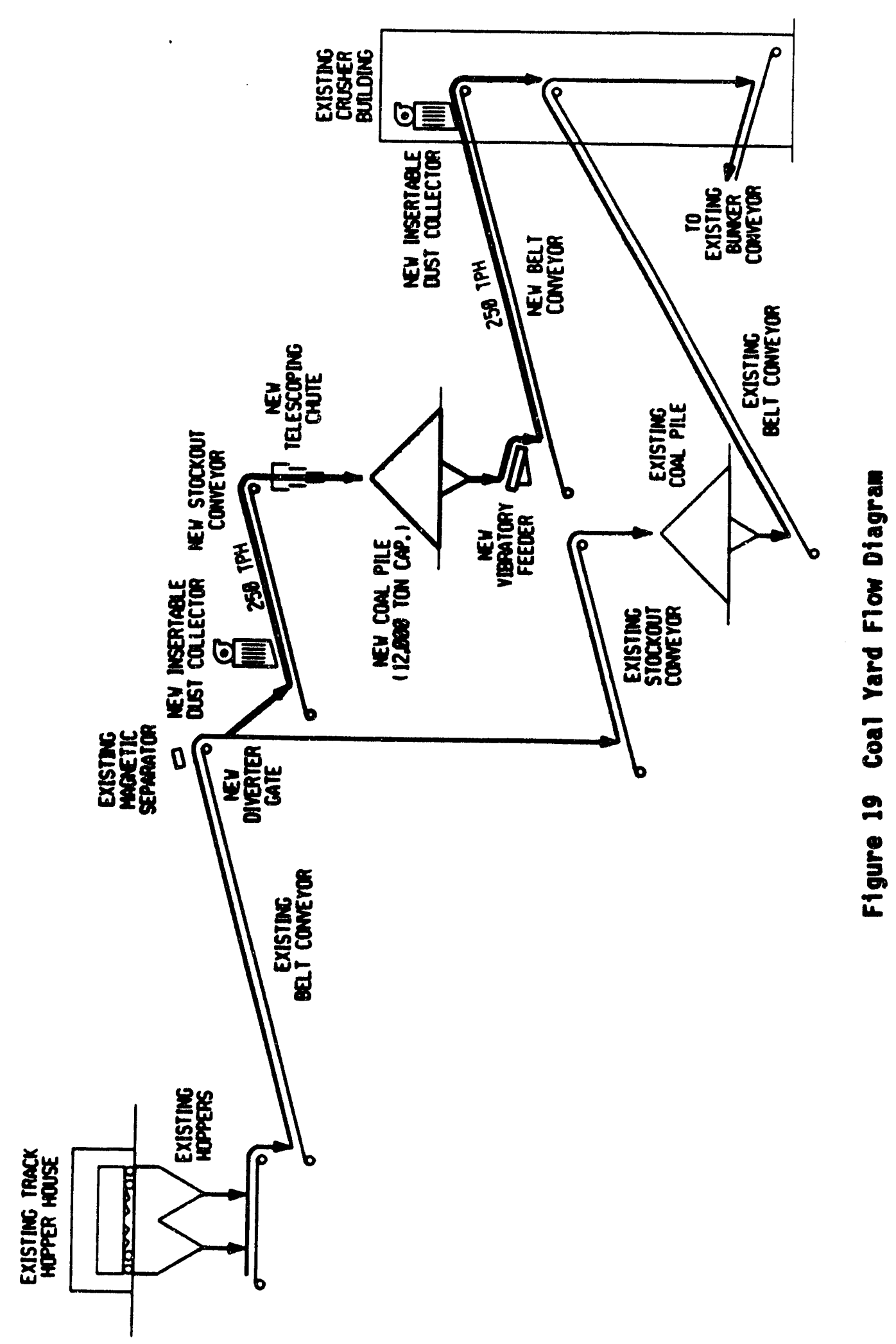

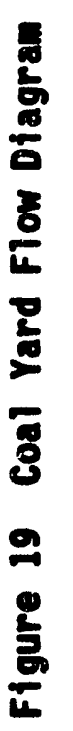




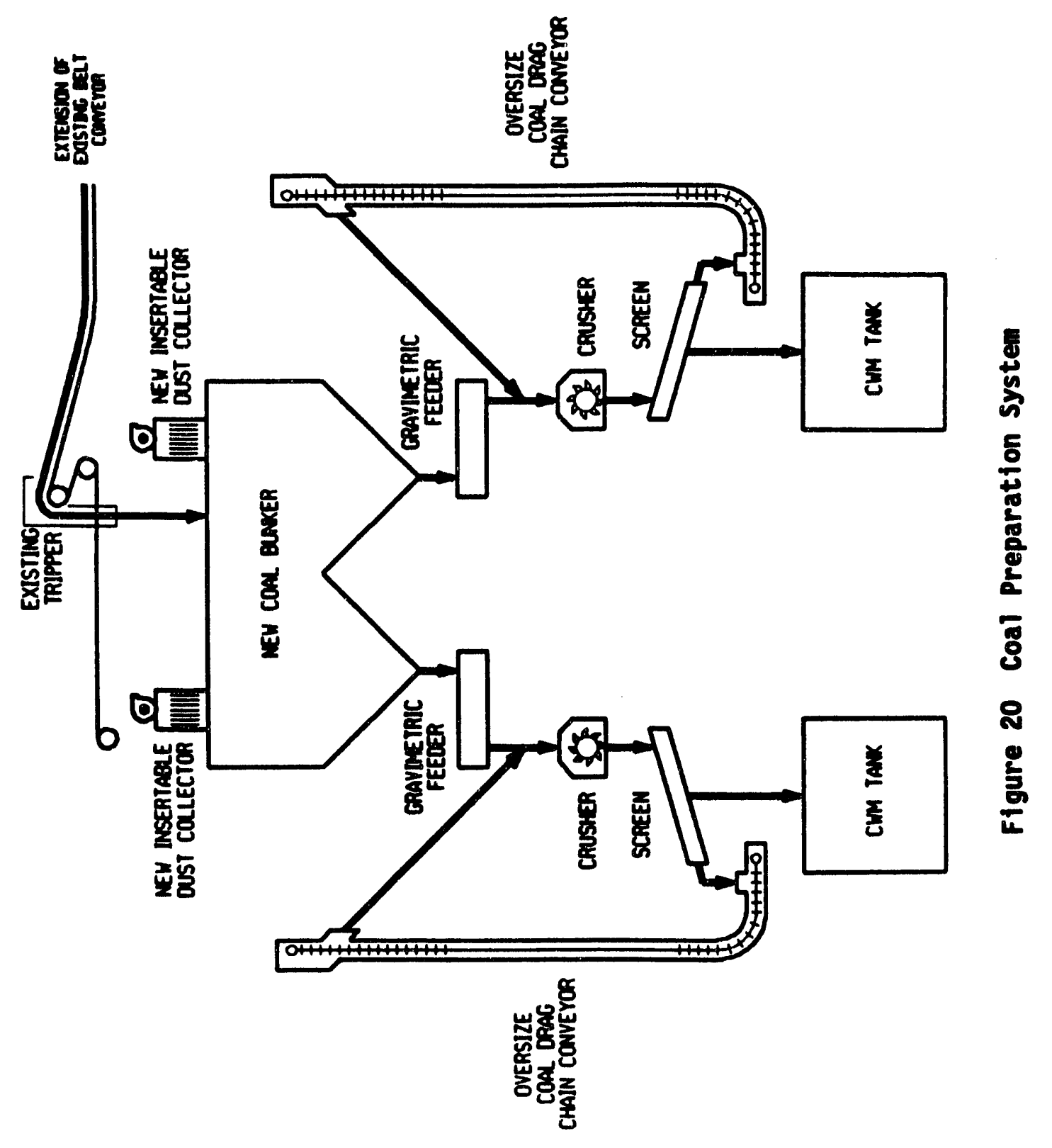


The tripper conveyor feeding the coal bunkers is extended to serve the new CPFBC bunker, which has two hoppers and a storage capacity for approximately 16 hours of coal above each hopper. The bunker has two vent filters to allow dust-free ventilation. Each coal bunker hopper feeds a single train of coal preparation equipment. Each train includes a gravimetric feeder, a crusher, a screen, and a slurry mix tank, where the coal is mixed with dolomite and water to form a coal/dolomite siurry. The coal screen separates the oversized coal particles from the flow path and feeds them into a serpentinetype drag chain conveyor, which transports the oversized coal back into the upstream crusher.

The coal handling system for Cases 3, 4, 5, and 6 is shown schematically in Figure 21. The coal hand'ing system includes the following major equipment:

- Truck hopper

- Belt feeder

- Bucket elevator

- Gravimetric feeder
- Coal storage silo (200 tons capacity)

- Crusher

- Reclaim conveyor

- Miscellaneous chutes, gates, etc.

Sized coal $(3 / 4$ in. $x 0)$ is delivered by trucks to the site and is unloaded to a receiving (truck) hopper. From the truck hopper, coal is conveyed to the new coal silo using a belt feeder, a bucket elevator, and a shuttle conveyor. Coal from the silo is conveyed to the coal bunker inside the slurry preparation building by a tripper conveyor. The new CPFBC bunker has two hoppers and a storage capacity for approximately 16 hours of coal above each hopper. The bunker has two vent filters to allow dust-free ventilation. Each coal bunker hopper feeds a single train of coal preparation equipment. Each train includes a gravimetric feeder, a crusher, a screen, and a slurry mix tank, where the coal is mixed with dolomite and water to form a coal/dolomite slurry. The coal screen separates the oversized coal particles from the flow path and feeds them into a serpentine-type drag chain conveyor, which transports the oversized coal back into the upstream crusher.

\subsubsection{Delomite Handline System} major functions:

System Functions. The dolomite handling system provides the following

- Receives and unloads truck deliveries of dolomite

- Stores dolomite in a storage silo.

- Transfers dolomite from storage to surge bins inside the boiler house.

The dolomite systems for Case 1 and Case 2 are identical. Similar systems for Cases 3, 4, 5, and 6 are smaller. 


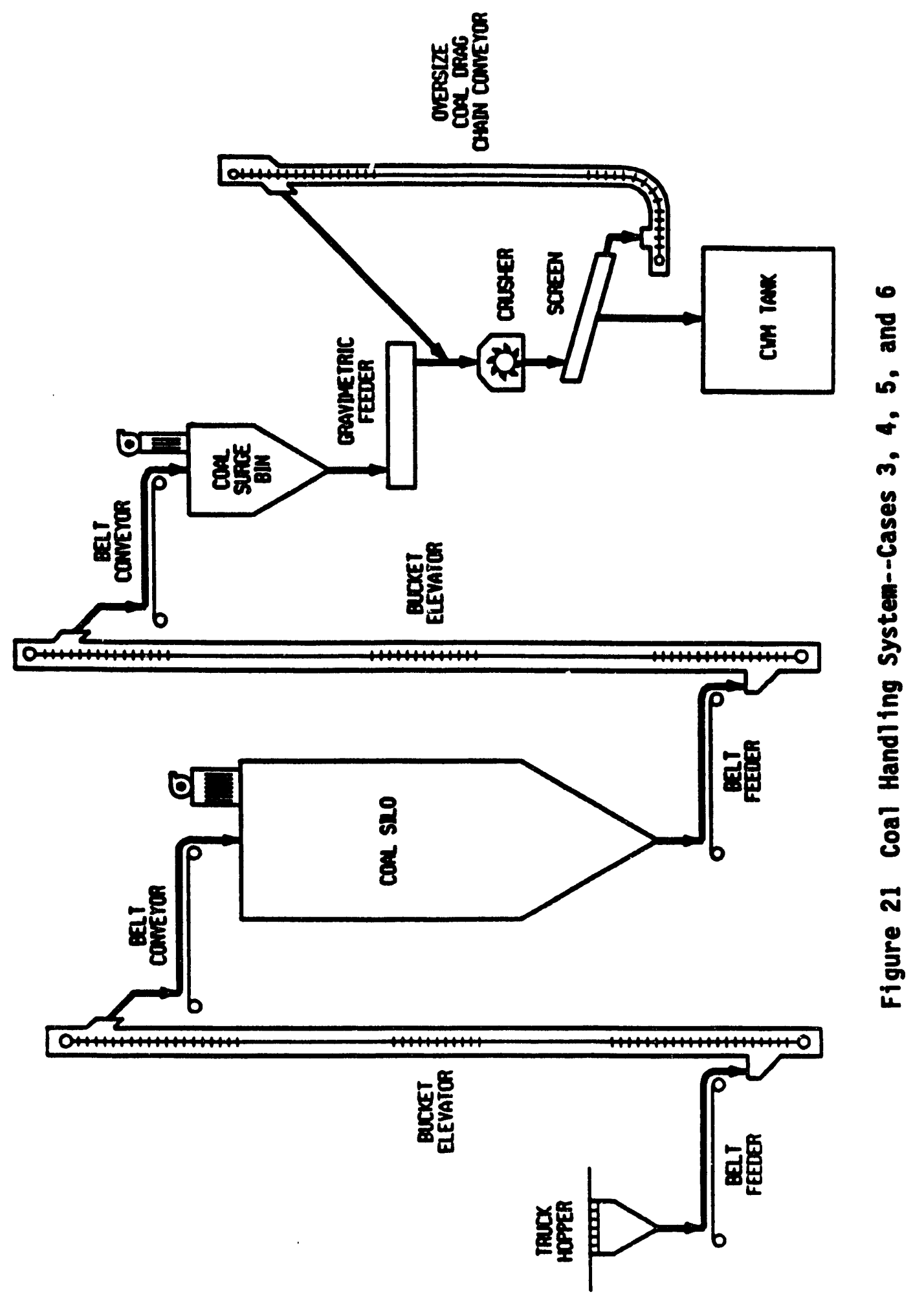


Desion Criteria. The system is based on these design criteria:

\begin{tabular}{|c|c|c|}
\hline & Cases 1 and 2 & Cases $3,4,5,6$ \\
\hline Truck unloading rate, $t / h$ & 27 & 27 \\
\hline Silo-to-surge bin transfer rate, $t / h$ & 16 & 16 \\
\hline $\begin{array}{l}\text { Dolomite density for volume sizing, } \\
\mathrm{lb} / \mathrm{ft}^{3}\end{array}$ & 45 & 45 \\
\hline $\begin{array}{l}\text { Dolomite density for structural } \\
\text { sizing, } 1 \mathrm{~b} / \mathrm{ft}^{3}\end{array}$ & 90 & 90 \\
\hline Dolomite storage requirements, days & 4 & 4 \\
\hline
\end{tabular}

System. Description. The dolomite handling system is shown schematically in Figure 22.

The dolomite receiving and storage system is designed to allow maintaining the supply of dolomite by receiving truck deliveries during a 40 -hiuur work week. To meet these supply requirements, approximately 14 trucks per day must be unloaded in an 8-hour shift. At an approximate unloading rate of one truck per hour, two trucks must be able to unload simultaneousiy. Two pressurized blower stations are provided to pneumatically convey dolomite from the delivery trucks to the dolomite storage silo. The dolomite storage silo 4-day capacities are:

\begin{tabular}{|cc|}
\hline Case & Ions \\
\hline 1 & 800 \\
2 & 800 \\
3 & 115 \\
4 & 175 \\
5 & 175 \\
6 & 105 \\
\hline
\end{tabular}

From the storage silo, dolomite is pneumatically conveyed in a pressure system to either of two surge bins. Each surge bin feeds one train of dolomite preparation equipment. Each train includes a gravimetric feeder, a screen, and a slurry mix tank, where dolomite is mixed with coal and water to form a coal/dolomite slurry. The dolomite screen separates the oversized dolomite particles from the flow path and feeds them onto a conveyor belt, common to both trains, which conveys the oversized dolomite to a waste bin.

The dolomite storage silo and surge bins have primary and secondary separators to capture and deposit the conveyed dolomite. The silo and surge bins also have vent filters to prevent dust emissions during venting. 


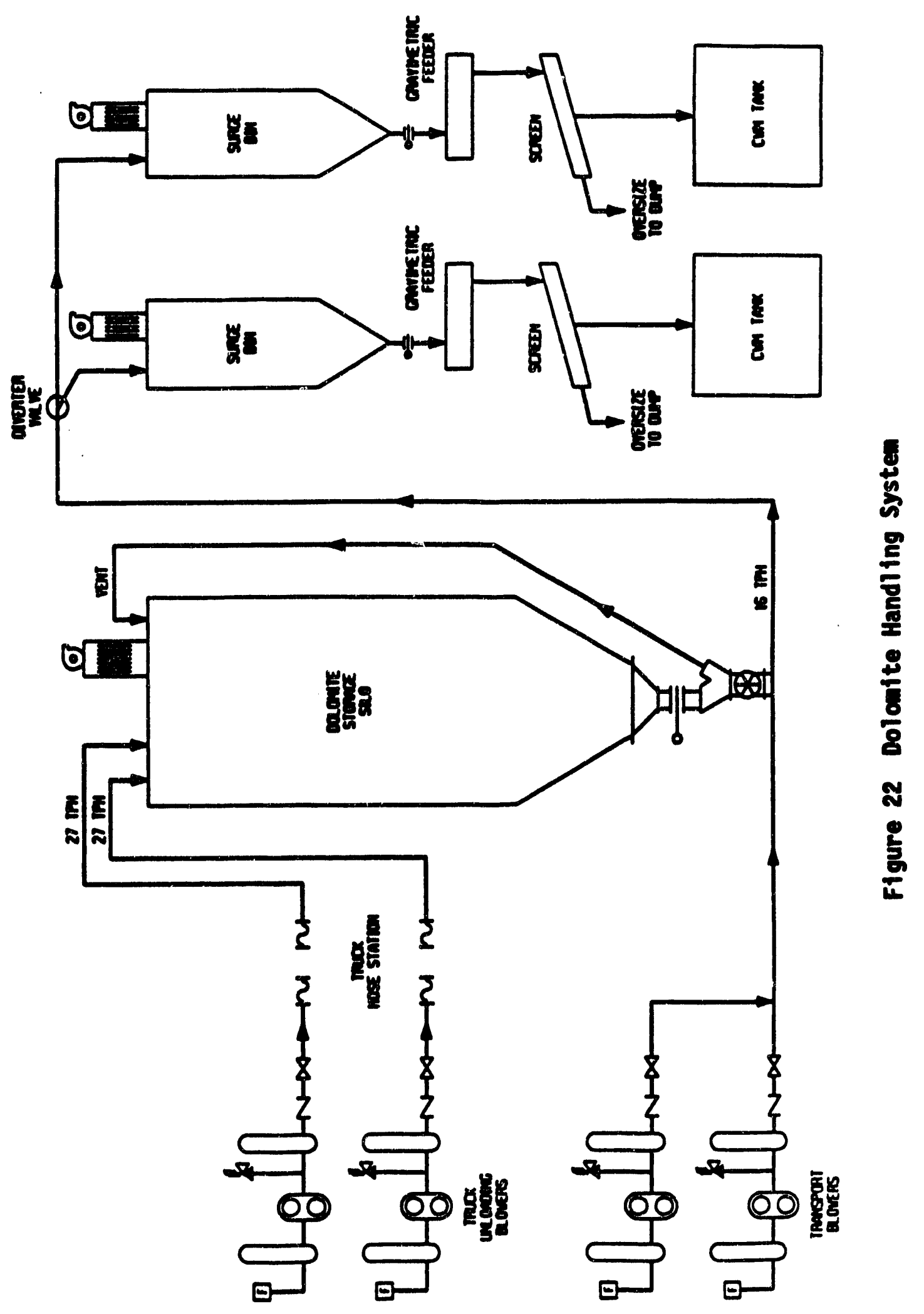




\subsection{3 slurry Systex}

One module of the two-module slurry system for Cases 1 and 2 is shown in Figure 23. Each train of the system is capable of 100-percent plant capacity; but normally, both modules operate at 50 percent of their capacity. In the event of equipment problems in one train, the other module will be brought up to full capacity to keep the plant on the line while repairs are being made.

Coal, sorbent, and water are combined in the mixing tank. The ratio of coal, sorbent, and water is 55:17:28 respectively. Agitators keep the slurry mixed in the tank. The slurry is pumped from the tank with piston pumps. In the Cases 1 and 2 systems, coal/sorbent slurry is fed to both the carbonizer and CPFBC. Separate pumps, valves, and flow meters are provided for each of the feed lines. They also have recirculation lines so that slurry flow can be continued even if the feed to the carbonizer or CPFBC must be stopped. This feature is required to prevent settling of solids in the lines. Atomizing air at a rate of about 5 percent of the mass flow of slurry is used to inject the slurry into the carbonizer and CPFBC.

The slurry system for Cases $3,4,5$, and 6 is the same as for Cases 1 and 2 except that only one module is required. A 16-hour holding capacity in the mixing tank provides a buffer for maintenance of the equipment upstream of the tank. This tank also has a recirculation pump to keep the slurry in suspension if agitator problems develop, eliminating redundancy upstream of the mixing tank. Since slurry feed in Cases 3, 4, 5, and 6 is only to the carbonizer or the PFBC, the one module shown in Figure 23 provides the redundancy required from the tank to the CPFBC or carbonizer. In each of these cases, both lines are sized for a full flow rate, but they will only be at 50-percent capacity during normal operation.

\subsection{CARBONITER/PFAC ISLAM}

\subsubsection{Garbonizar Subsustem}

The carbonizer subsystem is shown in Figure 24. It consists of the carbonizer, cyclone, barrier filter, and collecting hopper. The barrier filter will be discussed in Section 2.5. The design of the carbonizer subsystem is basically the same for Cases 1 through 5 . In fact, the size of the carbonizer and related equipment is similar for all of the cases. This situation was just a coincidence that resulted from the difference in system configuration between the larger and smaller plants. The larger plants were configured for maximum steam production. This type of operation requires that a greater proportion of the coal be directly burned in the PFBC, where steam can be generated. The smaller plants do not burn additional coal in the PFBC, so all the coal goes to the carbonizer.

The carbonizer is a jetting fluidized bed contained in a refractorylined pressure vessel. There is no heat-transfer surface in the carbonizer. The refractory consists of a 5-in. inner layer for thermal resistance and a 3-in. outer layer of hard-faced refractory for erosion resistance. Figure 25 shows the overall carbonizer dimensions for the different cases. The vessels are sized for $3 \mathrm{ft} / \mathrm{s}$ superficial gas velocity in the bed and $1.8 \mathrm{ft} / \mathrm{s}$ in the freeboard. 


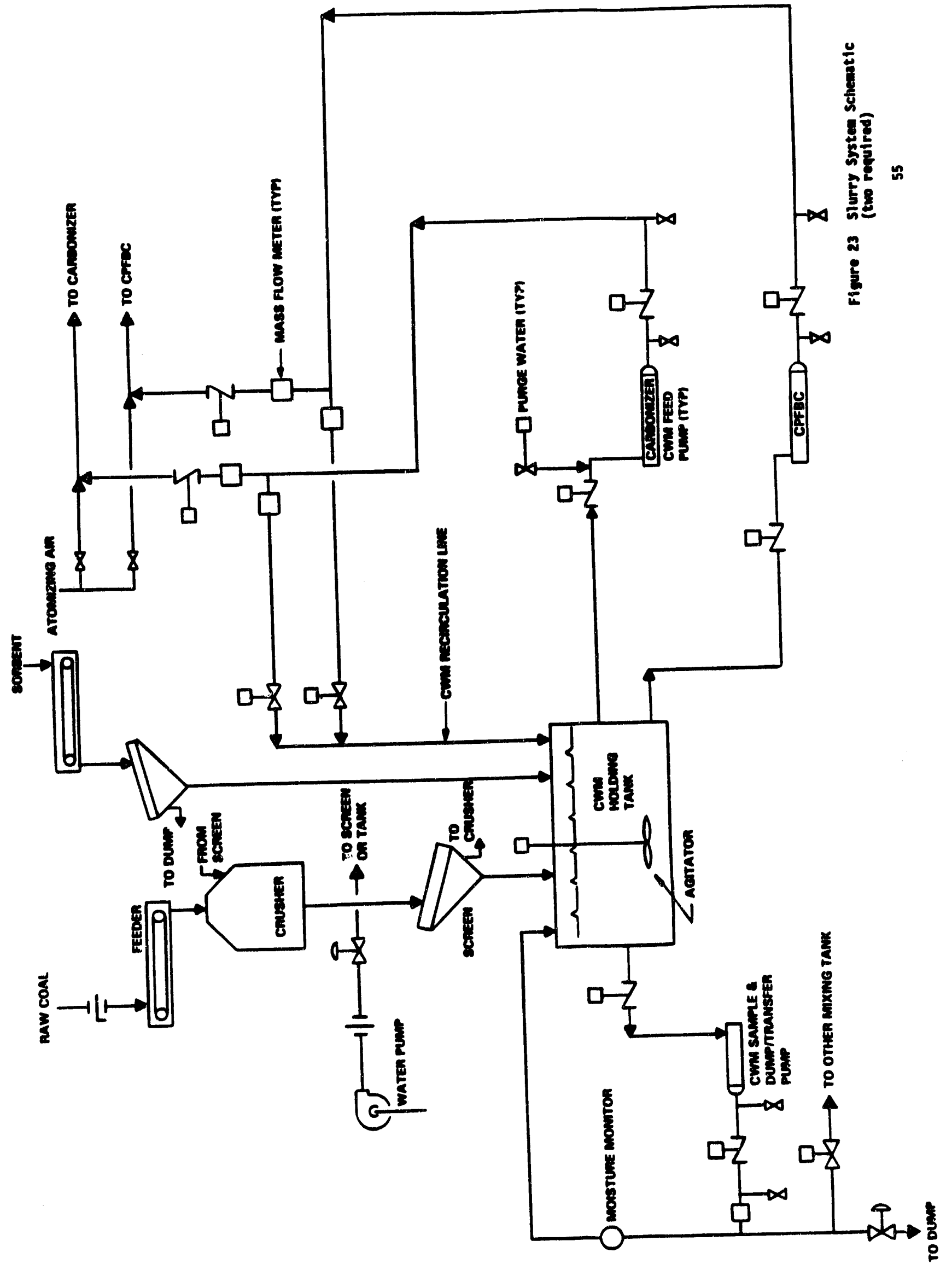



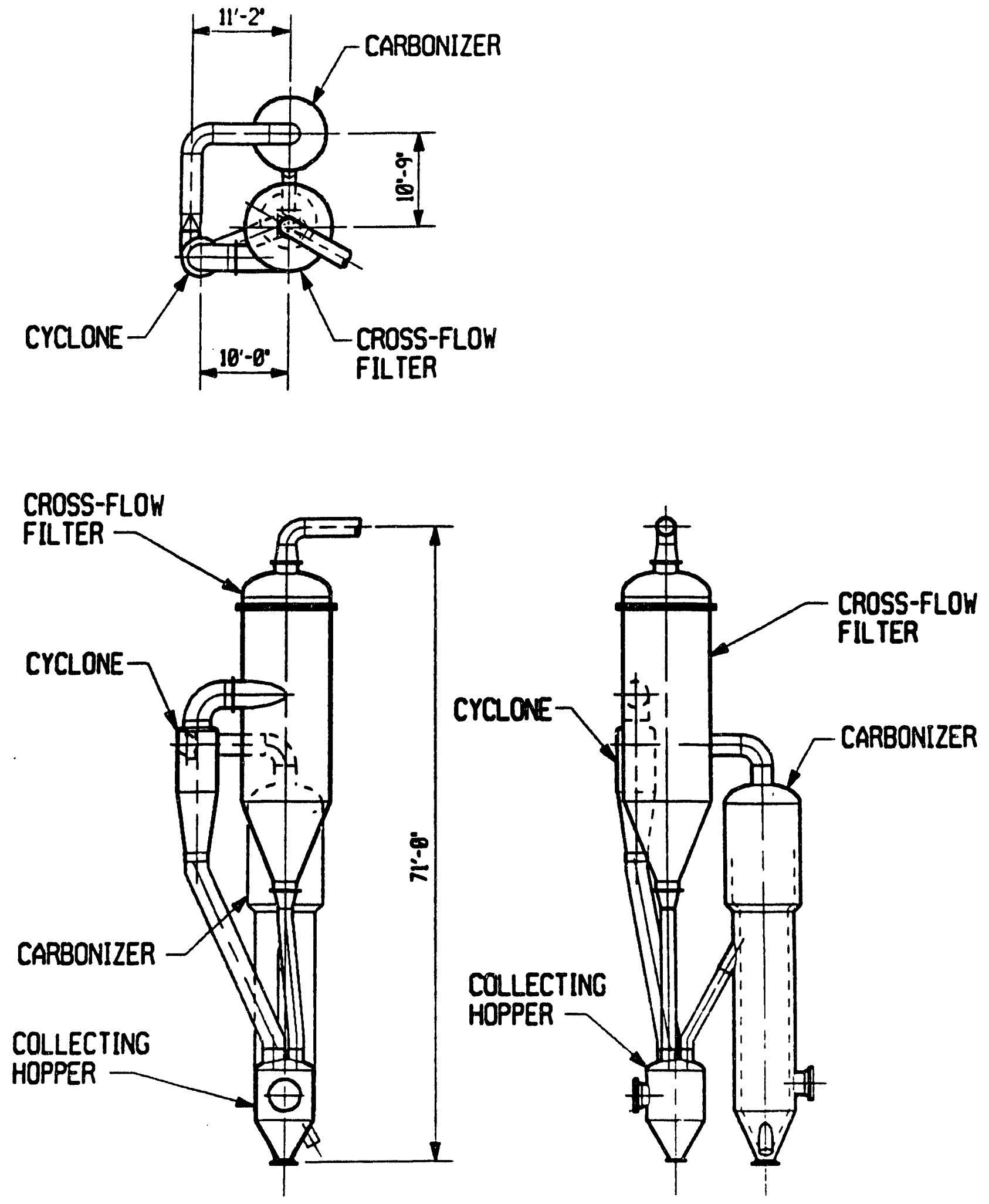

Figure 24 Carbonizer Subsystem--Plan and Elevation Views 

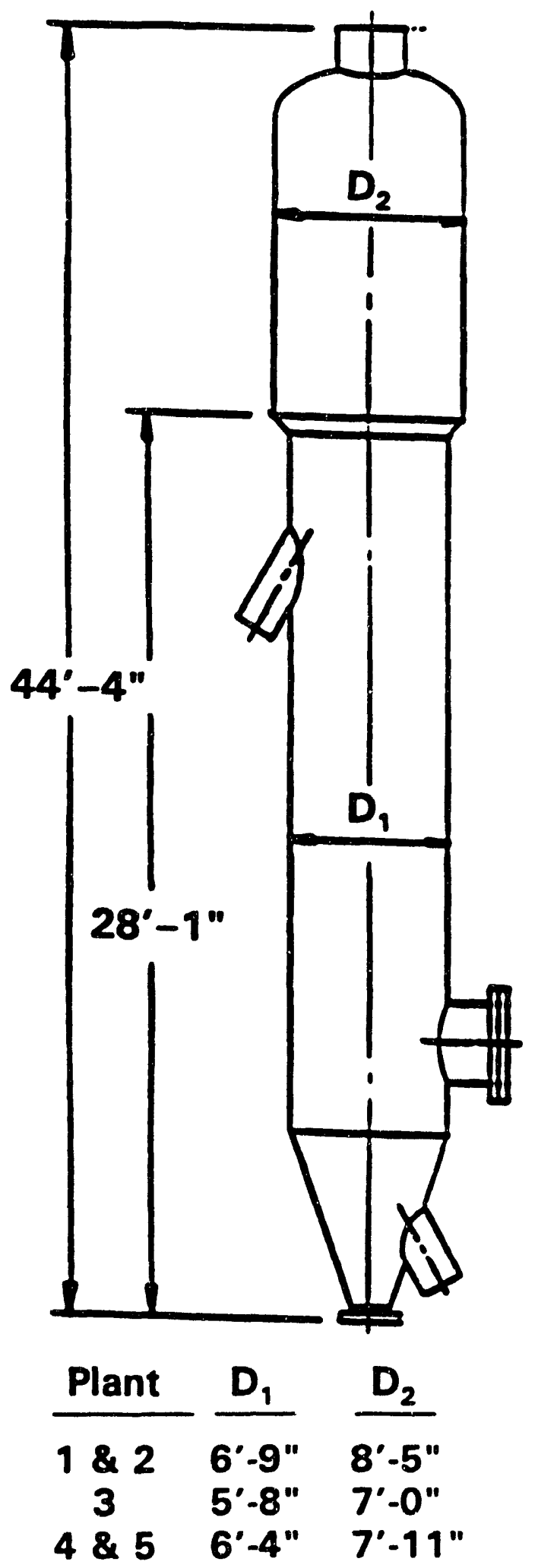

Figure 25 Carbonizer Dimensions
The coal/sorbent slurry is injected into the carbonizer near the bottom of the vessel. Air at a rate of 5 percent of the slurry mass flow is injected to atomize the slurry. An overflow nozzle $25 \mathrm{ft}$ above the jet removes solids from the carbonizer and limits the bed height to approximately this level. Other major penetrations of the vessel are a manway for out-ofservice maintenance, a bottom drain for removal of clinkers and bed draining during shutdown, and an exit pipe for the fuel gas.

Cyclone. The carbonizer subsystem has a single cyclone between the carbonizer outlet and the barrier filter. Solids captured by the cyclone drain to the hopper and from there are injected into the PFBC. The cyclones have been sized for an inlet velocity of $70 \mathrm{ft} / \mathrm{s}$ in each case, and the collection efficiency should be about 96 percent for the material expected to be elutriated from the carbonizer. Figure 26 shows the carbonizer cyclone dimensions for the different cases. These vessels are refractory lined with 5 in. of heatresistant refractory and 3 in. of hardfaced refractory for erosion resistance.

Collecting Hopper. The collecting hopper receives captured particulate solids from the carbonizer cyclone and barrier filter, as well as material from the bed drain. It operates at the carbonizer freeboard pressure, with trickle valves on the cyclone and barrier filter drain lines providing the required pressure seals. Solids from the collecting hopper drain into nitrogen-aeratud nonmechanical $\mathrm{N}$-valves for injection into the PFBC. If a CPFBC is used for combustion (Cases 1 and 2, for example), only one injection point--and thus only one $\mathrm{N}$-valve--is required. Bubbling bed PFBCs may require more than one injection point, depending on the crosssectional area and bed design.

The design of the collecting hopper for Cases 1 and 2 is shown in Figure 27. This collecting hopper has 


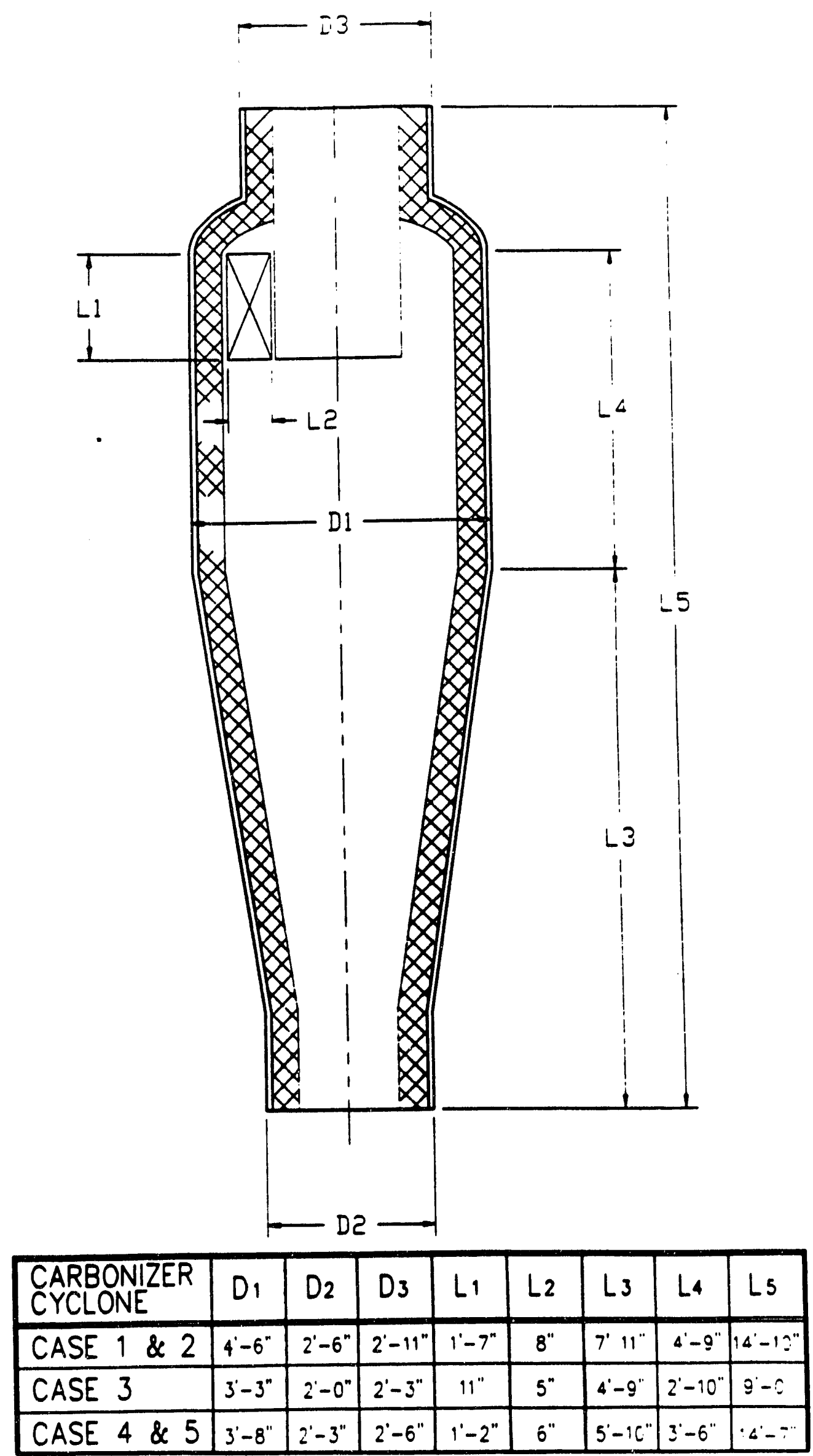

Figure 26 Carbonizer Cyclone 

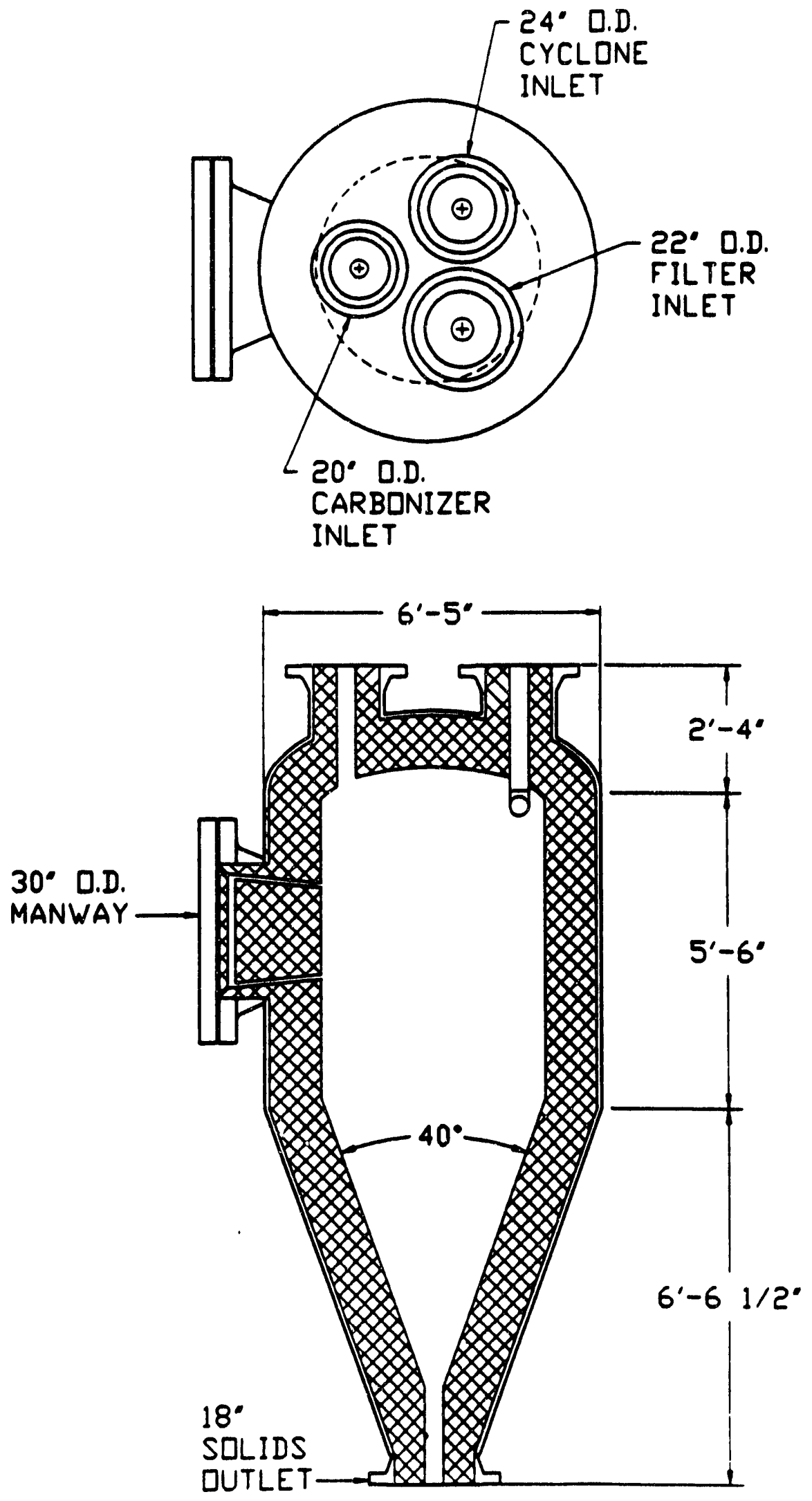

Figure 27 Carbonizer Collecting Hopper--Cases 1, 2, and 3 
only one outlet for the solids. Case 3 uses a jetting fluidized bed for the PFBC, and there is no reat-transfer surface in the bed. This design, also with only one solids injection point, uses the collecting hopper shown in Figure 27. Cases 4 and 5 use bubbling bed PFBCs and require three solids injection points for uniform distribution in the bed. The collecting hopper for these cases is shown in Figure 28. In this design, three conical sections within the pressure vessel divide the flow from the collecting hopper into three separate streams for injection into the PFBC.

N Valve. A slide valve and nonmechanical $N$ valve control the transfer of solids from the carbonizer subsystem to the PFBC. Nitrogen aeration precludes combustion of the char in the transfer process.

\subsubsection{PFBC Subsystem With CPFBC/FBHE Arrangement}

A typical arrangement of a PFBC subsystem with a CPFBC and an FBHE is shuwn in Figure 29. The dimensions shown are for Cases 1 and 2. In these cases, char and coal are burned in the CPFBC riser section, and heat is transferred to the steam in the FBHE. The subsystem consists of a CPFBC, cyclone, FBHE, and barrier filter.

The char/sorbent mixture from the carbonizer is fed to the CPFBC with the $N$ valve described in Section 2.4.1. Coal/sorbent slurry is fed to the CPFBC via a separate nozzle. Fluidizing air enters the bottom of the vessel and is distributed through nozzles in a grid plate. Solids that are removed from the flue gas stream in the cyclone flow to the FBHE. The pressure difference between the cyclone and the FBHE is sealed by the column of solids with a dip leg/seal pot arrangement.

The solids are fluidized in the FBHE. Air, the fluidizing medium, is injected into the CPFBC as secondary air after passing through the FBHE. Tube surface in the FBHE generates a portion of the steam load. The remainder of the stean load is generated in the HRSG. Solids can be bypassed around the tube bundles during start-up and partial-load operation. The transfer of solids from the FBHE to the CPFBC is accomplished with $\mathrm{J}$ valves. There are two $J$ valves, one for the bypass solids flow stream and one for the bed flow stream. By regulating the flow through these valves, the proportion of flow being bypassed can be controlled.

Circulating PFB Combustor. The CPFBC is a vertical, cylindrical, refractory-lined pressure vessel. The dimensions of this vessel for Cases 1 and 2 are shown in Figure 30. The refractory lining consists of 5 im. of heat-resistant refractory and $3 \mathrm{in}$. of hard-faced refractory for erosion resistance.

The lower, smaller-diameter zone is the primary combustion zone. The primary airflow rate is 50 percent of stoichiometry, and this portion of the CPFBC is sized for approximately $8 \mathrm{ft} / \mathrm{s}$ superficial gas velocity. The primary air enters a plenum at the bottom of the vessel and is injected into the bed through nozzles in a distributor plate.

Secondary air is injected into the CPFBC approximately $20 \mathrm{ft}$ above the primary air. At this location, the vessel diameter is larger to provide a superficial gas velocity of $12 \mathrm{ft} / \mathrm{s}$ with the total gas flow. There are six secondary air ports radially distributed around the vessel to provide good distribution and mixing of the secondary air. 


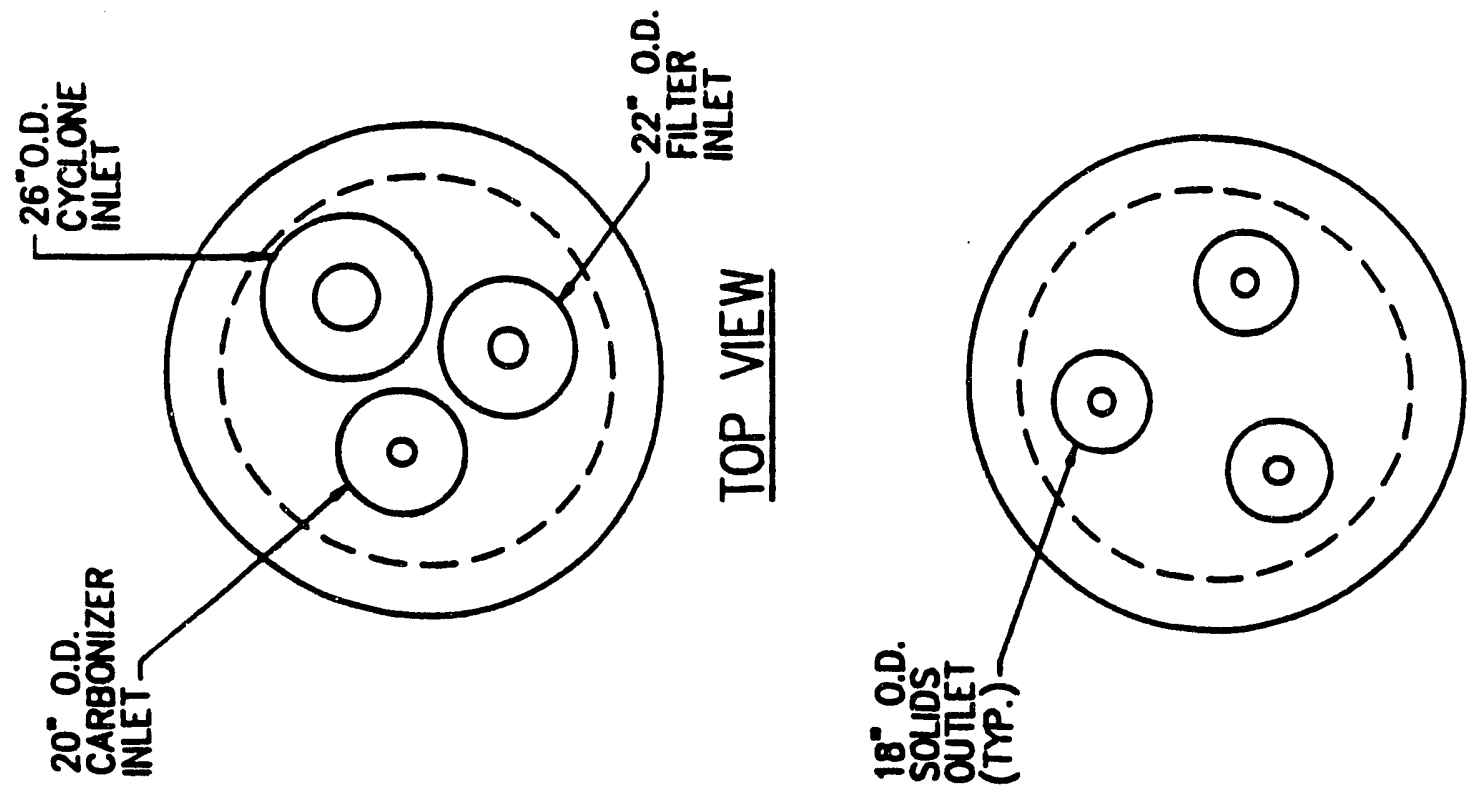

芷|

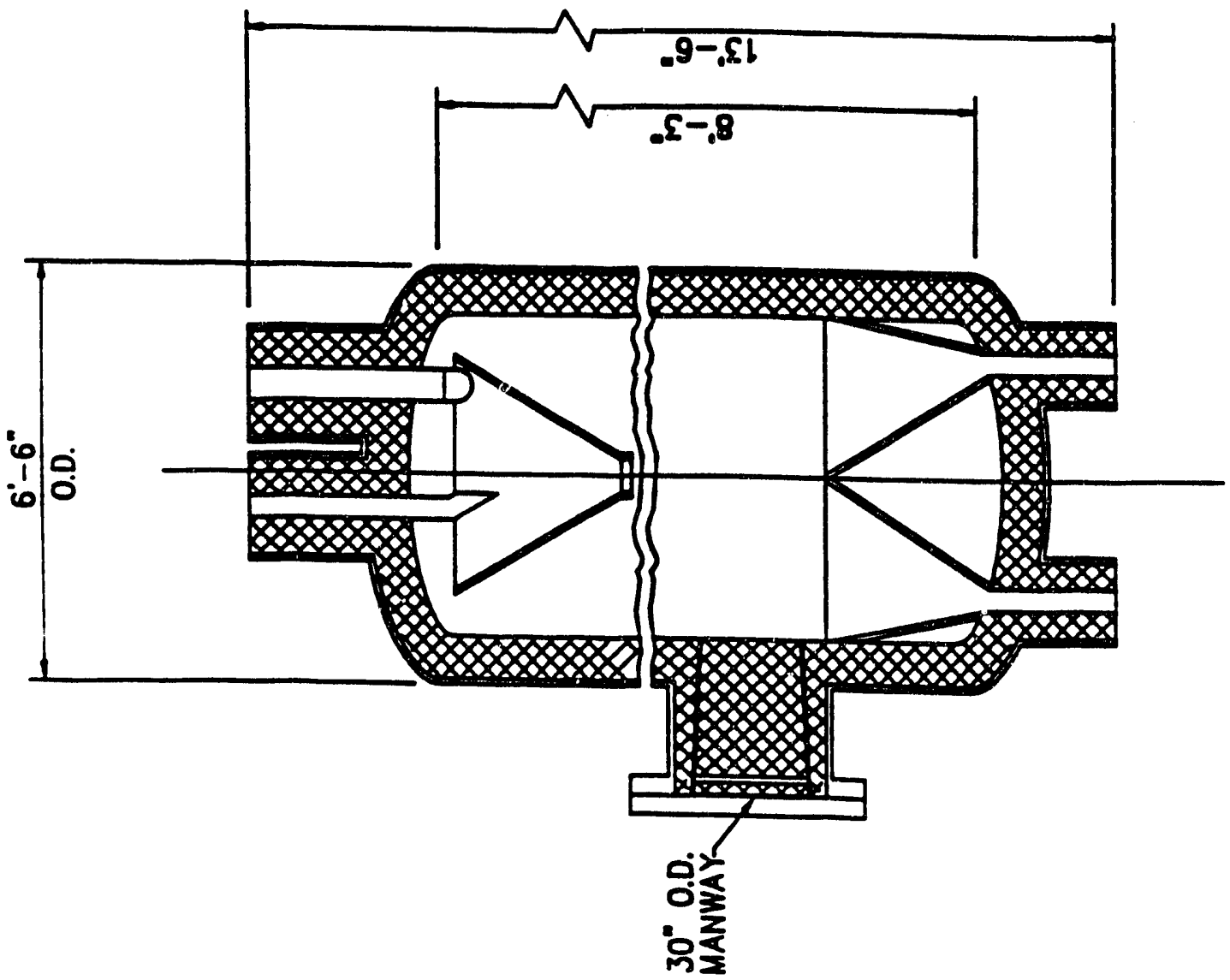




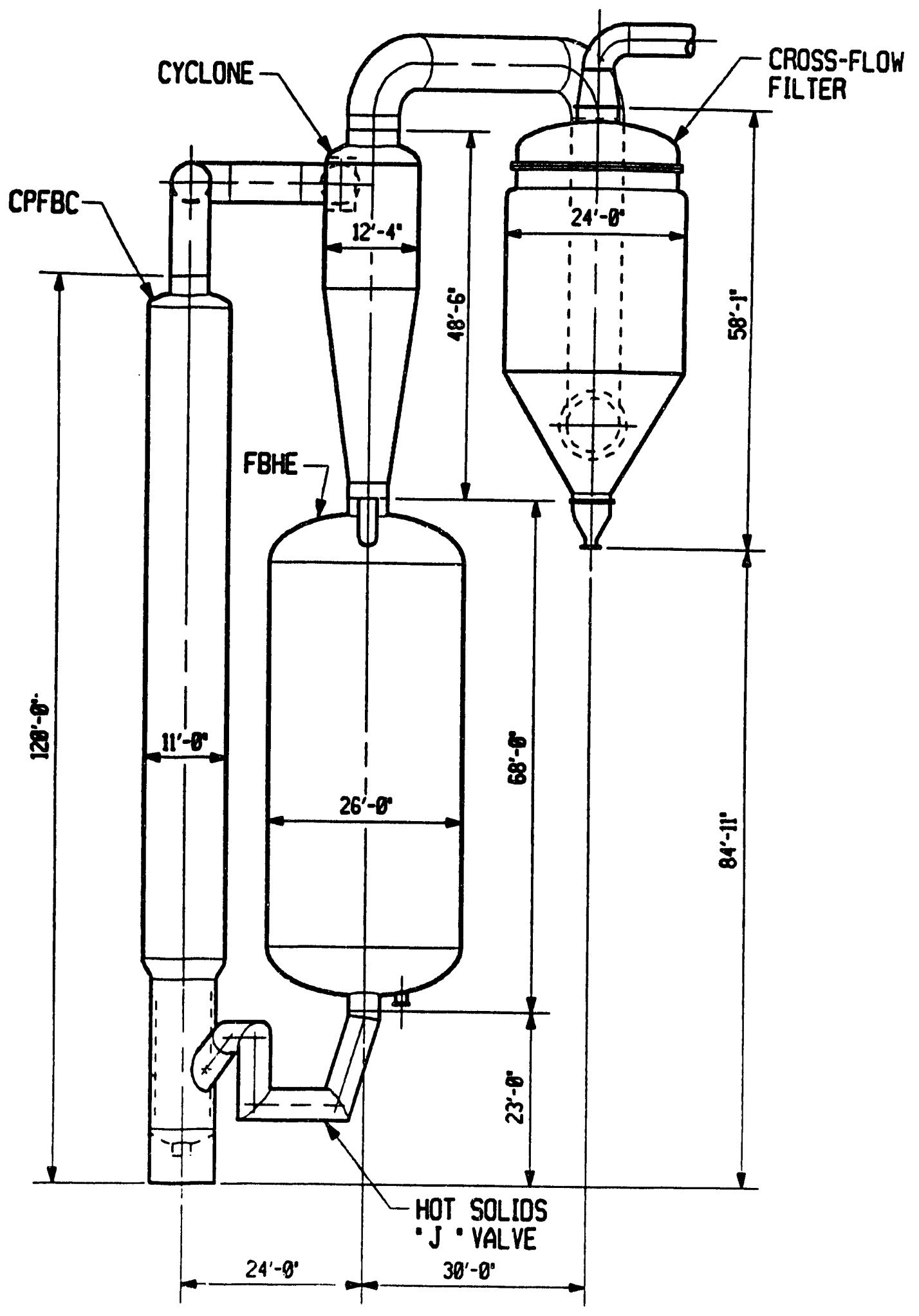

Figure 29 CPFBC/FBHE Arrangement 
(6)

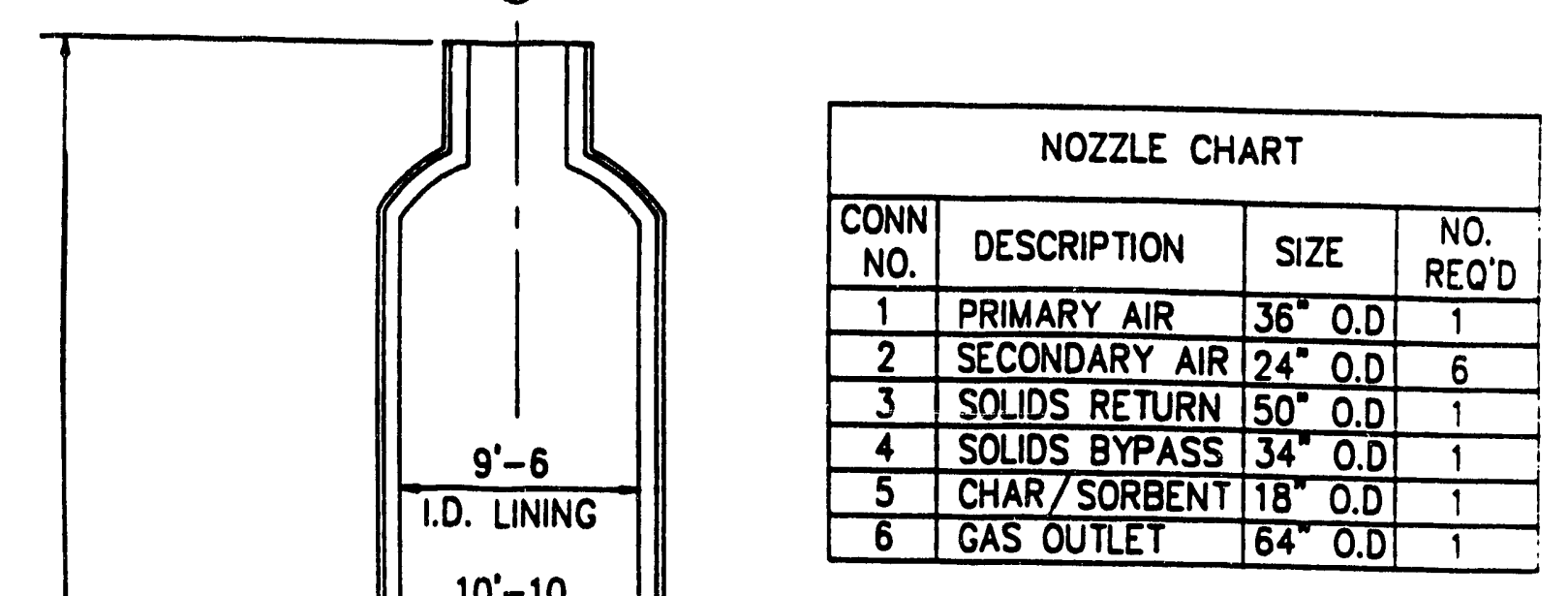

$10^{\circ}-10$

I.D. SHELL

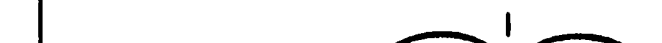


Flue gas and entrained solids leave the combustor at $1600^{\circ} \mathrm{F}$ through a nozzle at the top of the vessel. This stream then goes to the cyclone through an insulated pipe.

Cyclone. The cyclone separates the entrained solids from the flue gas stream and delivers them to the FBHE. The dimensions for the PFBC cyclone are shown in Figure 31. This cyclone is sized for a $70 \mathrm{ft} / \mathrm{s}$ inlet velocity.

Fluidized Bed Heat Exchanger. Sensible heat from the circulated solids is transferred to the steam cycle in the FBHE. The rest of the heat duty for the steam cycle is transferred in the HRSG. The FBHE portion of the steam cycle duty can vary considerably, depending on how the second-generation system is configured and operated. For this reason, the FBHE design can also vary considerably among different plants.

The FBHEs in this study have one fluidized bed in a vertical pressure vessel. The utility 470-MWe conceptual design had a horizontal vessel with multiple cascading beds [2]. With the smaller steam flows of the industrial plants and the lack of a reheat cycle, lower costs can be realized with a single-bed vertical-vessel design.

The FBHE for Case 1 is shown in Figure 32. It consists of a fluidized bed boiler mounted inside a pressure vessel. The fluidizing air enters the vessel and flows through the space between the vessel wall and the boiler enclosure walls. It then enters a plenum beneath the bed and through nozzles into the bed. This flow arrangement ensures that any leakage will be into the boiler, thereby protecting the vessel walls from high-temperature gas.

Figure 33 shows the solids flow through the FBHE. The boiler waterwalls form an enclosure with three chambers. These chambers are the seal pot, bypass channel, and fluidized bed. Solids from the cyclone dip leg flow into the seal pot. The seal pot and the resultant head of solids in the dip leg form the pressure seal between the cyclone and the FBHE.

Solids flow from the seal pot to the bypass channel by overflowing through an opening in the tubewall that divides the two chambers. In the bypass channel, the solids flow is distributed between the bypass drain and the fluidized bed. This distribution results from the design of the chamber and the control of the solids flow rate in the bypass drain $J$ valve.

The opening in the tubewall between the bypass channel and the fluidized bed does not extend as low as the opening between the seal pot and the bypass channel. If solids are removed through the bypass drain at the same rate as they are entering the FBHE, the level of solids in the bypass channel will never get high enough for the solids to flow into the fluidized bed. Operating in this mode will result in complete bypassing of the solids around the fluidized bed. If fewer solids are removed through the bypass drain $J$-valve than are fed to the FBHE, the solids in the bypass channel will rise to the level of the opening between the bypass channel and the fluidized bed. At this point, a portion of the solids flow will enter the fluidized bed. By completely stopping the flow through the bypass drain, all the solids will flow through the fluidized bed.

The fluidized bed chamber contains evaporator and superheater tube bundles. The solids are fluidized by air that flows through nozzles at the bottom of the bed (rectangular cross section with 12- and 10-ft sides). The superficial velocity in the bed is $0.5 \mathrm{ft} / \mathrm{s}$. A drain at the bottom of the fluidized bed removes solids and returns them to the CPFBC through a $\mathrm{J}$ valve. 


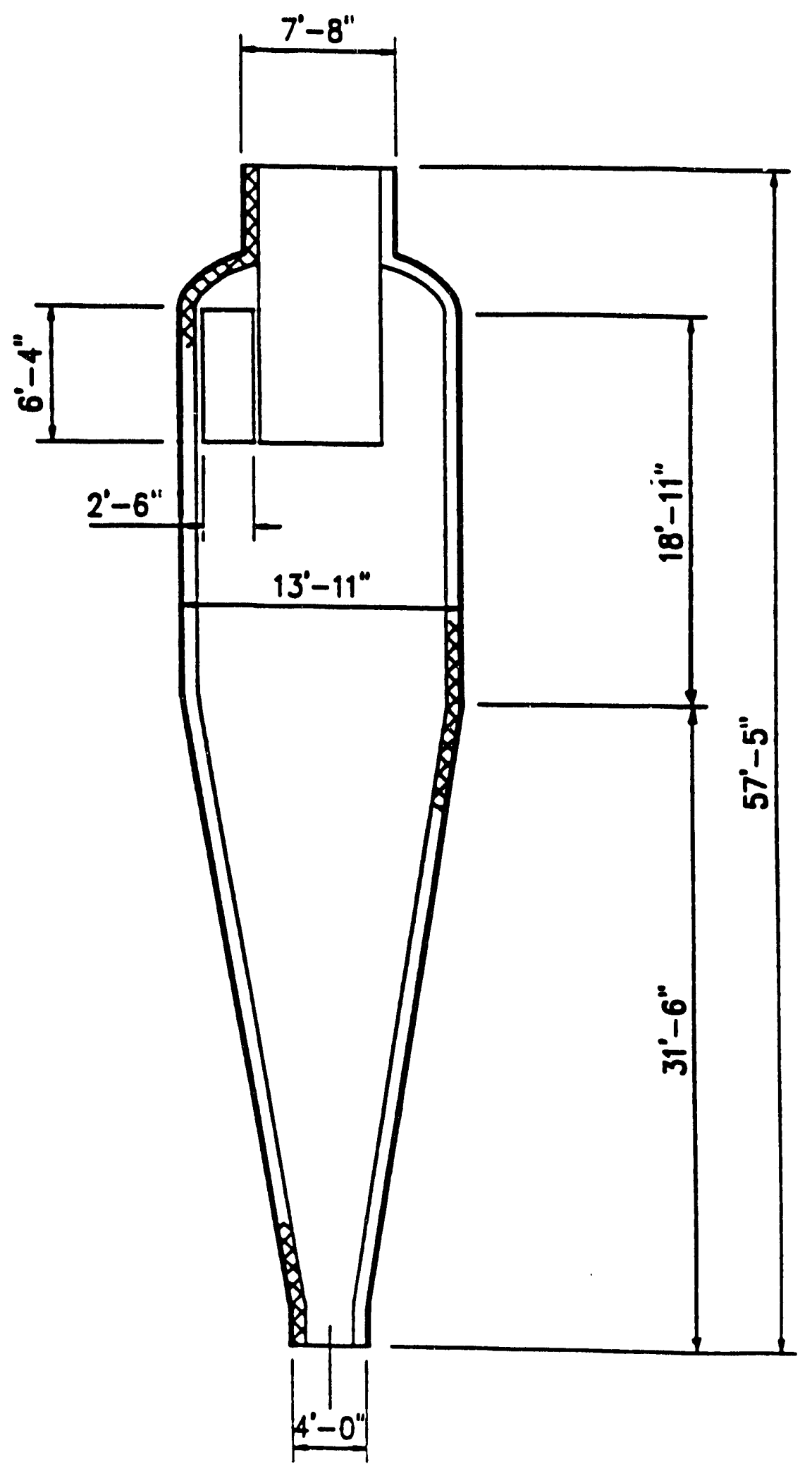

Figure 31 CPFBC Cyclone--Cases 1 and 2 


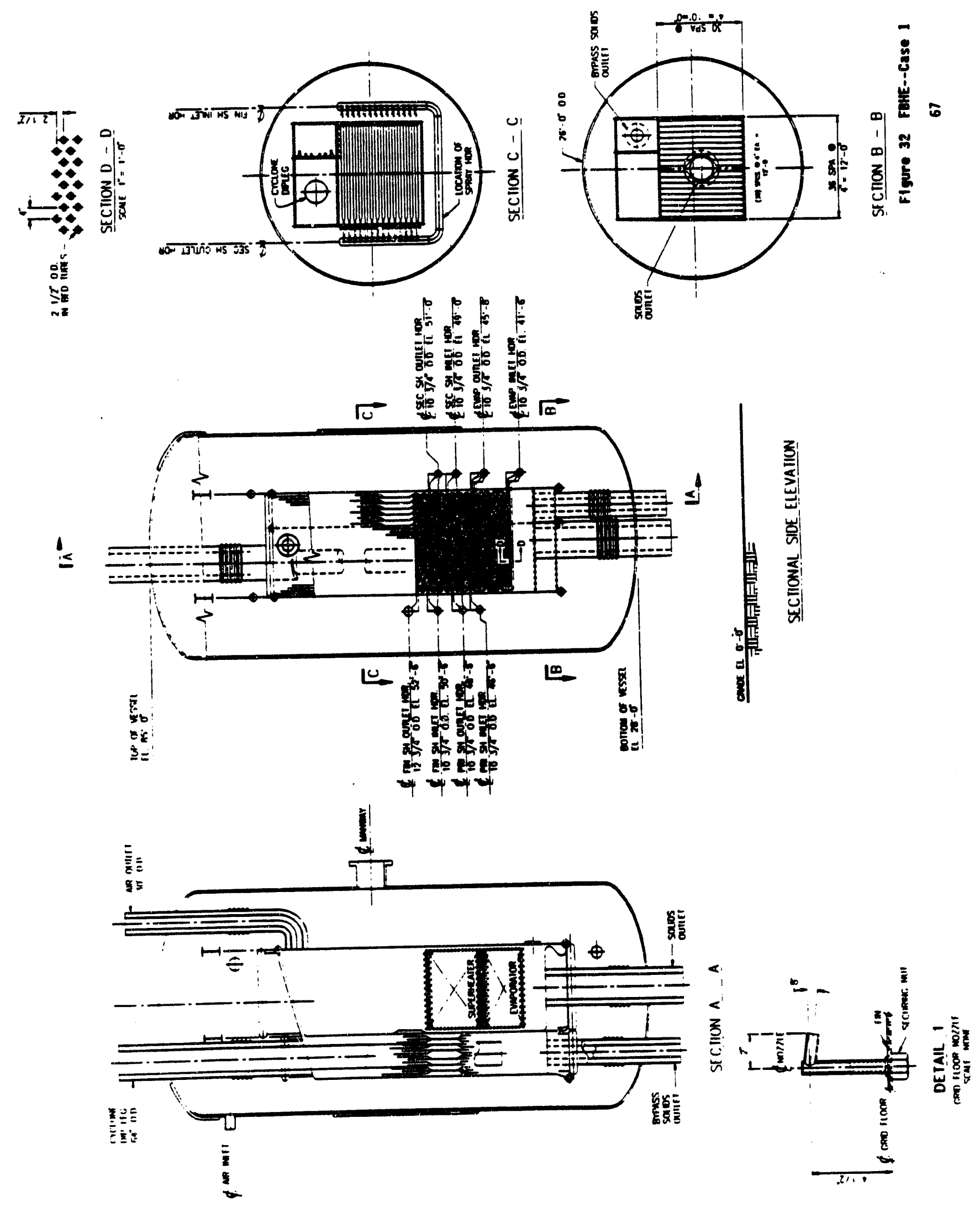




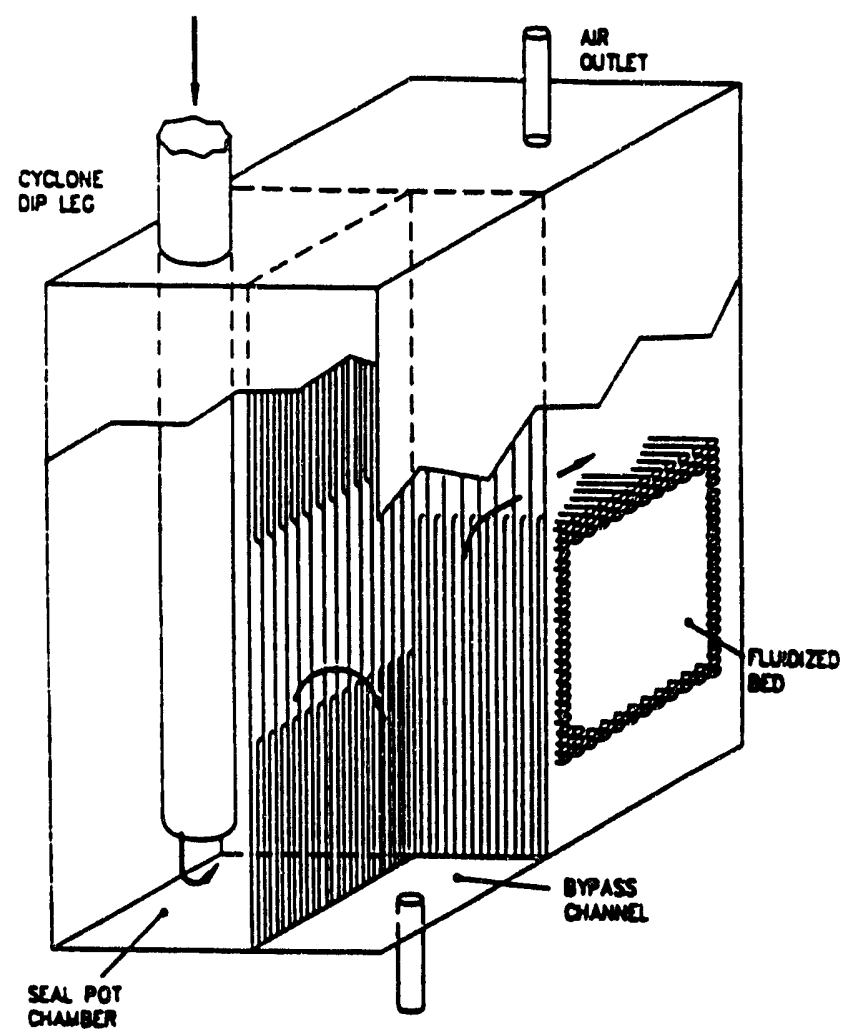

Figure 33 Solids Flow Through FBHE

The tube bundles have a density of 24.5 percent. This pattern is relatively dense, but it can be used because the particles in a circulating bed are relatively small and there is no combustion in the bed. The design is based on an outside heat-transfer coefficient of $80 \mathrm{Btu} / \mathrm{h} \cdot \mathrm{ft}^{2} \cdot{ }^{\circ} \mathrm{F}$ for the tubes in the bed. The outside heat-transfer coefficient to the wall tubes in the bed and freeboard are 50 and $30 \mathrm{Btu} / \mathrm{h} \cdot \mathrm{ft}^{2} \cdot{ }^{\circ} \mathrm{F}$ respectfully. The relatively dense packing of the tubes in the bed, the absence of combustion in the bed, and the relatively high solids flow rate through the bed will result in a temperature gradient from the top to the bottom of the bed. A gradient of $300^{\circ} \mathrm{F}$ was used in the design of this bed.

A schematic diagram of the steam circuitry for Case 1 is shown in Figure 34. This forced-circulation system has an external steam drum. Saturated steam and saturated water from the HRSG are fed to the steam drum. Witer is circulated through the FBHE evaporator tubes by the boiler circulation pump. The wall tubes and the tubes in the evaporator bundle are in parallel. Orifices properly distribute the water flow between the two circuits.

Steam from the drum goes to the superheater, which is divided into three sections to provide sufficient spray control. The spray control valves are within the pressure vessel in the transfer lines between the superheater sections. Table 4 lists the pressure parts for the Case 1 water/steam circuitry.

\subsubsection{PFBC Subsystem With Bubbling Bed Arrangement}

Because of their size and the process configuration, the small plants are better suited to bubbling bed PFBCs than to CPFBCs. As described in Section 2.2, the small plants use a second-generation process arrangement where a large portion of the airflow is bypassed around the PFBC and fed directly to 


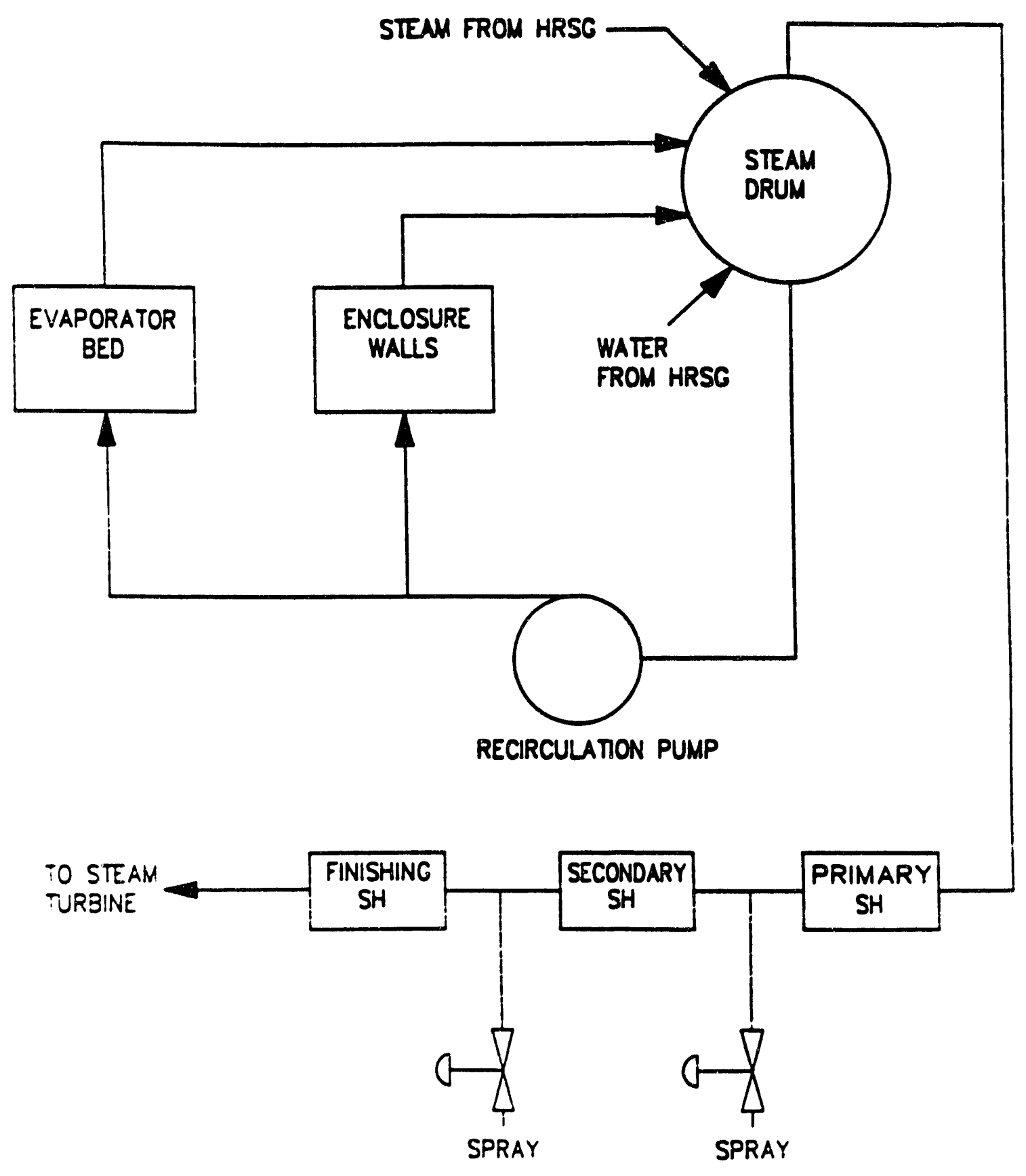

Figure 34 Steam Circuitry--Case 4 
Table 4 Steam Generator Pressure Parts--Case 1

\begin{tabular}{|c|c|c|}
\hline Description & Size & Material \\
\hline Evaporator Bundle & $2.5^{\prime \prime} 0.0 . \times 0.200^{n}$ & $S A-210-C$ \\
\hline Primary Superheater Bundle & $2.5^{\prime \prime} 0.0 . \times 0.180^{n}$ & TP347H \\
\hline Secondary Superheater Bundle & $2.5^{n}$ O.D. $\times 0.230^{n "}$ & TP347H \\
\hline Finishing Superheater Bundle & $2.5^{\prime \prime}$ O.D. $\times 0.300^{n}$ & TP347H \\
\hline $\begin{array}{l}\text { Evaporators: } \\
\text { Feeder Manifold } \\
\text { Feeders } \\
\text { Inlet Headers } \\
\text { Tubewalls } \\
\text { Outlet Headers }\end{array}$ & $\begin{array}{l}16^{\prime \prime} \operatorname{Sch} 160 \\
4^{\prime \prime} \operatorname{Sch} 40 \\
10^{n} \operatorname{Sch} 140 \\
3^{\prime \prime} 0.0 . \times 0.240^{\prime \prime} \\
10^{\prime \prime} \operatorname{Sch} 40 \\
\end{array}$ & $\begin{array}{l}\text { SA-106-C } \\
\text { SA-106-C } \\
\text { SA-106-C } \\
\text { SA-210-C } \\
\text { SA-106-C } \\
\end{array}$ \\
\hline Risers & $4^{\prime \prime} \operatorname{sen} 40$ & SA-106-C \\
\hline Riser Manifold & $18^{\prime \prime} \operatorname{Sch} 160$ & $S A-106-C$ \\
\hline $\begin{array}{l}\text { Primary Superheater: } \\
\text { Inlet Transfer Pipe } \\
\text { Inlet Header } \\
\text { Outlet Header } \\
\text { Transfer Pipe } \\
\end{array}$ & $\begin{array}{l}8^{n} \text { Sch } 80 \\
10^{\prime \prime} \text { Sch } 40 \\
10^{\prime \prime} \text { Sch } 140 \\
10^{\prime} \operatorname{Sch} 140 \\
\end{array}$ & $\begin{array}{l}\text { SA-106-C } \\
\text { SA-106-C } \\
\text { SA-106-C } \\
\text { SA-106-C } \\
\end{array}$ \\
\hline $\begin{array}{l}\text { Secondary Superheater: } \\
\text { Inlet Header } \\
\text { Outlet Header } \\
\text { Transfer Pipe } \\
\end{array}$ & $\begin{array}{l}10^{\prime \prime} \text { Sch } 140 \\
10^{\prime \prime} \text { Sch } 160 \\
10^{\prime \prime} \text { Sch } 100 \\
\end{array}$ & $\begin{array}{l}\text { SA-106-C } \\
\text { SA-355-P22 } \\
\text { SA-355-P22 } \\
\end{array}$ \\
\hline $\begin{array}{l}\text { Finishing Superheater: } \\
\text { Inlet Header } \\
\text { Outlet Header } \\
\text { Transfer Pipe } \\
\end{array}$ & $\begin{array}{l}10^{\prime \prime} \operatorname{Sch} 160 \\
12.75^{n} 0.0 . \times 2.13^{n+} \\
12^{n} \operatorname{Sch} 160\end{array}$ & $\begin{array}{l}S A-355-P 22 \\
S A-355-P 22 \\
S A-355-P 22 \\
\end{array}$ \\
\hline
\end{tabular}


the topping combustor. This process arrangement and the reduction in throughput because the plant is smaller makes a bubbling more reasonable than a circulating bed. For example, a CPFBC for Cases 4 and 5 would have a diameter of only $2 \mathrm{ft}$ and would be approximately $100 \mathrm{ft}$ high. In addition to the CPFBC, an FBHE and solids recirculation system would be required, adding to the complexity and expense of the system. In contrast, a bubbling bed PFBC would require only a single bed, in a vessel that could be completely shop fabricated and transported.

These PFBCs have been designed to minimize the problems that could occur from the burning of char in a bubbling PFBC. Superficial velocities in the bed are kept at $3 \mathrm{ft} / \mathrm{s}$ to minimize tube erosion, and bed heights are maintained at $11 \mathrm{ft}$ to give sufficient residence time for carbon burnout. Because Case 3 has an adiabatic bed, tube erosion is not even a factor in this plant.

The injection of the char and sorbent into the PFBC is more critical in the bubbling bed designs. The mixing within the bed is not as good as with a CPFBC, so care must be taken to have sufficient injection points to distribute the char/sorbent stream. Cases 4 and 5 each have a bubbling bed with air injected through multiple nozzles. These PFBCs use three char/sorbent injection points to obtain an injection point for every $9 \mathrm{ft}^{2}$ of bed cross section. Since Case 3 has no tubes in the bed, a jetting fluidized bed is used, allowing only one char/sorbent injection point.

It is also beneficial when burning char in a bubbling bed to have a bed as high as possible to achieve the maximum residence time for carbon burnout and sulfur capture. This goal is easier with pressurized systems than it is with atmospheric systems because the additional pressure drop is easier to accommodate. The beds for Cases 3, 4, 5, and 6 are $11 \mathrm{ft}$ deep.

Jetting PFBC (Case 3). The jetting PFBC for Case 3 is shown in Figure 35. The bed is sized for a superficial velocity of $3 \mathrm{ft} / \mathrm{s}$, which resuits in a vessel I.D. of $8 \mathrm{ft}-8 \mathrm{in}$. in the bed. The vessel is expanded to a $12 \mathrm{ft}$ 2 in. I.D. in the freeboard above the bed to minimize elutriation. Since Case 3 is an adiabatic PFBC, there are no tubes in the bed, and the vessel is lined with refractory to reduce its metal temperature and protect it from erosion. The refractory consists of a 5-in. thickness of thermal refractory and a 3-in. thickness of hard-faced refractory for erosion resistance.

The air jet and solids inlet are in the lower portion of the PFBC. Because of the mixing action of the jetting bed, only one solids injection point is required. This injection point is near the air jet in the $:-f t$ I.D. section of the PFBC. Of the required combustion air, 50 percent is injected through the central air jet. The remaining air is injected through ring spargers along the sloped section of the lower bed. Ash and spent sorbent are removed from the bottom of the bed.

Flue gas and any entrained solids leave the PFBC at $1600^{\circ} \mathrm{F}$ through a nozzle at the top of the vessel. This stream then flows to the cyclone through an insulated pipe.

Bubbling Bed PFBC (Cases 4, 5, and 6). Cases 4, 5, and 6 use bubbling bed PFBCs to burn the char and generate steam. The PFBC for Case 4 is shown in Figure 36. Except for the tube bundles, the Case 5 PFBC is identical in size and layout. Case 6 requires a slightly larger bed cross-sectional area, but it still fits into the same size vessel. Three char/sorbent injection points are required; these are on the front wall and each of the sidewalls. 


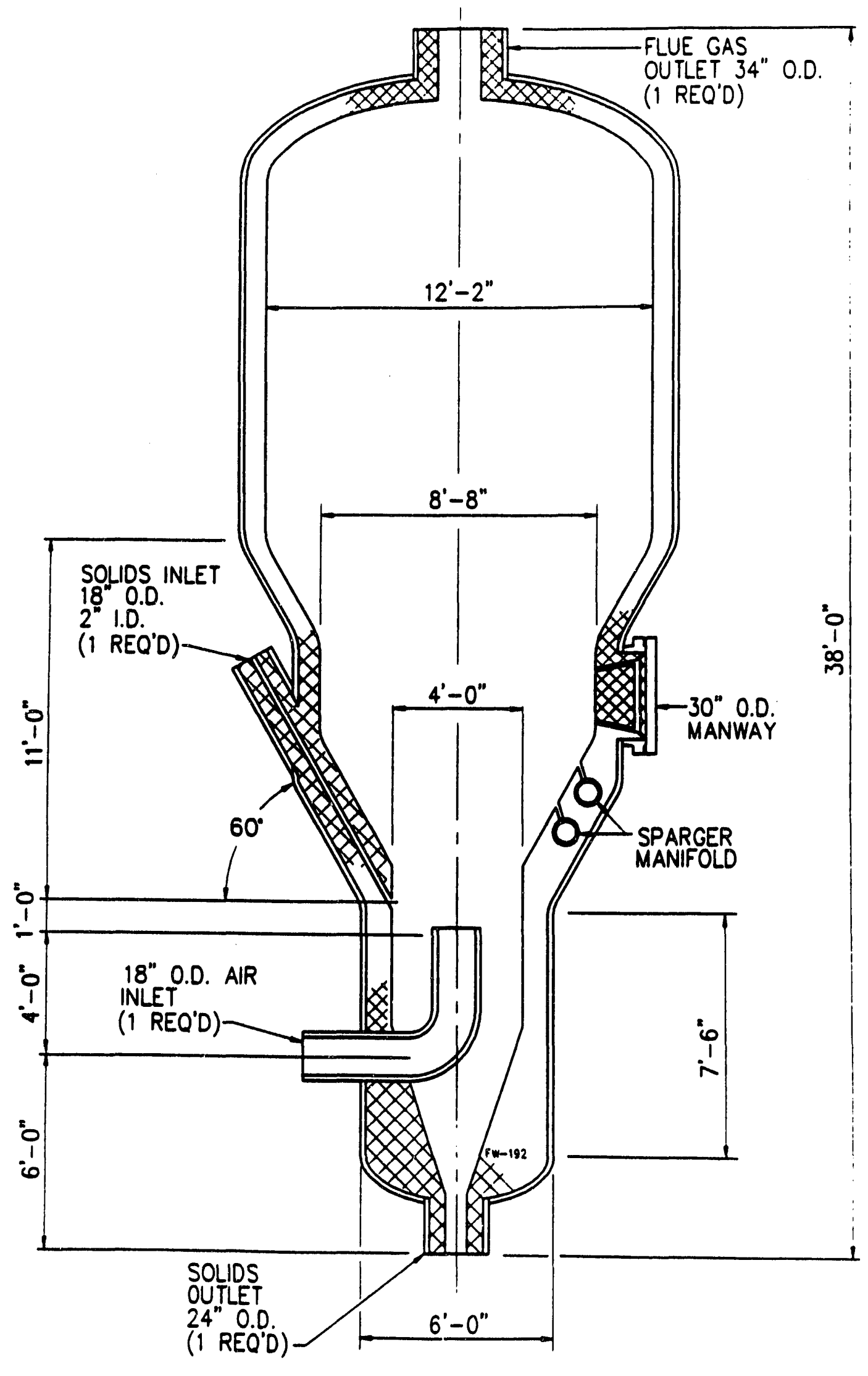

Figure 35 PFBC--Case 3 

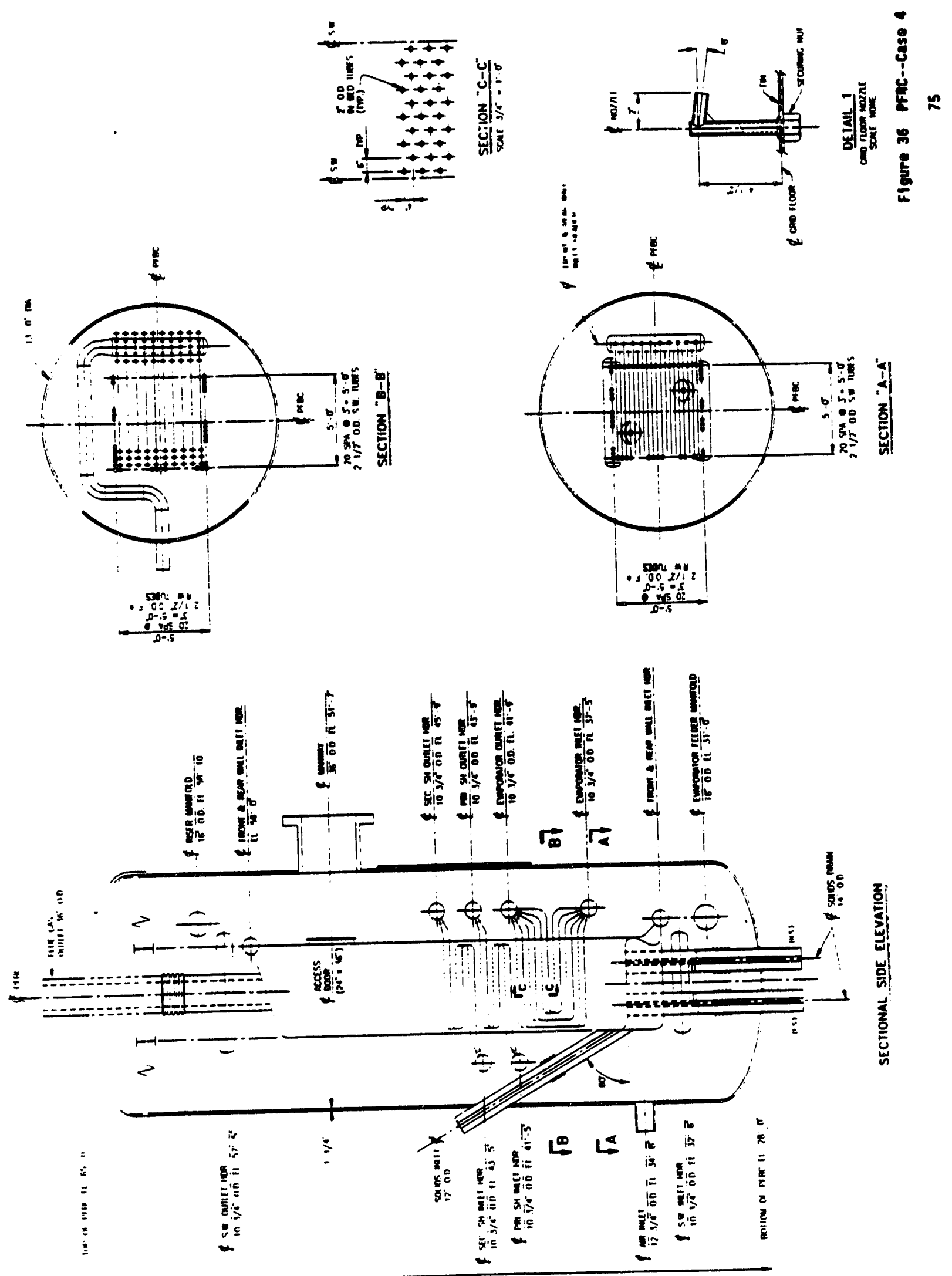
Combustion air enters the vessel and fills the volume between the vessel and the waterwall enclosure. This arrangement ensures that all leakage is into the waterwall enclosure, and hot gases are prevented from contacting the vessel wall. The air then flows into the bed area through nozzles.

The fluidized bed has a rectangular cross section that is a $5 \mathrm{ft} \times$ $5 \mathrm{ft}$ so that the superficial gas velocity in the bed is $3 \mathrm{ft} / \mathrm{s}$. As previously discussed, the bed height is $11 \mathrm{ft}$ to achieve sufficient residence time for the combustion of the char. These dual requirements result in relatively wide tube spacing in the bed so that it is evenly filled with the tubes. The tube density in the bed is 2.6 percent.

The flue gas from the combustion of the char leaves the waterwall enclosure and the pressure vessel through an insulated pipe at the top of the PFBC. Ash and spent sorbent are removed from two insulated drain lines at the bottom of the bed.

A schematic diagram of the Case 4 steam circuitry is shown in Figure 37. As with Case 1, the steam flow is forced circulation with an external steam drum. The only difference in the steam/water circuitry between Case 1 and Case 4 is that only one spray control is required in Case 4 so there are only two superheater sections. Table 5 lists the pressure parts for the steam/water circuitry.

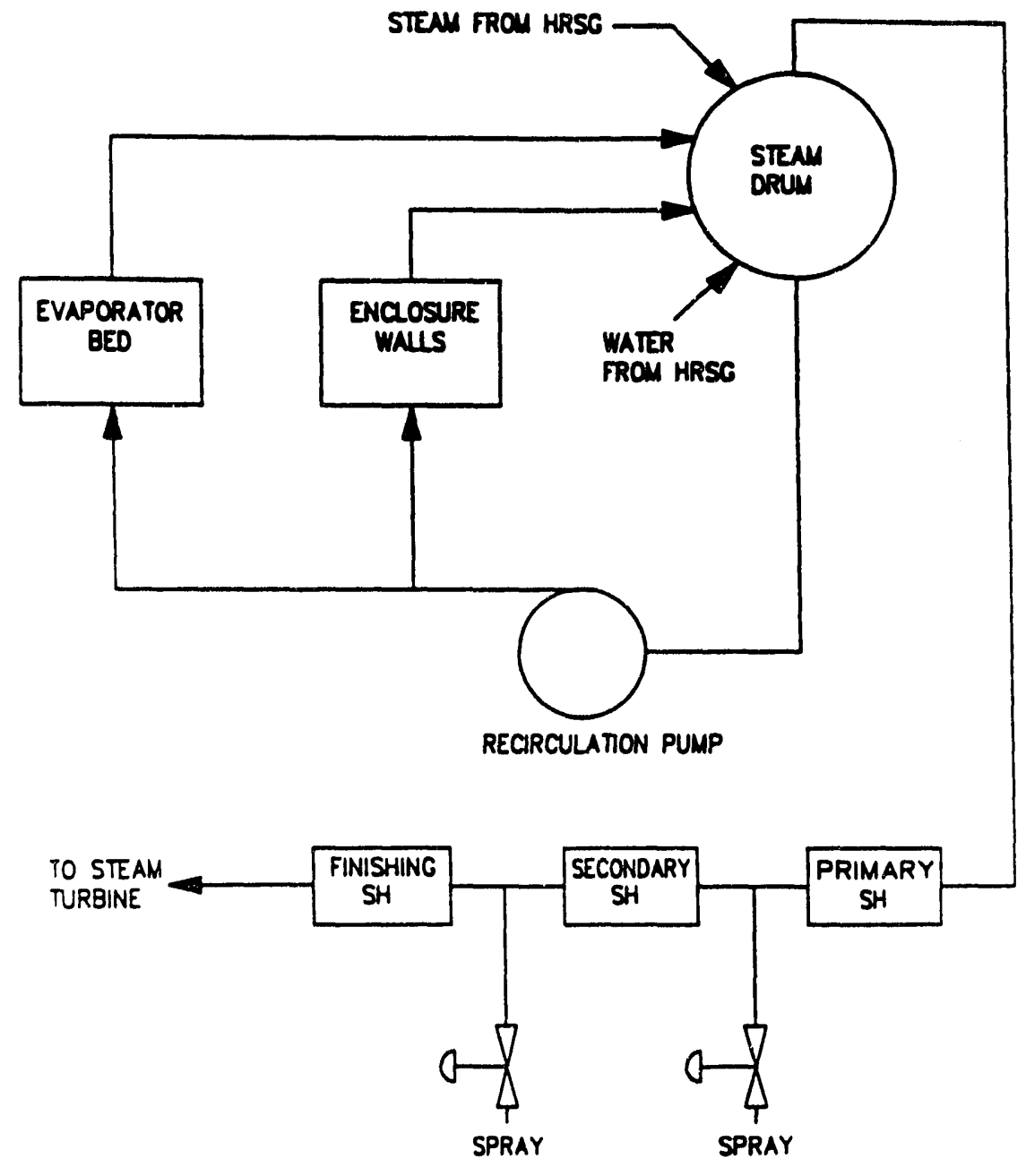

Figure 37 Steam Circuitry--Case 4 
Table 5 PFBC Stean Generator Pressure Parts--Case 4

\begin{tabular}{|c|c|c|}
\hline Description & Size & Material \\
\hline Evaporator Bundle & $2^{n} 0.0 . \times 0.180^{n "}$ & SA-106-C \\
\hline Primary Superheater Bundle & $2^{\prime \prime} 0.0 . \times 0.180^{\circ}$ & SA-213-T22 \\
\hline Secondary Superheater Bundl & $2^{\prime \prime} 0.0 . \times 0.180^{\circ "}$ & SA-213-T22 \\
\hline $\begin{array}{l}\text { Evaporator: } \\
\text { Feeder Manifold } \\
\text { Feeders } \\
\text { Inlet Headers } \\
\text { Tube Walls } \\
\text { Outlet Headers }\end{array}$ & $\begin{array}{l}16 " \operatorname{Sch} 120 \\
4^{\prime \prime} \operatorname{Sch} 40 \\
10^{\prime \prime} \operatorname{Sch} 120 \\
4^{\prime \prime} \operatorname{Sch} 40 \\
2.5^{\prime \prime} \times 0.200^{\prime \prime}\end{array}$ & $\begin{array}{l}\text { SA-106-C } \\
\text { SA-106-C } \\
\text { SA-106-C } \\
\text { SA-106-C } \\
\text { SA-210-C } \\
\end{array}$ \\
\hline Risers & $4 " \operatorname{Sch} 40$ & $S A-106-C$ \\
\hline $\begin{array}{l}\text { Primary Superheater: } \\
\text { Inlet Transfer Pipe } \\
\text { Inlet Header } \\
\text { Outlet Header }\end{array}$ & $\begin{array}{l}6 " \text { Sch } 80 \\
10^{n} \text { Sch } 120 \\
10^{n} \text { Sch } 120\end{array}$ & $\begin{array}{l}\text { SA-106-C } \\
\text { SA-106-C } \\
\text { SA-106-C }\end{array}$ \\
\hline $\begin{array}{l}\text { Secondary Superheater: } \\
\text { Inlet Transfer Pipe } \\
\text { Inlet Header } \\
\text { Outlet Header } \\
\text { Outlet Transfer Pipe }\end{array}$ & $\begin{array}{l}\text { 6" Sch } 80 \\
10^{\prime \prime} \text { Sch } 120 \\
10^{\prime \prime} \operatorname{Sch} 120 \\
6 " \operatorname{Sch} 80\end{array}$ & $\begin{array}{l}\text { SA-106-C } \\
\text { SA-106-C } \\
\text { SA-355-P22 } \\
\text { SA-355-P22 }\end{array}$ \\
\hline
\end{tabular}




\subsection{HOT GAS CLEANUP AND PIPING}

The equipment descriptions in this section pertain primarily to Case 1, the largest of the study cases. Equipment for the other study cases is described as variations from Case 1.

\subsubsection{Hot Gas Cleanup}

The first stage of hot gas cleanup for both the carbonizer and PFBC subsystems is the cyclones. These devices are described in Section 2.4. After passing through the cyclones, the gas streams from the carbonizer and the PFBC go to separate barrier filters. The barrier filters consist of filter elements mounted in pressure vessels. The filter elements are cleaned by a blow-back system, and the collected particulates are removed from the bottom of the vessels. In the blow-back system, nitrogen is used for the carbonizer barrier filter and air for the PFBC barrier filter.

Westinghouse cross-flow filters have been used in the design study. Candle filters would also be applicable as barrier filters for this system. Table 6 gives design data for the cross-flow filters.

\subsubsection{Hot Gas Piping}

Piping to and from the cyclones and cross-flow filters of the carbonizer and the CPFBC were designed for these velocities:

\begin{tabular}{|ll|}
\hline \multicolumn{1}{|c|}{ Piping Run } & $\mathrm{ft} / \mathrm{s}$ \\
\hline Dirty gas from carbonizer or CPFBC to cyclone & 70 \\
Partially cleaned gas at cyclone outlet & 64 \\
Partially cleaned gas from cyclone to cross-flow filter & $30-35$ \\
Clean gas from cross-flow filter to gas turbine & 150 \\
\hline
\end{tabular}

Cyclone outlets are short "Y" sections connecting the cyclones to the main pipes.

All hot gas piping is lined with 6 in. of two-component castable refractory, and final pipe diameters are adjusted to use standard pipe sizes. The clean gas lines to the turbine are lined with stainless steel to protect the turbine. This pipe has 5 in. of single-component castable refractory and 1 in. of KAOWOOL between the liner and the refractory. The pipe dimensions and parameters shown in Tables 7 and 8 for the carbonizer and CPFBC piping are based on the stated velocities. 


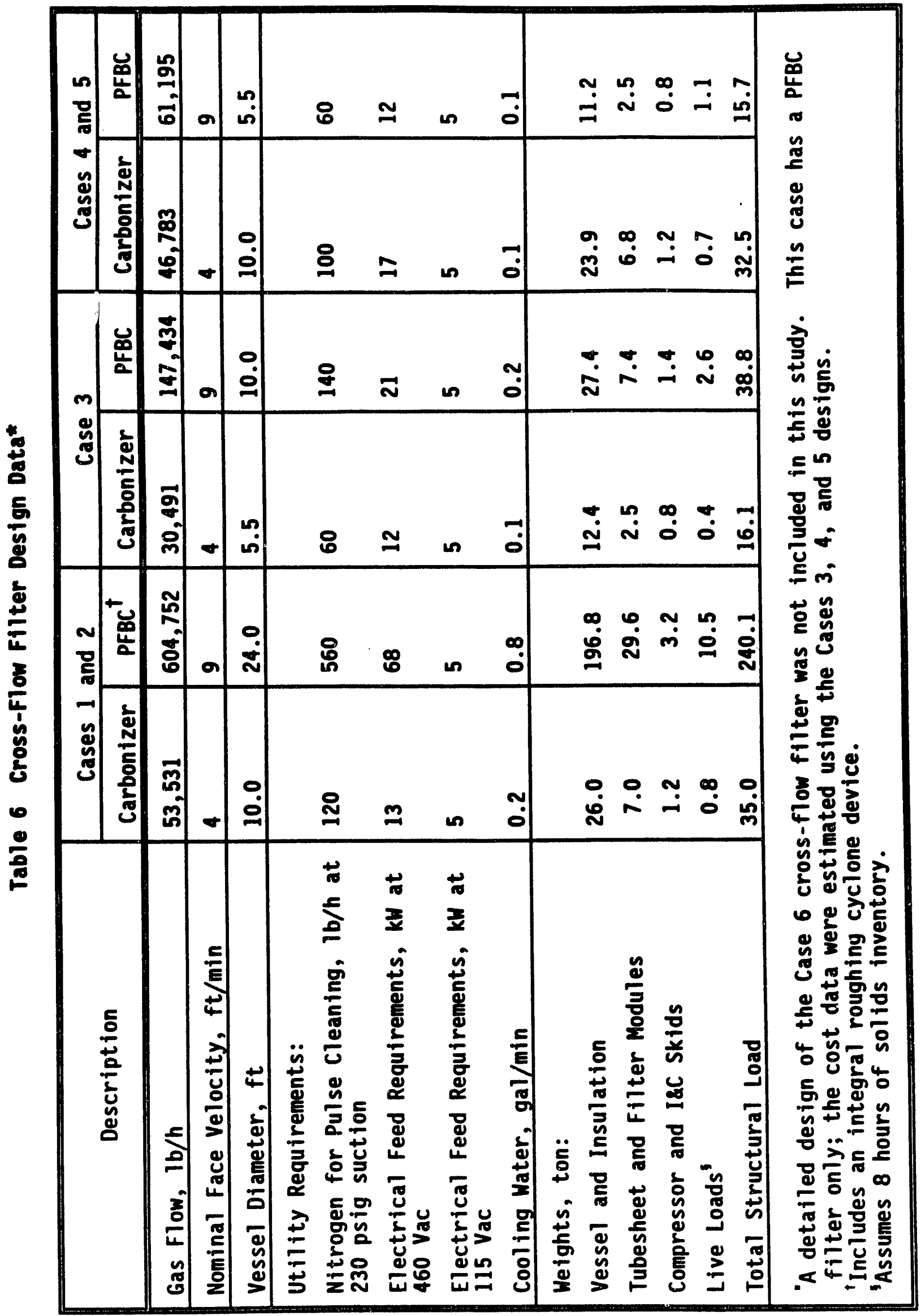


Table 7 Carbonizer Hot Gas Piping

\begin{tabular}{|l|l|l|l|l|}
\hline \multicolumn{1}{|c|}{ Description } & $\begin{array}{c}\text { Carbonizer } \\
\text { to } \\
\text { Cyclone }\end{array}$ & $\begin{array}{c}\text { Carbonizer } \\
\text { Cyclone } \\
\text { Outlet }\end{array}$ & $\begin{array}{c}\text { Cyclone } \\
\text { to Cross- } \\
\text { Flow } \\
\text { Filter }\end{array}$ & $\begin{array}{c}\text { Cross- } \\
\text { Flow } \\
\text { Filter to } \\
\text { Turbine }\end{array}$ \\
\hline \multicolumn{5}{|c|}{ Dimensions } \\
\hline $\begin{array}{l}\text { Calculated Minimum } \\
\text { I.D., in. }\end{array}$ & 14.1 & 14.9 & 21.8 & 9.8 \\
\hline $\begin{array}{l}\text { Refractory Thickness, } \\
\text { in. }\end{array}$ & 6 & 6 & 6 & 6 \\
\hline Actual pipe 0.D., in. & 28 & 30 & 36 & 24 \\
\hline Stainless Lining & no & no & no & yes \\
\hline & \multicolumn{5}{|c|}{ Parameters } & & \\
\hline Design Flow, ib/h & 53,531 & 53,531 & 53,531 & 53,531 \\
\hline Parallel Trains & 1 & 1 & 1 & 1 \\
\hline Flow/Train, lb/h & 53,531 & 53,531 & 53,531 & 53,531 \\
\hline Gas Pressure, psia & 162 & 159 & 159 & 157 \\
\hline Gas Temperature, ${ }^{\circ} \mathrm{F}$ & 1575 & 1571 & 1571 & 1551 \\
\hline $\begin{array}{l}\text { Volumetric Flow, } \\
\text { aft }^{3} / \text { min }\end{array}$ & 4,575 & 4,655 & 4,655 & 4,677 \\
\hline Design Velocity, ft/s & 70 & 64 & 30 & 150 \\
\hline Actual Velocity, ft/s & 60 & 48 & 26 & 113 \\
\hline
\end{tabular}


Table 8 CPFBC Hot Gas Piping

\begin{tabular}{|c|c|c|c|c|}
\hline Description & $\begin{array}{l}\text { CPFBC to } \\
\text { Cyclone }\end{array}$ & $\begin{array}{l}\text { CPFBC } \\
\text { Cyclone } \\
\text { Outlet }\end{array}$ & $\begin{array}{l}\text { Cyclone to } \\
\text { Cross-Flow } \\
\text { Filter }\end{array}$ & $\begin{array}{c}\text { Cross-Flow } \\
\text { Filter to } \\
\text { Turbine }\end{array}$ \\
\hline \multicolumn{5}{|c|}{ Dimensions } \\
\hline $\begin{array}{l}\text { Calculated Minimum } \\
\text { I.D., in. }\end{array}$ & 47.5 & 50.2 & 67.9 & 32.9 \\
\hline $\begin{array}{l}\text { Refractory Thickness, } \\
\text { in. }\end{array}$ & 6 & 6 & 6 & 6 \\
\hline Actual Pipe 0.D., in. & 62 & 64 & 82 & 48 \\
\hline Stainless Lining & no & no & no & yes \\
\hline \multicolumn{5}{|c|}{ Parameters } \\
\hline Design Flow, 1b/h & 604,752 & 604,752 & 604,752 & 604,752 \\
\hline Parallel Trains & 1 & 1 & 1 & 1 \\
\hline Flow/Train, lb/h & 604,752 & 604,752 & 604,752 & 604,752 \\
\hline Gas Pressure, psia & 147 & 144 & 144 & 143 \\
\hline Gas Temperature, $\bullet F$ & 1600 & 1600 & 1600 & 1596 \\
\hline $\begin{array}{l}\text { Volumetric Flow, aft }{ }^{3} / \\
\text { min }\end{array}$ & 51,765 & 52,807 & 52,807 & 53,112 \\
\hline Design Velocity, ft/s & 70 & 64 & 35 & 150 \\
\hline Actual Velocity, $\mathrm{ft} / \mathrm{s}$ & 66 & 62 & 34 & 132 \\
\hline
\end{tabular}




\subsection{MESTIMGHOUSE 151 GAS TURBINE AND TOPPING COMBUSTOR}

\subsubsection{Introduction}

The Model 151 combustion turbine is an engine design that evolved by combining previously developed, proven components with new design components. It is basically a modified version of the well-known W-25l combustion turbine that has been in service for more than 20 years. Performance data for the various W-251 combustion turbines are listed in Table 9. A description of the evolutionary process that produced the Model 151 follows.

\subsubsection{Development Path of the Model 151 Combustion Turbine}

The W251A. Design of the W251A was begun in 1963. This date marked the beginning of a new generation of modern, high-temperature combustion turbines with cooling of turbine blade-path components. As such, the W251A was designed with growth and upgrading potential built into the frame.

The W251A was designed using the proven, highly efficient W191 compressor with a higher pressure ratio to optimaliy match the higher turbine inlet temperature.

A new three-stage turbine with a cooled first-row stator vane and cooled rotor discs was added. The W251A turbine section was designed at very conservative loading levels, anticipating future growth. It included:

- A blade ring concept, with a patented "roll-out" system, provided for servicing all stationary vanes and rotating blades without removing the rotor and as an intermediate structure between the main cylinder and hot bladepath parts. This construction was similar to that used in large utility steam turbines.

- Precision cast vane segments for all rows to allow for additional thermal expansion.

- Cooled Row 1 vane segments.

- Segmented blade-path liners, called "ring segments," opposite the rotor blades, incorporated to provide for thermal expansion.

- Rotor cooling.

The first field start-up of the W251A occurred in 1967.

W251AA. In 1969 the W251AA was introduced. It had a newly designed higher-flow compressor and used the W251A turbine at a slightly higher firing temperature.

Three additional stages were added to the compressor to increase airflow and pressure ratio. While the major design changes were made in the compressor area, the following primary features were retained:

- Split-diaphragm construction

- Heavy industrial-type casing with horizontal joint

- Shrunk-on discs. 
4251B. The H251B, introduced in 1971, was a planned growth step from the W25IAA. The principal changes made were in turbine inlet temperature and the related turbine cooling to maintain about the same metal temperatures. The first-row blade and second-row vane were also cooled in the W251B.

Uparades of the 42518 . Table 9 lists the turbine inlet temperature for the initial $W 251 B$ as $1806^{\circ} \mathrm{F}$. This number represents the gas temperature at the entrance to the first rotating row of blades after expansion, cooling, and mixing at the exit of the first stator. The inlet temperature transiates to a combustor outlet temperature of $1866^{\circ} \mathrm{F}$. The later uprated version of the W251B, upon which the Model 151 is based, has a $1975^{\circ} \mathrm{F}$ combustor outlet temperature.

Table 9 Initial W251 Engine Configuration

\begin{tabular}{|l|l|l|l|l|}
\hline \multicolumn{1}{|c|}{ Description } & \multicolumn{1}{|c|}{ W191 } & W251A & W251AA & W251B \\
\hline First Start-Up Date & 1961 & 1967 & 1969 & 1971 \\
\hline Turbine Inlet Temperature, $\cdot F$ & 1450 & 1575 & 1640 & 1806 \\
\hline Airflow, Ib/s (ISO) & 270 & 270 & 353 & 353 \\
\hline Pressure Ratio & 8 & 8 & 10 & 11 \\
\hline Bearing Span, in. & 205.9 & 203.6 & 210.5 & 210.5 \\
\hline \multicolumn{5}{|c|}{ Compressor } \\
\hline Thermodynamic Design & W191 & W191 & W191 & W191 \\
\hline Stages Design & W191 & W191 & W251A+3 & W251AA \\
\hline Stages & 15 & 15 & 18 & 18 \\
\hline Inlet Guide Vane & fixed & fixed & fixed & Variable \\
\hline Rotor Construction & \multicolumn{5}{|c|}{ Shrunk on discs } \\
\hline Vane Assembly Construction & Horizontally split \\
\hline \multicolumn{5}{|l|}{ Combustion Section } \\
\hline Baskets & 6 & 8 & 8 & 8 \\
\hline Casing Construction & \multicolumn{5}{|c|}{ Horizontally split } \\
\hline \multicolumn{5}{|l|}{ Turbine } \\
\hline Thermodynamic design & W191 & W251A & W191 & W251A \\
\hline Stages & 5 & 3 & 3 \\
\hline Blading Cooled & 3 & IV IB,2V \\
\hline
\end{tabular}


The Model 151. One of the latest versions of the Model 251 combustion turbine is rated at about 38 MWe. To fill the need for a smaller capacity machine, the Model 251 was scaled down by a 0.76 factor. That is, stator and rotor blade heights were reduced by about 24 percent. This scale-down reduced the flow by the square of that factor and, consequently, its output by a similar amount. Thus the oil-fired Model 151 Base Load (ISO) rating is about 21 MWe. The machine retained the 18-stage compressor and 3-stage turbine of the 251B, although they were scaled down as mentioned. Table 10 lists the performance for the Model 151; it is this model that is adapted to the secondgeneration PFBC concept evaluated in this study.

Table 10 Model 151 Performance at ISO Conditions

\begin{tabular}{|l|l|l|l|l|}
\hline \multirow{2}{*}{ Description } & \multicolumn{2}{c|}{ Natural Gas } & \multicolumn{1}{c|}{ Distillate 0il } \\
\cline { 2 - 5 } & \multicolumn{1}{|c|}{ Base } & \multicolumn{1}{c|}{ Peak } & \multicolumn{1}{c|}{ Base } & \multicolumn{1}{c|}{ Peak } \\
\hline Power Output, kV & 21,140 & 22,820 & 20,600 & 22,250 \\
\hline Heat Rate, Btu/kWh & 12,770 & 11,990 & 12,430 & 12,230 \\
\hline Efficiency, $\boldsymbol{x}$ & 28.04 & 28.46 & 27.45 & 27.90 \\
\hline Exhaust Flow, 1b/h & 741,200 & 741,200 & 741,200 & 741,200 \\
\hline Exhaust Temperature, $\cdot \mathrm{F}$ & 964 & 1011 & 964 & 1011 \\
\hline
\end{tabular}

\subsubsection{The Model 151 Adapted to Second-Generation PFBC}

Adapting the Model 151 to the second-generation PFBC concept does not involve a totaliy new combustion turbine design. While the compressor and turbine blading require some degree of blade reorientation to effect a suitable match, the changes do not involve major redesign or analysis. The center section, however, is redesigned to bring most of the compressor air out of the machine so that it can be delivered to the coal carbonizer and PFBC. In addition, the conventional combustors, eight of them in the conventional machine, are el iminated; and an external combustion system is added, which also channels the hot gases back into the turbine casing.

The redesign of the combustion turbine center section is patterned after a similar application involving the combustion of blast furnace gas. That installation at the Kamaishi Works of Nippon Steel Corporation in Japan employed a modified Model 151 combustion turbine. A single external can-type combustor was designed to burn the lower-heating-value (LHV) gaseous fuel. The combustor contained six fuel nozzles, each with a small oil fuel nozzle at the center to ensure stable combustion of the very low (70 Btu/ $\mathrm{sft}^{3}$ ) heating value fuel. Figure 38 is a view of the blast furnace gas application. The single combustor is suspended beneath the main casing and is guided at the bottom.

Model 151 With Topping Combustion. As Figure 38 shows, compressor air leaves the main casing and surrounds and enters the single can-type combustor. In this scenario, air at roughly $600^{\circ} \mathrm{F}$ surrounds the combustor can; therefore, conventional metal construction can be used. In the topping combustion configuration, the compressor air partially surrounds the combustion system (see Figure 39), but most is sent to the PFBC to be used as combustion air. The 


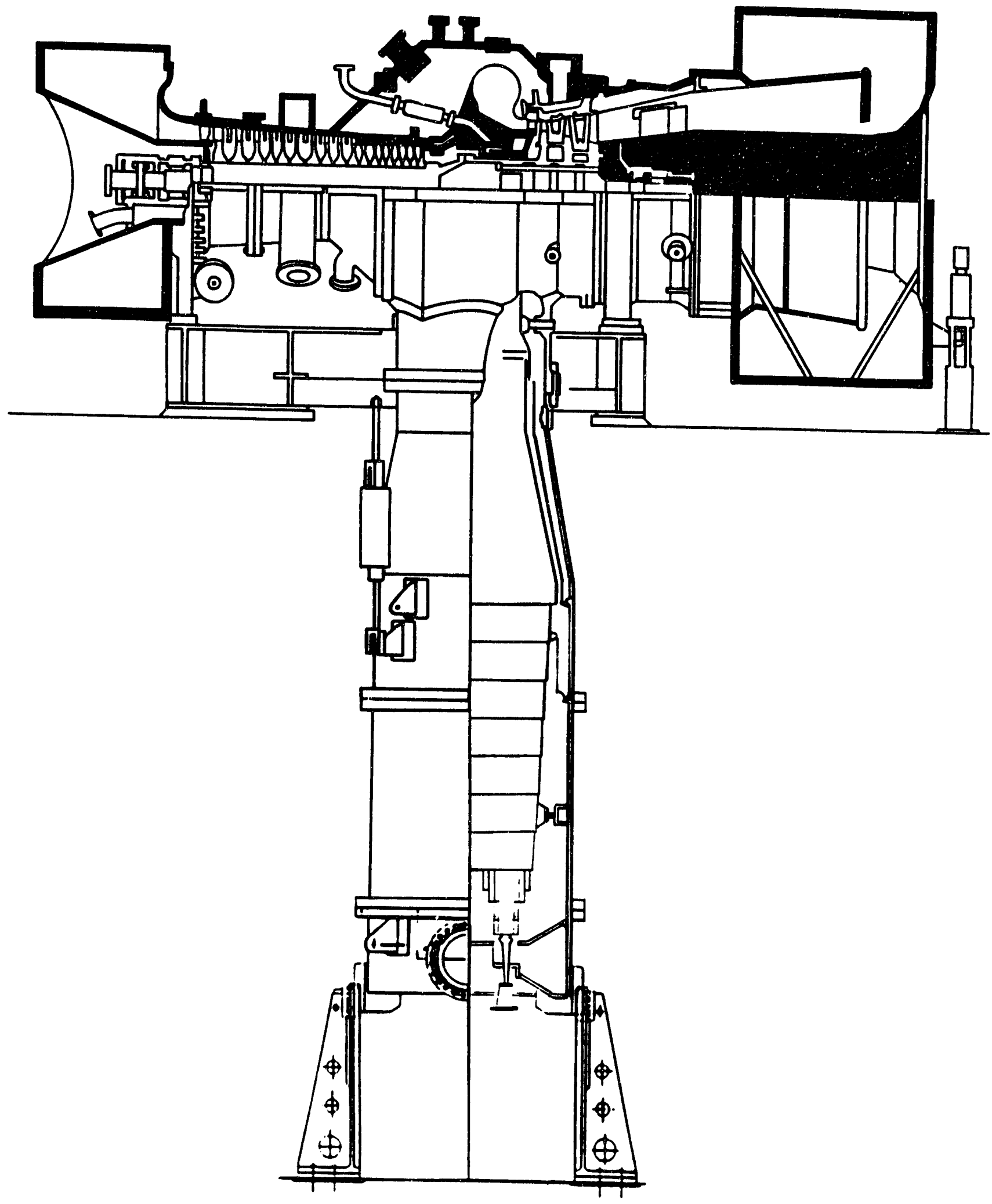

Figure 38 Model 151 With External Combustion System Adapted to Blast Furnace 


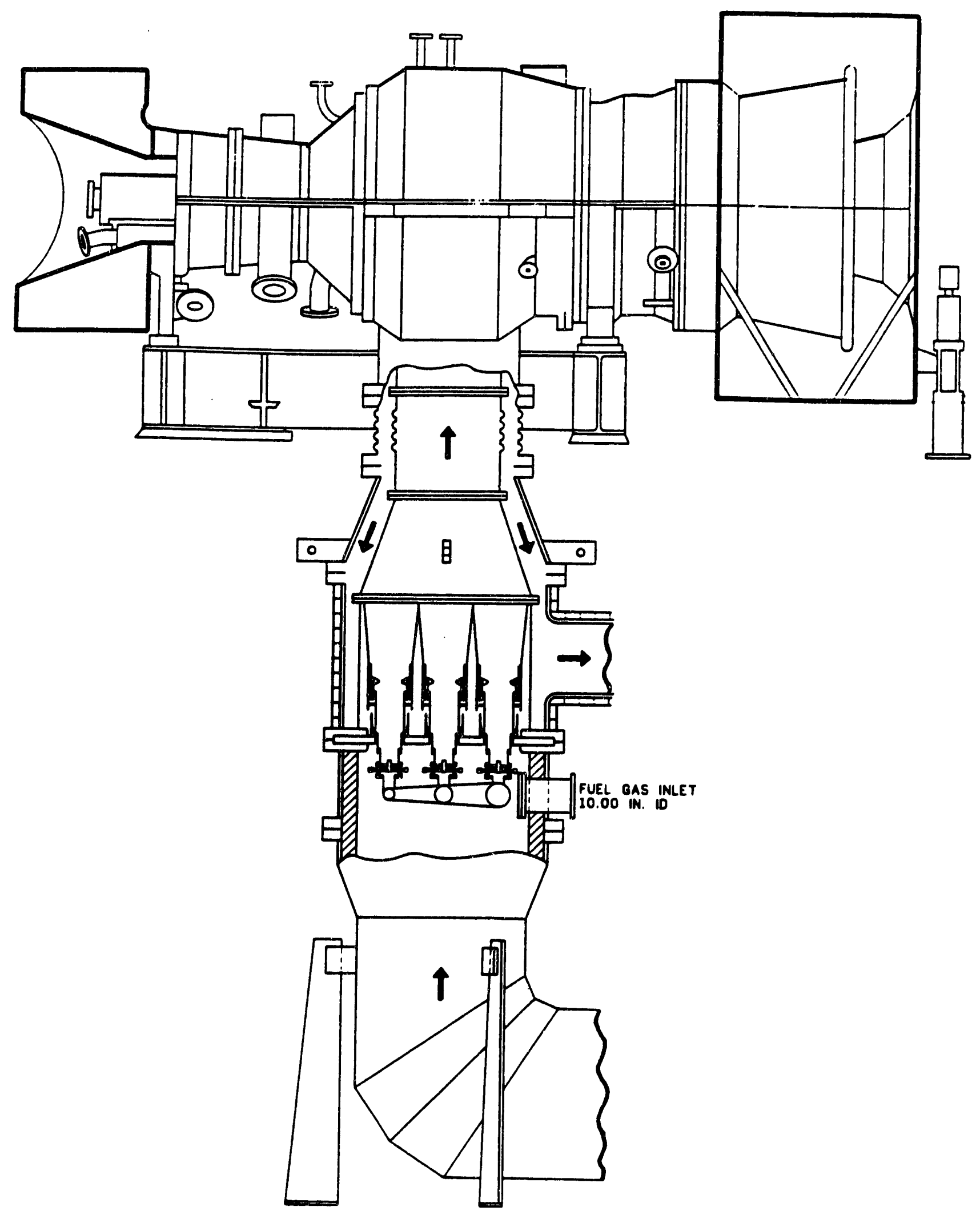

Figure 39 Model 151 With External Topping Combustion System Adapted to Second-Generation PFBC 
remainder is sent to the carbonizer (pyrolysis unit). Ultimately; vitiated air at $1600^{\circ} \mathrm{F}$ returns to the combustor along with $1600^{\circ} \mathrm{F}$ LHV fuel gas from the carbonizer.

The $1600^{\circ} \mathrm{F}$ vitiated air is too hot to provide combustor wall cooling for conventional combustor construction. In addition, the fuel-bound nitrogen (FBN) in the fuel gas must be liberated through specific processes that will preclude the formation of $\mathrm{NO}_{\mathrm{x}}$. Thus, in place of the large can-type combustor with multifuel nozzles, the patented multiannular swirl burner (MASB) is used [ㅍ].

A group of seven MASBs is housed within the external combustor housing, as shown in Figure 39. The compressor air leaves the main casing in an annular duct that surrounds the combustor housing and is piped to the PFBC and carbonizer. Figure 39 also shows that air leaves about half way down the combustor housing. The $1600^{\circ} \mathrm{F}$ vitiated air returning from the PFB combustion system enters the combustor housing at the bottom and provides the cooling and combustion air for the seven MASBs. A discussion of the combustors is presented in another section of this report.

\subsubsection{Conceptual Desion and General Description of the MASB}

Combustor Design. Because the air entering the combustor is $1600^{\circ} \mathrm{F}$ rather than the usual $700^{\circ} \mathrm{F}$ for gas turbines, the conventional type of combustor is not suitable. Both emissions and wall cooling problems preclude the use of the conventional design.

In selecting a combustor design to withstand the conditions expected in the topping application, the effective utilization of $1600^{\circ} \mathrm{F}$ air could satisfy the wall cooling challenge by maintaining a cooling air layer of substantial thickness. The creation of thick layers of cooling air at the leading edge of each inlet section is easily achieved if the combustor is made up of concentric annular passages. The MASB (Figure 40) introduces the entire combustion air quantity into the combustor via substantially thick radial annuli.

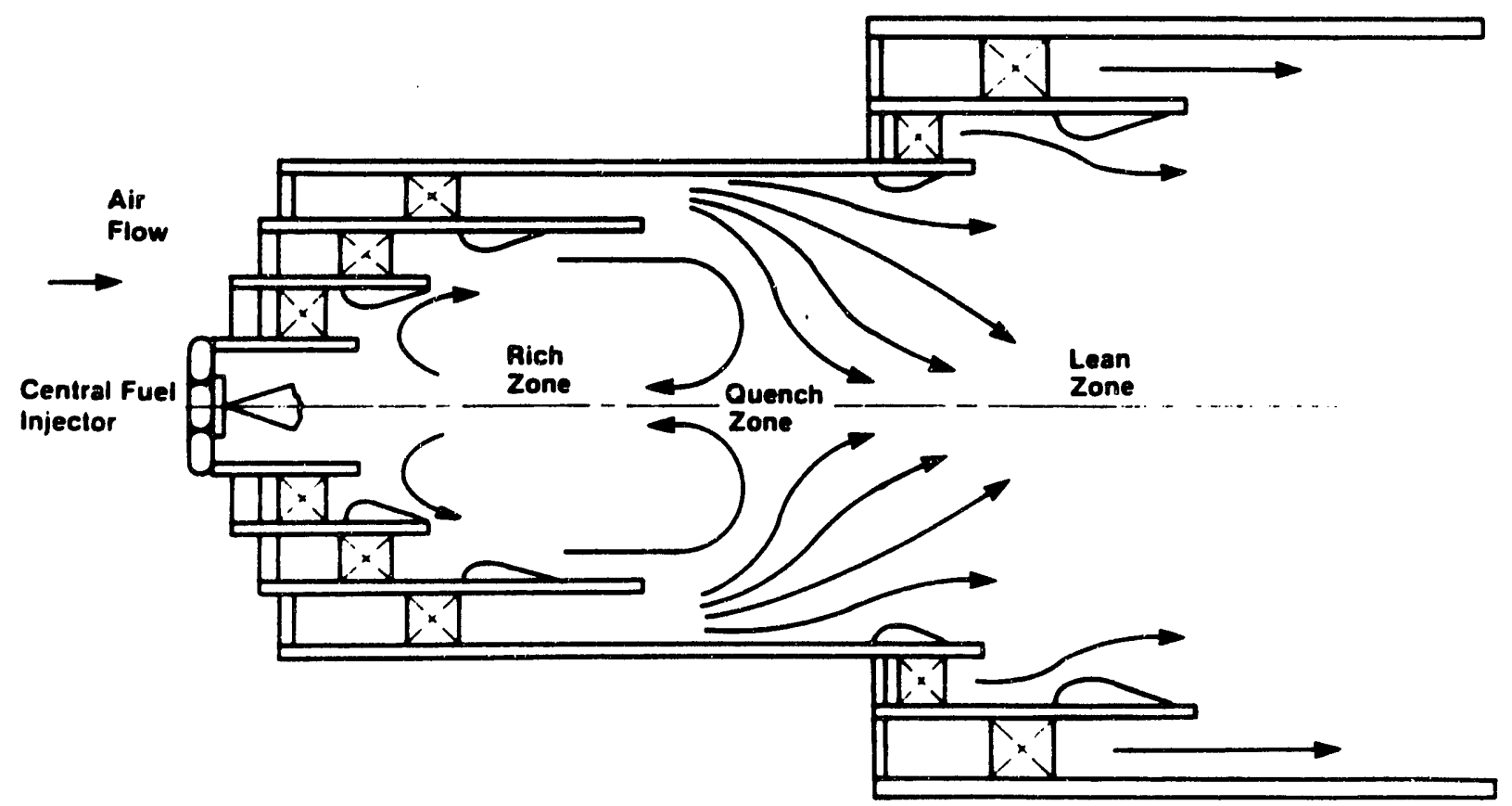

Figure 40 Airflow Patterns Within the MASB 
In an earlier DOE-sponsored topping combustor test program, a 10-in. MASB fired with methane was tested [4]. The engineering design and combustor development were carried out by a team at Westinghouse in Concordville, Pennsylvania. In that program wall temperatures were the major concern--just as they are in this effort. To thoroughly investigate the potential problem of excessive wall temperature, a two-phase test program was conducted. The first phase of the program fired the test MASB with methane using $850^{\circ} \mathrm{F}$ combustion air. Radiometers were placed in the rich zone of the MASB to measure flame radiation. Data from this first test confirmed the analysis performed during the design phase. The measured wall temperatures were actually sonewhat lower than those predicted before the test. Assumptions were adjusted accordingly, and wall temperature predictions were made for the second test, in which methane would be fired with $1400^{\circ} \mathrm{F}$ combustion air.

The test utilizing $1400^{\circ} \mathrm{F}$ combustion air yielded most encouraging results and corroborated the wall temperature predictions. The measured wall temperatures were less than $100^{\circ} \mathrm{F}$ higher than the combustion air temperature, and the condition of the combustor after the test was excellent--even though the calculated adiabatic flame temperature in the rich zone was $3964^{\circ} \mathrm{F}$.

In addition to the requirements based on wall cooling, there are three further considerations. One is that the high inlet air temperature could increase the generation of oxides of nitrogen ( $\mathrm{NO}_{\mathrm{x}}$ ) in the combustor. Second, $\mathrm{NO}_{x}$ potential from FBN must be considered; therefore, an inherently low-NOx design is preferable. Third, the combustor (if possible) should be able to function without having to preheat the air to $1600^{\circ} \mathrm{F}$; otherwise, the turbine could not be operated without the fluidized bed ("black-plant start"). To meet this third consideration, the design of choice has to have a recirculation zone where hot gases maintain the reaction process--even in the absence of a high air inlet temperature. The MASB has the characteristics to meet these considerations, as well.

Aerothermal Desion. The aerothermal design aspects of the MASB are thoroughily analyzed and discussed elsewhere [4]. Therefore, only the appropriate descriptions and findings are repeated in the following paragraphs.

Combustion Process in the MASB. The conceptual arrangement of the MASB in Figure 41 shows the salient feature of the combustor: the entire combustion airflow is admitted through axial-flow concentric, vane rows. These vane rows impart a tangential component (swirl) to the axially approaching air. The amount of swirl is different in each vane row, or swirler. Depending on the radial distribution of the swirl, the flow pattern briaks down at some axial distance into the burner, and a recirculation zone develops.

Injection of the fuel takes place in this recirculation zone-considered as the primary reaction zone of the MASB. The primary zone is surrounded by colder, unreacted air from swirlers adjacent to the primary zone; thus a rapid quenching of the reaction takes place roughly at the downstream end of the primary zone.

The mixture of unburned fuel and quench air progresses to the secondary reaction zone of the burner, where combustion reactions are completed at generally low temperatures because of the large surplus of air in this zone. A relatively small fraction of the total airflow, say 10 percent, can be introduced further downstream, either axially or in the form of radial jets, to adjust the exit temperature profile. This profile air does not take part in the combustion process. 
Burner Aerodynamics. A key feature of this MASB design is that it requires very little film cooling air. As a result, almost all of the air entering the combustor is available for the effective management of the flow and mixing process. For the radial distribution of the swirl entering the combustor, the designer may consider two bounding cases:

- Free vortex flow, in which the magnitude of the swirl velocity varies in inverse proportion to the radial distance from the combustor axis $(H=$ constant $/ r)$

or

- Forced vortex flow (solid-body-type rotation), in which the swirl velocity is directly proportional to the radial distance $(W=$ constant $r$ )

reasons:

In the present design, free vortex flow was chosen for several

- First, free vortex flow provides a more uniform radial profile of the axial velocity, which means that air supplied from a constant pressure area is ready to enter the combustor without need to establish some radial pressure distribution upstream of the combustor to control the flow rate in the individual annuli of the MASB.

- Second, free vortex flow gives lower pressure drop across the combustor. The MASB pressure drop is lower than that of conventional combustors by more than 50 percent.

- Third, the free vortex flow was shown in previous experiments to provide better wall cooling.

- Fourth, it concentrates the fuel-rich mixture ratio on the flame axis in the primary combustion zone by delayed mixing, thereby making the combustion air staging for $\mathrm{NO}_{\mathrm{x}}$ reduction more effective. This latter effect occurs because of a combination of highly swirling flow near the flame axis on the one hand and a positive radial density gradient, on the other [2].

However, in reality the free vortex flow transforms in the central core of the flow into solid body rotation because of the gas viscosity, which does not permit attaining infinite rotational velocity in the center of the rotation. The resultant combination of free and forced vortex flows, referred to as a Rankine vortex, is illustrated in Figure 41.

Low jetting velocity for the fuel is desirable to keep the turbulence level low at the flame boundary. This goal requires a large fuel injector and flow passage in this design. Figure 42 shows the conceptual layout of one MASB. Note the fuel flow passage at the exit of the fuel nozzle. It is about 5 in. in diameter.

A unique feature is employed in this fuel nozzle to aid in the control of $\mathrm{NO}_{\mathrm{x}}$ emissions. About 10 percent of the rich zone combustion air is admit ied at the upstream end of the first swirler set, as shown in Figure 42. Its purpose is to help control $\mathrm{NO}_{\mathrm{x}}$, as described later.

fuel nozzle.

The center section of the fuel nozzle assembly is the natural gas 


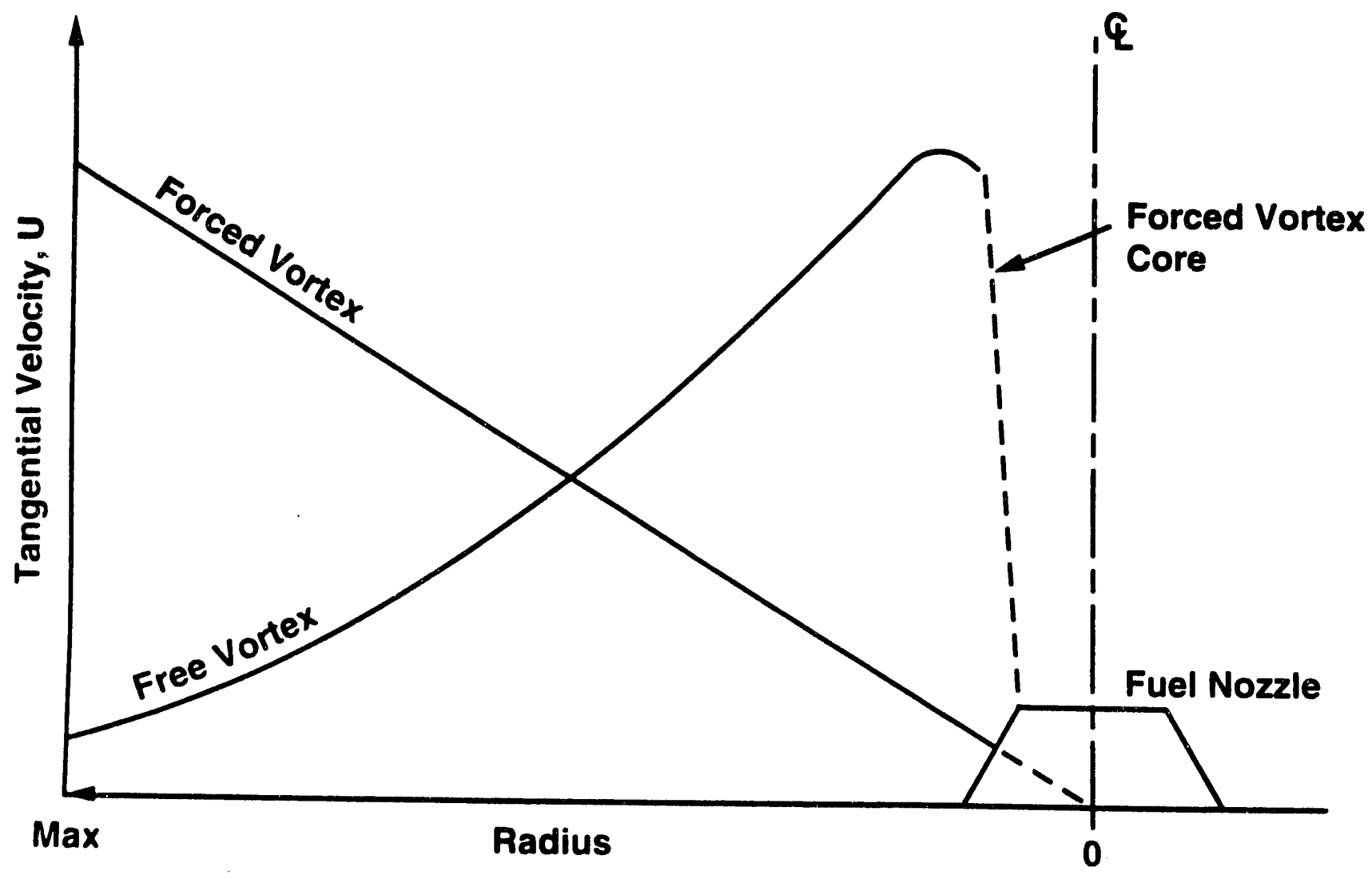

Figure 41 Velocity Characteristic of Free and Forced Vortex Flow

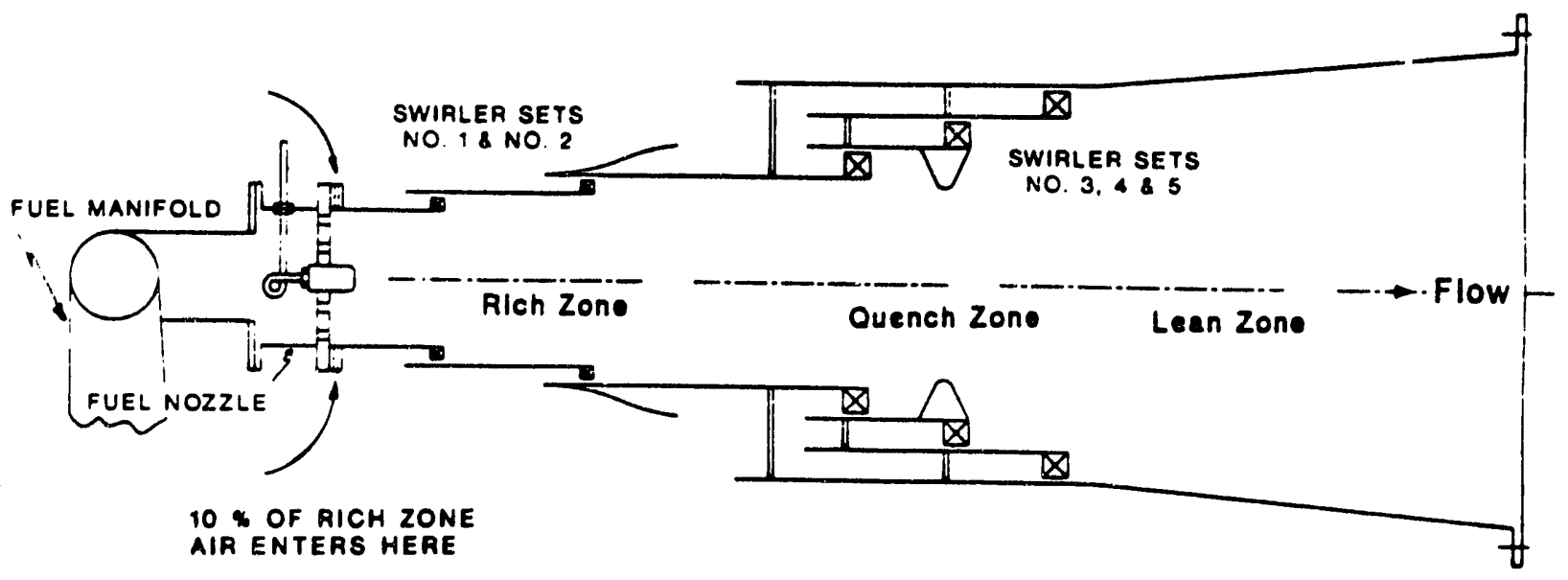

Figure 42 Conceptual Layout of MASB 
Enissions. The control of $\mathrm{NO}_{\mathrm{x}}$ is enhanced by the introduction of a small quantity of combustion air early in the combustion process. This is intended to stimulate quick initiation of combustion to proceed through specific processes which preclude the formation of $\mathrm{NO}_{x}$ from $\mathrm{FBN}$.

The MASB is designed to operate under staged combustion conditions to reduce $\mathrm{NO}_{\mathrm{x}}$ emissions to a minimum. Nitrogen oxides are formed in three main processes:

- The fixation of atmospheric nitrogen at high temperature and lean combustion according to the so-called atom shuttle Zeldovich reactions

- The fixation of atmospheric nitrogen by hydrocarbon fragments in the fuel-rich initial stages of a hydrocarbon fuel/air flame (called prompt $\mathrm{NO}_{\mathrm{x}}$ )

- The oxidation of organically bound nitrogen compounds to NO in lean flames.

In the rich-lean concept of the MASB, there is sufficient oxygen to sustain the reactions for the first process 1 isted.

In the second process, it is inevitable that No will be formed; therefore, it is important to initiate pyrolysis of the fuel early, so that the prompt NO can go through the reduction-reaction paths and then the final steps necessary to be destroyed and to produce molecular nitrogen.

The fixation of atmospheric nitrogen, $N_{2}$, by hydrocarbon radicals such as $\mathrm{CH}$ and $\mathrm{CH}_{2}$ leads to the formation of cyanides, mainly $\mathrm{HCN}$. The cyanides then react with $\mathrm{OH}$ and $\mathrm{O}$ radicals to form amines by hydrogen abstraction reactions and NO by their further oxidation. The process is illustrated by reactions RI through RB.

\section{"Prompt No" Formation Reactions:}

Hydrocarbon Fragments Generate Cyanide (HCN)

$$
\begin{aligned}
& \mathrm{CH}_{2}+\mathrm{N}_{2} \cdots->\mathrm{HCN}+\mathrm{NH} \\
& \mathrm{CH}+\mathrm{N}_{2} \cdots->\mathrm{HCN}+\mathrm{N}
\end{aligned}
$$

Hydrogen Abstraction Generates Amonia Radicals (NH, $\mathrm{NH}_{2}$ )

$$
\begin{aligned}
& \mathrm{HCN}+\mathrm{OH} \cdots \rightarrow \mathrm{CN}+\mathrm{H}_{2} \mathrm{O} \\
& \mathrm{HCN}+\mathrm{OH} \cdots->\mathrm{HNCO}+\mathrm{H} \\
& \mathrm{HNCO}+\mathrm{H} \cdots->\mathrm{NCO}+\mathrm{H}_{2} \\
& \mathrm{HNCO}+\mathrm{H} \cdots->\mathrm{NH}_{2}+\mathrm{CO} \\
& \mathrm{NCO}+\mathrm{H} \cdots->\mathrm{NH}+\mathrm{CO}
\end{aligned}
$$




$$
\mathrm{NH}+\mathrm{O}-\ldots \rightarrow \mathrm{NO}+\mathrm{H}
$$

Following the NO formation reaction, two destruction routes are possible. NO can be reduced either by reacting with ammonia $\left(\mathrm{NH}_{\mathrm{i}}, \mathrm{N}\right)$ species to form molecular nitrogen (Reaction R9 through R11) or by reacting with hydrocarbon radicals such as $\mathrm{CH}$ and $\mathrm{CH}_{2}$ to provide hydrogen cyanide (Reactions $\mathrm{R} 12$ through R15) that, in turn, is converted to $\mathrm{NH}_{\mathrm{i}}$ through Reactions $\mathrm{R3}$ through R7. The ammonia species thus formed are subsequently destroyed through Reactions R16 through R20.

Destruction Paths for NO:

Reduction with Ammonia (Not significant at conditions of MASB)

$$
\begin{aligned}
& \mathrm{NO}+\mathrm{NH}_{2} \cdots \rightarrow \mathrm{N}_{2} \mathrm{H}+\mathrm{OH} \\
& \mathrm{NO}+\mathrm{NH}_{2} \cdots \cdots \mathrm{N}_{2}+\mathrm{H}_{2} \mathrm{O} \\
& \mathrm{NO}+\mathrm{NH} \cdots>\mathrm{N}_{2}+\mathrm{OH}
\end{aligned}
$$

Reaction with Hydrocarbon Fragments to give Cyanide (HCN) which feeds Reactions R3 through R7

$$
\begin{aligned}
& \mathrm{CH}+\mathrm{NO}-\cdots>\mathrm{HCN}+\mathrm{O} \\
& \mathrm{CH}_{2}+\mathrm{NO}-\cdots>\mathrm{HCN}+\mathrm{OH} \\
& \mathrm{CH}_{2}+\mathrm{NO}-\cdots>\mathrm{CH}_{2} \mathrm{O}+\mathrm{N} \\
& \mathrm{CH}_{3}+\mathrm{NO} \cdots-\rightarrow \mathrm{HCN}+\mathrm{H}_{2} \mathrm{O}
\end{aligned}
$$

The paths through which the NO reduction passes are influenced by temperature, fuel equivalence ratio, and reaction time. Maintaining a rich zone temperature above $2600^{\circ} \mathrm{F}$ but below $3100^{\circ} \mathrm{F}$ is essential. Maintaining the primary zone rich, along with keeping it at a high temperature, promotes Reactions R12 through R15. These reactions then proceed through Reactions R3 through R8, as mentioned earlier. NO reduction through its reaction with NHi (R9 through R11) is not significant at the rich-zone conditions of the MASB. Consequently, the route in which $\mathrm{CH}_{i}$ reacts with $\mathrm{NO}$ provides the means for producing ammonia species (R3 through $R 7$ ) that can be reduced directiy to molecular nitrogen by Reactions R16 through R20. 
Final Steps of the $\mathrm{NO}_{\mathrm{x}}$ Reduction Path at Lower Temperature $\left(2600^{\circ} \mathrm{F}\right)$ :

$$
\begin{array}{lll}
\mathrm{NH}+\mathrm{N} & \cdots>\mathrm{N}_{2}+\mathrm{H} \\
\mathrm{NH}+\mathrm{NH} \cdots & \cdots & \mathrm{N}_{2}+\mathrm{H}+\mathrm{H} \\
\mathrm{NH}+\mathrm{NH}_{2} \cdots \rightarrow>\mathrm{N}_{2} \mathrm{H}_{2}+\mathrm{H} \\
\mathrm{N}_{2} \mathrm{H}_{2}+\mathrm{H} \cdots>>\mathrm{N}_{2} \mathrm{H}+\mathrm{H}_{2} \\
\mathrm{~N}_{2} \mathrm{H}+\mathrm{H} \cdots>\mathrm{N}_{2}+\mathrm{H}_{2}
\end{array}
$$

FBN, newly formed NO, and organic nitrogen compounds from the second process can be converted to $\mathrm{N}_{2}$ in fuel-rich flame regions if the temperature is sufficiently high and the residence time sufficiently long for these reactions.

The previous discussion centered on the formation of "prompt $\mathrm{NO}_{x}$ " and how it is destroyed through the control of temperature and fuel-air mixture in the rich zone. The third process, the formation of NO in the lean zone as a result of fuel ammonia, is also suppressed. A high percentage of the fuel ammonia is converted to $\mathrm{N}_{2}$ and $\mathrm{H}_{2}$ in the rich zone in R16 through R2O before it enters the lean zone.

The MASB design provides the means to achieve low $\mathrm{NO}_{x}$ in $\mathrm{R} 16$ through R20 by incorporating two features:

- A small amount of air is fed at the front of the first swirler assembly (described earlier).

- The third combustor cylinder is lengthened.

The small amount of air is insufficient to produce ignition, but its temperature is high enough to start fuel pyrolysis. The pyrolyzed fuel will then be mixed with more air as it moves out of the fuel injection area and into the zone where air from Swirlers 1 and 2 is entering.

The final mixture will still be fuel rich, with an equivalence ratio of 1.5; it will also be hot. (Equivalence ratio is defined as the artual fuel/air ratio to the stoichiometric fuel/air ratio.)

High temperature is important for the chemical reactions that convert NO and other nitrogen species to $N_{2}$ in the fuel-rich region. For effective reaction, the temperature should be above $2600^{\circ} \mathrm{F}$, and this has been accomplished by the steps taken to maintain a 1.5 equivalence ratio.

Configurational Effect of a Longer Residence Time. For effective reaction it is not enough to provide the desired mixture of oxidizer and reactants. Sufficient residence time must be provided for the reactions to take place, as well. The lengthening of the fuel-rich first part of the MASB serves this purpose. The air introduced through Swirlers 1 and 2 must be uniformly mixed with the fuel before quench zone air from Swirler 3 is added. The increased length of the third combustor cylinder serves this additional purpose. 
Burner Mechanical Desian and Installation. The view of the MASB arrangement shown in Figure 43 further explains the arrangement. The MASB assembly is basically three separate pieces. The first is the fuel nozzle, which bolts to the fuel gas manifold. The second is the rich zone swirlers, Sets 1 and 2, which bolt to the face of the fuel nozzle. These two components, secured at the fuel gas manifold, are free to expand and adjust to the hot environment produced by the hot fuel gas and the hot, vitiated air.

The seven sets of fuel nozzles and rich zone swirlers extend upward and protrude through a flanged joint that houses a series of seven cylinders mounted to a grid plate. These cylinders are guides for the lower end of the third MASB piece, which makes up Swirler Sets 3, 4, and 5. A conventional spring clip is attached to the extended inside ring of Swirler Set 3 of each MASB. These spring clips fit into the cylinders at the lower flange. The other end of the third piece is secured in an upper grid-type plate at the upper flange.

\subsubsection{Fuel System}

Euel Gas Valving. The LHV gas produced by the carbonizer for the gas turbine combustion system has a heating value about 10 percent of natural gas. Although the temperature in the combustor rises by about $350^{\circ} \mathrm{F}$ in this plant, as opposed to about $1400^{\circ} \mathrm{F}$ in conventional gas turbine operation, the LHV fuel gas fiow is still two to three times greater than the simple-cycle natural-gas fuel requirement. In addition, the low-energy fuel gas temperature is approximately $1550^{\circ} \mathrm{F}$, as opposed to about $60^{\circ} \mathrm{F}$ for natural gas. Because of these factors, the plant fuel gas valving requirements are more severe than those for a natural-gas-fired turbine.

Figure 44 is a schematic representation of the low-energy fuel gas system with the valving identified. The fuel gas is brought from the carbon-

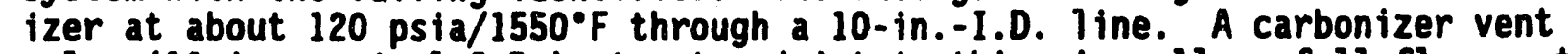
valve (10-in. nominal I.D.) at a tee joint in this pipe allows full-flow venting of the fuel gas to the flare in the event of a system upset. The 10-in. overspeed trip valve is downstream of this tee. Another vent valve between the trip valve and the fuel throttle valve allows venting of the fuel system next to the turbine. An isolation valve (10-in. nominal I.D.) is positioned at the combustion system inlet; it works in conjunction with the overspeed trip valve.

In the event of a plant upset or sudden loss of load, the fuel gas valve system must quickly interrupt gas flow to the turbine and bypass the fuel gas to the flare. Because of the relatively large sizes and $1550^{\circ} \mathrm{F}$ temperature involved, these valves are not currently marketed by the normal gas turbine valve suppliers. However, conversations with these suppliers have indicated that current technology supports their design and manufacture and that an extensive R\&D development effort should not be required.

A backup/start-up natural-gas fuel system is also part of the overall fuel system. Its component parts are analogous to those of the carbonizer fuel gas system, but are much smaller and need not be designed for a high operating temperature. 


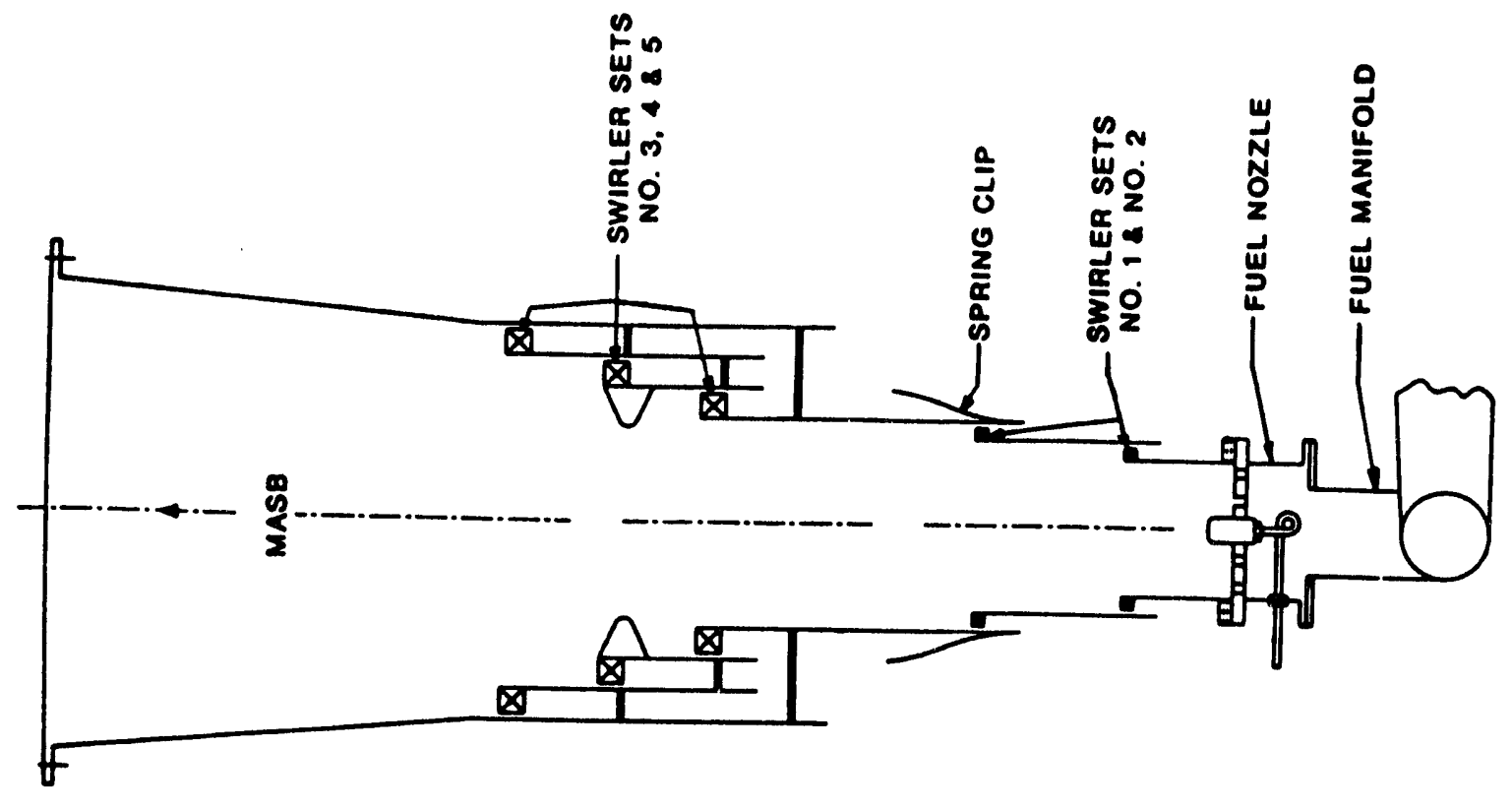

总

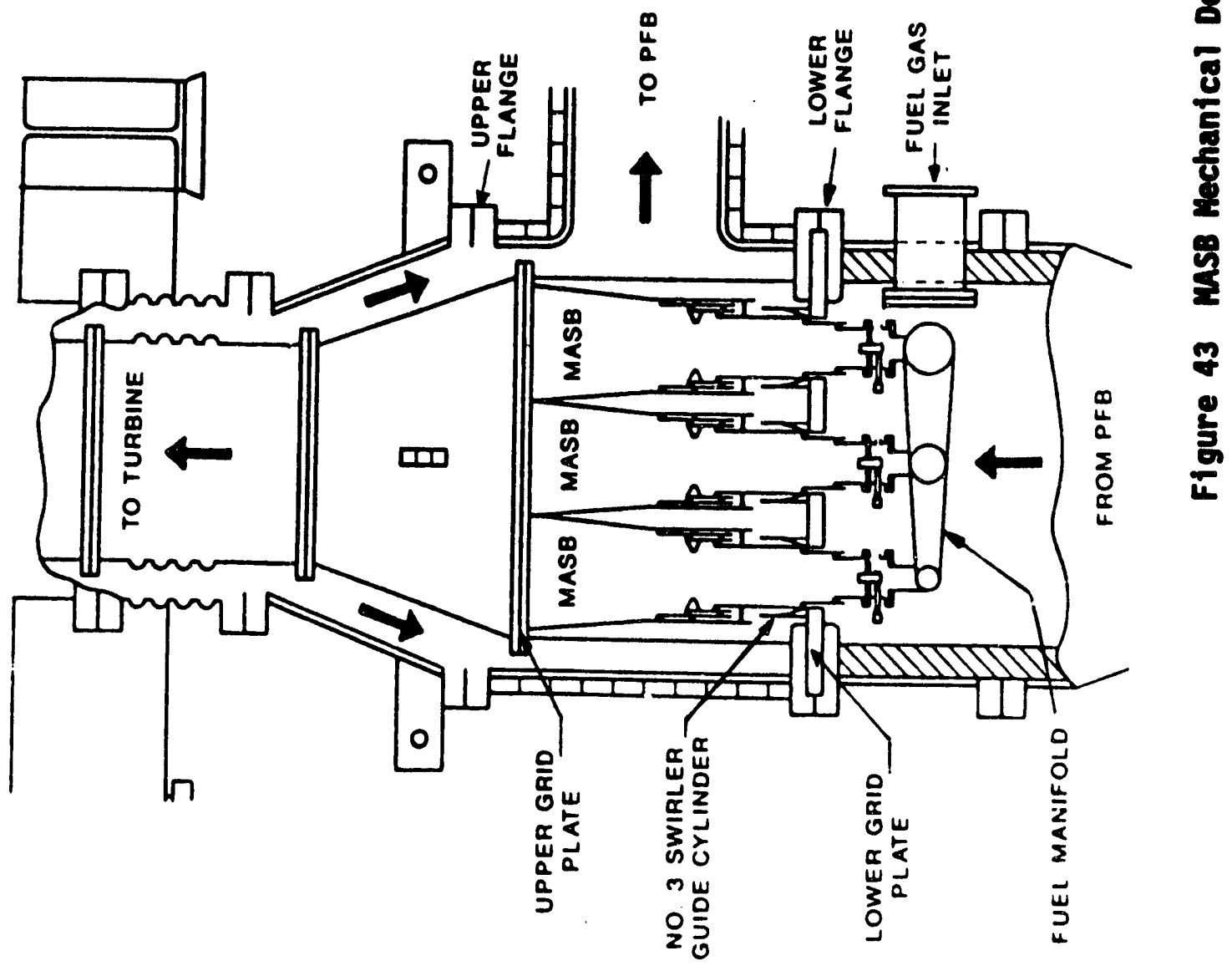




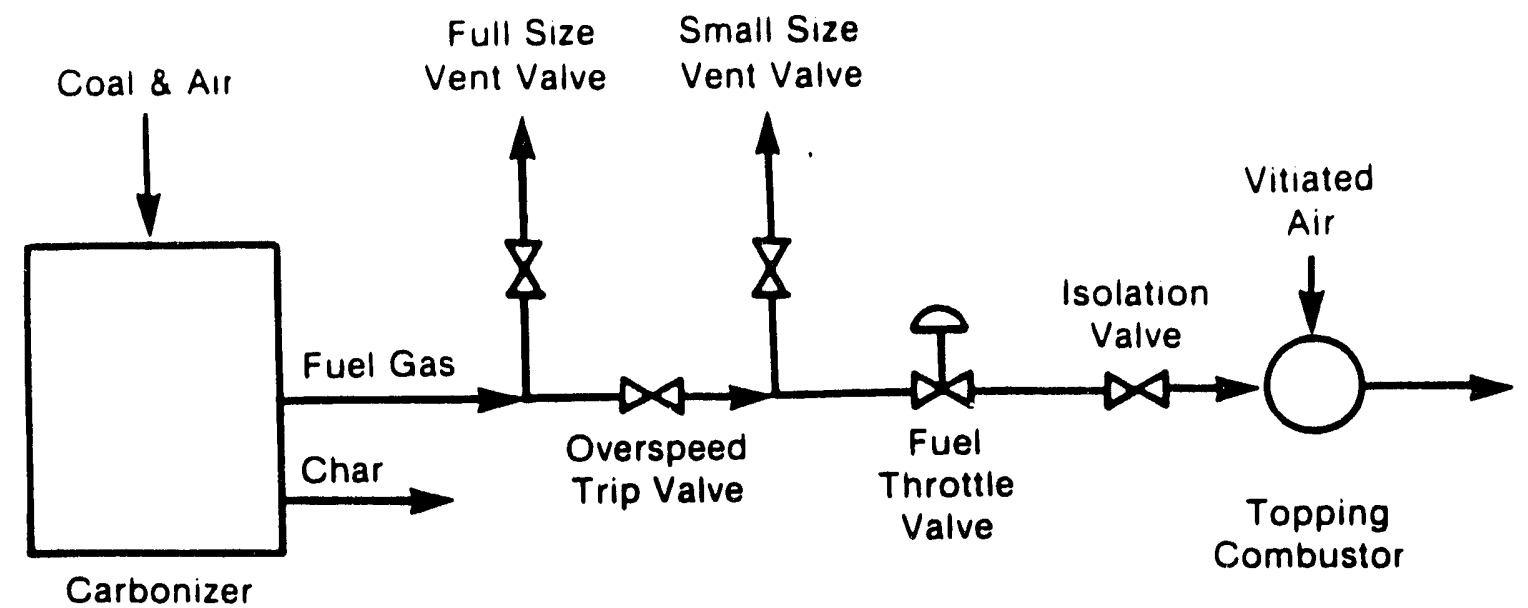

Figure 44 Fuel Gas System Schematic

\subsubsection{Pressurized Fluidized Bed Combustor Bypass System}

The fuel gas system contains relatively large valves to regulate or shut off the flow of fuel to the topping combustor in the event of a plant upset, change of load, or loss of load. An additional system of valves is required to ensure overspeed protection for the gas turbine.

Because of the large inventory of hot, pressurized air in the PFBC subsystem and piping, merely shutting off the fuel is not sufficient for overspeed protection. The considerable pressurized air and thermal energy that exist in the PFBC system from the compressor discharge to the topping combustor inlet gas turbine/generator unit must be controlled to prevent excessive overspeed and subsequent catastrophic failure.

Two scenarios relate to the use of the PFBC bypass system for overspeed protection:

- An externally caused event (e.g., the loss of load when a breaker opens because of some occurrence outside the plant)

- An internally caused event such as loss of lube oil to the turbine/generator bearings.

Loss of Load--External Event. The sudden loss of gas turbine load causes the rapid acceleration of the unit, and the topping combustor fuel system reacts quickly to halt the flow of fuel to the topping combustor. Another system of valves comes into play simultaneously. This system is shown conceptually in Figure 45 and schematically in Figure 46 . Although a full analysis and investigation of the design, configuration, operation, and dynamics of this valve system are beyond the scope of this study, the proposed concept should protect the gas turbine from overspeed.

Compressed air is extracted and vitiated air is reintroduced to the hot section of the turbine during normal operation. Therefore, a set of valves must work in unison and in conjunction with the fuel system to handle this large volume of air and thermal energy entering and leaving the PFBC system. At first indication of a loss of load and the resultant acceleration of the gas turbine unit, Valves $A, B$, and $C$ in Figures 45 and 46 are actuated. Valve $A$ (normally open, 24 in.-I.D. carbonizer/PFBC inlet valve) closes. At 


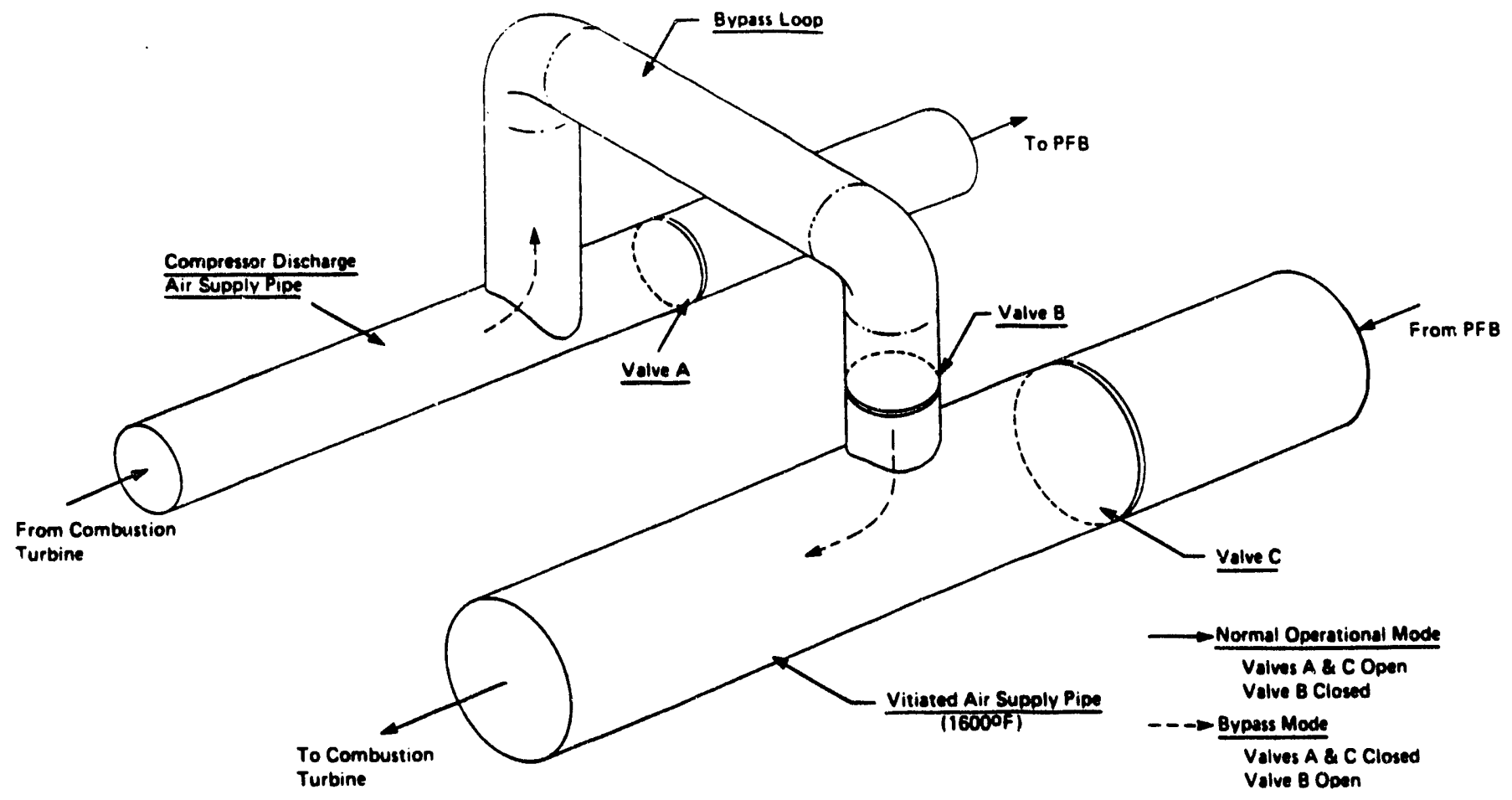

Figure 45 Conceptual Arrangement--PFBC Bypass System

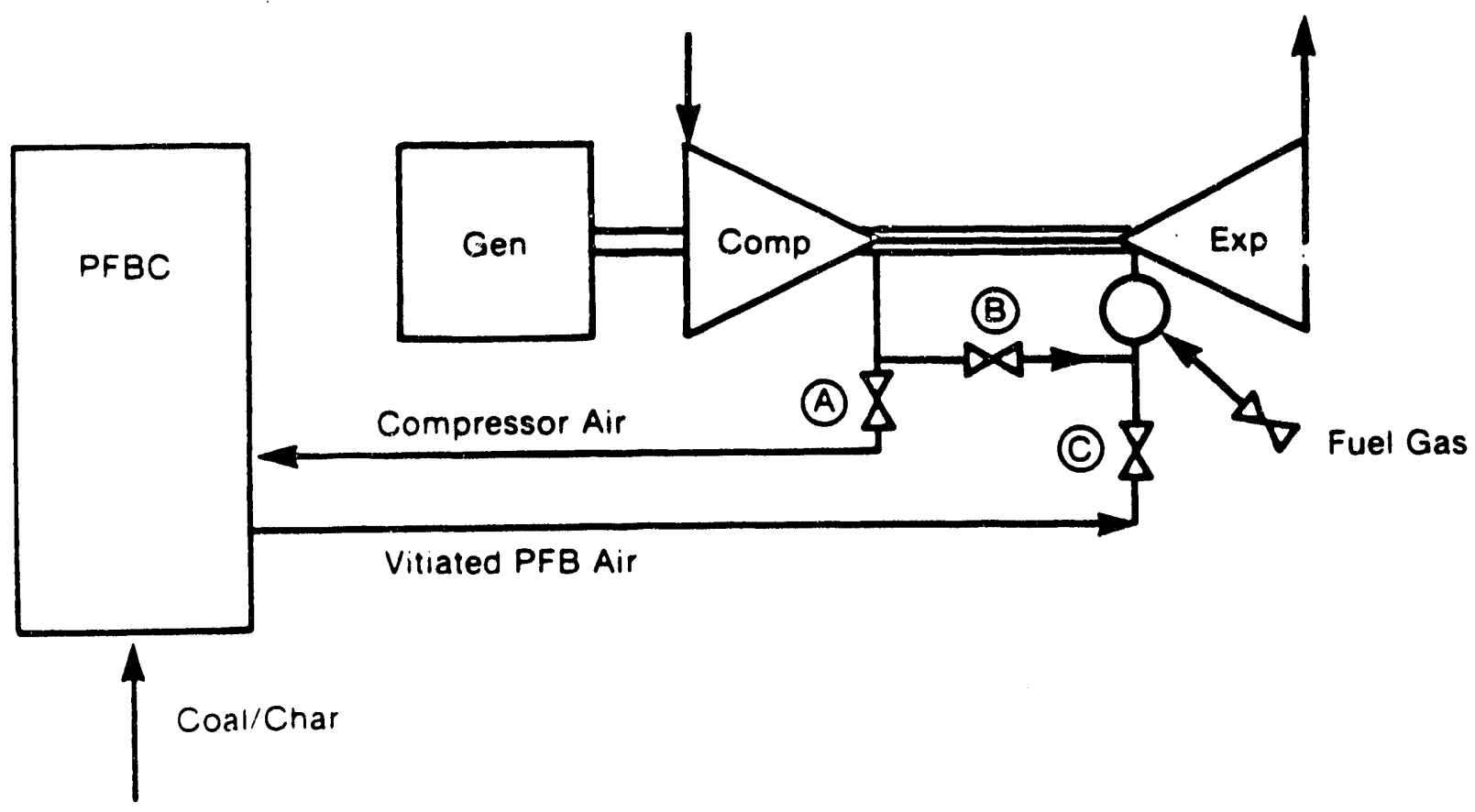

Figure 46 Schematic Arrangement--PFBC Bypass System 
the same time, Valve B (normally closed, 20 in.-I.D. carbonizer/PFBC bypass valve) opens, and Valve C (normally open, 34-in.-I.D. PFBC outlet valve) closes. In these new positions, the compressor air bypasses the carbonizer and PFBC systems and is routed directiy to the topping combustors.

Preliminary calculations indicate that the PFBC bypass system, working with the fuel gas bypass system, will protect the gas turbine from overspeed. In addition, there are a few variations in valve operation that can aid in handling this overspeed problem. Because the gas turbine compressor is equipped with inlet guide vanes, flow can be varied to some degree, depending on the vare position. If the inlet guide vanes are partially closed during normal operation; having them fully open during the overspeed event will increase airflow; increase compressor work; and, in turn, help decelerate the turbomachinery. In addition, by judicious positioning of the carbonizer/PFBC bypass valve (Valve B), the discharge pressure of the compressor can be kept high, increasing the compressor work and enhancing gas turbine deceleration even further. Anything that can safely increase compressor work aids in controlling the overspeed problem.

The turbomachinery goes through several operating levels during this rapid train of events. The following paragraphs present a brief look at some of these operating levels and their effects on overspeed.

At the first instant of load loss, steady-state operating parameters prevail. The PFBC vitiated air at $1591^{\circ} \mathrm{F}\left(9^{\circ} \mathrm{F}\right.$ temperature loss between PFBC and gas turbine) is raised to $1950^{\circ} \mathrm{F}$ in the topping combustor, and the combined vitiated air and fuel flows enter the turboexpander at the rated inlet pressure (about 137 psi). Immediately upon sensing overspeed, the fuel gas overspeed protection actuates, closing off the fuel flow. Thus the flow to the turbine hot section is reduced about 8 percent, and the turboexpander inlet temperature approaches $1591^{\circ} \mathrm{F}$, the vitiated air temperature.

At this same instant of load loss, the valves in the PFBC bypass system are actuated. The PFBC inlet valve (Valve A) closes; the PFBC bypass valve (Valve $B$ ) operis; and the PFBC outlet valve (Valve $C$ ) closes. This set of events, in conjunction with the fuel shutoff event, rapidiy rectifies the situation where damage resulting from overspeed could occur. The cooler compressor air mixes with the smaller amount of vitiated air leaking through the PFBC outlet valve. By adjusting the bypass valve (Valve B), the compressor pressure ratio is elevated, increasing compressor work, which aids the deceleration process.

The amount of air leaking around Valves $A$ and $C$ is of prime imporiance with regard to unit coastdown time. Under the conditions set forth in this instance (loss of load from an external event), the coastdown time is of lesser importance because none of the gas turbine equipment is at fault. Therefore, normal turbine auxiliaries and components are intact, and the unit can either be resynchronized or shut down and put on turning gear, eventually. The section that follows addresses valve leakage and its importance under other load-loss conditions.

Loss of Load--Internal Event. Many of the possible emergency shutdown situations that occur within the plant boundary require the combustion turbine to coast down as rapidly as practical. For example, if high vibration suddenly occurs at one of the turbine or generator bearings, rapid shutdown might be of prime importance to preclude major damage or, possibiy, catastrophic failure. Because the large shutoff valves at the compressor discharge and 
combustor inlet leak to some extent in the closed position, a quantity of hot, vitiated air is mixed with the compressor air that bypasses the PFBC during the coastdown interval. The amount of leakage is a vital factor in determining the coastdown time. If the quantity leaked is too large, the coastdown is not rapid enough, and another valve has to be put in the PFBC bypass system to minimize the leakage.

A particularly useful parameter that can be used to gain insight into the amount of leakage tolerable during emergency shutdown is the turbine "Stodola Number, S." This parameter has a variety of other names, including flow parameter and swallowing capacity. It is a measure of the effective flow area of the expander and is a function of flow, temperature, pressure, and rotational speed.

Assuming the unit is running at the desired speed, a simplified version of the Stodola Number is:

$$
S=m \cdot(T)^{0.5} / p
$$

where:

$$
\begin{aligned}
m & =\text { Mass flow, } 1 \mathrm{~b} / \mathrm{s} \\
T & =\text { Absolute temperature, } \cdot R \\
p & =\text { Inlet pressure, psia. }
\end{aligned}
$$

The Stodola value for the plant combustion turbine is 60.5 based on $183 \mathrm{lb} / \mathrm{s}, 137 \mathrm{psia}$, and $1591^{\circ} \mathrm{F}$. This number is calculated for expander inlet conditions at rated load.

As mentioned earlier, when the fuel is shut off, there is an almost immediate drop in flow and temperature into the expander since the inlet temperature drops to about $1591^{\circ} \mathrm{F}$ and the flow diminishes by about 8 percent to $168 \mathrm{lb} / \mathrm{s}$. Using the Stodola formula, the corresponding expander inlet pressure becomes:

$$
P=168(2051)^{0.5} / 60.5=126 \text { psia }
$$

Thus the expander inlet pressure drops from about 137 to 126 psia in about 1 second because fuel is shut off. Acting simultaneously with the fuel shutoff, the PFBC bypass valving transfers the compressor flow directly to the expander. Ignoring valve leakage for the present and considering only the compressor discharge flow and temperature at the moment of shutdown, the required expander inlet pressure becomes:

$$
P=162.5(1095)^{0.5} / 60.5=89 \text { psia }
$$

Because the valves must act within 1 or 2 seconds, the inlet pressure to the expander will be between 89 and 126 psia at the end of that interval. It is certainly less than 126 psia, because the PFBC shutoff valve eliminates most of the PFBC flow; and it is certainly more than 89 psia, because there is leakage past the valves. If 10 percent of the compressor flow were still to pass through the PFBC, the resultant inlet pressure would be about 92 psia. The mixed temperature of the air and $P F B C$ leakage is about $730^{\circ} \mathrm{F}$. With this pressure and temperature, the turbomachinery will certainly be in a coastdown mode, but the deceleration rate needs to be quantified. 
As mentioned in the previous subsection, by positioning the bypass valve (Valve B in Figures 45 and 46 correctly, compressor work can be increased, which will aid in solving the problem. In addition, the booster compressor in the power plant extracts about 7 percent of the turbocompressor airflow for transport air and the carbonizer. If a vent valve were placed in the extraction pipe, to open when load dump occurs, leakage past the PFBC exit valve could be reduced further.

Specific information about the valves, a detailed analysis of the dynamics of the power train, and an analysis of the transient behavior of the pressure vessels and piping are required to quantify the gas turbine coastdown characteristics under the referenced loss-of-load conditions. Although such analyses are beyond the scope of this study, we believe that the proposed bypasses and operating techniques can be made to protect the gas turbine during these conditions.

\subsubsection{Installation of Model 151 With Topping Combustion}

Figures 47 and 48 are the outline drawings of the Model 151 adapted to topping combustion. The drive train is installed on an elevated platform with the combustion system suspended underneath. The external combustion system is attached at the underside of the drive train platform and is guided at the bottom. Expansion joints are part of the inner and outer ducting from the main casing to allow for thermal growth.

The air-cooled, open, ventilated generator/exciter package is shown at the left on Figure 48. The generator is connected to the compressor end of the combustion turbine through a vertical offset double helical gear.

The combustion turbine has a 16-stage axial flow compressor and a 3-stage axial turboexpander. The turbine air inlet system includes the plenum, duct work, transitions, gaskets, silencer, and filter. The conventional exhaust duct and silencer are omitted and are replaced with an expansion joint/duct system that connects to the heat-recovery apparatus. These component changes are not shown on Figure 48.

The turbine auxiliary system includes: the diesel engine-driven starting device; lube oil system with shaft-driven main pump, ac auxiliary pump, and dc emergency pump; torque converter; auxiliary gear; and motordriven turning gear system.

The air-conditioned control packaged is located at the right on figure 48. The lube oil cooler location has some flexibility. It is shown in its optimum location for a conventional installation; but it can be relocated to suit other types of installations. Not shown on the figure are the details of the natural-gas fuel system and the carbonizer fuel gas system.

\subsection{ALLISON 501 GAS TURBINE AND TOPPING COMBUSTOR}

\subsubsection{Combustor and Turbine Skids}

The topping combustor and turbine for the smaller cogeneration systems (Cases 3, 4, 5, and 6) are mounted on structural steel skids. Each of the turbines is mounted on a power systems skid, and its topping combustor is mounted on an adjacent combustor system skid, as shown in Figure 49 . Interconnecting piping between the skids carries the products of combustion from the topping combustor to the turbine. These products result from burning 


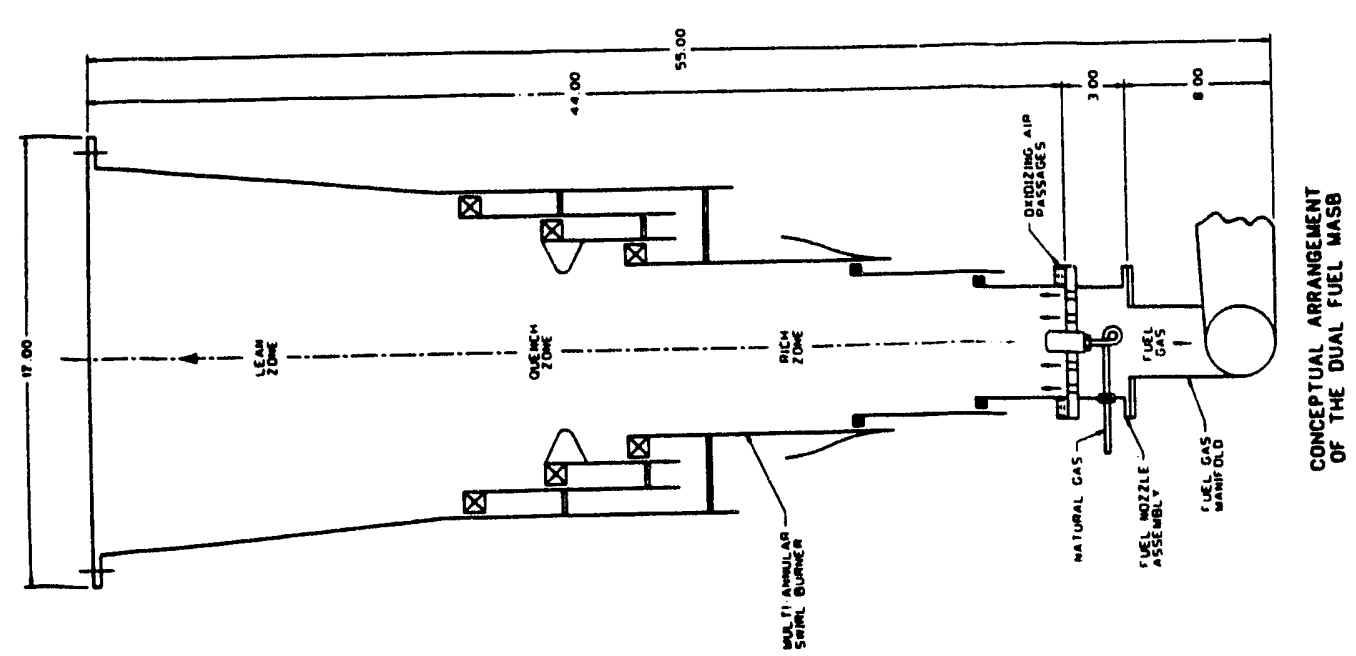

퐁

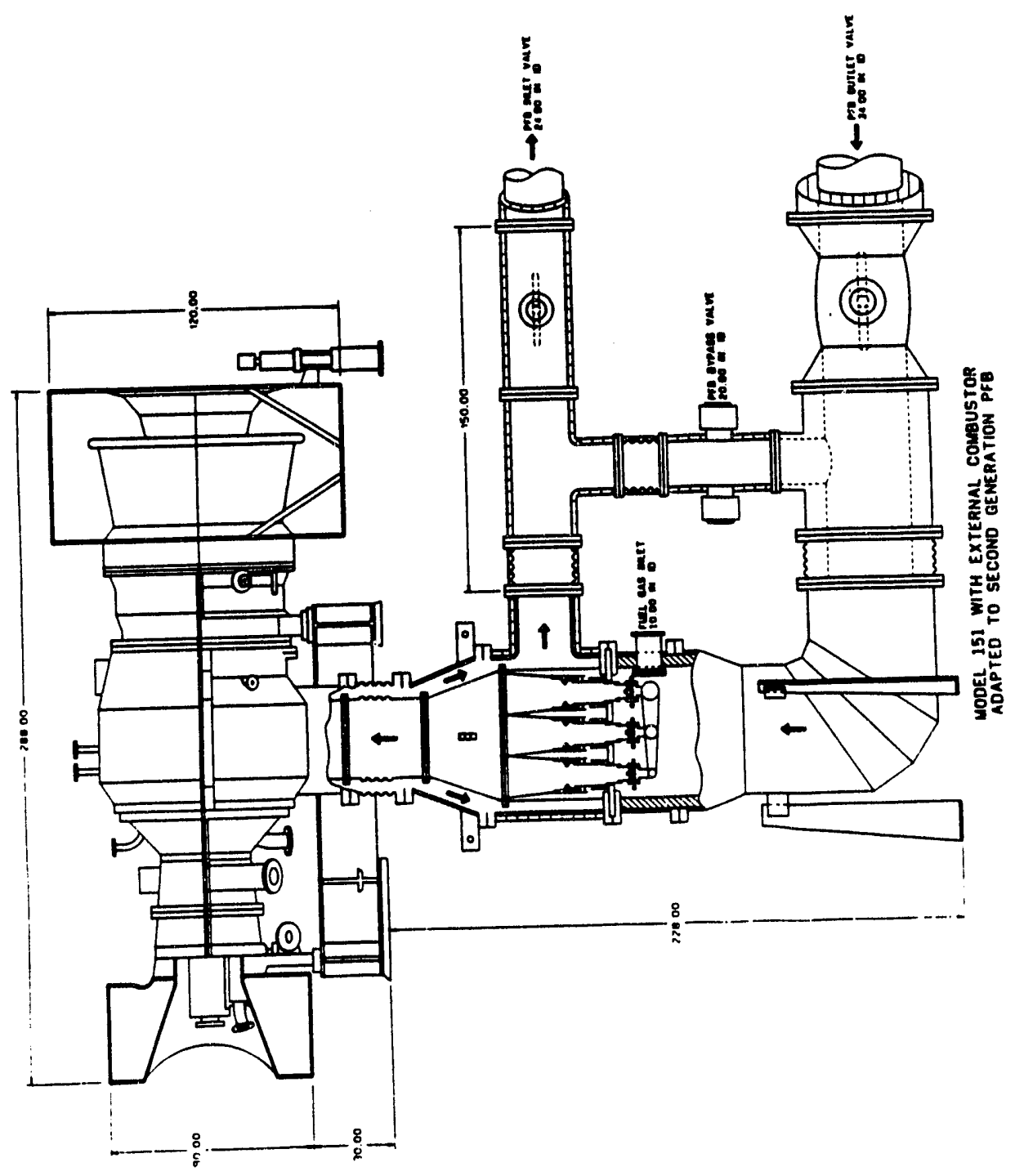



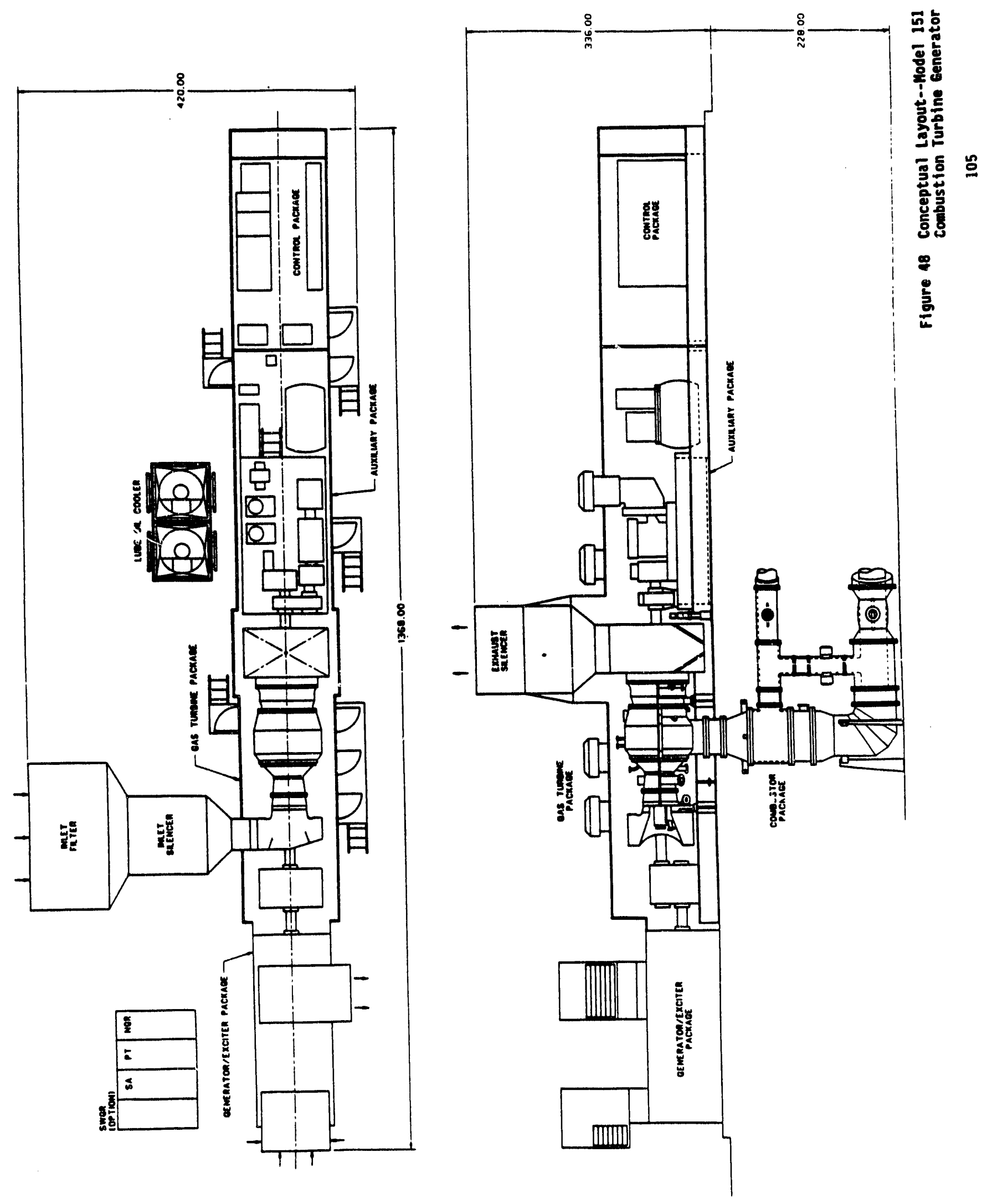


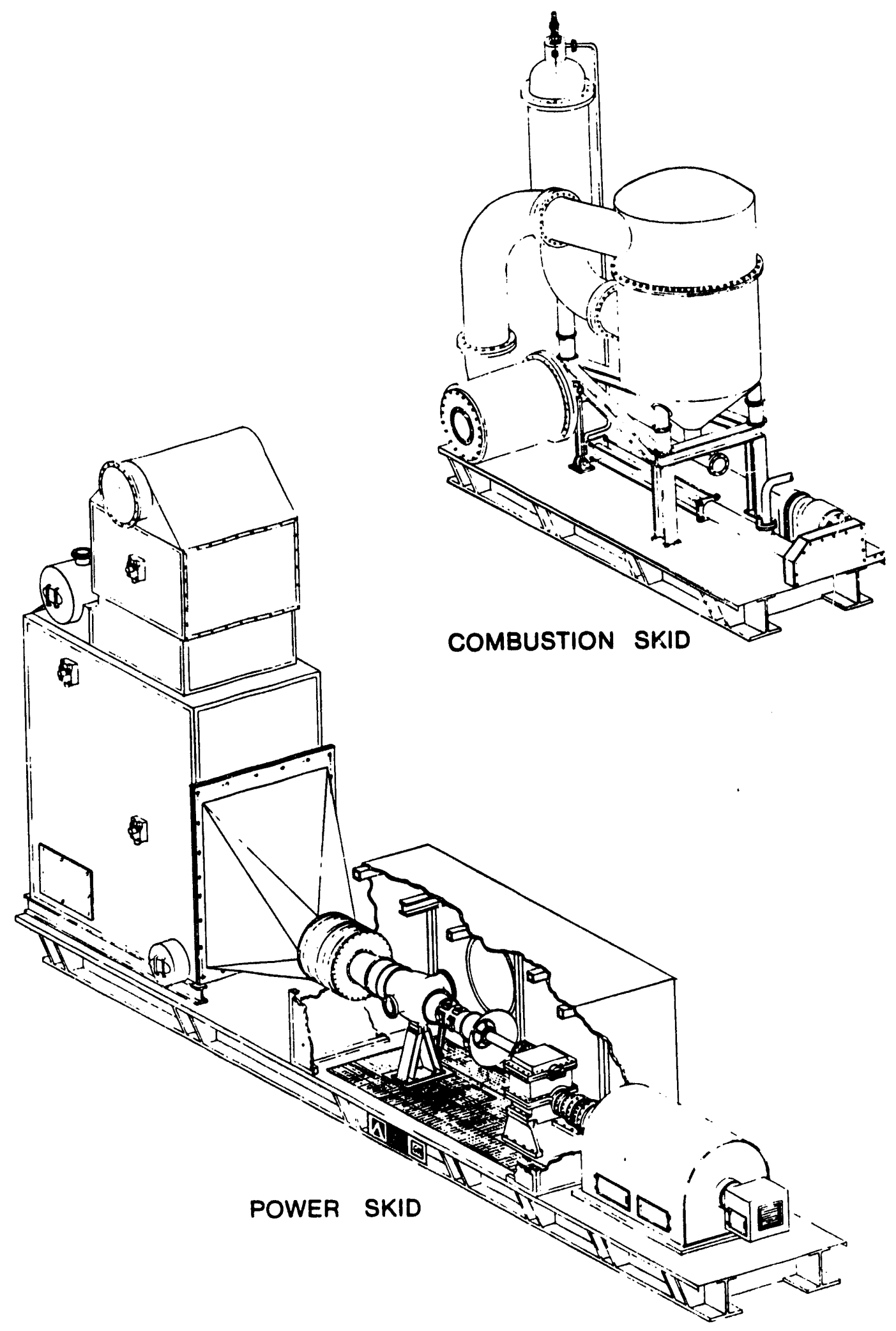

Figure 49 Power System/Combustion System Skids 
the carbonizer coal gases with the $1600^{\circ} \mathrm{F}$ gases from the PFBC. Not illustrated in Figure 49 is the ducting of both turbine exhausts to a single HRSG.

The power system skid includes the turbine; gearbox; electricity generator set; and other start-up, control, and miscellaneous equipment listed in Table 11. The turbine and gearbox are within one enclosure, and the generator set is within a second enclosure on the skid. The power skid arrangement is similar to the skid arrangement for commercial gas-fired cogeneration systems that use the Allison 501 KB turbines.

\subsubsection{Topping Combustor}

- Requirements: The second-generation PFBC cogeneration systems must meet or better New Source Performance Standards (NSPS) for emissions. Local, morestringent specifications must often also be met to minimize site selection restrictions and broaden potential applications for regions such as California. Sulfur and particulate emissions for the second-generation PFBC cogeneration systems are controlled using sulfur sorbents and hot gas filtration. The staged rich-quench-lean ( $R Q L)$ topping combustors for each turbine are designated to control $\mathrm{NO}_{\mathrm{x}}$ from thermal sources and from the high levels of FBN in coal.

- RQL Combustor $\mathrm{NO}_{\mathrm{x}}$ Performance: Allison Division of General Motors has been developing a rich-quench-lean (RQL) combustor in a Department of Energy project on direct coal-fired turbines. Figure 50 shows emissions data from tests of a bench-scale RQL combustor using a coal/water fuel that would produce $1100 \mathrm{ppm} \mathrm{NO}$ if all the FBN were converted to $\mathrm{NO}_{\mathrm{x}}$. The data show that low $\mathrm{NO}_{x}$ levels in the vicinity of $40 \mathrm{ppm}$ and lower were produced by the combustor. Combustion efficiencies greater than 99 percent have also been achieved with this combustor.

The topping combustor for the second-generation PFBC smaller cogeneration systems is based on the experience from the combustor developed during the direct-coal-fired turbine program. The same rich-quench-lean combustion approach and construction approach (refractory-lined steel piping) are used. Although the combustion and construction concepts are the same, differences in the advanced PFBC application from the direct-coal-fired application result in some differences in the combustion equipment and design. These differences are associated with the topping combustor using a low-Btu coal gas rather than a coal slurry, higher-temperature $\left(1600^{\circ} \mathrm{F}\right)$ vitiated air from the PFBC, and no quench zone particulate cleanup compared with the direct-coal-fired turbine combustor.

- ROL Topping Combustor: Figure 51 illustrates the topping combustor for the smalier second-generation PFBC cogeneration systems. The vertical vessel contains the rich combustion zone. Quench air enters at the bottom of this vessel immediately before a $90-\mathrm{deg}$ turn into the lean combustion zone. Figure 52 indicates the flows entering the rich, quench, lean, and dilution zones of the topping combustor. The rich zone is operated with relatively low levels of oxidant to inhibit $\mathrm{NO}_{x}$ formation from FBN. The quench and lean zones are designed for rapid quenching, uniform mixing, and relatively low-temperature burnout to inhibit thermal $\mathrm{NO}_{\mathrm{x}}$ formation. Air injected into the dilution zone lowers the gas temperature to the inlet value for the turbine. 


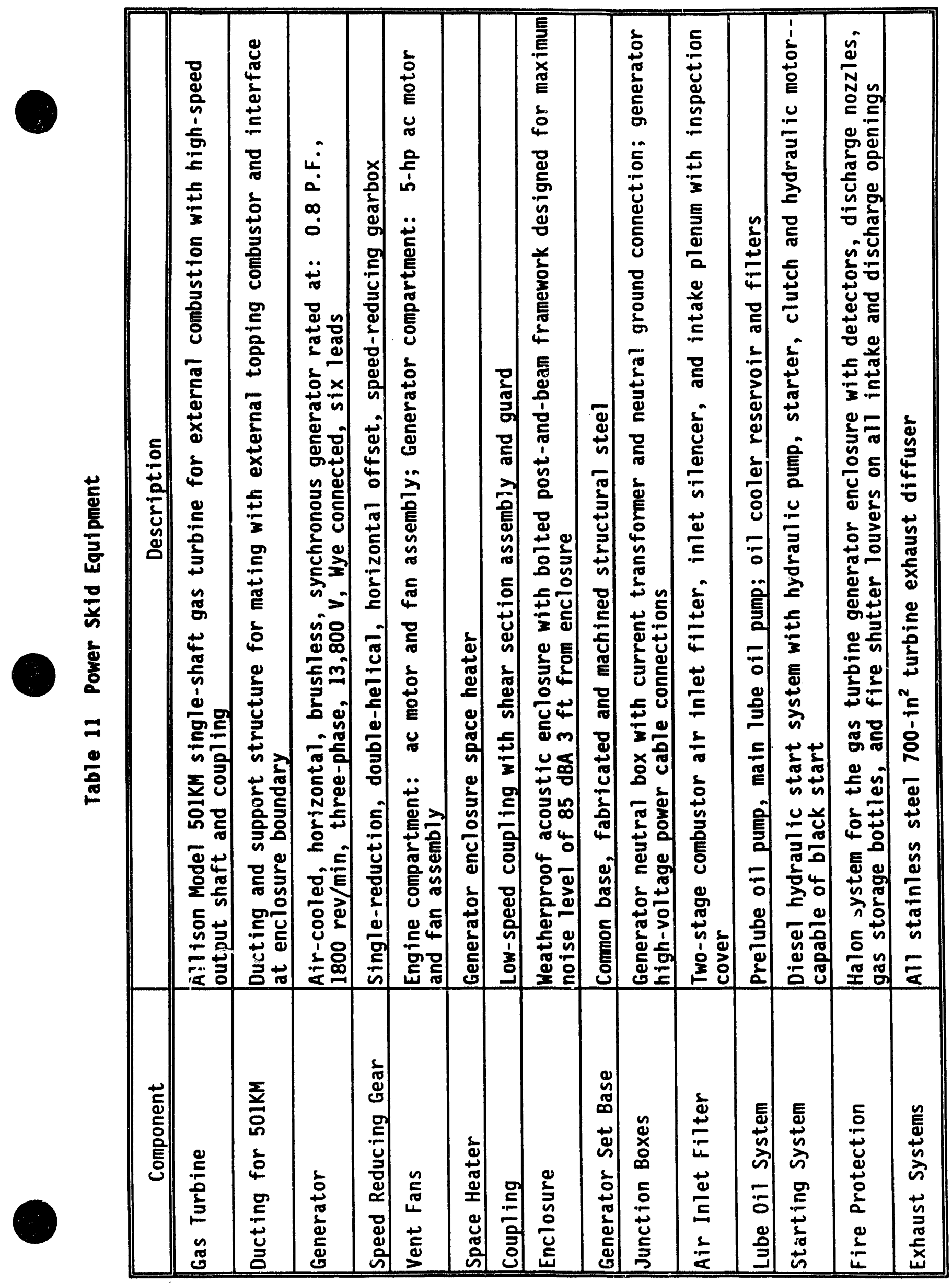




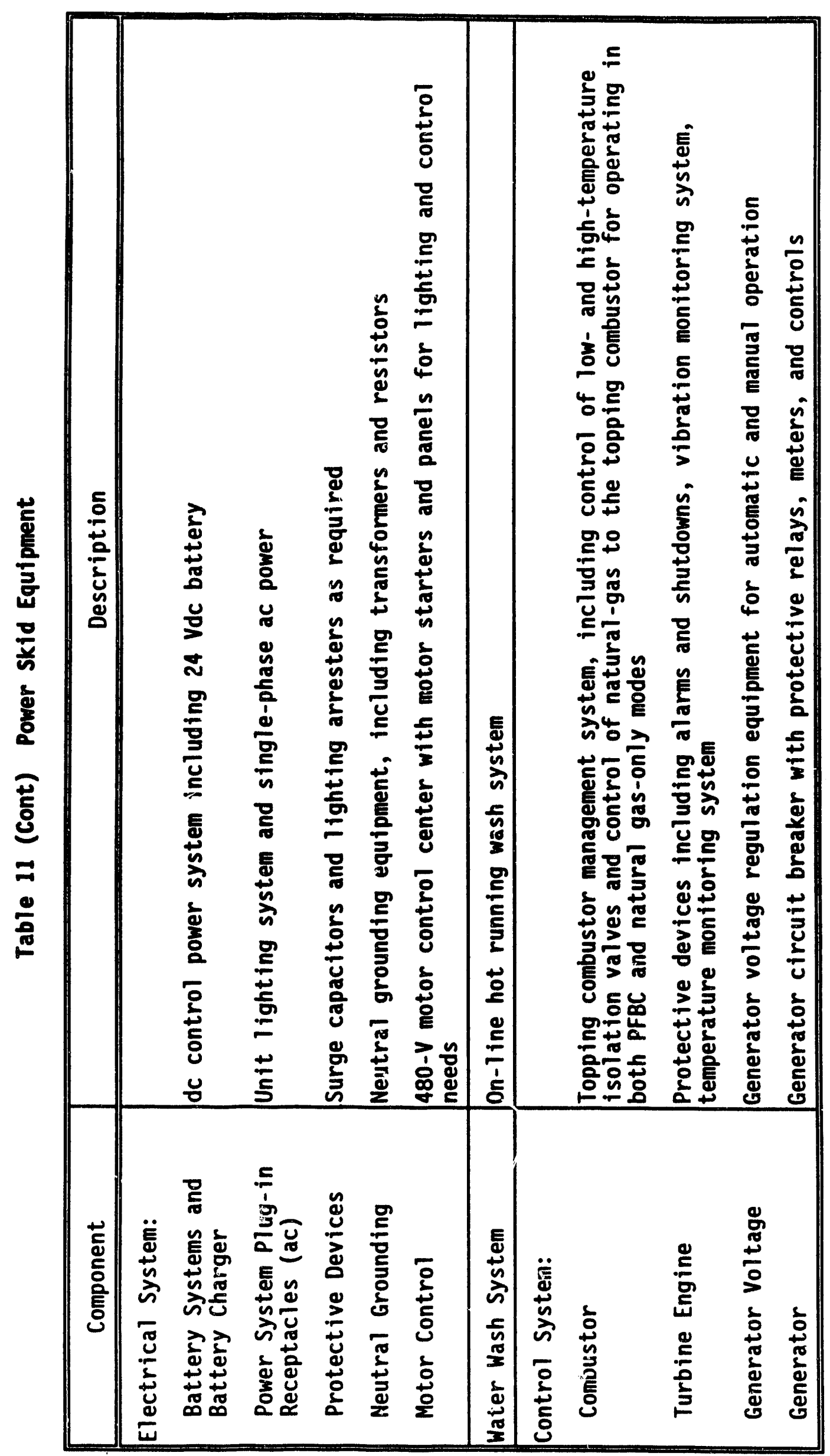




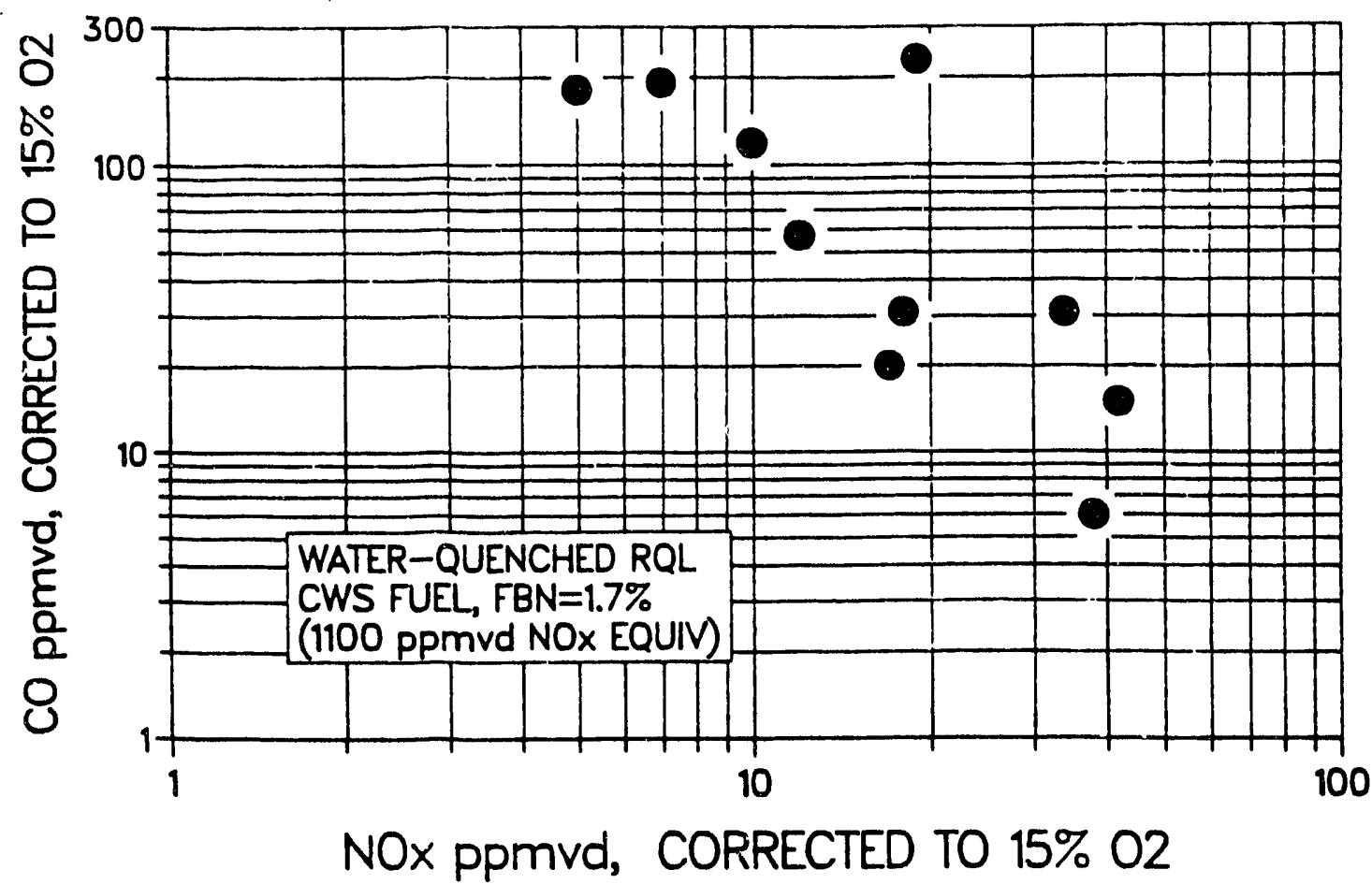

Figure $50 \mathrm{RQL}$ Lean-Zone Emissions From Coal/Nater Slurry--CO vs. $\mathrm{NO}_{x}$ Corrected to 15-Percent Exhaust $\mathrm{O}_{2}$

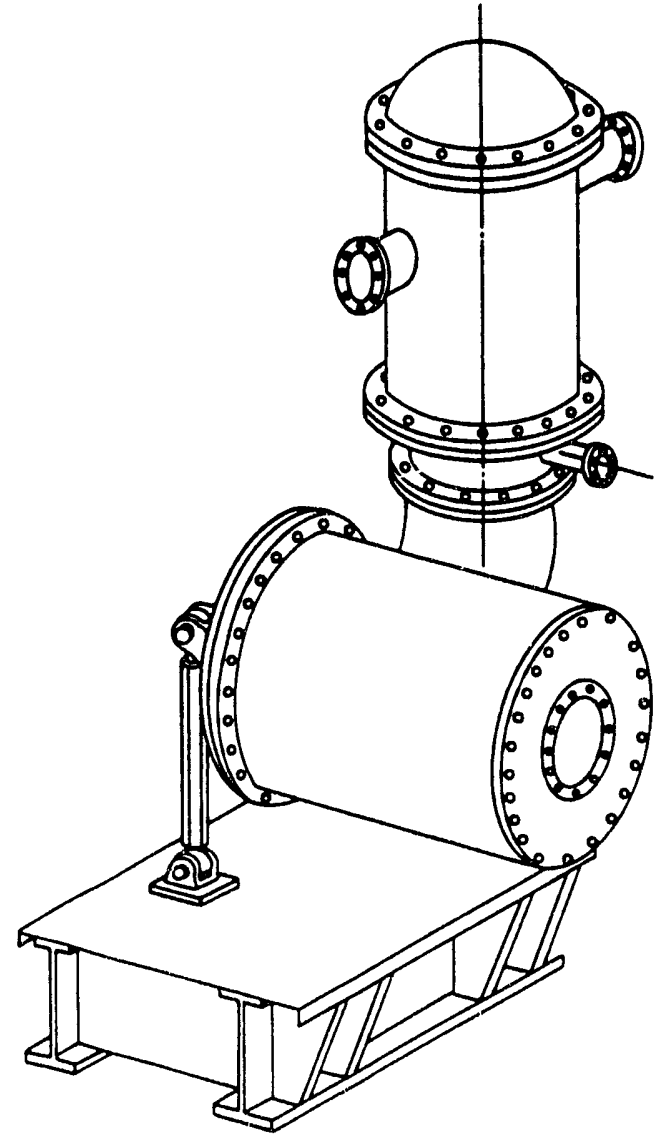

Figure 51 RQL Topping Combustor for Smaller Second-Generation PFBC Cogeneration Systems 


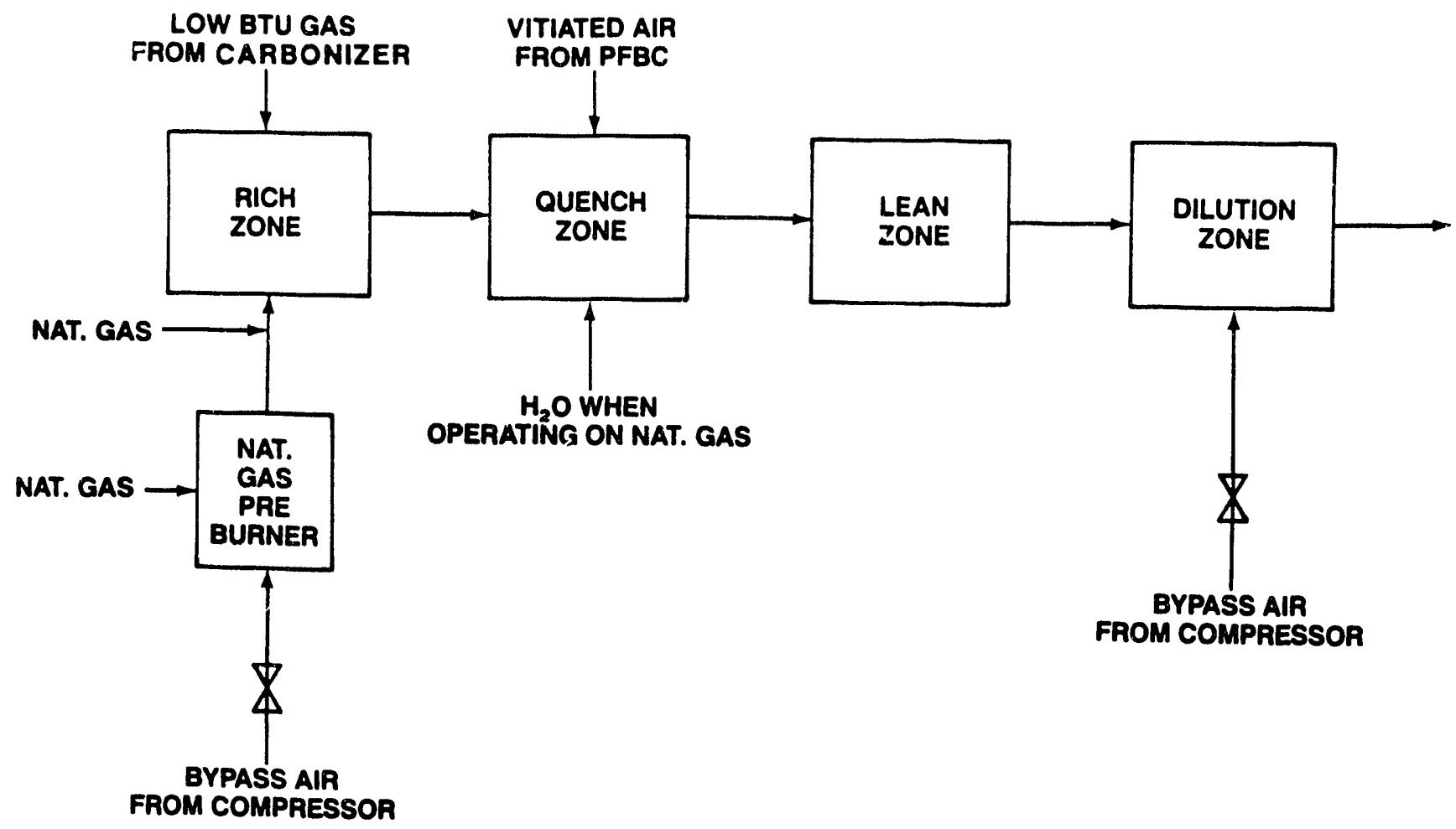

Figure 52 Schematic of Flows to Rich, Quench, Lean, and Dilution Zones of Topping Combustor

For start-up, natural gas is burned in a natural-gas burner with bypass air from the turbine compressor. System operation with natural gas is also possible in the event that coal combustion components are out of service (e.g., during maintenance). In this case, natural gas is injected just upstream of the rich zone, and water is injected for quenching after the rich zone.

Figure 53 shows a cross section of the topping combustor. For operation with coal products, the low-Btu gas from the carbonizer and the bypass air from the compressor enter tangentially on opposite sides of the rich zone to produce a cyclonic flow pattern. Vitiated air from the PFBC is injected at the quench zone. The resultant stream enters tangentialiy into the lean zone to produce a cyclonic flow pattern for final burnout. Bypass air from the turbine compressor is injected at the inlet of the draft tube, which operates as a dilution zone and directs the flow into the turbine.

\subsubsection{Gas Turbines}

The Allison 501 gas turbine for the smaller cogeneration systems (Cases $3,4,5$, and 6 ) is an industrial derivative of an aeronautical engine. More than 14,000 of these engines and 1200 of their industrial derivatives have been manufactured by Allison Division of General Motors. More than 420 Model $501 \mathrm{~KB} / \mathrm{KB} 5$ have operated with generator sets.

The Model 501 KM turbine for the second-generation PFBC system is a modified Model 501 KB5 engine. The six internal can combustors and the center casing of the Model 501 KB5 are replaced with a modified center section with ducting to take the compressor discharge to the external combustor and receive 


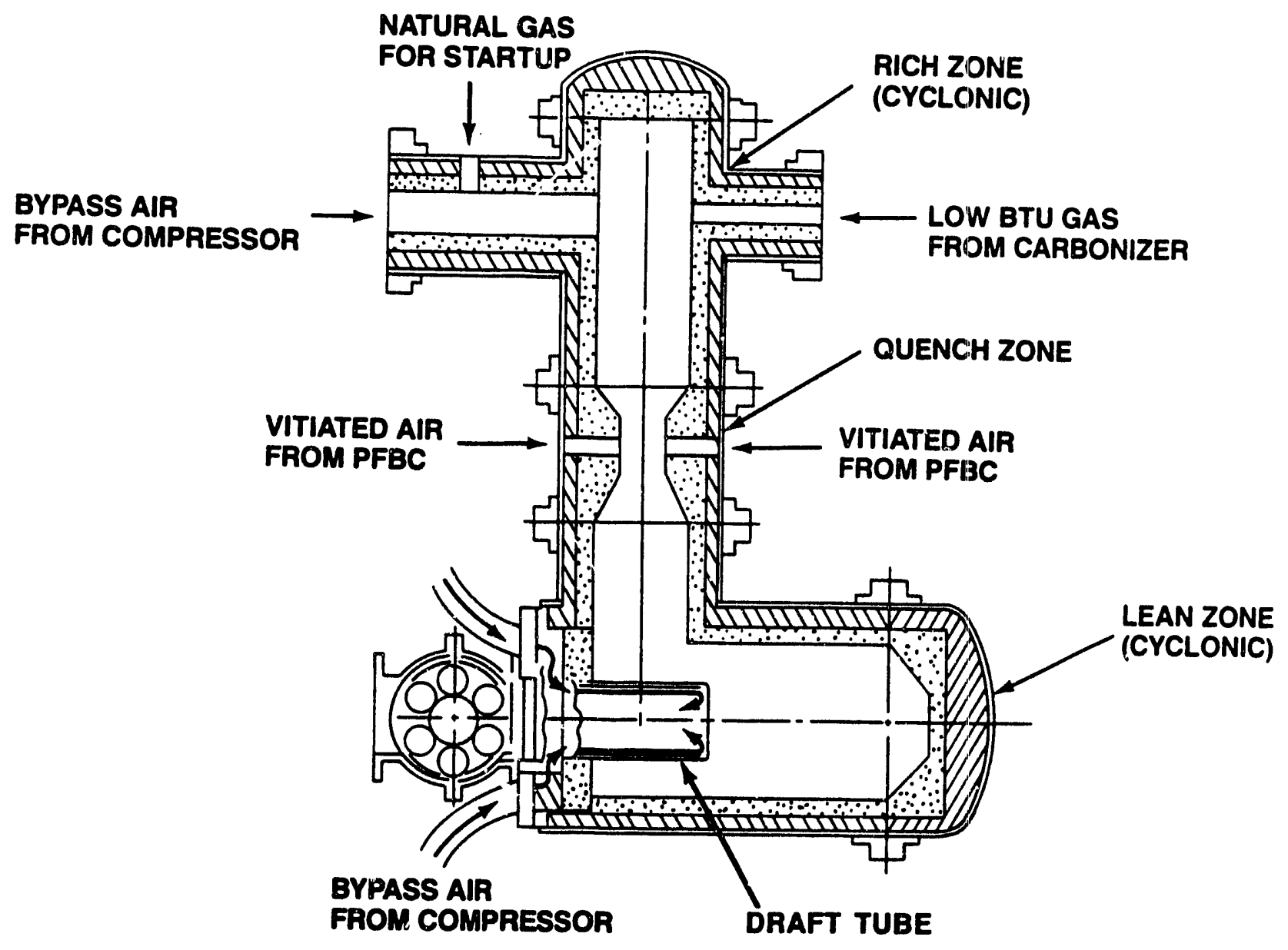

Figure 53 RQL Topping wasibustor--Cross Section.

and direct combustion products into the turbine expander. A Model $501 \mathrm{KM}$ prototype engine was tested in 1990 in the Allison/DOE Advanced Coal-Fueled Gas Turbine Systems Program.

Figure 54 illustrates the Model $501 \mathrm{KM}$ turbine and shows the original Model 501 KB5 part and the new Model 501 KM parts. Compressor discharye air exits the new center section through the two large flanged ducts. Combustion products are brought back into the engine from the topping combustor through the internal duct in the center section (see Figure 55). This internal duct connects to the lean-zone draft tube illustrated in Figure 53. The large internal duct divides into six ducts that enter the transition sections to the first stator vane row of the turbine expander.

The vanes and blades of the turbine expander are protected with coatings that have demonstrated high corrosion and erosion resistance in past coal-fired PFBC cascade tests. Rhodium aluminide coatings are used for the stator vanes. Platinum aluminide and MCrAly coatings are used for the rotor blades. 


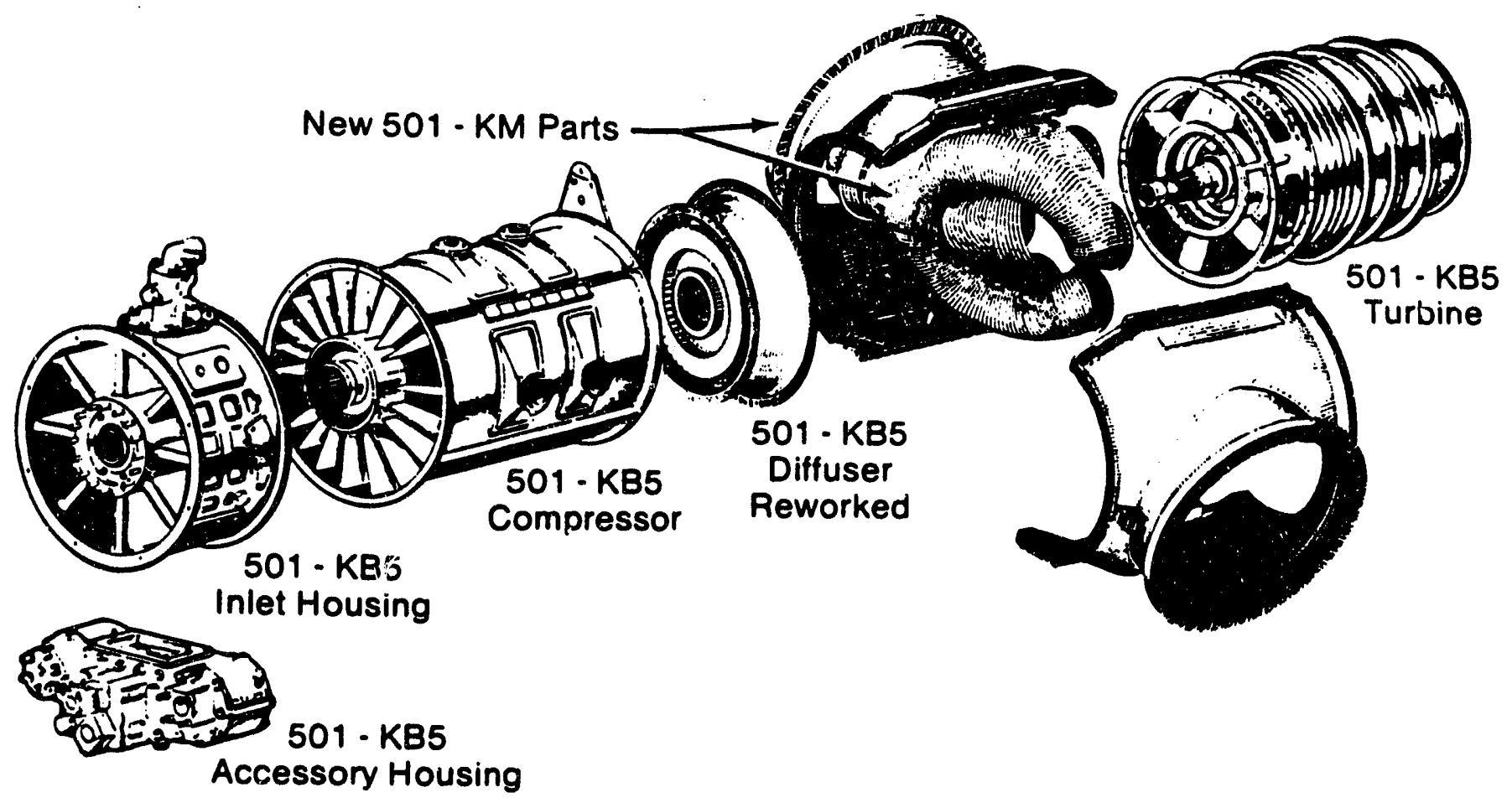

Figure 54 Model 510 KM Turbine

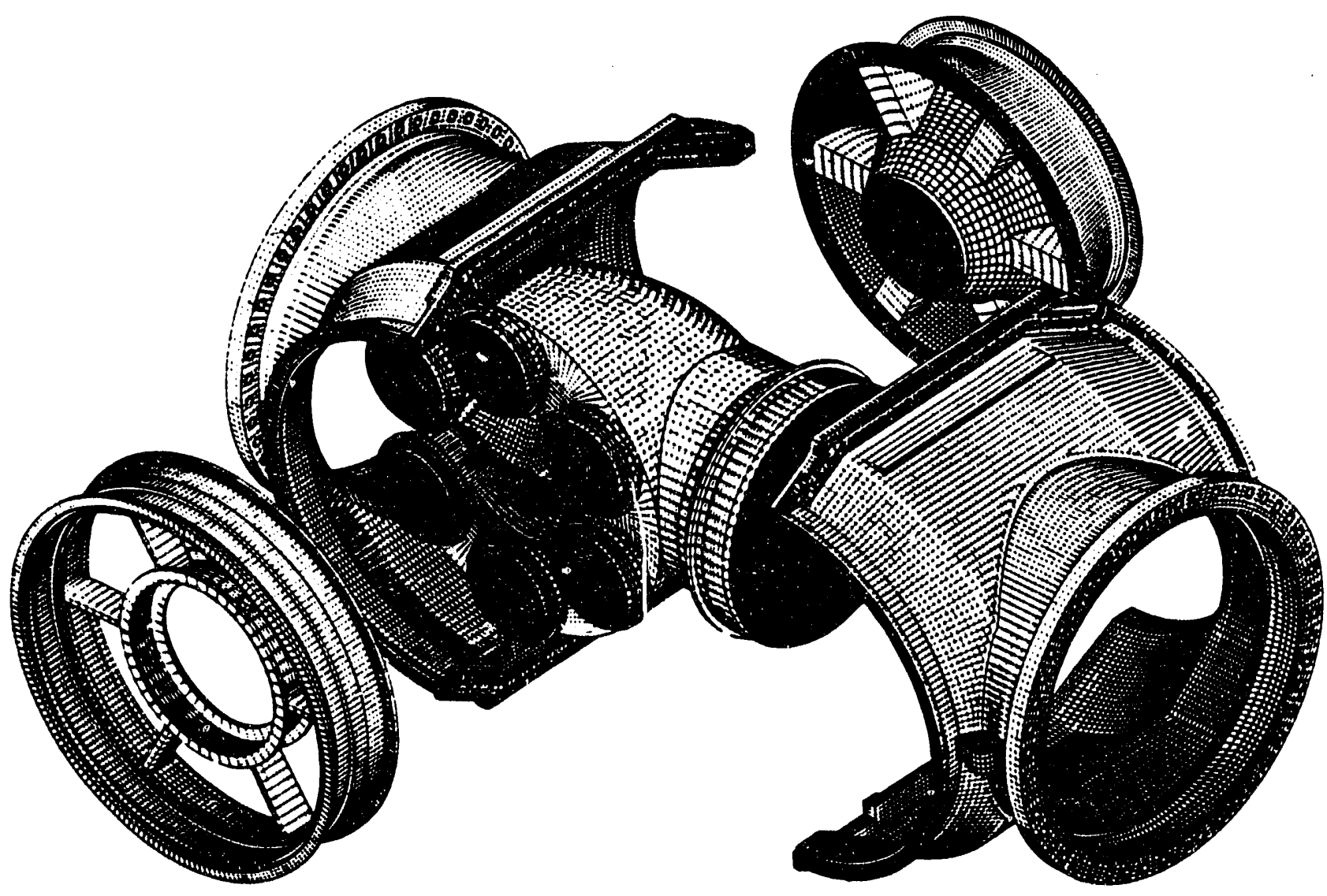

Figure 55 Internal Duct in Center Section of Model $501 \mathrm{KM}$ Turbine 
The equipment descripticiss in this section pertain primarily to

Case 1, the largest of the study cases. Equipment for the other study cases is described as variations from Case 1.

\subsubsection{Steam and Feedwater System}

The Steam and Feedwater System uses conventional steam-based power generation equipment. The steam systems for Cases 1 and 4 produce steam for back-pressure steam turbines. In Cases 2, 3, and 5, the steam turbine is eliminated, and steam is generated at $150 \mathrm{psig} \mathrm{(process} \mathrm{steam} \mathrm{pressure} \mathrm{re-}$ quirements). Included in this section are descriptions of the system functions, design criteria, and major equipment.

System Functions. The Steam and Feedwater System furnishes condensate-quality feedwater to the HRSG and, for all cases except Case 3, to the FBHE. Cleaned, preheated, and pressurized water--to the level necessary for providing steam to the steam turbine-generator, to meet process requirements, or both--is converted to steam in the heat exchangers. After the usable energy is converted into mechanical energy in the turbine (Cases 1 and 4), the exhaust steam at 150 psig is conveyed to the existing steam header for the plant process steam requirements.

Process condensates are collected in a condensate storage tank, then passed through a condensate polisher system to remove impurities; clean condensate is then conveyed to a deaerator. Makeup water is also added to the deaerator.

Design Criteria. Design criteria for the systems are primarily shown on the plant heat and mass balances (in Section 4) which define the flows, pressures, and temperatures necessary to produce the power output and the process steam requirements:

\begin{tabular}{|ll|}
\hline Case 1 & $1200 \mathrm{psig} / 950^{\circ} \mathrm{F}$ \\
Case 2 & $150 \mathrm{psig} /$ saturated \\
Case 3 & $150 \mathrm{psig} /$ saturated $^{\circ}$ \\
Case 4 & $700 \mathrm{psig} / 750^{\circ} \mathrm{F}$ \\
Case 5 & $150 \mathrm{psig} \mathrm{saturated}$ \\
Case 6 & $700 \mathrm{psig} / 750^{\circ} \mathrm{F}$ \\
\hline
\end{tabular}

The main steam piping is designed for a pressure drop of $5.0 \mathrm{psi}$ $100 \mathrm{ft}$ pipe length at the maximum continuous rating (MCR) of steam generation, while limiting steam velocity to $20,000 \mathrm{ft} / \mathrm{min}$. Steam velocity is i imited to $12,000 \mathrm{ft} / \mathrm{min}$ for a $150-\mathrm{psig}$ steam line. The feedwater flow velocity is limited to $8 \mathrm{ft} / \mathrm{s}$ for feedwater suction and $15 \mathrm{ft} / \mathrm{s}$ for the feedwater dis charge line. The flow velocity for condensate piping is 1 imited to $10 \mathrm{ft} / \mathrm{s}$. 
Major Equipment. The major equipment in the Steam and Feedwater System is described in the following bulleted items:

- Heat Recovery Steam Generators. Heat is recovered from the exhaust of the combustion turbine. Feedwater is heated, boiled, and superheated (Cases 1, 4 , and 6 only) with the recovered heat. The HRSGs work in conjunction with the FBHE or the PFBC to provide the total steam flow. In each case, one HRSG is provided, associated with one combustion turbine.

\begin{tabular}{|c|c|c|c|c|c|c|}
\hline Description & Case 1 & Case 2 & Case 3 & Case 4 & Case 5 & Case 6 \\
\hline \multicolumn{7}{|c|}{ Gas Side } \\
\hline Flow. $1 \mathrm{~b} / \mathrm{h}$ & 757,275 & 757,275 & 251,000 & 256.560 & 256,660 & 251.757 \\
\hline Temperature In. 'f & 1.050 & 1.050 & 1.066 & 1,056 & 1.066 & 1.066 \\
\hline Temperature Out, 'F & 280 & 280 & 280 & 280 & 280 & 280 \\
\hline \multicolumn{7}{|c|}{ Water In } \\
\hline Flow. $1 \mathrm{~b} / \mathrm{h}$ (feedwater) & 393.042 & 509,530 & 53,075 & 83,090 & 98,900 & 81.534 \\
\hline Pressure. psia & 1.515 & 225 & 225 & 900 & 225 & yoo \\
\hline Temperature, 'F & 242.7 & 240.4 & 240.4 & 242.7 & 240.4 & 241.6 \\
\hline \multicolumn{7}{|c|}{ Steam Out } \\
\hline Flow, ib/h (Steam) & 24,925 & 107,270 & 51.840 & 42,150 & 47.265 & 39,427 \\
\hline Pressure, psia & 1.342 & 184.4 & 184.4 & 795.8 & 184.4 & 795.8 \\
\hline Temperature, $F$ & 581.6 & 375 & 375 & 517.6 & 375.1 & 507.6 \\
\hline \multicolumn{7}{|c|}{ Water Out } \\
\hline Flow, Ib/h (Water) & 367.870 & 398,950 & $N / A$ & 40.500 & 50.200 & 41,686 \\
\hline Pressure, psia & 1,342 & 184.4 & N/A & 795.8 & 184.4 & 795.8 \\
\hline Temperature, 'f & 571.6 & 365.1 & $n / A$ & 507.6 & 365.1 & 517.6 \\
\hline
\end{tabular}

- Steam Turbine. One back-pressure steam turbine generates power from the high-pressure steam in Cases 1, 4, and 6. Exhaust from the turbine is at $150 \mathrm{psig}$. There is no steam turbine in Cases 2, 3, and 5.

\begin{tabular}{|c|c|c|c|}
\hline Description & Case 1 & Case 4 & Case 6 \\
\hline \multicolumn{4}{|c|}{ Steam In let } \\
\hline Pressure, psia & 1.214 .7 & 714.7 & 720.0 \\
\hline Temperature, ' $F$ & 949.8 & 750 & 750 \\
\hline \multicolumn{4}{|c|}{ Steam Exhaust } \\
\hline Pressure, psia & 164.7 & 164.7 & 164.7 \\
\hline Power Generated, Mue & 20.3 & 2.1 & 2.0 \\
\hline Turbine Speed, rev/min & 3,600 & 3,600 & 3,600 \\
\hline
\end{tabular}


- Deaerator. One full-size deaerator is provided. The deaerator is a direct-contact, tray-type heater, where steam is used to preheat and deaerate condensate and makeup water.

\begin{tabular}{|l|l|l|l|l|l|l|}
\hline \multicolumn{1}{|c|}{ Description } & Case 1 & Case 2 & Case 3 & Case 4 & Case 5 & Case 6 \\
\hline Capac ity of Deaerated Water, Ib/h & 393,000 & 510,000 & 60,000 & 85,000 & 109,200 & 81,500 \\
\hline Operat ing Pressure, psia & 25 & 25 & 25 & 25 & 25 & 25 \\
\hline Storage Capacity, min & 10 & 10 & 10 & 10 & 10 & 10 \\
\hline Oxygen Content Guarantee, Cc/L & 0.005 & 0.005 & 0.005 & 0.005 & 0.005 & 0.005 \\
\hline Out let Water Temperature. $\cdot F$ & 240 & 240 & 240 & 240 & 240 & 240 \\
\hline
\end{tabular}

- Condensate Pumps. Condensate pumps take water from the condensate storage tank and raise the water pressure to the level necessary to convey condensate to the deaerator. Two, 100-percent capacity, centrifugal pumps are provided.

\begin{tabular}{|l|l|l|l|l|l|l|}
\hline \multicolumn{1}{|c|}{ Description } & Case 1 & Case 2 & Case 3 & Case 4 & Case 5 & Case 6 \\
\hline Capac ity, gal/min & 500 & 625 & 70 & 100 & 125 & 100 \\
\hline Total Discharge Head, ft & 135 & 135 & 120 & 120 & 120 & 120 \\
\hline Mozor, hp & 40 & 40 & 5 & $7-1 / 2$ & $7-1 / 2$ & $7-1 / 2$ \\
\hline
\end{tabular}

- Condensate Polisher. Condensate polisher removes particulates and contaminants continuousiy from condensate before discharging to the deaerator. Two, 100-percent-capacity zeolite units are provided.

\begin{tabular}{|c|l|l|l|l|l|l|}
\hline Description & Case 1 & Case 2 & Case 3 & Case 4 & Case 5 & Case 6 \\
\hline Capacity, ga 1/min & 500 & 625 & 70 & 100 & 125 & 100 \\
\hline
\end{tabular}

- Feedwater Pumps. Feedwater pumps take water from the deaerator for the HRSG. Two, 100-percent capacity, feedwater pumps are provided.

\begin{tabular}{|l|l|l|l|l|l|l|}
\hline \multicolumn{1}{|c|}{ Description } & Case 1 & Case 2 & Case 3 & Case 4 & Case 5 & Case u \\
\hline Capacity, gal/min & 850 & 1100 & 140 & 200 & 250 & 200 \\
\hline Total Head, psig & 1500 & 210 & 215 & 900 & 215 & 900 \\
\hline Motor, hp & 1000 & 250 & 30 & 200 & 50 & 200 \\
\hline Water Temperature. .F & 240 & 240 & 240 & 240 & 240 & 240 \\
\hline
\end{tabular}

\subsubsection{Makeup Water System}

In Cases 1 and 4, steam is generated at $1200 \mathrm{psig} / 950^{\circ} \mathrm{F}$ and $700 \mathrm{psig} /$ $750^{\circ} \mathrm{F}$ respectively. High-purity makeup water is required in these cases to remove silica and other impurities from the makeup water. In the other cases, steam is generated at 150 psig (saturated), and silica is not a major concern. 
Therefore, a demineralized makeup water system was selected for Cases 1 and 4 , and a zeolite softener system was selected for Cases 2, 3, and 5.

\section{Demineralized Makeup Nater System--(Cases 1 and 4).}

System Function. The Demineralized Water System shown in Figure 56 provides a makeup supply of acceptable-quality demineralized water to the feedwater system. The demineralizer system, supplied by filtered water from the existing filtered-water storage tank, removes dissolved solids from the inlet water via ion exchange, utilizing strong acid cation and strong base anion units.

System Description. The cycle makeup demineralizer system consists of two skid-mounted trains, each capable of delivering $300 \mathrm{gal} / \mathrm{min}$ for Case 1 and $60 \mathrm{gat} / \mathrm{min}$ for Case 4. Each train consists of a cation demineralizer and an anion demineralizer. Normally, one train satisfies the system requirements, and the second train is in a regenerated standby condition. During normal operation, the system is monitored, and unacceptable conditions are brought to the operator's attention by an alarm.

The cation and anion demineralizers of each train are designed for regeneration after 24 hours of operation. Cation and anion demineralizer regeneration requirements are based on throughput, conductivity, or both. The effluent from the demineralizer is monitored continuously for conductivity and silica.

Regeneration of the demineralizers is automatic when manually initiated, and the regeneration system can be overridden for manual operation. Any faults in the regeneration process are brcught to the operator's attention by an alarm, and the process reverts automaticaliy to a safe shutdown condition until the operator can clear the faults.

\section{Equipment Description.}

- Cation Demineralizer. The demineralizer vessel is mounted on the skid with piping, valves, and instrumentation. Installed inside the demineralizer are Type 316 stainless steel influent, effluent, and regenerant distribution systems. The unit is complete with service backwash, regenerant, drain, resin filling, resin removal, piping, valves, controls, and instruments.

- Anion Demineralizer. The demineralizer vessel is mounted on the skid with interconnecting piping, valves, controls, and instrumentation. The unit is complete with service backwash, regenerant, drain, resin filling, resin removal, piping, valves, controls, and instruments.

- Regenerant Chemical Pumps, Piping, and Valves. Pumps transfer regenerant chemicals from the respective storage tanks to the chemical dilution mixing tees. Sulfuric acid pumps (vertical, centrifugal, submerged-type) are topmounted on the acid storage tank. Sodium hydroxide pumps (reciprocating, diaphragm-type) are mounted on a concrete pad. The adjustment of the pump stroke length is manual. A damper on the pump discharge line reduces pressure fluctuations. 


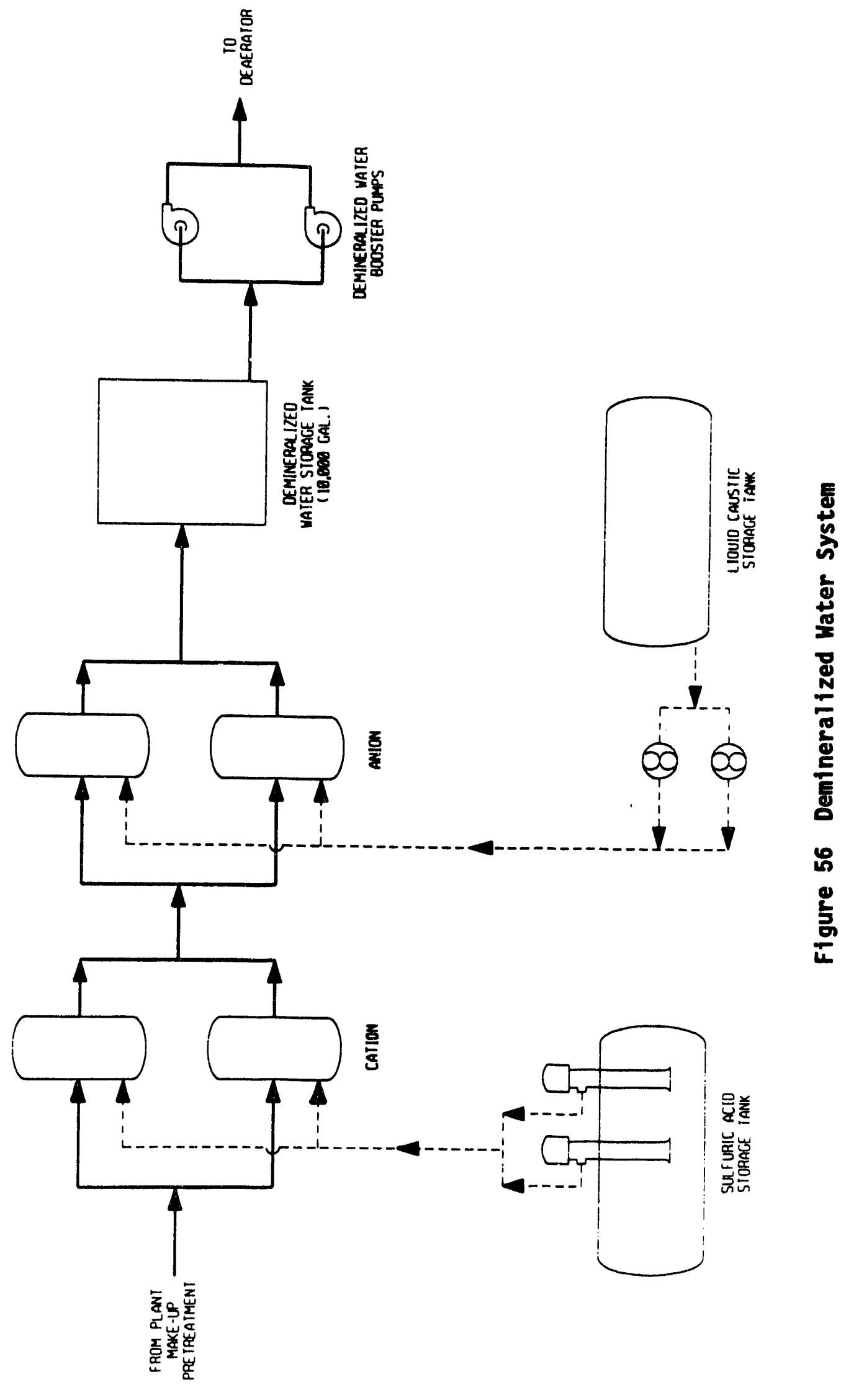


Zeolite Makeup Water System--(Cases 2, 3. and 5). The Sodium Zeolite Softener System provides a makeup supply of acceptable-quality water to the feedwater system. The system is designed to deliver $37 \mathrm{gal} / \mathrm{min}(40 \mathrm{gal} / \mathrm{min}$ for Cases 3 and 5) of softened water continuously. Brine is used for the regeneration of the strong cation resin.

\section{Compressed Air System.}

System Functions. Compressed air is used primarily in the carbonizer and PFBC to carbonize and burn the coal. Requirements for the compressed air system depicted in Figure 57 are based on the heat and mass balance. Except for "shop air" and "instrument air," the gas turbine compressor supplies the entire plant with compressed air. The turbocompressor air pressure is adequate for the PFBC, but it is increased by booster compressors for the carbonizer and for purge and miscellaneous requirements. The compressed air system is identical for Cases 1 and 2 and smaller, but similar, for Cases 3, 4, 5, and 6 .

\section{Design Criteria.}

- The design criteria for the booster compressors are set by the process pressure needs listed on the heat and mass balance diagram. Two 100percent-capacity compressors serve the PFBC and carbonizer.

- The instrument air is typical 100 psig with a $-40^{\circ} \mathrm{F}$ pressure dewpoint. Shop air is also standard at 100 psig. Neither use is shown in the overall heat and mass balance.

- A small amount of service air is needed at the highest pressure for purging and miscellaneous uses.

- The ceramic cross-flow filter booster compressor size and pressure were determined using data from Westinghouse test reports of laboratory-scale units and projections of commercial-size plants.

\section{System Description.}

- Carbonizer Booster Compressor. For Cases 1 and 2, the carbonizer requires air at 167 psia to overcome line losses and gas turbine fuel pressure drops. The FBHE $J$ valves also require air at this pressure. A booster "blower" was chosen to do this because a compressor would need precooling. The design is a straight radial blade unit operating at $3600 \mathrm{rev} / \mathrm{min}$, with spindle bearings. The wheel diameter is 29.5 in., and nominal operating power is 154 bhp. Because of the combination of 167 psia outlet pressure and $634^{\circ} \mathrm{F}$ inlet temperature, it is a custom-designed blower.

The units for Cases 3, 4, and 5 are smaller and have a 176 psia outlet pressure and a $720^{\circ} \mathrm{F}$ inlet temperature. These are also custom-designed blowers.

- Ceramic Cross-Flow Filter Blowback Compressor. Air for the ceramic crossflow filter is first cooled in a shell-and-tube-type heat exchanger and then dewatered in a separator before being boosted to 205.5 psia (216 psia for cases 3, 4, and 5). In addition to its primary use for blowback air for the cross-flow filter, this compressor supplies air for purging and miscellaneous uses. 

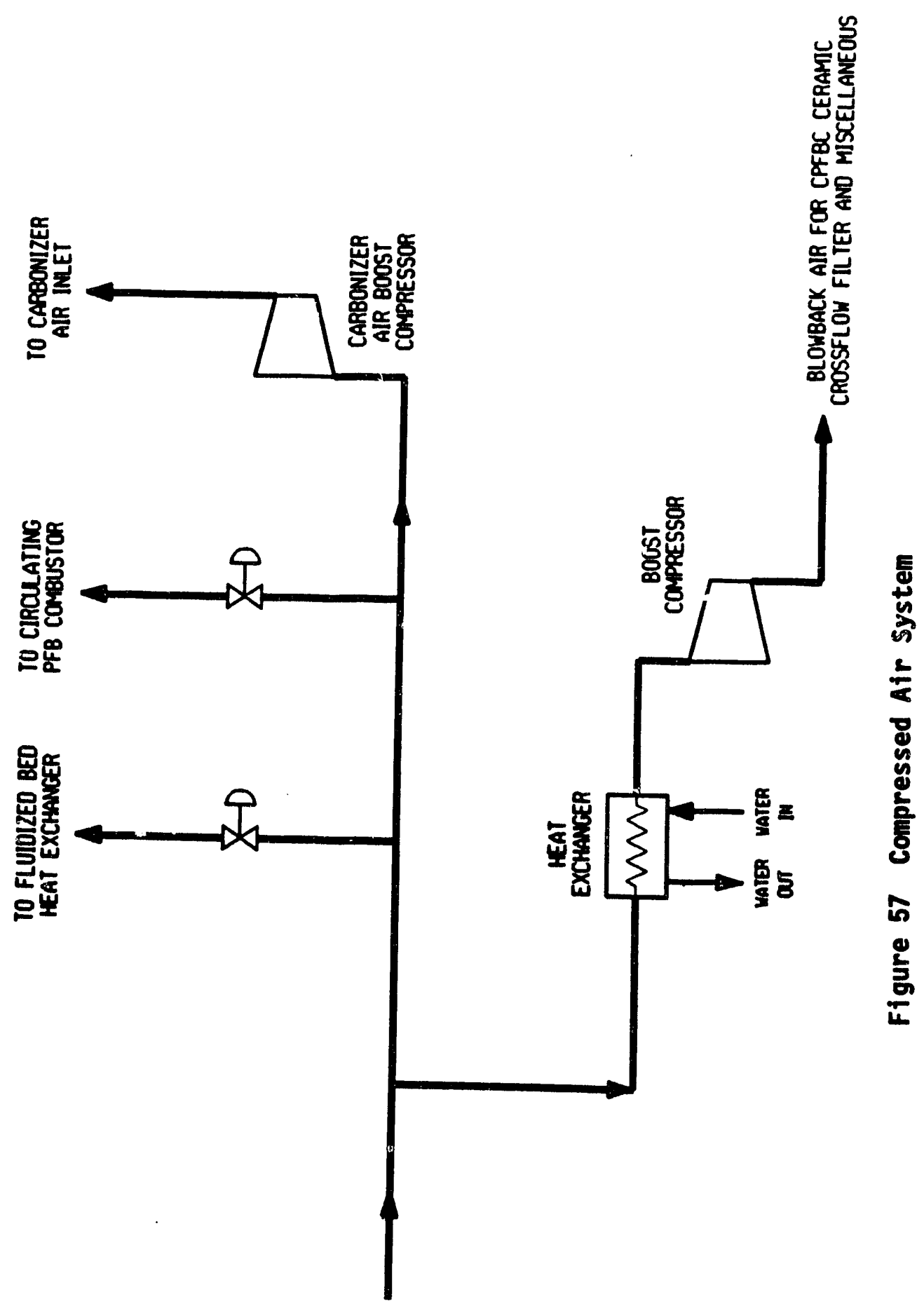

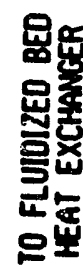

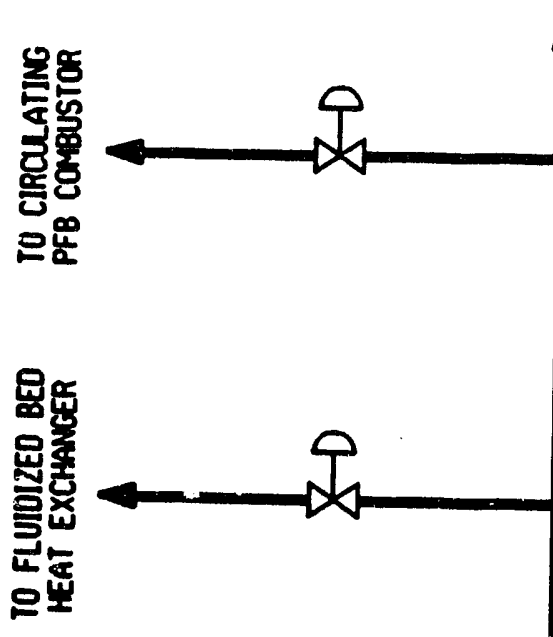

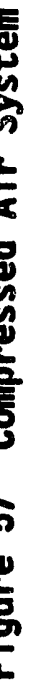

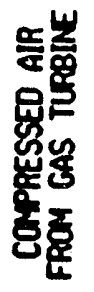


- Auxiliary Air Compressor. The auxiliary air compressor supplies 100 psig air for instruments and for miscellaneous intermittent shop uses. There is only one compressor; the existing instrument air compressors are for backup.

An aftercooler, a cyclone water separator, and a $150-\mathrm{ft}^{3}$ air receiver follow the compressor. The instrument air system has a desiccant-type air dryer, which provides air up to $-40^{\circ} \mathrm{F}$ dewpoint. Ambient air is used for the inlet.

- Stack Desion. The stack design is based on the following parameters:

- Stack height approximately two times the tallest plant structure

- Stack gas velocity at the top limited to $80 \mathrm{ft} / \mathrm{s}$

- Draft loss in the stack limited to 2 in. $\mathrm{H}_{2} \mathrm{O}$.

The stack has a full-height, galvanized steel, exterior ladder with safety climb device; aviation obstruction lighting system meeting current FAA requirements; one 4-ft-wide 360-deg galvanized steel platform at El. $90 \mathrm{ft}$ above the ground floor for sampling and monitoring; and a lightning protection system in accordance with NFPA. Stack dimensions are:

\begin{tabular}{|l|c|c|}
\hline Dimensions & $\begin{array}{c}\text { Cases 1 } \\
\text { and 2 }\end{array}$ & $\begin{array}{c}\text { Cases 3, 4, 5, } \\
\text { and 6 }\end{array}$ \\
\hline Stack Height, ft & 200 & 150 \\
\hline I.D. at Top, ft & 8 & 4.75 \\
\hline
\end{tabular}

- Flare System. A flare stack is required to provide a safe discharge point for combustible gases during start-up, shutdown, and upset conditions. The flare stack is $55 \mathrm{ft}$ high with a 36-in. I.D. and is of the self-supporting type. The stack is lined for high-temperature service. The flare stack system includes the required number of pilots (to sustain the flame), flame-monitoring instrumentations, and stainless steel piping from the carbonizer area to the stack. The stack is in an open area with a clear radial area of $150 \mathrm{ft}$ surrounding it. Any other streams of combustible gases that require discharge are also discharged to the flare. The flare system for Case 2 is identical to the one for Case 1. Systems $\mathrm{fc}^{\circ}$ Cases 3, 4, and 5 are smaller; but similar.

- Nitrogen Supply and Distribution. This system provides nitrogen for blanketing, purging, and other miscellaneous uses where an inert gas is required for safety, to avoid problems created by moisture, or a combination of these needs. Nitrogen is stored in bottles and is distributed through the plant through a manifold piping system. Plant nitrogen requirements for Cases 1 and 2 are presented in Table 12. 
Table 12 Plant Nitrogen Requirements

\begin{tabular}{|l|c|}
\hline \multicolumn{1}{|c|}{ Description } & $\begin{array}{c}\text { Use Rate } \\
(\mathrm{lb} / \mathrm{h})\end{array}$ \\
\hline $\begin{array}{l}\text { Blow-Back Gas for Carbonizer Ceramic } \\
\text { Cross-Flow Filter (at 230 psig) }\end{array}$ & 120 \\
\hline Coriveying Char From Carbonizer to CPFBC & 60 \\
\hline $\begin{array}{l}\text { Miscellaneous, Including Purge of Flue } \\
\text { Gas Instrumentation, Sampling, etc. }\end{array}$ & 20 \\
\hline Total & 200 \\
\hline
\end{tabular}

\subsubsection{Industrial Naste Treatment System}

Industrial wastewater from power house operation is collected, treated in an on-site system, and discharged to an adjacent stream. The system treats wastewater from the following sources:

- Coal pile runoff

- Contaminated yard drains

- Boiler blowdown
- Water treatment wastes

- Miscellaneous low-volume wastes

The treated effluent will meet all Federal, State, and local regulations for total suspended solids, oil and grease, total iron, and total manganese. The system is similar for Cases 1 and 2 . For Cases 3,4 , and 5 , the smali amount of industrial waste generated from waste treatment and boiler blowdown is taken to the existing industrial waste treatment facility. No new equipment is provided.

Design criteria. The system design flow is determined as follows:

- Continuous (Daily) Flowe (gal/d):

\begin{tabular}{|l|c|}
\hline Boiler Blowdown & 44,000 \\
\hline Water Treatment Wastes & 20,000 \\
\hline Miscellaneous Low-Volume Wastes & 8,000 \\
\hline Total & 72,000 \\
\hline
\end{tabular}

- Intermittent flows (Coal Pile Run off):

\begin{tabular}{|l|c|}
\hline Coal Pile Runoff, Including Contaminated Yard Area (gal) & 107,000 \\
\hline Treated Runoff in 3 Days (gal/d) & 36,000 \\
\hline
\end{tabular}


- Ireatment Plant Desion Flow Rate, gal/d (gal/min):

\begin{tabular}{|l|l|}
\hline Continuous (Daily) Flows & $72,000 \quad(50)$ \\
\hline Intermittent Flows & $36,000 \quad(25)$ \\
\hline Total & $108,000(75)$ \\
\hline
\end{tabular}

Equipment Description. The industrial waste treatment system employs the following unit processes and operations:

- Flow Equalization. Contaminated rainfall runoff is collected in a synthetic-membrane-lined, earthen basin and is pumped to the treatment system at a controlled rate. The raw waste sump has sufficient surge capacity to equalize short-term peak flows such as water treatment backwashes.

- Neutralization. Acidic wastewater is neutralized with hydrated lime in a two-stage system. Each neutralization tank is fiberglass, with a 10-min reaction time at design flow. Each tank is equipped with a pH probe and a controller, which automatically feeds lime slurry to the respective tank to control pH. Each tank is equipped with a fixed-mount mixer to completely mix lime slurry with the wastewater. There is an integral lime storage silo/lime slurry makeup system.

- Oxidation. Air is fed to the second-stage neutralization tank through a sparge pipe to oxidize any remaining ferrous iron to the ferric stato. The air is supplied by a compressor, which also furnishes air for operation of sludge pumps and the filter press.

- Flocculation. Flocculation to promote particle size growth is provided in a fiberglass tank with a 10-minute minimum retention time at design flow. The tank is equipped with a low-rpm variable-speed agitator. Polymer smulsion is drawn directly from a 55-gal drum and is diluted and fed to the flocculation tank by a polymer feed unit.

- Clarification/Thickening. Overflow from the flocculation tank enters a platetype clarifier/thickener for suspended solids separation. Soijds settle between the inclined plates to the thickener zone, while the clarified supernatant rises from the plates to discharge through flow-distribution orifices. The integral thickener section includes a picket-fence-type scraper mechanism, which further concentrates the sludge.

- Sludge Dewatering. Thickened sludge is pumped to a holding tank, which allows one-shift operation of the dewatering equipment and provides some further thickening. From the holding tank, the sludge is pumped to a plate-and-frame filter press for dewatering. The filter press produces a sludge cake of 35 wt\% or higher dry solids. The filter press cake is dropped from the press into a sludge dump truck or dumpster. Filtrate is returned to the raw waste sump.

The coal pile runoff basin, the raw waste sump, and the lime storage and feed system are outdoors. The remaining treatment system components are in a heated building. 


\subsubsection{Ash and Spent Sorbent Removal System}

jor functions:

System Functions. The ash handling system provides the following ma-

- Continuously removes ash from the CPFBC

- Stores the ash

- Loads ash into trucks for disposal

ria:

Design criteria. The system is based on the following design crite-

\begin{tabular}{|l|l|l|l|l|}
\hline \multicolumn{1}{|c|}{ Description } & $\begin{array}{c}\text { Cases 1 } \\
\text { and 2 }\end{array}$ & Case 3 & $\begin{array}{l}\text { Cases 4 } \\
\text { and 5 }\end{array}$ & Case 6 \\
\hline Design Ash Generation Rate, t/h & 8.6 & 1.27 & 1.93 & 1.18 \\
\hline Pneumatic Ash Conveying Rate, $\mathrm{t} / \mathrm{h}$ & 20 & 5 & 5 & 5 \\
\hline $\begin{array}{l}\text { Ash Bulk Density (for volume } \\
\text { design), } \mathrm{lb} / \mathrm{ft}^{3}\end{array}$ & 45 & 45 & 45 & 45 \\
\hline Silo Storage Capacity, days & 3 & 3 & 3 & 3 \\
\hline
\end{tabular}

The Ash Handling System is the same for Cases 1 and 2 and smaller, but similar, for Cases 3,4 , and 5 .

System Description. The Ash Handling System is shown schematically in Figure 58. Ash from the FBHE and from the ceramic cross-flow filter flows by gravity to two 100-percent capacity screw coolers, which cooi the ash to $300^{\circ} \mathrm{F}$. One screw cooler normally operates while the other is on standby. Ash is continuously removed from the screw cooler by a pneumatic vacuum conveying line, which transports ash to the ash storage silo. Ash may also be conveyed from the standby ash cooler when it is operating. However, ash can only be removed from one ash cooler at a time.

A steel silo stores the ash. It has a primary and secondary separator on the silo roof to capture and deposit the conveyed asi into the silo. A silo vent filter, also on the silo roof, prevents dust emissions while venting the silo.

For ash removal from the silo, a fluidizing air system aids the discharge of ash to the unloading equipment. The fluidizing air system includes a system of fluidizing air pads, mounted on the floor of the silo, which fluidize the ash and direct the fluidized ash toward the discharge opening. There aie two blower packages--each with silencers, relief valve, check valve, and fluidizing air heater (to prevent condensation at the fluidizing air pads).

A wet, pug-mill-type unloader receives ash from the silo discharge chute and mixes and conditions the ash with water. The conditioned ash is then discharged through a chute into open ash transport truck. The wet pug mill unloader has a capacity of $150 \mathrm{t} / \mathrm{h}$ for Cases 1 and 2 , and $15 \mathrm{t} / \mathrm{h}$ for Cases 3,4 , and 5 ; it discharges an ash/water mixture with a 5- to 15-percent moisture content. 


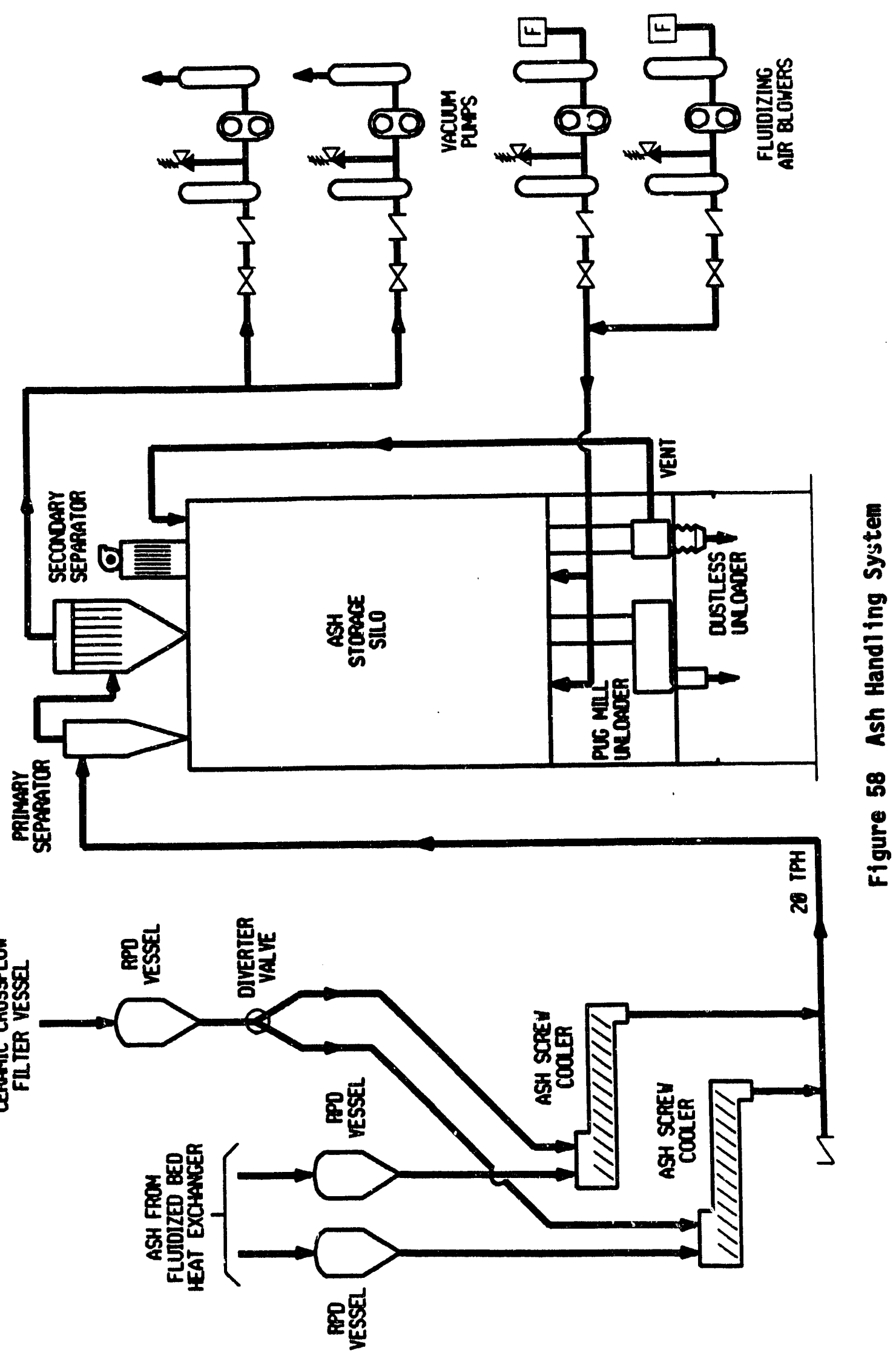


A dry unloader discharges ash from the storage silo into an enclosed bulk hauler. The dry unloader has a telescopic spout with an electric winch; it has an exhaust fan to prevent dust emissions during unloading. The exhaust fan vents the air to the top of the silo.

Ash removal is accomplished during a 40-hour work week using 21 ashhauling trucks daily, eack removing 20 tons of ash per load (allowing approximately 23 minutes for each truck to load).

\subsubsection{Plant Electrical Equipment}

The plant electrical system consists of the equipment listed below, identified by study case.

\begin{tabular}{|c|c|c|c|c|c|c|}
\hline \multirow{2}{*}{ Equipment } & \multicolumn{6}{|c|}{ Study Case } \\
\hline & 1 & 2 & 3 & 4 & 5 & 6 \\
\hline $\begin{array}{l}\text { Combustion Turbine Generator } \\
\text { Steam Turbine Generator } \\
\text { Generator Step-Up Transformer } \\
\text { Station Ser'ice Transformers } \\
\text { Auxiliary Transformers } \\
\text { Protective Relaying } \\
\text { Medium-Voltage Unit Substation } \\
\text { Low-Voltage Unit Substation } \\
\text { Motor Control Centers (MCLs) } \\
\text { Uninterruptible Power Supply } \\
\text { Direct Current Power System } \\
\text { Motors } \\
\text { Grounding and Lightning Protection } \\
\text { Heat Tracing } \\
\text { Lighting }\end{array}$ & $\begin{array}{l}x \\
x \\
x \\
x \\
x \\
x \\
x \\
x \\
x \\
x \\
x \\
x \\
x \\
x \\
x\end{array}$ & $\begin{array}{l}x \\
x \\
x \\
x \\
x \\
x \\
x \\
x \\
x \\
x \\
x \\
x \\
x\end{array}$ & $\begin{array}{l}x \\
x \\
x \\
x \\
x \\
x \\
x \\
x\end{array}$ & $\begin{array}{l}x \\
x \\
x \\
x \\
x \\
x \\
x \\
x \\
x \\
x \\
x \\
x \\
x \\
x \\
x\end{array}$ & $\begin{array}{l}x \\
x \\
x \\
x \\
x \\
x \\
x \\
x\end{array}$ & $\begin{array}{l}x \\
x \\
x \\
x \\
x \\
x \\
x \\
x \\
x \\
x \\
x \\
x \\
x \\
x \\
x\end{array}$ \\
\hline
\end{tabular}

The equipment descriptions in this section pertain primarily to Case 1, the largest of the study cases. Equipment for the other study cases is described as variations from Case 1.

Distribution System. Plant power generation consists of one 21-kV combustion gas turbine generator and one 20-kV steam turbine generator. Electrical systems power station auxiliary loads and station service loads. The 13.8-kV generator and distribution switchgear has two generator breakers, two breakers for step-up power transformers for connection to the existing primary substation and two feeder breakers for the $4160-V$ double-ended unit substation (Refer to Figure 59.)

Utilization voltages for Case 1 are $13.8 \mathrm{kV}, 4160 \mathrm{~V}, 480 \mathrm{~V}, 480 / 277 \mathrm{~V}$, and $208 / 120 \mathrm{~V}$. Generation voltage is $13.8 \mathrm{kV}$. Voltages for Case 2 are the same, except that the $4160-V$ application is omitted. Geliorator leads and feeds to the substation power transformers are insulated cable. 


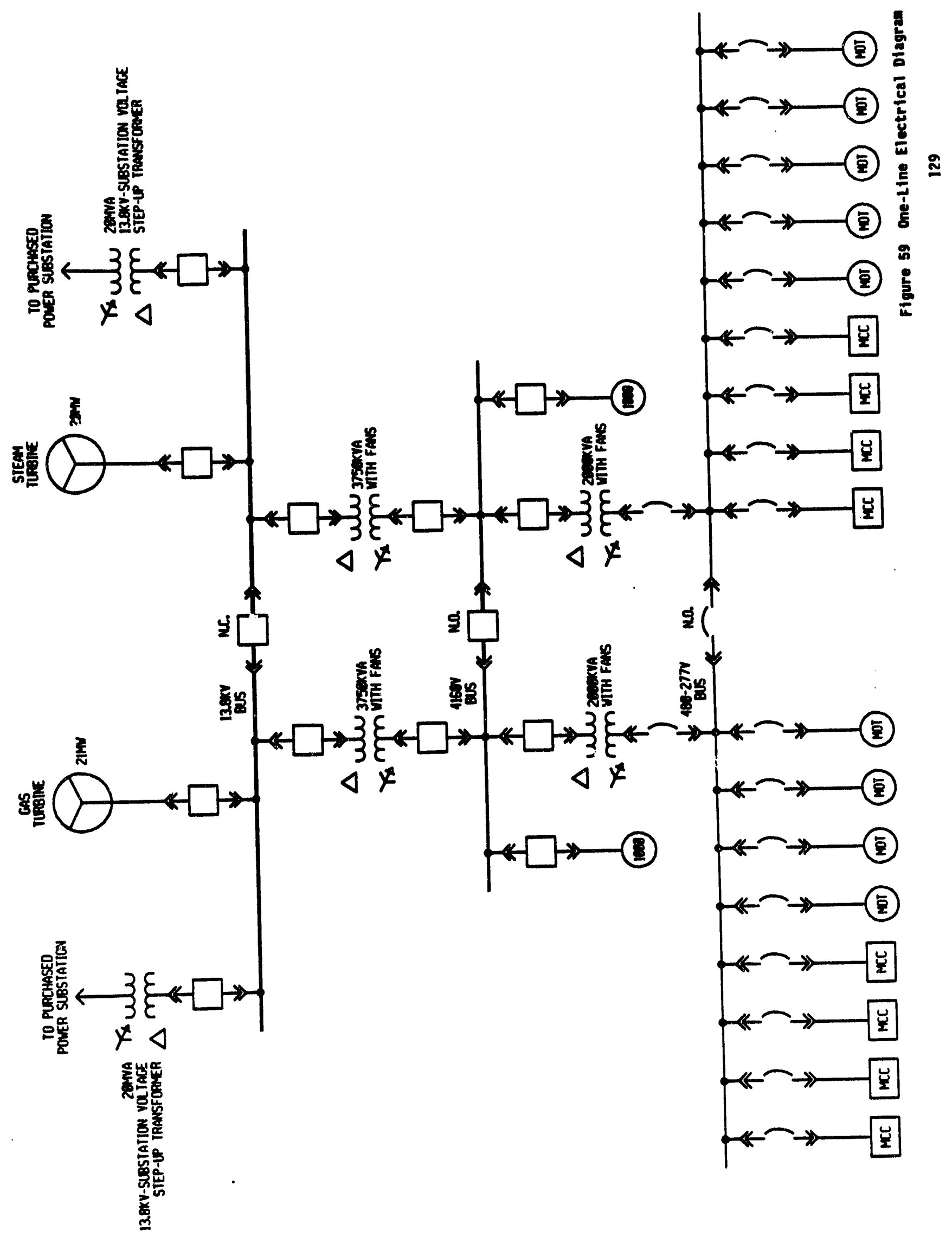


The $4160-V$ double-ended unit substation powers the feedwater pump motors, and the $4160 / 480-V$ power transformers. The $480-V$ double-ended unit substation has a bus tie breaker. The $480-V$ buses power $480-V$ motors (125 to $250 \mathrm{hp}$ ) and eight 480-V MCCs, six for plant auxiliary loads and two for plant station service.

A $460-V$ unit-essential MCC receives normal power from a $480-V$ substation and emergency power from the outside utility source. The unit-essential MCC feeds a battery, battery charger, and dc panel. A dc supply from the panel feeds an ac inverter for an uninterruptible power supply to the computer and critical power supplies, with an alternative feed directly from the unitessential MCC through a regulating transformer.

Combustion Turbine Generator. The combustion turbine drives a 13.8-kV, three-phase, $60 \mathrm{~Hz}$ generator rated at $21 \mathrm{MVa}$ at a 0.9 power factor. The generator is complete with turning gear, seal system, lube oil system, and starting system. The exciter is a shaft-driven air-cooled brushless type.

The combustion turbine generator unit is supplied as a package, which includes: starting package, electrical/control package, surge equipment and potential transformers in a cubicle, and fire protection.

Steam Turbine Generator. The steam turbine drives a $3600-\mathrm{rev} / \mathrm{min}$, 0.50 short-circuit ratio, standard continuous rating, $13.8 \mathrm{kV}$, three-phase, $60 \mathrm{~Hz}$ generator rated at $20 \mathrm{MVa}$. The air-cooled generator has a 0.9 power factor. It is complete with turning gear and lube oil system. The shaftdriven exciter system consists of a permanent magnet pilot exciter and an ac exciter with a rotating amature and stationary field winding.

Generator Step-Up Transformers. The main step-up transformers are three phase, $60 \mathrm{~Hz}, 55^{\circ} \mathrm{C} / 65^{\circ} \mathrm{C}$ rise, forced oil and air cooled, sized to carry the maximum generator output (minus the parasitic loads) at rated power factor and 95-percent rated voltage with a $30^{\circ} \mathrm{C}$ average ambient. The 1 imiting generating factor is the turbine. The transformer impedance is standard for the MVa rating. The transformer has delta-connected low-voltage and solidgrounding-wye high-voltage windings. They are equipped with two 2-1/2 percent, no-load, full-capacity ANBN taps on the high-voltage windings and high-voltage metal oxide surge arresters. Bushing current transformers in the proper accuracy class are included for metering and relaying.

Station Service Transformers. The station service $4160 \mathrm{~V}$ transformers are three-phase, $60-\mathrm{Hz}, 80^{\circ} \mathrm{C}$ rise, forced-air, self-cooled, dry or cast resin type. The transformer impedance is standard for the MVa rating. The transformers have delta-connected high-voltage and wye-connected low-voltage windings with neutral brought out for a low-resistance grounding system. They are equipped with two 2-1/2 percent, no-load, full-capacity ANBN taps on the highvoltage windings. In addition to standard accessories, the transformers have tank-mounted secondary resistors enclosed in metal grills for grounding the neutral of each low-voltage winding. Bushing current transformers in the proper accuracy class are included for metering and relaying.

Auxiliary Transformers. The station service low-voltage power transformers are three-phase, $60 \mathrm{~Hz}, 800 \mathrm{EC}$ rise, forced-air, self-cooled dry or cast resin type for indoor use. The transformers have delta-connected highvoltage and wye-connected low-voltage windings with the neutral brought out for a solid ground connection. 
Protective Relaying. Protective relays in the electrical system isolate faulted or overloaded equipment and cables to minimize equipment damage and limit the extent of system outages. Generators, step-up transformers, and station service transformers have primary and backup relaying.

Medium-Voltage Unit Substation. The 4160-V unit substation has double-ended switchgear with integral transformers and a normally open tie breaker separating the two buses. The switchgear consists of 4.16-kV metal clad, NEMA I assemblies feeding large motors, and a 480-V unit substation. Each switchgear lineup includes provisions for future additions on each end. The switchgear assembly incorporates draw-out circuit breakers equipped with current transformers, protective and auxiliary relays, ammeters, indicating lights, cable terminations, and other special required devices.

Low-Voltage Unit Substation. The 480-V unit substation has doubleended switchgear with integral transformers at each end and a normally open tie breaker separating the two switchgear buses. Standard transformer impedances are used. The switchgear is 600-V class in a NEMA I metal enclosure with drawout components.

Motor Control Centers. Motor control centers are located throughout the plant in areas of concentrated loads. They are $460 \mathrm{~V}$, in NEMA enclosures to suit the environment, made of standard modules, 20 in. deep. All devices are front mounted.

Uninterruptible Power Supply System. The Uninterruptible Power Supply System furnishes a reliable source of $120-V$ ac power and control voltage to equipment vital for plant operation and shutdown. The system consists of:

- An inverter - A manual bypass switch

- A static switch

- A 120-Vac vital ac distribution panel

The inverter takes normal power from the 125-Vdc power system. The inverter output is connected to a static switch; upon failure of the inverter, the switch automatically transfers it to an alternative 120-Vac supply.

The uninterruptible power supply is sized to feed the following loads (plus 20-percent margin):

- Combustion controls and burner management

- Turbine generators/electrohydraulic control system

- Turbine supervisory instruments
- Recorders and indicators

- Other essential instrumentation

- Critical components of plant control systems

Direct Current Power System. A 125-Vdc system furnishes control power to the various switchgear and power feeds to the uninterruptible power supply, emergency lighting, and motors such as those that drive the emergency bearing and seal-oil pumps. The system consists of a battery, battery charger, and dc distribution panels. Battery capacity provides emergency lighting and control power for orderly plant shutdown, enables uninterrupted operation of vital 
equipment via the uninterruptible power supply system, and enables breaker operation to set up a plant restart.

Motors. Except for special applications, all ac motors are squirre1cage induction type with Class B insulation designed for full-voltage starting; all have the lowest possible locked-rotor current consistent with good performance and design. The motors match the inertia and speed-torque requirements of the driven equipment. Where required, medium-voltage motors are designed to start and accelerate the connected load with an applied voltage of 80 percent of rated voltage.

Motor enclosures are normally fully guarded, open, drip-proof for indoor service, and weather-protected NEMA Type II for outdoor service. Motors $200 \mathrm{hp}$ and lower are totally enclosed, fan cooled (TEFC) for outdoor service. Regardless of size, all motors subject to fire protection spray water are totally enclosed, fan cooled unless limited by size to a totally enclosed, noncooled (TENC) enclosure. Explosion-proof motors are provided where required for service in hazardous locations.

Motor voltage ratings and power supply source are shown in Table 13.

Table 13 Motor Voltage Rating and Power Supply Service

\begin{tabular}{|l|c|c|l|}
\hline \multicolumn{1}{|c|}{ Horsepower } & Voltage & Phase & \multicolumn{1}{c|}{ Supply Source } \\
\hline 1500 and up & 13,200 & 3 & $3.8-\mathrm{kV}$ switchgear \\
\hline 300 to 1000 & 4,000 & 3 & $4.16-\mathrm{kV}$ switchgear \\
\hline 125 to 250 & 460 & 3 & $480-V$ switchgear \\
\hline $1 / 2$ to 100 & 460 & 3 & $480-V$ MCC or individual starter \\
\hline Less than $1 / 2 *$ & 115 & 1 & $\begin{array}{l}\text { Lighting cabinets or 120-V dis- } \\
\text { tribution panels }\end{array}$ \\
\hline $\begin{array}{l}\text { *Fractional hp motors less than 1/2 hp used for reversing service, } \\
\text { such as motors on valve operators, are three phase, } 460 \mathrm{~V} \text {. }\end{array}$ \\
\hline
\end{tabular}

Totally enclosed and explosion-proof motors have a 1.00 service factor. Drip-proof and weather-protected motors have a 1.15 service fätor. The service factor is not infringed upon by normal continuous loads.

All medium-voltage motors include resistance temperature devices for overload detection. All medium-voltage motors and valve motor operators have space heaters, and all outdoor motors above $50 \mathrm{hp}$ have space heaters that automatically activate when the motor is idle.

Grounding and Lightning Protection. The grounding system is a permanent and continuous system designed to provide safety to personnel, protection to equipment, and a minimum input of electrical noise to control and instrumentation signals. 
The plant grounding grid is made of buried copper grounding loops around each facility/building, a buried grounding grid in the switchyard for step-and-touch potential protection, and buried grounding grids for step-andtouch potential on both sides of fences and gates where applicable. The grounding grid is designed for a resistance to ground of less than 1 ohm. All grids and loops are connected at two places (minimum).

All building, structural, and outdoor tank steel is connected by copper cable to the main plant ground grid. Electrical continuity is maintained for all structural steel used as a grounding path. All medium-voltage equipment is connected to the plant grounding grid by copper cable. Small miscellaneous equipment lower than $600 \mathrm{~V}$, in remote locations, may be grounded to the building steel and conduit system, providing electrical continuity to ground is maintained. Electronic devices have isolated signal grounds, chassis and enclosure grounds, and electrical power source grounds for safety and to minimize electrical noise to the controllers from external sources. Instrument cable shields are grounded at one end only to prevent circulating currents, unless otherwise recommended by the instrument manufacturer.

Metal oxide-type station lightning arresters on the high-voltage side of the main step-up transformers and station service transformers protect insulation from voltage surges. High buildings are protected by air terminals in accordance with the Lightning Protection Code, NFPA No. 78.

Heat Tracing. Where required, freeze protection is provided for outdoor piping, gauges, and instrumentation with self-regulated parallel-type heat cable. Space heaters are utilized for items that are not suitable for heating cable application. Heating cable circuits are supplied from distribution panels similar to those used for lighting circuits and are controlled by thermostats.

Liohting. Normal, emergency, and egress lighting is provided for the station, remote buildings, and associated outdoor areas within the plant boundary.

Normal lighting is energized from three-phase four-wire lighting panels throughout the plant. Each lighting panel is fed from local 480-277 V panels or $480-208 Y / 120 V$ transformers that are fed from the nearest MCC. Yard and roadway lighting is supplied at $277 \mathrm{~V}$ from the nearest MCC or power distribution cabinet.

Lighting illumination levels are calculated in accordance with the recommended levels of illumination listed in the latest edition of the National Electrical Code.

Emergency dc lighting in the building and in the control room permits safe egress. For outlying miscellaneous buildings, emergency lighting is from self-contained battery-charged lamp units. High-intensity discharge fixtures are installed in indoor plant areas. Incandescent fixtures are used for the emergency lighting system and for exit lights. Fixtures are explosion proof in hazardous areas of the coal handling system.

Wire for lighting systems is Type RHW (moisture and heat resistant rubber cable), run in either conduit or tray. All fluorescent and pendant lighting fixtures have Type So high-temperature flexible cord for wiring from the outlet box to the fixture. Conduit for lighting systems can be rigid, intermediate conduit (IMC), electrical metal tubing (EMT), or a combination of these, depending on the application. 
Miscellaneous Small Power Systems. Miscellaneous small power systems provide the plant with electrical supply for convenience outlets, storage equipment, building services, and similar requirements. The systems are 208Y/ $120 \mathrm{~V}$, three phase, four wire. They consist of step-down transformers (fed from the plant 480-V distribution), panelbcards, and branch circuit wiring feeding various loads.

\subsection{REFERENCES}

1. S. J. Wright, R. Fairclough, and R. Booth, "The Engineering and Operating Experience of Firing Coal-Water Slurries to the Grimethorpe PressurisedFluidised Bed Combustor," Proceedings of the 1989 International Conference on Fluidized Bed Combustion, Vol. 1, April 1989.

2. R. V. Garland and A. Robertson, "Operating Envelopes for SecondGeneration PFBC Combined Cycle Plants," ASME 88-JPGC/GT-5, 1988.

3. J. M. Beèr, British Patent No. $45652 / 65$ (1965), U.S. Patent No. 4845940 (1989).

4. G. Vermes, P. Pillsbury, and R. Garland, "Generic Studies of Advanced Fluid Bed Air Heater Technology: Topical Report No. 5, Energy Distribution and Combustor Development," DOE/CE/40543-5, U.S. Technical Information Center, U.S. Department of Energy, Springfield, Virginia, 1986, pp. 5-94. 
Section 3

PLANT COSTING BASIS

This section describes the approach, basis, and methods for evaluating capital and operating costs of the industrial-size second-generation PFB combustion power plant. The values determined using this approach are presented in subsections of Section 4 .

The capital costs, operating costs, and expenses were established consistent with the EPRI Technical Assessment Guide (TAG) methodology [1], the project Ground Rules Document, and the plant scope identified in Section 2 . The cost of each component was quantitatively developed to enhance credibility and establish a basis for subsequent comparisons and modification as the technology is further developed.

\subsection{COSTING PARAMETERS}

- Total plant cost values are expressed in December 1989 dollars.

- The estimates represent a mature technology plant, or " $n^{\text {th" }}$ plant (i.e., it does not include costs associated with a first-of-a-kind plant).

- The estimates represent addition of a complete power plant facility unit at an existing plant with tie-in to existing systems where reasonable, with the exception of the exclusions listed in Section 3.2.3.

- The estimate boundary limit is defined as the total additional plant facility within the "fence line," including tie-in to existing coal receiving, water supply system, and process steam supply, but terminating at the high side of the main power transformers.

- The site is within the Ohio River Valley, southwestern Pennsylvania/eastern Ohio, but not specifically sited within the region except that it is considered to be at an existing representative industrial facility.

- Terms used in connection with the estimate are consistent with the current EPRI TAG [1] .

- Costs are grouped according to a process/system-oriented code of accounts; all reasonably allocable components of a system or process are included in the specific system account in contrast to a facility, area, or commodity account structure.

- The basis for equipment, materials, and labor costing is described in Section 3.2 .

- Design engineering services, including construction management and contingencies bases, are examined in Section 3.2.2.

- The operating and maintenance expenses and consumables costs were developed on a quantitative basis. 
- The operating cost was determined on the basis of the number of operators required.

- The maintenance cost was evaluated on the basis of relationships of maintenance cost to initial capital cost

- The cost of consumables was determined on the basis of individual rates of consumption, the unit cost of each consumable, and the plant annual operating hours.

Each of these expenses and costs is determined on a first-year basis and subsequently levelized over the life of the plant through application of a levelizing factor to determine the value that forms a part of the economic evaluation.

\subsection{CAPITAL COST}

The capital cost, specifically referred to as Total Plant cost (TPC) for the mature second-generation PFB combustion power plant, was estimated using the EPRI methodology identified in Figure 60. The major components of TPC consist of bare erected cost, engineering and home office overheads and fee plus contingencies.

The capital cost for each case was determined through the process of separately estimating the cost of every significant piece of equipment, component, and bulk quantity identified. A Code of Accounts was developed to provide the required structure for the estimate. The Code facilitates the consistent allocation of individual costs that were developed by various companies. The selected code structure, although not identical, is similar to other PFB combustion estimate code structures to permit future cost comparisons if desired. The Code facilitates recognition of estimated battery 1 imits and the scope included in each account. This code is presented in Table 14 along with the scope of each accoint.

\subsubsection{Bare Erected Cost}

The bare erected cost level of the estimate, also referred to as the sum of process capital and general facilities capital, consists of the cost for: factory equipment, field materials and supplies, direct labor, indirect field labor, and indirect construction costs. Factory equipment or major equipment costing was determined by the various project team members.

- Carbonizer and related equipment: Foster Wheeler

- PFBC and related equipment: Foster Wheeler

- Ceramic Cross Flow Filter: Westinghouse R\&D

- Combustion Turbine Package: Westinghouse Power Generation Business Unit; Allison Gas Turbine Division-General Motors Corporation

- Balance-of-Plant Major Systems (Based on vendor budgeting quotes): G/C

- Other Equipment (Based on in-house pricing data): G/C 
Field Materials and Supplies

Factory Equipment

Direct Field Labor
Indirect Field Labor (e.g., Misc: Labor Services, Payroll Burden, Tools, and Contractor Facilities) Included With Direct Labor Indirect Construction Costs (shown separately)

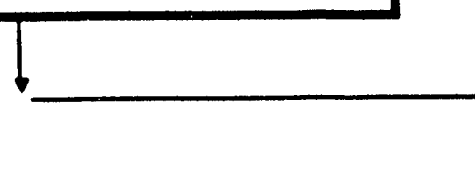

Bare Erected Cost

(Process Capital and General Facilities)

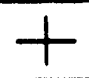

Engineering and Home Offices Overhead and Fee

Contingencies (Process and Project)

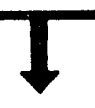

TOTAL PLANT COST (TPC)

$+$

Allowance for Funds Used During Construction (Interest During Construction)

Escalation During Construction

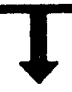

TOTAL PLANT INVESTMENT (TPI)

(AT IN-SERVICE DATE)

$+$

\begin{tabular}{|c|}
\hline Prepaid Royalties (None) \\
\hline Preproduction (Start-Up) Costs \\
\hline Inventory Capital (Working Capital) \\
\hline Initial Catalyst and Chemical Charges \\
\hline Land \\
\hline
\end{tabular}

TOTAL CAPITAL REQUIREMENT (TCR)

Figure 60 Components of Capital Costs 
Table 14 Code of Direct Accounts Summary

\begin{tabular}{|c|c|}
\hline Account Number & Account Title \\
\hline 1 & $\begin{array}{l}\text { COAL and SORBENT HANDLING } \\
\text { Coal Stackout and Reclaim Equipment } \\
\text { Coal Storage Bin } \\
\text { other Coal Handling Equipment } \\
\text { Sorbent Receiving and Unloading Equipment } \\
\text { Sorbent Storage Bin } \\
\text { other Sorbent Handling Equipment } \\
\text { Coal and Sorbent Handling Foundations and Structures }\end{array}$ \\
\hline 2 & $\begin{array}{l}\text { COAL AND SORBENT PREPARATION AND FEEDING } \\
\text { Prepared COal Storage and Feed Equipment } \\
\text { Coal Injection System } \\
\text { Miscellaneous Coal Preparation and Feed } \\
\text { Prepared Sorbent Storage and Feed Equipment } \\
\text { Sorbent Injection System } \\
\text { Foundations and Structures }\end{array}$ \\
\hline 3 & $\begin{array}{l}\text { FEEDWATER AND MISCELLANEOUS SYSTEMS AND EQUIPMENT } \\
\text { Feedwater System } \\
\text { Makeup Treatment, Pretreating, and Storage } \\
\text { Other Feedwater and Condensate Subsystems } \\
\text { Service Water Systems } \\
\text { Other Boiler Plant Systems } \\
\text { Fuel Oil Supply System } \\
\text { Waste Treatment Equipment } \\
\end{array}$ \\
\hline 4 & $\begin{array}{l}\text { CARBONIZER, PFBC BOILER, AND ACCESSORIES } \\
\text { Carbonizer } \\
\text { PFBC } \\
\text { PFBC Heat Exchanger (FBHE) } \\
\text { Interconnect ing Pipe } \\
\text { Miscellaneous PFBC Equipment } \\
\text { Other PFBC Equipment } \\
\text { Major Component Rigging } \\
\text { Foundations and Supports } \\
\end{array}$ \\
\hline 5 & $\begin{array}{l}\text { HOT GAS CLEAN-UP AND HOT GAS PIPING } \\
\text { Carbonizer Gas/Tar Cross-Flow Filter Module } \\
\text { PFBC Gas Cross-Flow Filter Module } \\
\text { Hot Gas Piping } \\
\text { Blow-Back Air Supply System } \\
\text { Foundations and Supports } \\
\end{array}$ \\
\hline 6 & $\begin{array}{l}\text { COMBUSTION TURBINE ACCESSORIES } \\
\text { Combustion Turbine Generator } \\
\text { Combustion Turbine Accessories } \\
\text { Compressed Air Piping } \\
\text { Foundations and Supports } \\
\end{array}$ \\
\hline 7 & $\begin{array}{l}\text { HRSG, DUCTING, AND STACK } \\
\text { HRSG } \\
\text { HRSG Accessories } \\
\text { Ductwork } \\
\text { Stack } \\
\text { Foundations }\end{array}$ \\
\hline
\end{tabular}


Table 14 (Cont) Code of Direct Accounts Summary

\begin{tabular}{|c|c|}
\hline Account Number & Account Title \\
\hline 8 & $\begin{array}{l}\text { STEAM TURBINE GENERATOR, AND AUXILIARIES } \\
\text { Steam Turbine Generator and Accessories } \\
\text { Turbine Plant Auxiliaries } \\
\text { Steam Piping } \\
\text { Foundations }\end{array}$ \\
\hline 9 & $\begin{array}{l}\text { COOLING WATER SYSTEM } \\
\text { Makeup Water System } \\
\text { Component Cooling Water System } \\
\text { Foundations and Structures } \\
\end{array}$ \\
\hline 10 & $\begin{array}{l}\text { ASH/SPENT SORBENT RECOVERY AND HANDLING } \\
\text { Ash Coolers } \\
\text { FBHE Ash Depressuring Equipment } \\
\text { HGCU Ash Depressuring Equipment } \\
\text { High-Temperature Ash Piping } \\
\text { Other Ash-Recovery Equipment } \\
\text { Ash Storage Silos } \\
\text { Ash Transport and Feed Equipment } \\
\text { Miscellaneous Ash-Handl ing Equipment } \\
\text { Foundations and Structures }\end{array}$ \\
\hline 11 & $\begin{array}{l}\text { ACCESSORY ELECTRIC PLANT } \\
\text { Generator Equipment } \\
\text { Station Service Equipment } \\
\text { Switchgear and Control Equipment } \\
\text { Conduit and Cable Tray } \\
\text { Wire and Cable } \\
\text { Protective Equipment } \\
\text { Standby Equipment } \\
\text { Main Power Transformer } \\
\text { Foundations } \\
\end{array}$ \\
\hline 12 & $\begin{array}{l}\text { INSTRUMENTATION AND CONTROLS } \\
\text { Carbonizer/PFBC/FBHE Control Equipment } \\
\text { Combustion Turbine Control Equipment } \\
\text { Steam Turbine Control Equipment } \\
\text { Other Major Component Control Equipment } \\
\text { Signal Processing Equipment } \\
\text { Control Boards, Panels, and Racks } \\
\text { Computer and Auxiliaries } \\
\text { Instrument Wiring and Tubing } \\
\text { Other Instrumentation and Controls } \\
\end{array}$ \\
\hline 13 & $\begin{array}{l}\text { IMPROVEMENTS TO SITE } \\
\text { Site Preparation } \\
\text { Site Improvements } \\
\text { Site Facilities } \\
\end{array}$ \\
\hline
\end{tabular}


G/C obtained budgetary quotes for all the major balance-of-plant

equipment. Upon receipt of each individual quote, its value was compared with the expected value for that component or system to confirm that cost levels were appropriate and to verify that the quoted scope represented the required scope. The list of major equipment that was costed on the basis of vendor quotes includes:

- Coal and dolomite handling

- Deaerator and heat exchangers

- Major pumps, blowers, and compressors

- Water-treating packages
- HRSG

- Steam Turbine Generator

- Chimney

- Ash Handling System

The list of quoted equipment is not complete, but it does identify the major quotes received.

Other equipment, minor secondary systems, and materials were estimated by $G / C$ on the basis of in-house data consisting of other project cost data and relationships, catalog data, and standard utility unit cost data.

The labor cost to install the equipment and materials was estimated on the basis of unit man hours applied to the appropriate quantities to arrive at total installation man hours for each item or bulk quantity. These man hours were then evaluated using a variety of wage rates. Labor costing was determined on a multiple contract labor basis, with the labor cost including direct and indirect labor costs plus fringe benefits and allocations for contractor expenses and markup. This information was supplemented, in many cases, with equipment labor relationship data to determine the labor cost.

The indirect labor cost was estimated at 7 percent of direct labor to recognize the cost of construction services and facilities not provided by the individual contractors. The facility cost represents the estimate for miscellaneous temporary facilities such as construction road and parking area construction and maintenance; installation of construction power; installation of construction water supply and general sanitary facilities; and general and miscellaneous labor services such as jobsite cleanup and construction of general safety and access items.

\subsubsection{Total Plant cost (TPC)}

The TPC level of the estimate consists of the bare erected cost plus engineering and contingencies.

The engineering costs represent the cost of architect/engineer services for design, drafting, and project construction management services. The cost for the PFBC plant engineering was determined at 6.5 percent applied to the bare erected cost on an individual account basis. The cost for engineering services provided by the equipment manufacturers and vendors is included directly in the equipment costs.

Allowances for process and project contingencies are also considered as part of the TPC. Some of the process technology used in the various systems is still in the development stage. Continuing process development tends 
to increase the cost of plant components as problems are discovered and re. solved. In an attempt to account for the uncertainty in equipment design, performance, and cost, a process contingency was added to the estimated cost of pertinent components and systems. The values are representative of value applied in other second-generation PFB combustion plant studies [?].

Consistent with conventional power plant practices, a general project contingency was added to the total plant cost to cover project uncertainty and the cost of any additional equipment that could result from a detailed design. Based on EPRI criteria, the cost estimate contains elements of Classes I, II, and III level estimates. As a result, on the basis of the EPRI guidelines, a nominal value of 15 percent was used to arrive at the plant nominal cost value. This project contingency is intended to cover the uncertainty in the cost estimate itself, whereas the process contingency covers the uncertainty in the technical development level of specific equipment. In both cases the contingencies represent costs that are expected to occur. This process was repeated for each case evaluated.

\subsubsection{Capital Cost Estimate Exclusions}

Although the estimate is intended to represent a complete PFBC plant, there remain several qualifications/exclusions:

- Sales tax is not included (considered to be exempt).

- On-site fuel transportation equipment (such as barge tug, barges, yard locomotive, bulldozers) is not included.

- Allowances for unusual site conditions (such as piling, extensive site access, excessive dewatering, extensive inclement weather) are not included.

- Switchyard (transmission plant) is not included. The costed scope terminates at the high side of the main power transformer.

- Costs of any existing on-site facilities or equipment associated with the existing industrial complex are not included.

- Ash disposal facility is excluded, other than the 3-day storage in the ashstorage silos. (The ash disposal cost is accounted for in the ash disposal charge as part of consumables costs; refer to Section 3.3.3.)

- Royalties are not included.

\subsection{OPERATING COSTS AND EXPENSES}

The operating costs and related maintenance expenses described in this section pertain to charges associated with operating and maintaining the second generation PFBC power plant over its expected life. 
The costs and expenses associated with operating and maintaining the plant include:

- Operating Iabor

- Maintenance

- Material

- Labor
- Administrative and Support Labor

- Cunsumables

- By-Product Credit (if applicable)

- Fuel Cost

The values for thase items were determined consistent with EPRI TAG methodology [1]. These costs and expenses are estimated on a first-year basis in December 1989 dollars. The first-year costs assume normal operation and do not include the initial start-up costs.

The operating labor, maintenance material and labor, and other laborrelated costs are combined and then divided into two components: fixed 0\&M, which is independent of power generation, and variable 0\&M, which is proportional to power generation. The first-year operating and maintenance cost estimate allocation is based on the plant capacity factor.

The other operating costs, consumables, and fuel, are determined on a daily 100-percent operating capacity basis and adjusted to an annual plant operation basis.

The development of the actual values was performed on a $G / C$ model that is consistent with TAG. The inputs for each category of operating costs and expenses are identified in the succeeding subsections with a more-specific discussion of the evaluation processes.

\subsubsection{Operating Labor}

The cost of operating labor was estimated on the basis of the number of operating jobs (OJ) required to operate the plant (on an average-per-shift basis). The operating labor charge (OLC) expressed in first year \$/KW was then computed using the average labor rates:

$$
\text { OLC }=\frac{(0 \mathrm{~J}) \times \text { (labor rate } \times \text { labor burden }) \times(8760 \mathrm{~h} / \mathrm{yr})}{\text { (net capacity of plant at full load in } \mathrm{kW})}
$$

The operating labor requirements were determined on the basis of inhouse representative data for the major plant sections (such as coal handling and steam turbine plant). These data were supplemented by estimates of the manpower required for the carbonizer, PFBC, and HGCU sections to arrive at total plant operating requirements.

\subsubsection{Maintenance}

Since the development of the maintenance labor and maintenance material costs are so interrelated in this methodology, their cost bases are discussed together. Annual maintenance costs (according to EPRI's methodology [1]), are estimated as a percentage of the installed capital cost. The percentage varies widely, depending on the nature of the processing conditions and the type of design. 
On the basis of $G / C$ in-house data and EPRI guidelines for determining maintenance costs, representative values expressed as a percentage of system cost were specified for each major system. The rates were applied against individual estimate accounts. Using the corresponding TPC values, a total annual (first-year) maintenance cost was calculated, including both material and labor components.

Since the maintenance costs are expressed as maintenance labor and maintenance materials, a maintenance labor/materials ratio of 40:60 was used for this breakdown. The operating costs, excluding consumable operating costs, are further divided into fixed and variable components. Fixed costs are essentially independent of capacity factor and are expressed in $\$ / \mathbf{k W}-\mathrm{yr}$. Variable costs are incremental, directly proportional to the amount of power produced, and expressed in milils/kWh. Separation of operating costs into fixed and variable components was based on the assumption that the portion of the operating cost that is fixed is proportional to the expected nominal capacity factor for the plant. The balance of the cost is expressed as a variable component. The assumption is predicated on EPRI guidelines and other utility experience. The equations for these calculations are:

Fixed O\&M = Capacity Factor (CF) $x$ Total O\&M (\$/kW.yr) Variable $0 \& M=[(1-C F) \times$ Total $08 M(\$ / k W \cdot y r) \times 1000 \mathrm{mil1s} / \$] /(C F \times 8760 \mathrm{~h} / \mathrm{yr})$

The administrative and support labor cost is the only 0\&M overhead charge included in the cost studies. It is a charge for administrative and support labor, which is taken as 30 percent of the operating and maintenance labor. Other general and administrative expenses are not included.

\subsubsection{Consumables}

The feedstock and disposal costs are those consumable expenses associated with PFB combustion power plant operation. Consumable operating costs are developed on a first-year basis and subsequently levelized over the 30-year life of the plant. The consumables category consists of water, chemicals, other consumabies, and waste disposal.

The "water" component pertains to the water acquisition charge for water required for the plant steam cycle and for miscellaneous services.

The "chemicals" component consists of:

- A composite water makeup and treating chemicals requirement in which unit cost and the ratio of chemicals to water were based on data from comparable plants

- The liquid effluent chemical category, representing the composite chemical requirement for wastewater treating, in which unit cost and quality were developed similar to the water makeup and treating chemicals

- The dolomite required for injection into the PFBC boiler in which the unit cost is the EPRI standard limestone cost, which is comparable to the expected dolomite cost.

The "other consumables" component consists of gases, primarily the nitrogen required for transport and blanketing. The unit cost for gases was based on pricing furnished by an industrial gas supplier. 
The "waste disposal" component pertains to the cost allowance for offsite disposal of plant solid wastes. The ash represents the combined FBHE and cleanup system quantity. The unit cost for disposal is based on an adjusted EPRI value [1].

\subsection{REFERENCES}

1. Electric Power Research Institute, Technical Assessment Guide, Vol. 1, EPRI P-4463-SR, Palo Alto, California, December 1986.

2. Foster Wheeler Development Corporation, "Second-Generation Pressurized Fluidized Bed Combustion Plant: Conceptual Design and Optimization of a Second-Generation PFB Combustion PIant," Phase 1 Task 1 Report," September 1989. 
The conceptual designs of industrial second-generation PFB combustion plants are based on the design of the second-generation PFB combustion plant developed under Phase 1 Task 1 of this contract. The main differences are size and steam utilization. The industrial plants have smaller thermal ratings (29 to $197 \mathrm{MW}$ vs. $1041 \mathrm{MW}$ ) and smaller power outputs (6 to $40 \mathrm{MW}$ vs. $453 \mathrm{MW}$ ) than the utility-sized plant; and most of the steam generated in the industrial plants is used for industrial processes, whereas all of the steam in the utility plant is used to generate power.

Six industrial-sized plants were investigated in this study--two larger second-generation plants (Cases 1 and 2), three smaller second-generation plants (Cases 3, 4, and 5), and one smalier "1-1/2 generation" plant (Case 6). The cases are tabulated below and discussed in the sections shown.

- Section 4.1--Case 1: 353,000 lb/h Steam and $40 \mathrm{MW}$

- Section 4.2--Case 2: 442,000 1b/h Steam and $20 \mathrm{MW}$

- Section 4.3--Case 3: 46,000 1b/h Steam and $6 \mathrm{MW}$

- Section 4.4--Case 4: 75,000 1b/h Steam and $9 \mathrm{MW}$

- Section 4.5--Case 5: $86,000 \mathrm{1b} / \mathrm{h}$ Steam and $7 \mathrm{MW}$

- Section 4.6--Case 6: 73,000 1b/h Steam and $9 \mathrm{MW}$

The topping combustor in Case 6 is fueled by natural gas; the topping combustors in Cases 1 through 5 are fueled by coal gas produced by carbonizers.

The discussion for each plant is presented in four subsections:

- Plant Description

- Plant Performance
- Plant Capital Costs

- Plant Operating Costs

The description and cost portions are brief overviews. Sections 2 and 3 of this report contain more detailed descriptions of equipment and cost estimating methods. 


\section{1}

CASE 1: 353,000 LB/H STEAM AND 40 MM

Case 1 is the largest of the industrial plants, using both a gas turbine and a steam turbine to generate power.

\subsubsection{Plant Description}

The second-generation PFB combustion cogeneration plant is designed to produce process steam as the main product and electric power as a byproduct. An air-blown carbonizer converts the coal/sorbent/water slurry into a low-Btu fuel gas for a gas turbine topping combustor. The char produced by the carbonizer is combined with additional slurry fuel and burned in a CPFBC, preheating the topping combustor oxidant and also generating steam. The fuel gas from the carbonizer is burned in the topping combustor of a gas turbine.

Steam is generated by an HRSG at the gas turbine exit and by the PFBCs. The steam is expanded through a back-pressure turbine, then sent to process.

Figure 61 is a process flow diagram of the plant, showing the functional arrangement of the major plant systems. The major systems listed below are described in more detail in the subsections that follow.

- Slurry Preparation System

- Carbonizer

- Circulating PFB Combustor and Fluidized Bed Heat Exchanger

- Ash Cooling and Disposal
- Topping Combustor and Combustion Turbine

- Heat-Recovery Steam Generator

- Back-Pressure Steam Turbine

- Condensate System

- Compressed Air System

Slurry Preparation System. Raw coal is fed by two gravimetric feeders to a crusher, where it is crushed, screened, and dropped into slurry tanks equipped with agitators. Sized dolomite sorbent is screened and added to the slurry tanks. Water is added to give a coal/water ratio of $70: 30$ by weight.

After leaving this holding tank, the coal/sorbent/water slurry is pumped to both the carbonizer and the CPFBC, where it is atomized by compressed air and injected into the vessels.

Carbonizer. In this cogeneration arrangement, 27.7 percent of the slurry is used by the carbonizer to make fuel gas for the topping combustor, with the remaining slurry going to the CPFBC to make steam. In the fluidized carbonizer, the coal and sorbent are converted into a low-Btu gas and a mixed solid containing char and spent sorbent. Both the carbonizer and the CPFBC operate at $1600^{\circ} \mathrm{F}$. 


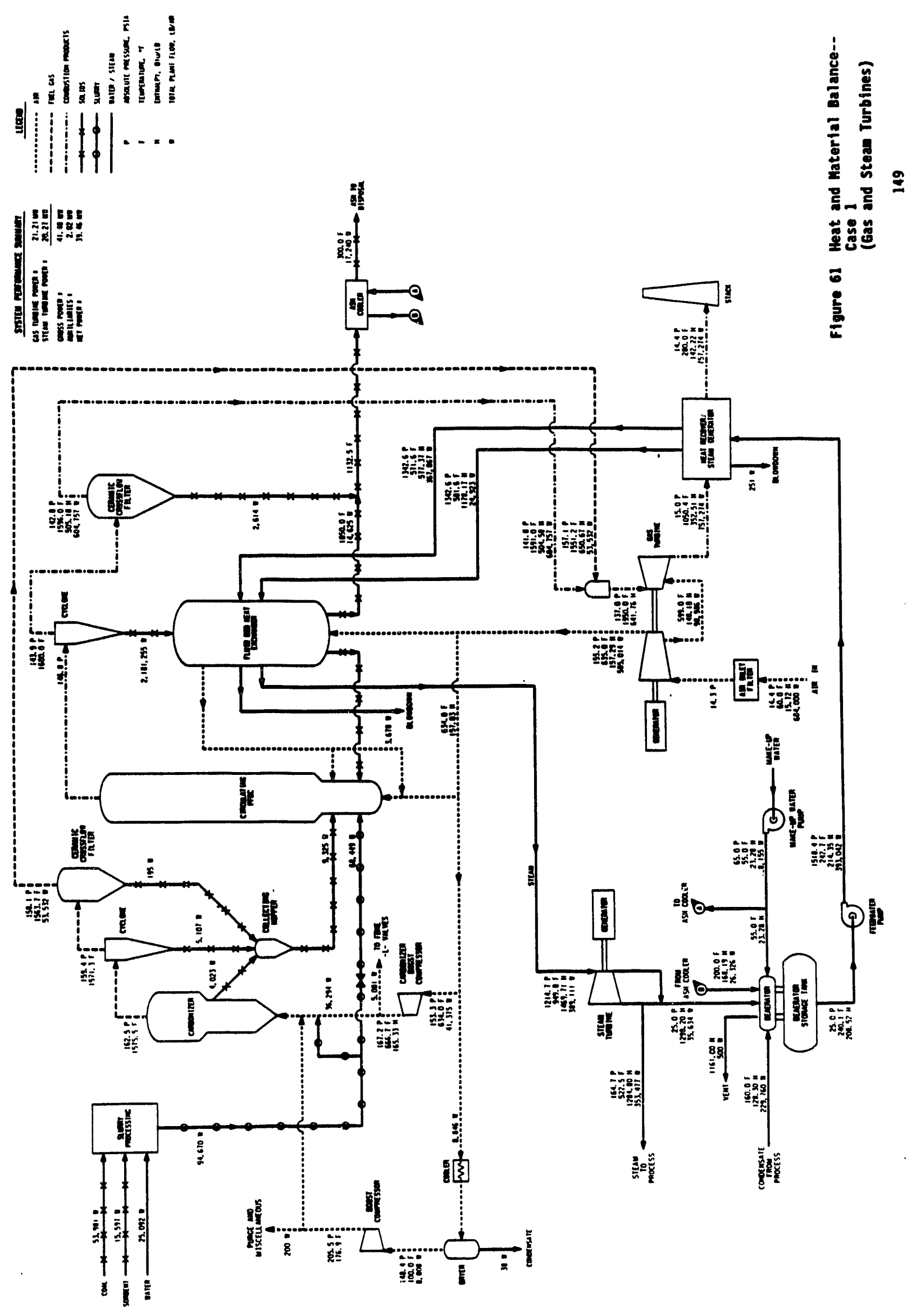


Char and spent sorbent are separated from the carbonizer fuel gas at three locations. An overflow drain in the carbonizer allows solids to fall to a collecting hopper. This hopper also receives solids collected by the cyclones and the ceramic cross-flow filters in the fuel gas cleanup system. Solids from the collecting hopper are fed to the CPFBC by " $N$ " valves, which are kept fluidized with a small flow of nitrogen.

Circulating PFB Combustor and Heat Exchangers. The CPFBC receives all of the char mixture from the carbonizer and 72.3 percent of the coal/sorbent slurry as fuel. The air to the CPFBC is partially vitiated and heated to about $1600^{\circ} \mathrm{F}$. The CPFBC is designed to operate with minimum ( 30 percent) excess air to achieve maximum process steam output from the plant. The corresponding plant excess air is 33 percent.

The combustion products of the CPFBC are cleaned by cyclones and ceramic cross-flow filters. Solids captured by the cyclones are recirculated to the PFBCs. Energy from coal and char combustion is used in the PFBC to generate 94 percent of the steam. The PFBC also superheats the high-pressure steam for the steam turbine.

Ash Cooling and Disposal. Excess solids from the PFBC are extracted from the heat exchanger at $1050^{\circ} \mathrm{F}$, depressurized through a Restricted Pipe Discharge (RPD) vessel, and then cooled in a screw cooler. Solids collected by the cross-fiow filters are also depressured in the RPD vessels and then cooled in screw coolers.

Compressed Air System. Except for turbine cooling flows required by the gas turbine, all of the air produced by the gas turbine compressor is collected from the compressor discharge and ducted to the carbonizer/CPFBC area. This air, pressurized to $10 \mathrm{~atm} / 635^{\circ} \mathrm{F}$, supplies four subsystems:

- Booster compressors, which provide pressurization and atomizing air at 50 psi above the carbonizer entry pressure. The air is cooled and dried before being compressed by the booster compressors.

- Carbonizer booster compressors, which provide secondary air to the carbonizers. These compressors provide a 17-psi boost to the carbonizer oxidant. They are needed to ensure that the fuel gas will have adequate pressure above the vitiated oxidant at the topping combustors. These compressors are not precooled.

- PFBC fluidizing air.

- CPFBC primary combustion air.

Topping Combustor and Combustion Turbine. Clean fuel gas from the carbonizers and the vitiated air product of the CPFBCs are conveyed to the gas turbine by ceramic-insulated hot-gas piping. These pipes have metallic liners on the inner diameter to protect the turbine from eroded ceramic material. A carbon steel outer liner provides structural strength to these pipes.

The fuel gas and vitiated air are oxidized in the MASBs installed under the gas turbine. The nominal exit temperature of the MASB is $1950^{\circ} \mathrm{F}$. Combustion products from the MASB expand through the expander section of the gas turbine, producing about $21 \mathrm{MW}$ (net) in the gas turbine unit. 
Heat-Recovery Steam Generator. The gas exiting the gas turbine flows through an HRSG, where it is cooled to $280^{\circ} \mathrm{F}$ by producing steam and heated feedwater. Gas exiting the HRSG is then ducted to the stack.

The HRSG and PFBC are closely tied in steam production. The HRSG provides all of the economizing and a small position of the evaporating duty, and the PFBC provides the rest of the evaporating duty and any superheat that is required.

Together, the PFBC and HRSG provide about 99 percent of the required steam energy. The remaining 1 percent of steam cycle thermal input comes from the ash screw coolers in the form of condensate heating.

Back-Pressure Steam Turbine. The steam is expanded through a backpressure steam turbine before being released to process. The turbine is a 1200-psig unit with a throttle inlet temperature of $950^{\circ} \mathrm{F}$. The turbine exhaust pressure is slightly above the required process steam pressure of 150 psig. About 9 percent of the exhaust steam is used as an energy source for the deaerator, with the rest going to process.

Condensate system. Heating and deaeration of low-pressure condensate is provided primarily by extraction steam. The deaerator operates at 25 psia/ $240^{\circ} \mathrm{F}$. About 20 percent of the condensate is diverted around the feedwater heater to cool the ash screw coolers. The hot water leaving the screw coolers is discharged directly into the deaerator.

Water from the deaerator is pressurized by electrically driven booster pumps and feedwater pumps. Two 60-percent-capacity pump trains are provided. The feedwater flow is split between the two HRSG, and is heated by the HRSG economizer sections to $571^{\circ} \mathrm{F}$.

Feedwater leaving each of the HRSG economizers is split into two streams. The first stream feeds the high-pressure drum in the HRSG. The water is evaporated in the HRSG and piped over to the PFBC and mixed with steam produced there. The rest of the feedwater is piped to the evaporator in the PFBC, where it is heated to steam. The combined steam flows are superheated to $954^{\circ} \mathrm{F}$ for the stean turbine.

\subsubsection{Plant Performance}

The second-generation PFB combustion cogeneration plant has an overall thermal efficiency of 82.8 percent, based on the HHV of coal. Table 15 summarizes plant performance. Table 16 lists plant auxiliary power requirements.

Steam-generating heat exchangers are located in the PFBC vessel of the fluidized bed combustor, in the HRSG at the exhaust end of the gas turbine, and in the ash screw coolers. Thermal performance parameters for these exchangers are tabulated in Table 17.

Table 18 lists the heat and material balance for the entire plant. 
Table 15 Plant Summary Performance Data--Case 1

\begin{tabular}{|l|r|r|r|r|r||}
\hline \multicolumn{1}{|c|}{ Description } & $\begin{array}{c}\text { Flow } \\
(\mathrm{lb} / \mathrm{h})\end{array}$ & $\begin{array}{c}\text { Enthalphy } \\
(\mathrm{Btu} / \mathrm{lb})\end{array}$ & $\begin{array}{c}\text { Power } \\
(\mathrm{kW})\end{array}$ & $\begin{array}{c}\text { Energy } \\
\left(10^{6} \mathrm{Btu} / \mathrm{h}\right)\end{array}$ & $\begin{array}{c}\text { Energy } \\
\text { Output }(\mathrm{K})\end{array}$ \\
\hline Process Steam & 353,477 & $1,284.80$ & & 454.15 & \\
\hline (Returned Condensate) & $(229,760)$ & 128.30 & & $(29.48)$ & \\
\hline (Makeup Water) & $(128,148)$ & 23.10 & & $(2.96)$ & \\
\hline Steam Energy Output & & & & 421.71 & 76 \\
\hline Gas Turbine Power & & & 21,212 & 72.40 & \\
\hline Stean Turbine Power & & & 20,271 & 59.18 & \\
\hline Plant Auxiliaries & & & $(2,022)$ & $16.90)$ & \\
\hline Electric Power Output & & & 39,460 & 134.67 & \\
\hline Total Energy Output & & & & 556.38 & \\
\hline Coal Energy Input (HHV) & 53,981 & 12,452 & & 672.17 & \\
\hline Net Thermal Efficiency & & & & & 82.77 \\
\hline
\end{tabular}

Table 16 Auxiliary Summary--Case 1

\begin{tabular}{||l|r|}
\hline \multicolumn{1}{|c|}{ Item } & KW \\
\hline Transport Booster Compressor & 49 \\
\hline Carbonizer Booster Compressor & 104 \\
\hline Condensate Pumps & 7 \\
\hline Feedwater Pumps & 692 \\
\hline Boiler Forced-Circulation Pumps & 241 \\
\hline Circulating Water Pumps & 3 \\
\hline Cooling Tower Fans & 1 \\
\hline Gas Turbine Auxiliaries & 100 \\
\hline Steam Turbine Auxiliaries & 123 \\
\hline Rail Unloading and Stacker/Reclaimer & 25 \\
\hline Coal Handling & 11 \\
\hline Dolomite Handling & 129 \\
\hline Coal and Sorbent Feed & 132 \\
\hline Ash Cooling and Handling & 98 \\
\hline Slurry Preparation & 157 \\
\hline Service Water & 19 \\
\hline Miscellaneous & 121 \\
\hline Stepdown Transformer & 10 \\
\hline Total Auxiliaries & 2022 \\
\hline
\end{tabular}


Table 17 Heat Exchanger Performance--Case 1

\begin{tabular}{|c|c|c|c|c|c|}
\hline \multirow{2}{*}{ Components } & \multirow{2}{*}{$\begin{array}{c}\text { Thermal } \\
\left(10^{6} \mathrm{Btu} / \mathrm{h}\right)\end{array}$} & \multirow{2}{*}{$\begin{array}{l}\text { Duty } \\
(\%)\end{array}$} & \multirow{2}{*}{$\begin{array}{l}\text { Flow } \\
(1 \mathrm{~b} / \mathrm{h})\end{array}$} & \multicolumn{2}{|c|}{$\begin{array}{l}\text { Temperature } \\
\left({ }^{\circ} \mathrm{F}\right)\end{array}$} \\
\hline & & & & Inlet & outlet \\
\hline $\begin{array}{l}\text { FBHE Evaporator } \\
\text { Water/Steam } \\
\text { CPFBC }\end{array}$ & 230.85 & 44.3 & 367,867 & $\begin{array}{r}571.6 \\
1600.0\end{array}$ & $\begin{array}{r}581.6 \\
1600.0\end{array}$ \\
\hline $\begin{array}{l}\text { FBHE Superheater } \\
\text { Steam } \\
\text { CPFBC }\end{array}$ & 119.66 & 23.0 & 389,111 & $\begin{array}{r}581.6 \\
1600.0\end{array}$ & $\begin{array}{r}953.5 \\
1600.0\end{array}$ \\
\hline $\begin{array}{l}\text { HRSG Evaporator } \\
\text { Water/Steam } \\
\text { Gas }\end{array}$ & 15.80 & 3.0 & $\begin{array}{r}25,174 \\
757,274\end{array}$ & $\begin{array}{r}571.6 \\
1050.4\end{array}$ & $\begin{array}{l}581.6 \\
980.8\end{array}$ \\
\hline $\begin{array}{l}\text { HRSG Economizer } \\
\text { Water } \\
\text { Gas }\end{array}$ & 150.50 & 28.9 & $\begin{array}{l}393,042 \\
757,274\end{array}$ & $\begin{array}{l}242.7 \\
980.8\end{array}$ & $\begin{array}{l}571.6 \\
280.0\end{array}$ \\
\hline $\begin{array}{l}\text { Ash Screw Cooler } \\
\text { Water } \\
\text { Ash }\end{array}$ & 3.81 & 0.7 & $\begin{array}{l}26,326 \\
17,240\end{array}$ & $\begin{array}{r}55.1 \\
1132.5\end{array}$ & $\begin{array}{l}200.0 \\
300.0\end{array}$ \\
\hline Heat Exchanger Total & 520.62 & & & & \\
\hline
\end{tabular}




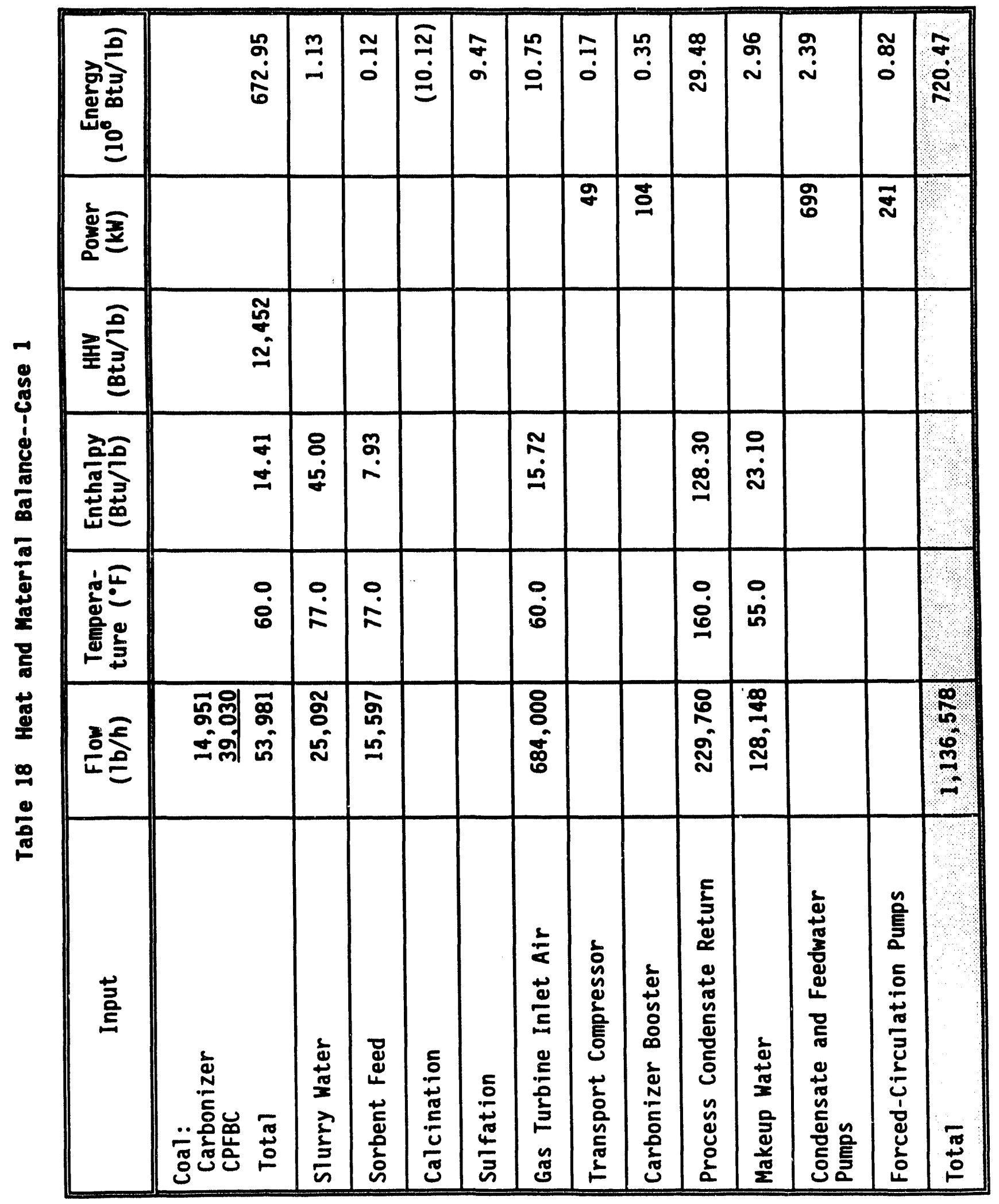




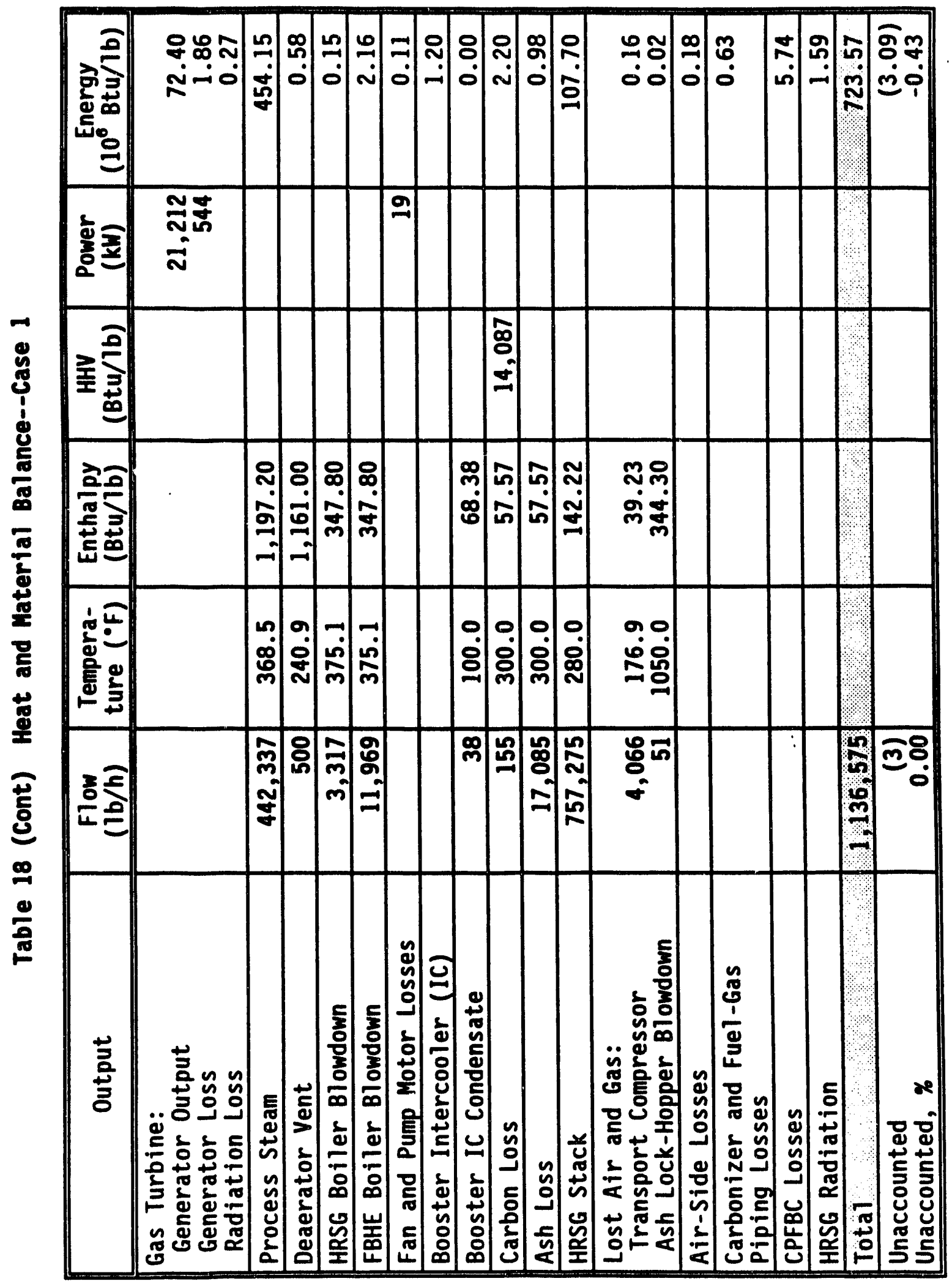




\subsubsection{Plant Capital Cost}

Capital requirements of the plant are listed in Table 19. The assumptions and methods used to estimate these costs are described in Section 6 .

\subsubsection{Plant Operating Costs}

Annual operating costs were estimated from the costs of fuel, feedstocks, plant labor, maintenance, and other items, as listed in Table 20.

The total annual operating cost, together with fixed costs associated with the TCR are key components of the levelized cost of steam. The steam costs of all systems are compared in Section 6. 
要

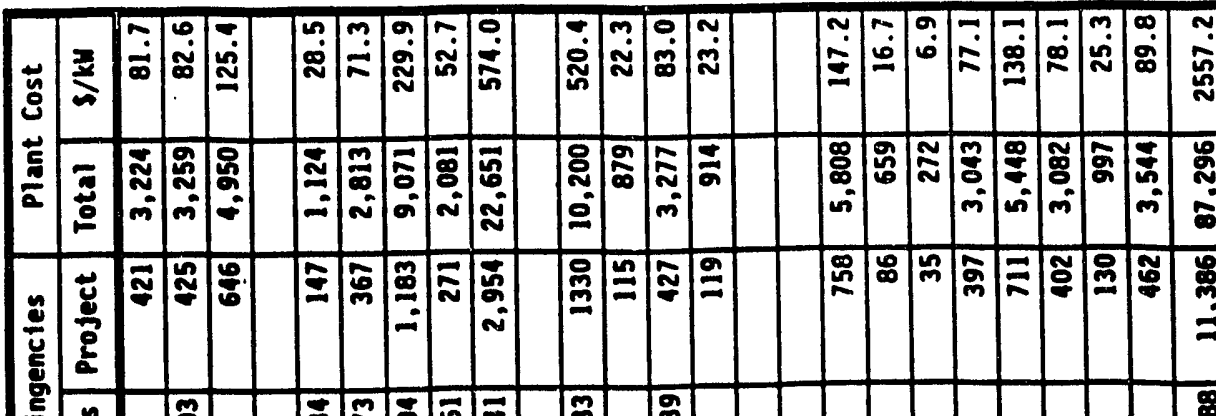

旁

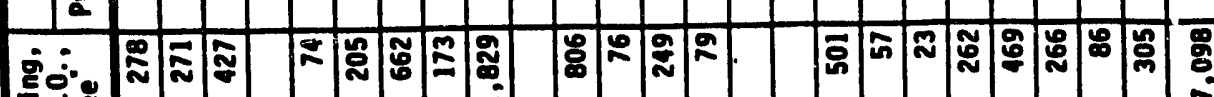

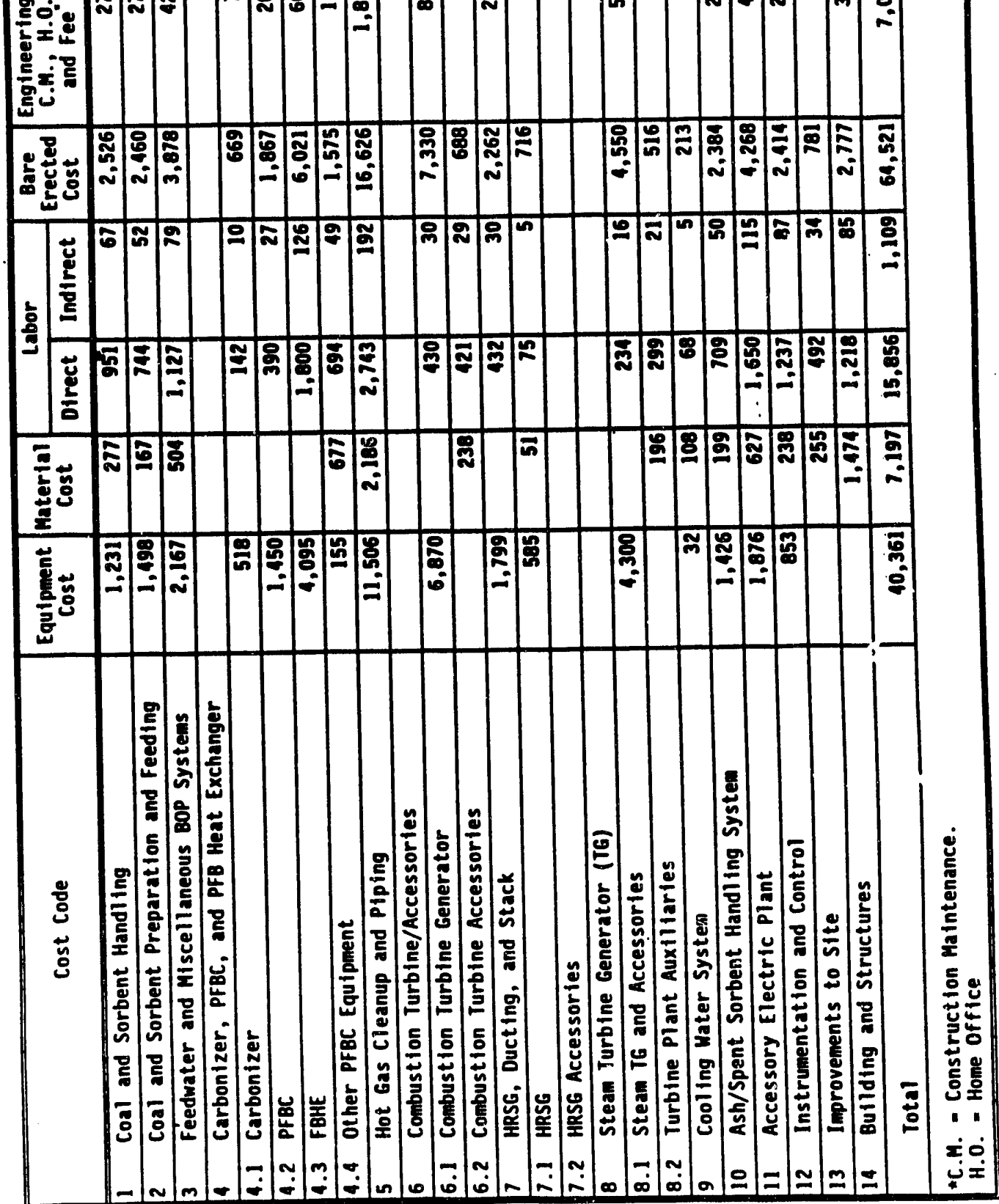


Table 20 Annual Operating Costs--Case 1 (Capacity Factor = 80\%)

\begin{tabular}{|c|c|c|c|}
\hline Cost Categories & Quantity & $\begin{array}{c}\text { Unit } \\
\text { Price, } \$\end{array}$ & $\begin{array}{l}\text { Total } \\
5 \times 10^{3}\end{array}$ \\
\hline Fuel: Pittsburgh No. 8 Coal & $\begin{array}{l}53,981 \mathrm{lb} / \mathrm{h} \\
672.1710^{6} \mathrm{Btu}\end{array}$ & $1.50 / 10^{6} \mathrm{Btu}$ & 7,066 \\
\hline $\begin{array}{l}\text { Consumable Materials: } \\
\text { Dolomite } \\
\text { Nitrogen } \\
\text { Raw Water } \\
\text { Water Treatment Chemicals } \\
\text { (40\% of water cost) }\end{array}$ & $\begin{array}{l}7.8 \mathrm{t} / \mathrm{h} \\
28 \mathrm{sft}^{3} / \min \\
315 \mathrm{gal} / \mathrm{min}\end{array}$ & $\begin{array}{l}18.80 / \mathrm{t} \\
0.29 / 100 \mathrm{sft}^{3} \\
0.75 / 1000 \mathrm{gal}^{3}\end{array}$ & $\begin{array}{r}1,028 \\
34 \\
99 \\
40\end{array}$ \\
\hline Ash Disposal Costs & $8.62 \mathrm{t} / \mathrm{h}$ & $9.75 / t$ & 589 \\
\hline $\begin{array}{l}\text { Plant Labor: } \\
\text { Operators } \\
\text { Supervision and Clerical } \\
\text { (20\% of 08M) }\end{array}$ & $11 /$ shift & $24.65 / \mathrm{h}$ & $\begin{array}{r}1,900 \\
896\end{array}$ \\
\hline Maintenance Costs & & & 2,578 \\
\hline Total Operating costs & & & 14,230 \\
\hline
\end{tabular}


Case 2 produces the most process steam of the industrial plants.

\subsubsection{Plant Description}

The second-generation PFBC cogeneration plant is designed to produce process steam as the main product and electric power as a byproduct. An airblown carbonizer converts coal/sorbent/water slurry into a low-Btu fuel gas for a gas turbine topping combustor. The char produced by the carbonizer is combined with additional slurry fuel and burned in a circulating PFBC (CPFBC), preheating the topping combustor oxidant and also generating steam. The fue1 gas from the carbonizer is burned in the topping combustor of a gas turbine.

Steam is generated by an HRSG at the gas turbine exit and by the PFBCs. The steam is sent to process.

Figure 62 is a process flow diagram of the plant, showing the functional arrangement of the major plant systems. The major systems are described in more detail in these subsections:

- Slurry Preparation System

- Carbonizer

- Circulating PFB Combustor and Fluidized Bed Heat Exchanger

- Ash Cooling and Disposal
- Compressed Air System

- Topping Combustor and Combustion Turbine

- Heat Recovery Steam Generator

- Condensate System

Slurry Preparation System. Raw coal is fed by two Gravimetric feeders to a crusher, where it is crushed, screened, and dropped into agitated slurry tanks. Sized dolomite sorbent is screened and added to the slurry tanks. Water is added to give a coal/water ratio of 70:30 by weight:

After leaving this holding tank, the coal/sorbent/water slurry is pumped to both the carbonizer and the CPFBC, where it is atomized by compressed air and injected into the vessels.

Carbonizer. In this cogeneration arrangement, 27.7 percent of the slurry is used by the carbonizer to make fuel gas for the topping combustor, with the remaining slurry going to the CPFBC to make steam. In the fluidized carbonizer, the coal and sorbent are converted into a low-Btu gas and a mixed solid containing char and spent sorbent. Both the carbonizer and the CPFBC operate at $1600^{\circ} \mathrm{F}$.

Char and spent sorbent are separated from the carbonizer fuel gas at three locations. An overflow drain in the carbonizer allows solids to fall to a collecting hopper. This hopper also receives solids collected by cyclones and by ceramic cross-flow filters in the fuel gas cleanup system. Solids from the collecting hopper are fed to the CPFBC by " $N$ " valves, which are kept fluidized with a small flow of nitrogen. 


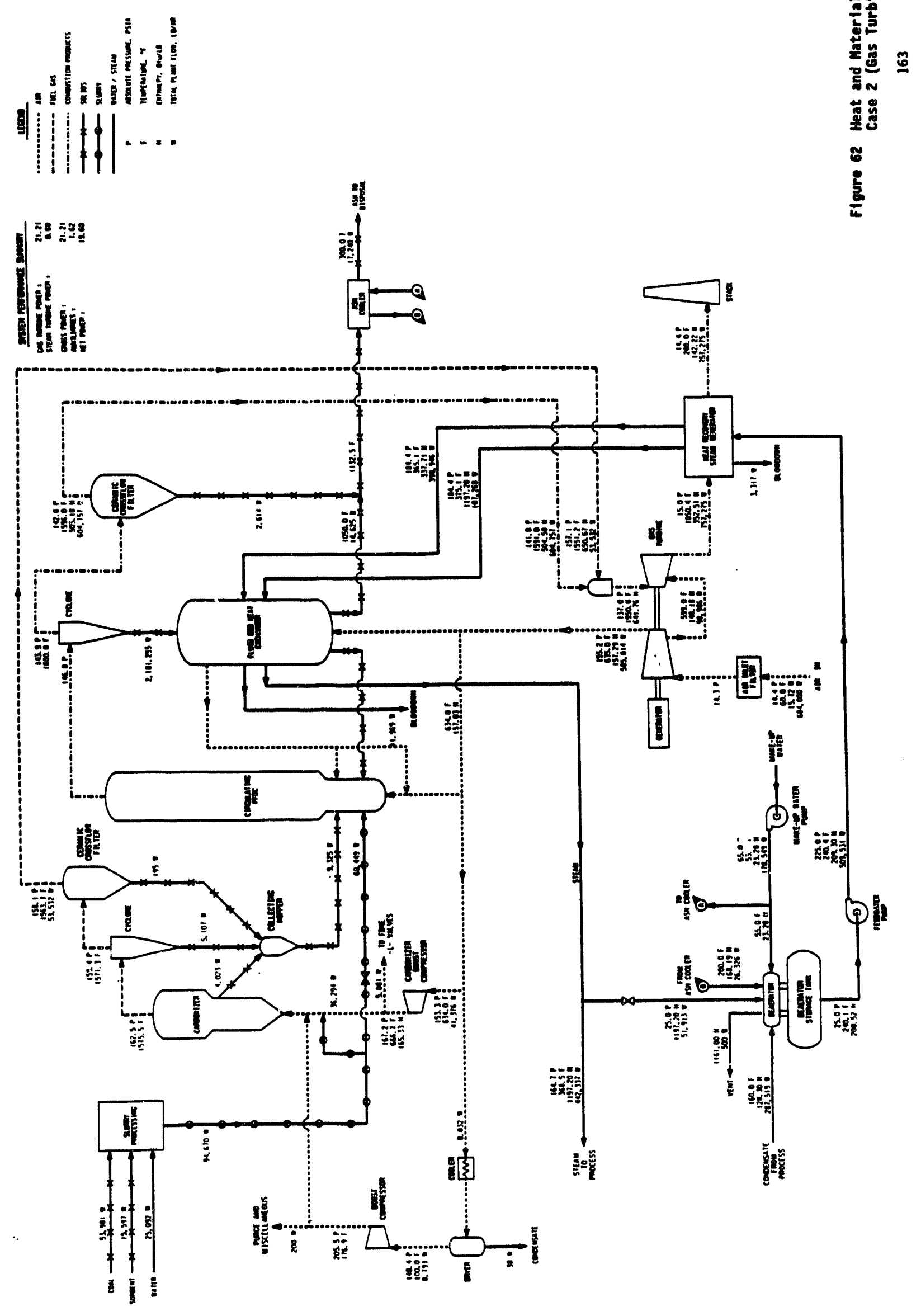


Circulating PFB Combustor and Fluid Bed Heat Exchangers. The CPFBC receives as fuel all of the char mixture from the carbonizer and 72.3 percent of the coal/sorbent slurry. Air to the CPFBC is partially vitiated and heated to about $1600^{\circ} \mathrm{F}$. The CPFBC is designed to operate with minimum (3n percent) excess air to achieve maximum process steam output from the plant. The corresponding plant excess air is 33 percent.

The combustion products of the CPFBC are cleaned by cyclones and ceramic cross-flow filters. Solids captured by the cyclones are recirculated to the PFBCs. Energy from coal and char combustion is used in the PFBC to generate 78 percent of the steam.

Ash Cooling and Disposal. Excess solids from the PFBC are extracted from the heat exchanger at $1050^{\circ} \mathrm{F}$, depressured through a RPD vesse1, and then cooled in a screw cooler. Solids collected by the cross-flow filters are also depressured in the RPD vessels and then cooled in screw coolers.

Compressed Air system. Except for turbine cooling flows required by the gas turbine, all of the air produced by the gas turbine compressor is collected from the compressor discharge and ducted to the carbonizer/CPFBC area. This air, pressurized to $10 \mathrm{~atm} / 635^{\circ} \mathrm{F}$, supplies four subsystems:

- Booster compressors, which provide pressurizing and atomizing air at 50 psi above the carbonizer entry pressure. The air is cooled and dried before being compressed by the boost compressors.

- Carbonizer booster compressors, which provide secondary air to the carbonizers. These compressors provide a 17-psi boost to the carbonizer oxidant; they are needed to ensure a fuel gas with adequate pressure above the vitiated oxidant at the topping combustors. These compressors are not precooled.

- PFBC fluidizing air.

- CPFBC primary combustion air.

Topping Combustor and Combustion Turbine. Clean fuel gas from the carbonizers and the vitiated air product of the CPFBCs are conveyed to the gas turbine by ceramic-insulated hot gas piping. These pipes have metallic liners on the inner diameter to protect the turbine from eroded ceramic material. A carbon steel outer liner strengthens to these pipes structurally.

The fuel gas and vitiated air are oxidized in the MASBs installed under the gas turbine. The nominal exit temperature of the MASB is $1950^{\circ} \mathrm{F}$. combustion products from the MASB expand through the expander section of the gas turbine, producing about $21 \mathrm{MW}$ (net) in the gas turbine unit.

Heat Recovery Steam Generator. The gas leaving the gas turbine flows through an HRSG, where it is cooled to $280^{\circ} \mathrm{F}$ by producing steam and heated feedwater. Gas exiting the HRSG is then ducted to the stack.

The HRSG and PFBC are closely tied in steam production. The HRSG provides all of the economizing and a small portion of the evaporating duty, and the PFBC provides the balance of the evaporating duty.

Together, the PFBC and HRSG provide about 99 percent of the required steam energy. The remaining 1 percent of steam thermal input is provided by the ash screw coolers in the form of condensate heating. 
Condensate System. Heating and deaeration of low-pressure condensate is provided primarily by extraction steam. The deaerator operates at 25 psia/ $240^{\circ} \mathrm{F}$. About 15 percent of the condensate is diverted around the feedwater heater to cool the ash screw coolers. The hot water leaving the screw coolers is discharged directly into the deaerator.

Water from the deaerator is pressurized by electrically driven booster pumps and feedwater pumps. Two 60-percent capacity pump trains are provided. The feedwater flow is split between the two HRSGs and is heated by the HRSG economizer sections to $365^{\circ} \mathrm{F}$.

Feedwater leaving each of the HRSG economizers is split into two streams. The first stream feeds the high-pressure drum in the HRSG. The water is evaporated in the HRSG and piped over to the PFBC, where it is mixed with steam produced there. The balance of the feedwater is piped to the evaporator in the PFBC, where it is heated to steam. This dry, saturated steam is then sent to process.

\subsubsection{Plant Performance}

The second-generation PFBC cogeneration plant has an overall thermal efficiency of 82.7 percent, based on the HHV of coal. Table 21 summarizes the performance of the plant. Table 22 lists its auxiliary power requirements.

Steam-generating heat exchangers are located in the PFBC vessel of the fluidized bed combustor, in the HRSG at the exhaust end of the gas turbine, and in the ash screw coolers. Thermal performance parameters for these exchangers are given in Table 23.

Table 24 lists the heat and material balance for the entire plant. 
Table 21 Plant Summary Performance Data--Case 2

\begin{tabular}{|c|c|c|c|c|c|}
\hline Description & $\begin{array}{l}\text { Flow } \\
(1 \mathrm{~b} / \mathrm{h})\end{array}$ & $\begin{array}{l}\text { Enthalphy } \\
(\text { Btu/lb) }\end{array}$ & $\begin{array}{l}\text { Power } \\
\text { (kW) }\end{array}$ & $\begin{array}{c}\text { Energy } \\
\left(10^{6} \mathrm{Btu} / \mathrm{h}\right)\end{array}$ & $\begin{array}{c}\text { Energy } \\
\text { Output }(\%)\end{array}$ \\
\hline Process Steam & 442,337 & $1,197.20$ & & 529.57 & \\
\hline (Returned Condensate) & $(287,519)$ & 128.30 & & $(36.89)$ & \\
\hline (Makeup Water) & $(170,599)$ & 23.10 & & $(3.94)$ & \\
\hline Stean Energy Output & & 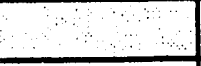 & 3 & 488.74 & 88 \\
\hline Gas Turbine Power & & & 21,212 & 72.40 & \\
\hline Plant Auxiliaries & & & $(1,612)$ & (5.51) & \\
\hline Electric Power Output & & 3 & 19,600 & 66.89 & 12 \\
\hline Total Energy Output & & 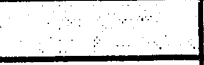 & & 556.63 & 100 \\
\hline Coal Energy Input (HHV) & 53,981 & 12,452 & & 672.17 & \\
\hline Net Thermal Efficiency & & & & & 82.66 \\
\hline
\end{tabular}

Table 22 Auxiliary Summary--Case 2

\begin{tabular}{|l|r|}
\hline \multicolumn{1}{|c|}{ Item } & KW \\
\hline Transport Booster Compressor & 49 \\
\hline Carbonizer Booster Compressor & 104 \\
\hline Condensate Pumps & 10 \\
\hline Feedwater Pumps & 120 \\
\hline Boller Forced-Circulation Pumps & 365 \\
\hline Circulating Water Pumps & 3 \\
\hline Cooling Tower Fans & 1 \\
\hline Gas Turbine Auxiliaries & 100 \\
\hline Steam Turbine Auxiliaries & 160 \\
\hline Rail Unloading and Stacker/Reclaimer & 25 \\
\hline Coal Handling & 11 \\
\hline Dolomite Handling & 129 \\
\hline Coal and Sorbent Feed & 132 \\
\hline Ash Cooling and Handling & 98 \\
\hline Slurry Preparation & 157 \\
\hline Service Water & 19 \\
\hline Miscellaneous & 121 \\
\hline Stepdown Transformer & 8 \\
\hline Total Auxiliaries & 1612 \\
\hline
\end{tabular}


Table 23 Heat Exchanger Performance--Case 2

\begin{tabular}{|c|c|c|c|c|c|}
\hline \multirow{2}{*}{ Components } & \multirow{2}{*}{$\begin{array}{c}\text { Thermal } \\
\left(10^{\circ} \mathrm{Btu} / \mathrm{h}\right)\end{array}$} & \multirow{2}{*}{$\begin{array}{l}\text { Duty } \\
(\%)\end{array}$} & \multirow{2}{*}{$\begin{array}{l}\text { Flow } \\
(1 \mathrm{~b} / \mathrm{h})\end{array}$} & \multicolumn{2}{|c|}{$\begin{array}{c}\text { Temperature } \\
\left({ }^{\circ} \mathrm{F}\right)\end{array}$} \\
\hline & & & & Inlet & Outlet \\
\hline $\begin{array}{l}\text { PFBC Evaporator } \\
\text { Water/Steam } \\
\text { CPFBC }\end{array}$ & 350.96 & 67.4 & 398,946 & $\begin{array}{r}365.1 \\
1600.0\end{array}$ & $\begin{array}{r}375.1 \\
1600.0\end{array}$ \\
\hline $\begin{array}{l}\text { HRSG Evaporator } \\
\text { Water/Steam } \\
\text { Gas }\end{array}$ & 97.28 & 18.7 & $\begin{array}{l}110,585 \\
757,275\end{array}$ & $\begin{array}{r}365.1 \\
1050.4\end{array}$ & $\begin{array}{l}375.1 \\
610.6\end{array}$ \\
\hline $\begin{array}{l}\text { HRSG Economizer } \\
\text { Water } \\
\text { Gas }\end{array}$ & 69.01 & 13.2 & $\begin{array}{l}509,531 \\
757,275\end{array}$ & $\begin{array}{l}240.4 \\
610.6\end{array}$ & $\begin{array}{l}365.1 \\
280.0\end{array}$ \\
\hline $\begin{array}{l}\text { Ash Screw Cooler } \\
\text { Water } \\
\text { Ash }\end{array}$ & 3.82 & 0.7 & $\begin{array}{l}26,326 \\
17,240\end{array}$ & $\begin{array}{r}55.0 \\
1132.5\end{array}$ & $\begin{array}{l}200.0 \\
300.0\end{array}$ \\
\hline Heat Exchanger Iotal & 521.07 & 100.0 & & & \\
\hline
\end{tabular}




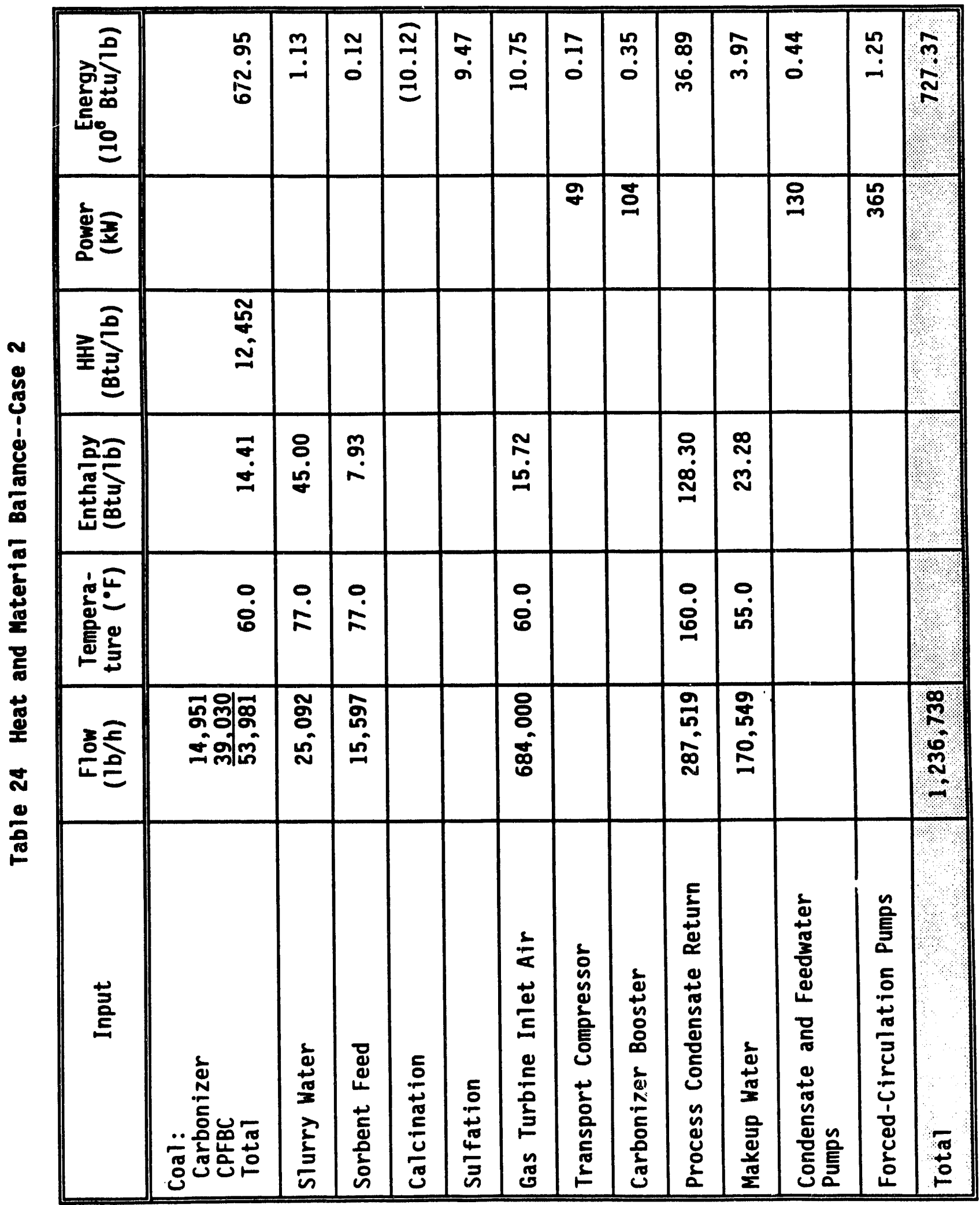




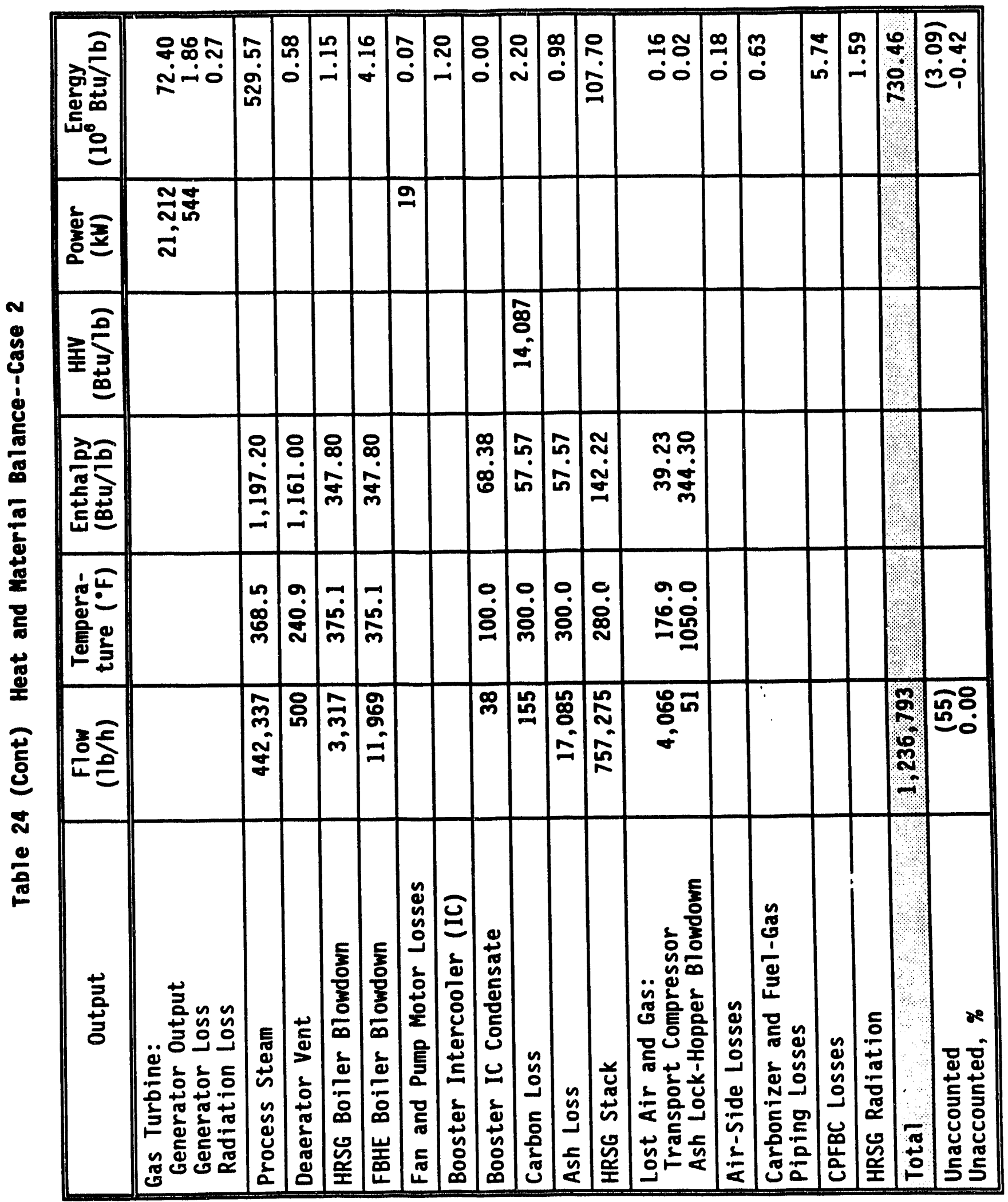




\subsubsection{Plant Capital Cost}

The capital requirements of the plant are 1isted in Table 25 . The assumptions and methods for estimating these costs are described in Section 6.

\subsubsection{Plant Operating Costs}

Annual operating costs were estimated from the costs of fuel, feedstocks, plant labor, maintenance, and other items as listed in Table 26.

The total annual operating cost and the fixed costs associated with the total capital requirements are key components of the levelized cost of steam. The cost of steam for all systems is compared in Section 6 . 


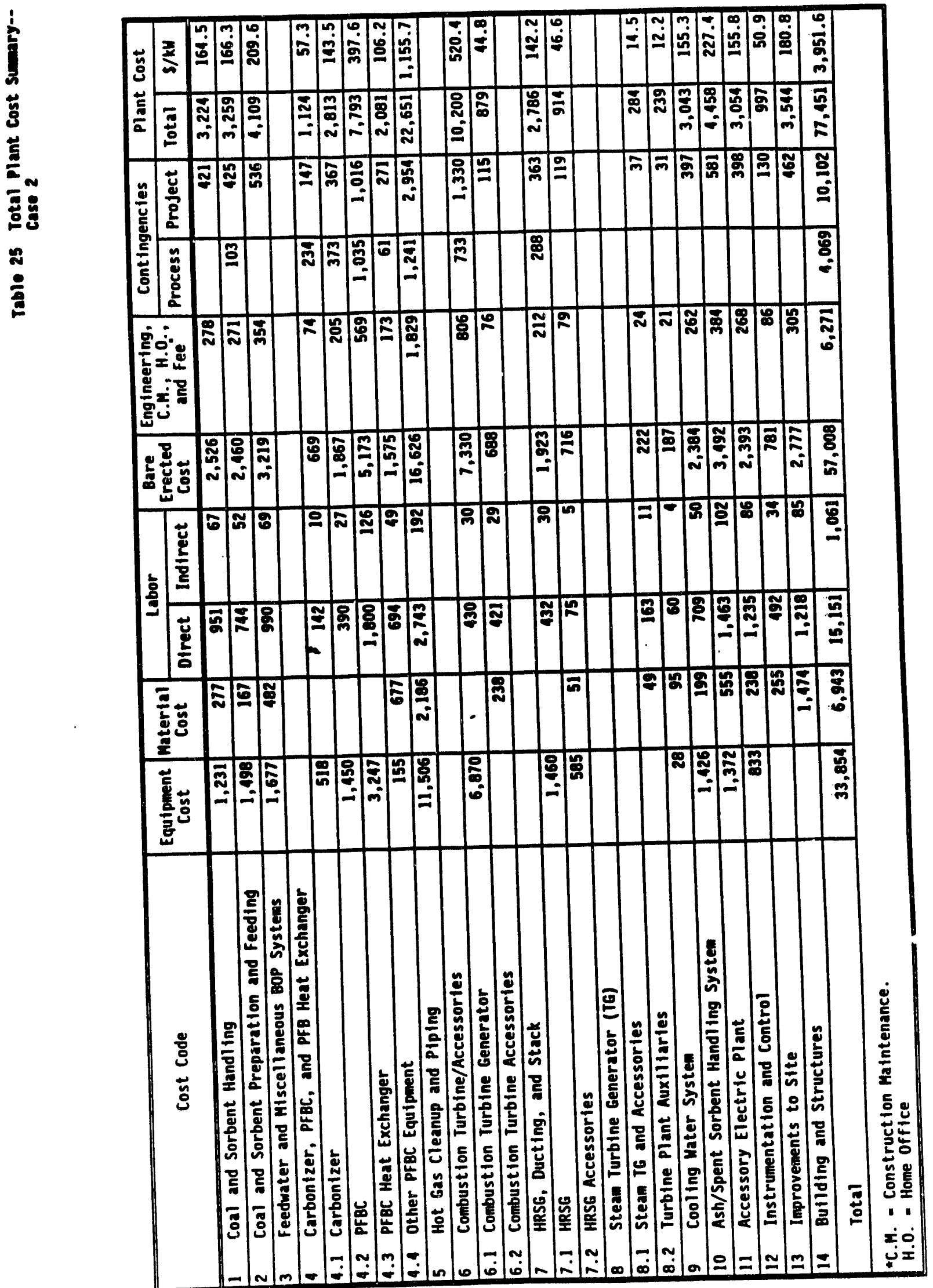


Table 26 Annual Operating Costs--Case 2 (Capacity Factor = 80\%)

\begin{tabular}{|c|c|c|c|}
\hline Cost Categories & Quantity & $\begin{array}{c}\text { Unit } \\
\text { Price, } \$\end{array}$ & $\begin{array}{l}\text { Total } \\
\$ \times 10^{3}\end{array}$ \\
\hline Fue1: Pittsburgh No. 8 Coal & $\begin{array}{l}53,981 \mathrm{lb} / \mathrm{h} \\
672.1710^{6} \mathrm{Btu} / \mathrm{h}\end{array}$ & $1.50 / 10^{6} \mathrm{Btu}$ & 7,071 \\
\hline $\begin{array}{l}\text { Consumable Materials: } \\
\text { Dolomite } \\
\text { Nitrogen } \\
\text { Raw Water } \\
\text { Water Treatment Chemicals } \\
\text { (40\% of water cost) }\end{array}$ & $\begin{array}{l}7.8 \mathrm{t} / \mathrm{h} \\
45 \mathrm{sft}^{3} / \mathrm{min} \\
371 \mathrm{gal}^{2} / \mathrm{min}\end{array}$ & $\begin{array}{l}18.80 / \mathrm{t} \\
0.29 / 100 \mathrm{sft}^{3} \\
0.75 / 1000 \mathrm{gal}\end{array}$ & $\begin{array}{r}1,028 \\
55 \\
117 \\
47\end{array}$ \\
\hline Ash Disposal Costs & $8.62 \mathrm{t} / \mathrm{h}$ & $9.75 / t$ & 589 \\
\hline $\begin{array}{l}\text { Plant Labor: } \\
\text { Operators } \\
\text { Supervision and Clerical } \\
(20 \% \text { of } 08 M)\end{array}$ & 9/shift & $24.65 / \mathrm{h}$ & $\begin{array}{r}1,943 \\
876\end{array}$ \\
\hline Maintenance Costs & & & 2,435 \\
\hline Total Operating costs & & & 14,162 \\
\hline
\end{tabular}


Case 3 has an adiabatic PFBC, so all steam is produced by the HRSG. This case has fewer pieces of equipment than any other industrial PFBC plant in this study.

\subsubsection{Plant Description}

The second-generation PFBC cogeneration plant is designed to produce process steam as the main product and electric power as a byproduct. An airblown carbonizer converts a coal/sorbent/water slurry into a low-Btu fuel gas for a gas turbine topping combustor. The char produced by the carbonizer is combined with additional slurry fuel and burned in an adiabatic PFBC, preheating the topping combustor oxidant. The fuel gas from the carbonizer is burned in the topping combustor of a gas turbine. process.

Steam is generated by an HRSG at the gas turbine exit, then sent to

Figure 63 is a process flow diagram of the plant, showing the functional arrangement of the major plant systems. The major systems are described in more detail below.

- Slurry Preparation System

- Carbonizer

- Adiabatic PFB Combustor

- Ash Cooling and Disposal
- Topping Combustor and Combustion Turbine

- Heat Recovery Steam Generator

- Condensate System

Slurry Preparation System. Raw coal is fed by two Gravimetric feeders to a crusher, where it is crushed, screened, and dropped into slurry tanks fitted with agitators. Sized dolomite sorbent is screened and added to the slurry tanks. Water is added to give a coal/water ratio of $70: 30$ by weight.

After leaving this holding tank, the coal/sorbent/water slurry is pumped to both the carbonizer and the PFBC, where it is atomized by compressed air and injected into the vessels.

Carbonizer. In this cogeneration arrangement, all of the slurry is used by the carbonizer to make fuel gas for the topping combustor. In the fluidized carbonizer, the coal and sorbent are converted into a low-Btu gas and a mixed solid containing char and spent sorbent. Both the carbonizer and the PFBC operate at $1600^{\circ} \mathrm{F}$.

Char and spent sorbent are separated from the carbonizer fuel gas at three locations. An overflow drain in the carbonizer allows solids to fall to a collecting hopper. This hopper also receives solids collected by cyclones and by ceramic cross-flow filters in the fuel gas cleanup system. Solids from the collecting hopper are fed to the PFBC by "N" valves, which are kept fluidized with a small flow of nitrogen. 


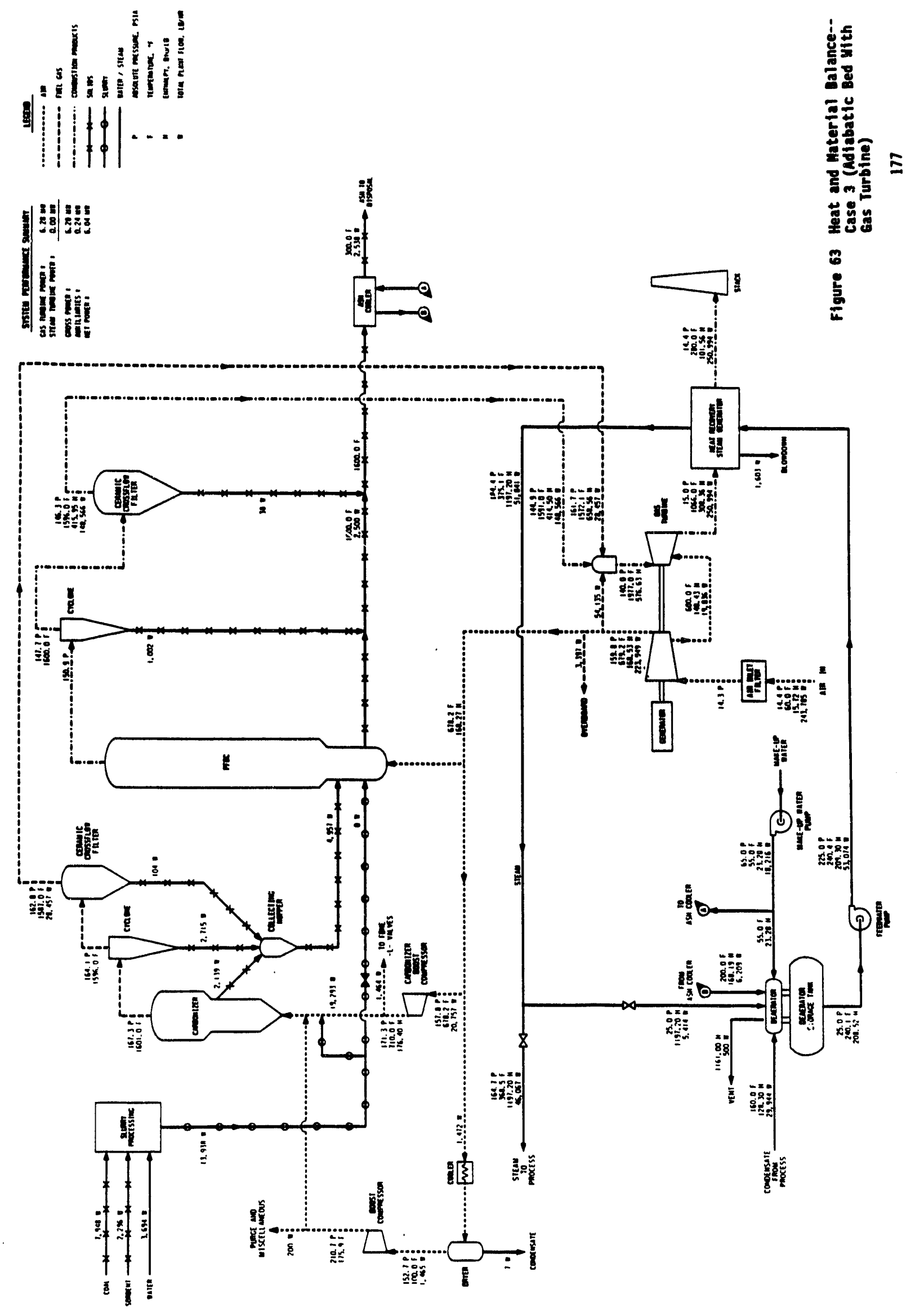


Adiabatic PFB Combustor. The PFBC receives as fuel all of the char mixture from the carbonizer. The air to the PFBC is partialiy vitiated and heated to about $1600^{\circ} \mathrm{F}$. To be adiabatic, the PFBC is designed to operate with 465-percent excess air. The corresponding plant excess air is 197 percent. The PFBC combustion products are cleaned by cyclones and ceramic cross-flow filters.

Ash Cooling and Disposal. Excess solids from the PFBC are extracted from the PFBC at $1600^{\circ} \mathrm{F}$, depressured through an RPD vessel, and then cooled in a screw cooler. Solids collected by the cross-flow filters are also depressured in the RPD vessels and then cooled in screw coolers.

Compressed Air system. Except for the turbine cooling flows required by the gas turbine, all of the air produced by the gas turbine compressor is collected from the compressor discharge and ducted to the carbonizer/PFBC area. This air, pressurized to 11 atm $/ 679^{\circ} \mathrm{F}$, supplies three subsystems:

- Booster compressors, which provide pressurizing and atomizing air at 50 psi above the carbonizer entry pressure. The air is cooled and dried before being compressed by the booster compressors.

- Carbonizer booster compressors, which provide secondary air to the carbonizers. These compressors, which supply the carbonizer oxidant, are needed to ensure that the fuel gas will have adequate pressure above the vitiated oxidant at the topping combustors. They are not precooled.

- PFBC combustion air.

Topping Combustor and Combustion Turbine. Clean fuel gas from the carbonizers and the vitiated air product of the PFBCs are conveyed to the gas turbine by ceramic-insulated hot gas piping. These pipes have metallic liners on the inner diameter to protect the turbine from eroded ceramic material. A carbon steel outer liner strengthens these pipes structurally.

The fuel gas and vitiated air are oxidized in the topping combustor of the gas turbine. The nominal exit temperature of the combustor is $1977^{\circ} \mathrm{F}$. Combustion products expand through the exparder section of the gas turbine, producing about $6 \mathrm{MW}$ (net) in the gas turbine unit.

Heat Recovery Steam Generator. The gas leaving the gas turbine flows through an HRSG, where it is cooled to $280^{\circ} \mathrm{F}$ by producing steam. Gas exiting the HRSG is then ducted to the stack.

The HRSG provides about 99 percent of the required steam energy. The remaining 1 percent of steam thermal input comes from the ash screw coolers in the form of condensate heating.

Condensate system. Heating and deaerating of low-pressure condensate is primarily by extraction steam. The deaerator operates at $25 \mathrm{psia} / 240^{\circ} \mathrm{F}$. About 15 percent of the condensate is diverted around the feedwater heater to cool the ash screw coolers. The hot water leaving the screw coolers is discharged directly into the deaerator.

Water from the deaerator is pressurized by electrically driven booster pumps and feedwater pumps. Two 60-percent capacity pump trains are provided. The feedwater flow is heated by the HRSG economizer sections to $375^{\circ} \mathrm{F}$. 
Feedwater leaving the HRSG economizer feeds the high-pressure drum in the HRSG. The water is evaporated to dry, saturated steam, then sent to process.

\subsubsection{Plant Performance}

The second-generation PFBC cogeneration plant has an overall thermal efficiency of 72.24 percent, based on the HHV of coal. Table 27 summarizes the performance of the plant. Table 28 lists its auxiliary power requirements.

Steam-generating heat exchangers are located in the HRSG at the exhaust end of the gas turbine and in the ash screw coolers. Thermal performance parameters for these exchangers are given in Table 29.

Table 30 lists the heat and material balance for the entire plant. 
Table 27 Plant Summary Performance Data--Case 3

\begin{tabular}{|l|r|r|r|r|r|}
\hline \multicolumn{1}{|c|}{ Description } & $\begin{array}{c}\text { Flow } \\
(1 \mathrm{~b} / \mathrm{h})\end{array}$ & $\begin{array}{c}\text { Enthalphy } \\
(\mathrm{Btu} / \mathrm{lb})\end{array}$ & $\begin{array}{c}\text { Power } \\
(\mathrm{kW})\end{array}$ & $\begin{array}{c}\text { Energy } \\
\left(10^{6} \mathrm{Btu} / \mathrm{h}\right)\end{array}$ & $\begin{array}{c}\text { Energy } \\
\text { Output }(\mathrm{K})\end{array}$ \\
\hline Process Steam & 46,067 & $1,197.20$ & & 55.15 & \\
\hline (Returned Condensate) & $(29,944)$ & 128.30 & & $(3.84)$ & \\
\hline (Makeup Water) & $(18,216)$ & 23.28 & & $(0.42)$ & \\
\hline Steam Energy Output & & & & 50.89 & 71 \\
\hline Gas Turbine Power & & & 6,280 & & \\
\hline Plant Auxiliaries & & & $(243)$ & $(6.90)$ & \\
\hline Electric Power Output & & & 6,037 & 20.60 & 100 \\
\hline Total Energy Output & & & & 71.49 & \\
\hline Coal Energy Input (HHV) & 7,948 & 12,452 & & 98.97 & \\
\hline Net Thermal Efficiency & & & & & 72.24 \\
\hline
\end{tabular}

Table 28 Auxiliary Summary--Case 3

\begin{tabular}{|l|r|}
\hline \multicolumn{1}{|c|}{ Item } & KW \\
\hline Transport Booster Compressor & 8 \\
\hline Carbonizer Booster Compressor & 51 \\
\hline Condensate Pumps & 1 \\
\hline Feadwater Pumps & 13 \\
\hline Boiler Forced-Circulation Pumps & 0 \\
\hline Circulating Hater Pumps & 1 \\
\hline Gas Turbine Auxiliaries & 50 \\
\hline Steam Turbine Auxiliaries & 17 \\
\hline Unloading and Stacker/Reclaimer & 4 \\
\hline Coal Handl ing & 2 \\
\hline Dolomite Handling & 19 \\
\hline Coal and Sorbent Feed & 19 \\
\hline Ash Cool ing and Handling & 14 \\
\hline Slurry Preparation & 23 \\
\hline Service Water & 3 \\
\hline Miscellaneous & 18 \\
\hline Stepdown Transformer & 1 \\
\hline Total Auxiliaries & 243 \\
\hline
\end{tabular}


Table 29 Heat Exchanger Performance--Case 3

\begin{tabular}{|c|c|c|c|c|c|}
\hline \multirow{2}{*}{ Components } & \multirow{2}{*}{$\begin{array}{c}\text { Thermal } \\
\left(10^{\circ} \mathrm{Btu} / \mathrm{h}\right)\end{array}$} & \multirow{2}{*}{$\begin{array}{l}\text { Duty } \\
(\%)\end{array}$} & \multirow{2}{*}{$\begin{array}{l}\text { Flow } \\
(1 \mathrm{~b} / \mathrm{h})\end{array}$} & \multicolumn{2}{|c|}{$\begin{array}{c}\text { Temperature } \\
\left({ }^{\circ} F\right)\end{array}$} \\
\hline & & & & Inlet & Outlet \\
\hline $\begin{array}{l}\text { HRSG Economizer } \\
\text { Water/Steam } \\
\text { Gas }\end{array}$ & 7.19 & 13.0 & $\begin{array}{r}53,074 \\
250,994\end{array}$ & $\begin{array}{l}240.4 \\
388.9\end{array}$ & $\begin{array}{l}365.1 \\
280.0\end{array}$ \\
\hline $\begin{array}{l}\text { HRSG Evaporator } \\
\text { Water } \\
\text { Gas }\end{array}$ & 47.34 & 85.4 & $\begin{array}{r}53,074 \\
250,994\end{array}$ & $\begin{array}{r}365.1 \\
1066.0\end{array}$ & $\begin{array}{l}375.1 \\
388.9\end{array}$ \\
\hline $\begin{array}{l}\text { Ash Screw Cooler } \\
\text { Water } \\
\text { Ash }\end{array}$ & 0.90 & 1.6 & $\begin{array}{l}3,876 \\
2,538\end{array}$ & $\begin{array}{r}55.1 \\
1600.0\end{array}$ & $\begin{array}{l}200.0 \\
300.0\end{array}$ \\
\hline Heat Exchanger Total & 55.43 & 100.0 & & & \\
\hline
\end{tabular}




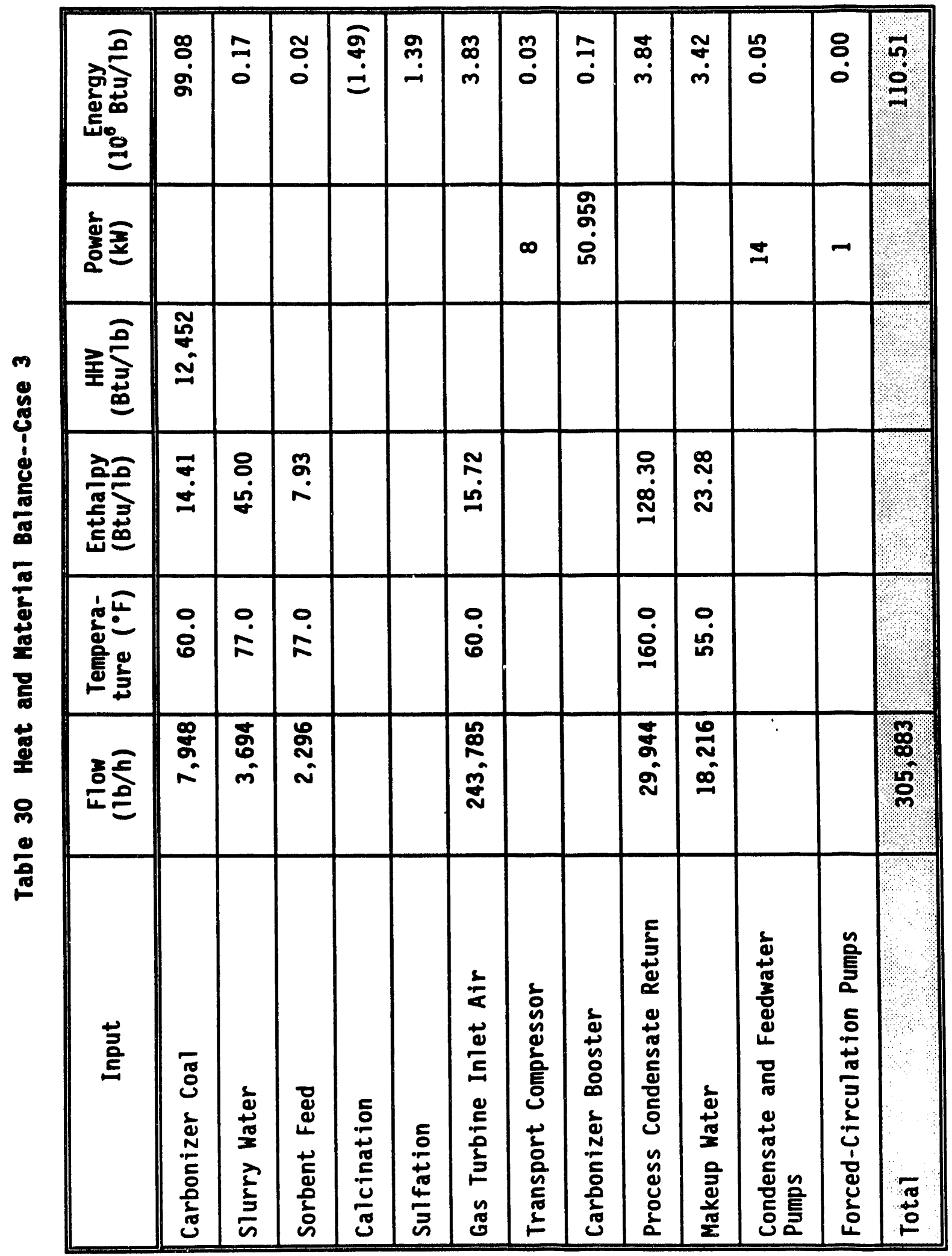




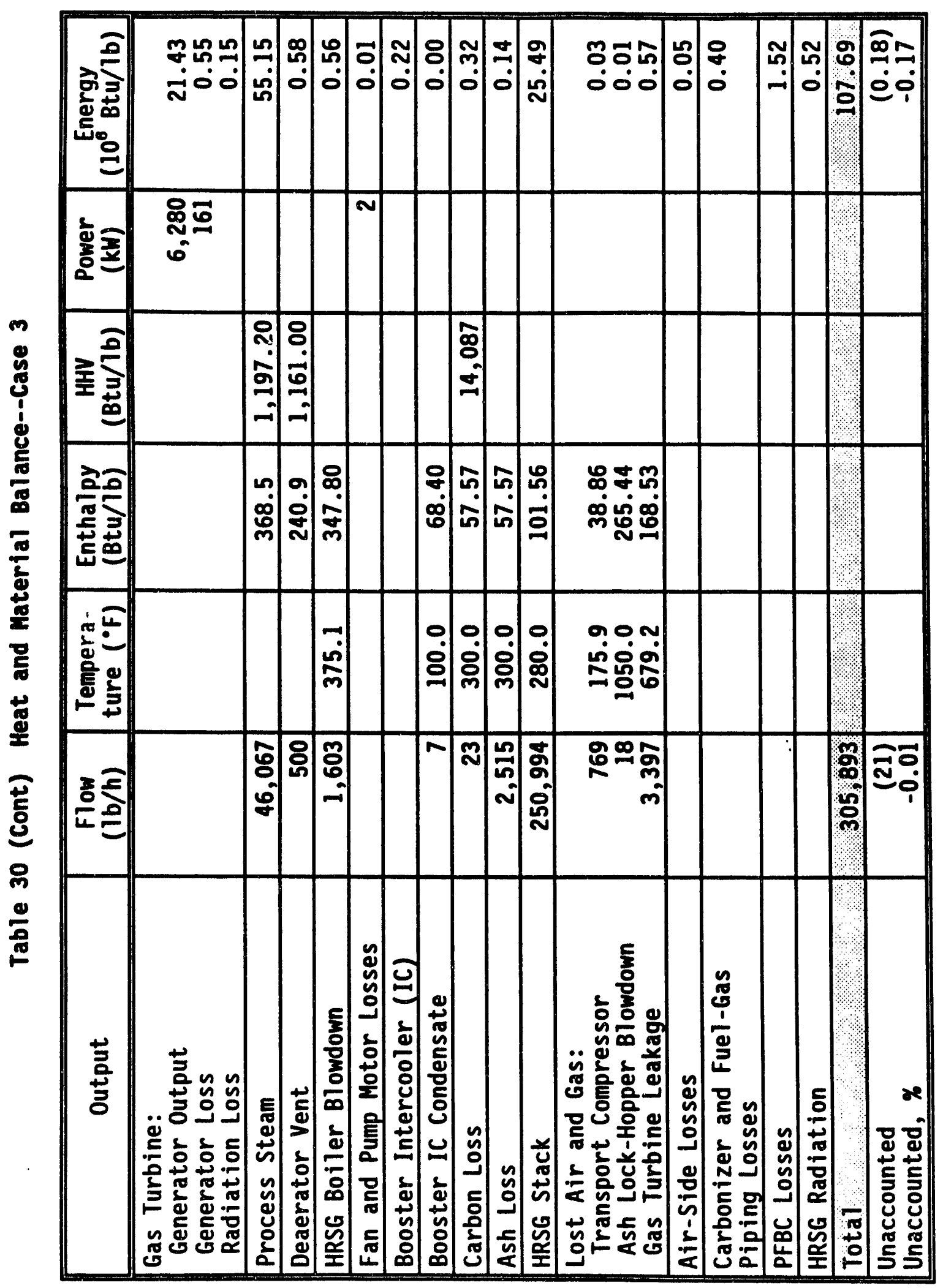




\subsubsection{Plant Capital Cost}

The capital requirements of the plant are given in Table 31 . The assumptions and methods used to estimate these costs are described in Section 6 .

\subsubsection{Plant Operating Costs}

Annual operating costs were estimated from the costs of fuel, feedstocks, plant labor, maintenance, and other items as listed in Table 32.

The total annual operating costs and the fixed costs associated with the total capital requirements are key components of the levelized cost of steam. The steam costs of all systems are compared in Section 6 . 


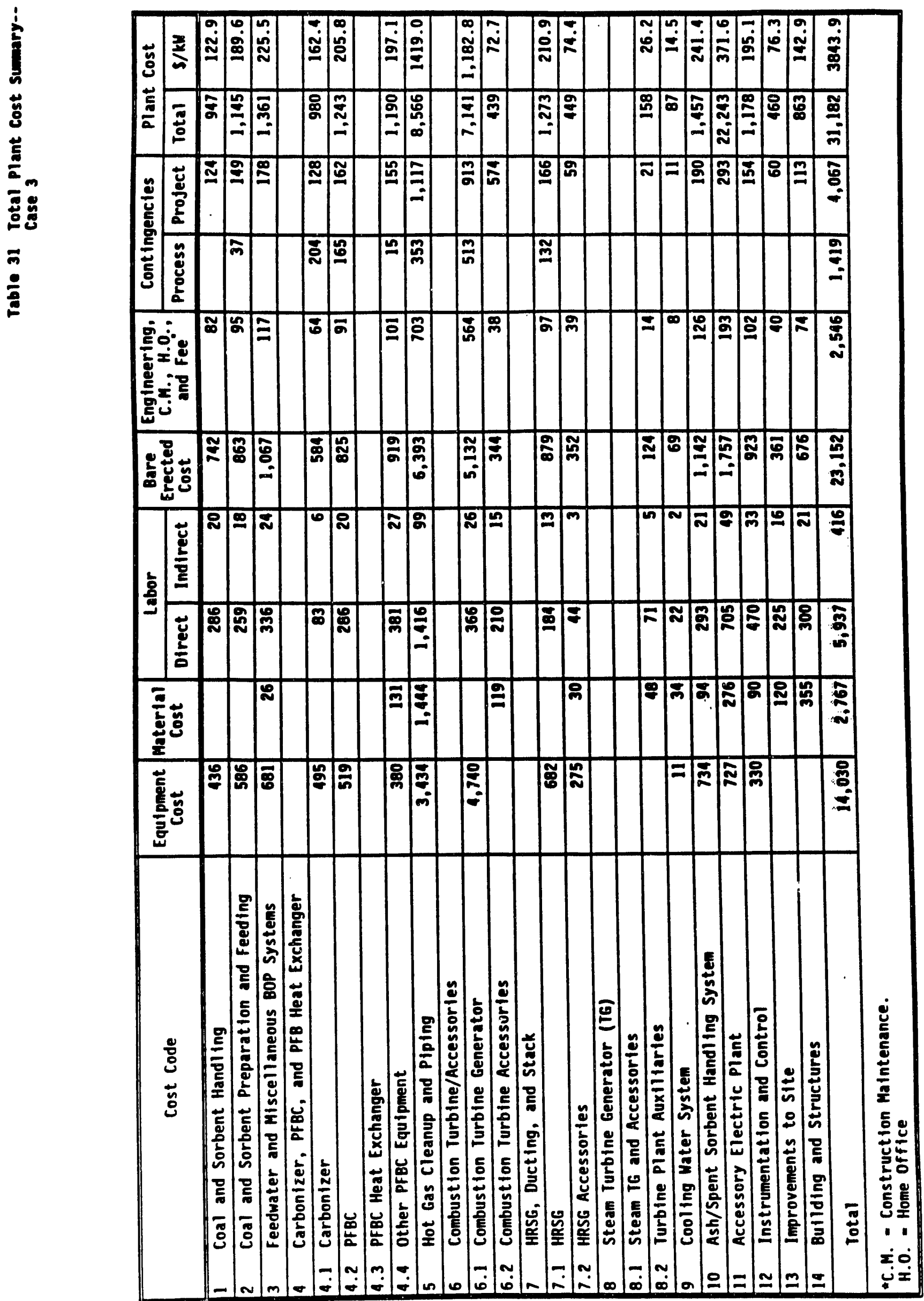


Table 32 Annual Operating Costs--Case 3 (Capacity Factor $=80 \%$ )

\begin{tabular}{|c|c|c|c|}
\hline Cost Categories & Quantity & $\begin{array}{c}\text { Unit } \\
\text { Price, } \$\end{array}$ & $\begin{array}{r}\text { Total } \\
5 \times 10^{3}\end{array}$ \\
\hline Fuel: Pittsburgh No. 8 Coal & $\begin{array}{l}7,984 \mathrm{lb} / \mathrm{h} \\
98.9710^{6} \mathrm{Btu} / \mathrm{h}\end{array}$ & $1.50 / 10^{3} \mathrm{Btu}$ & 1,041 \\
\hline $\begin{array}{l}\text { Consumable Materials: } \\
\text { Dolomite } \\
\text { Nitrogen } \\
\text { Raw Water } \\
\text { Water Treatment Chemicals } \\
\text { (40\% of water cost) }\end{array}$ & $\begin{array}{l}1.15 \mathrm{t} / \mathrm{h} \\
32 \mathrm{sft} / \mathrm{min} \\
41 \mathrm{gal} / \mathrm{min}\end{array}$ & $\begin{array}{l}18.80 / \mathrm{t} \\
0.29 / 100 \mathrm{sft}^{3} \\
0.75 / 1000 \mathrm{gal}^{3}\end{array}$ & $\begin{array}{r}151 \\
39 \\
13 \\
5\end{array}$ \\
\hline Ash Disposal Costs & $1.27 \mathrm{t} / \mathrm{h}$ & $9.75 / \mathrm{t}$ & 87 \\
\hline $\begin{array}{l}\text { Plant Labor: } \\
\text { Operators } \\
\text { Supervision and Clerical } \\
\text { (20\% of 08M) }\end{array}$ & $5.5 /$ shift & $24.65 / h$ & $\begin{array}{r}1,188 \\
798\end{array}$ \\
\hline Maintenance Costs & & & 905 \\
\hline Total Operating costs & & & 3,847 \\
\hline
\end{tabular}


Case 4 is a smaller plant with gas turbine and steam turbine power, similar in configuration to the larger Case 1.

\subsubsection{Plant Description}

The second-generation PFBC cogeneration plant is designed to produce process steam as the main product and electric power as a byproduct. An airblown carbonizer converts coal/sorbent/water slurry into a low-Btu fuel gas for a gas turbine topping combustor. The char produced by the carbonizer is combined with additional slurry fuel and burned in a bubbiing PFBC, preheating some of the topping combustor oxidant and generating steam. The fuel gas from the carbonizer is burned in the topping combustor of a gas turbine.

Steam is also generated by an HRSG at the gas turbine exit and sent to the PFBC. The steam leaving the PFBC is expanded through a back-pressure turbine and then sent to process.

Figure 64 is a process flow diagram of the plant, showing the functional arrangement of the major plant systems. The major systems are described in more detail below.

\section{- Slurry Preparation System \\ - Carbonizer \\ - PFB Combustor \\ - Ash Cooling and Disposal \\ - Compressed Air System}

\author{
- Topping Combustor and Combustion \\ Turbine \\ - Combustion Turbine \\ - Heat Recovery Steam Generator \\ - Back-Pressure Steam Turbine \\ - Condensate System
}

Slurry Preparation System. Raw coal is fed by two Gravimetric feeders to a crusher, where it is crushed, screened, and dropped into slurry tanks with agitators. Sized dolomite sorbent is screened and added to the slurry tanks. Water is added to give a coal/water ratio of 70:30 by weight.

After leaving this holding tank, the coal/sorbent/water slurry is pumped to the carbonizer where it is atomized by compressed air and injected into the vessel.

Carbonizer. In this cogeneration arrangement, all of the slurry is used by the carbonizer to make fuel gas for the topping combustor. In the fluidized carbonizer, the coal and sorbent are converted into a low-Btu gas and a mixed solid containing char and spent sorbent. Both the carbonizer and the PFBC operate at $1600^{\circ} \mathrm{F}$.

Char and spent sorbent are separated from the carbonizer fuel gas at three locations. An overflow drain in the carbonizer allows solids to fall to a collecting hopper. This hopper also receives solids collected by cyclones and by ceramic cross-flow filters in the fuel gas cleanup system. Solids from the collecting hopper are fed to the PFBC by "N" valves, which are kept fluidized with a small flow of nitrogen. 


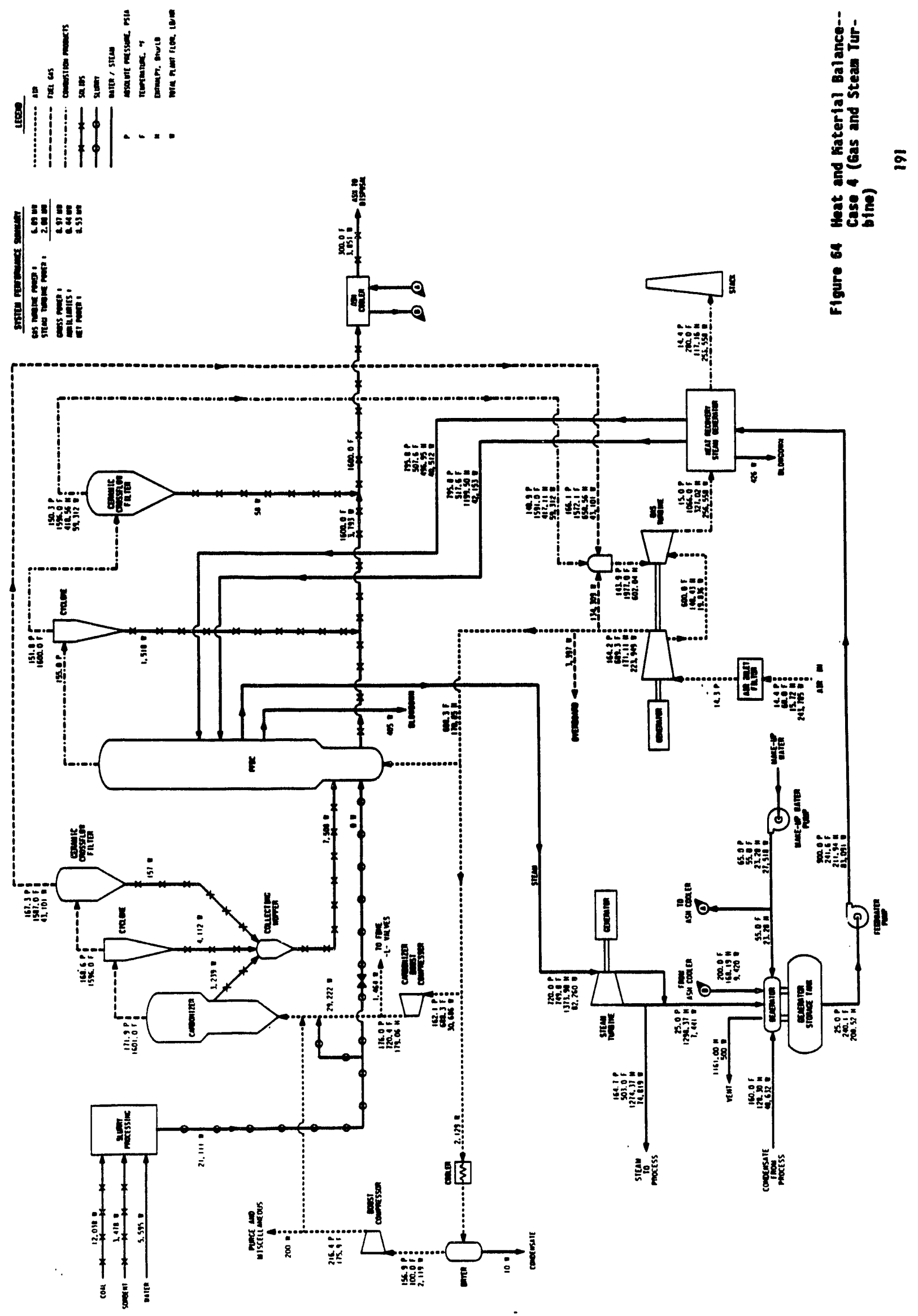


PFB Combustor. The PFBC, which receives all of the char/sorbent mixture from the carbonizer, is designed to operate with 40-percent excess air at $1600^{\circ} \mathrm{F}$. The corresponding plant excess air is 110 percent. Most of the air that does not go to the PFBC goes directly to the topping combustor. This type of process arrangement produces the maximum steam.

Heat-transfer surface in the PFBC generates 44 percent of the plant steam duty. The combustion products of the PFBC are cleaned by cyclones and ceramic cross-flow filters. The solids collected in the gas cleanup equipment and the solids drained from the bed go to the ash disposal system.

Ash Cooling and Disposal. Excess solids from the PFBC are extracted at $1600^{\circ} \mathrm{F}$, depressured through a RPD vessel, then cooled in a screw cooler. Solids collected by the cross-flow filters are also depressured in the RPD vessels and then cooled in screw coolers.

Compressed Air system. Except for turbine cooling flows required by the gas turbine, all of the air produced by the gas turbine compressor is collected from the compressor discharge and ducted to the carbonizer/PFBC area. This air, pressurized to 11 atm $/ 689^{\circ} \mathrm{F}$, supplies three subsystems:

- Booster compressors, which provide pressurizing and atomizing air at 50 psi above the carbonizer entry pressure. The air is cooled and dried before being compressed ijy the booster compressors.

- Carbonizer booster compressors, which provide secondary air to the carbonizers. These compressor's, which provide the carbonizer oxidant, are needed to ensure that the fuel gas will have adequate pressure above the vitiated oxidant at the topping combustors. The compressors are not precooled.

- PFBC combustion air.

Topping Combustor and Combustion Turbine. Clean fuel gas from the carbonizers and the vitiated air product of the PFBCs are conveyed to the gas turbine by ceramic-insulated hot gas piping. These pipes have metallic liners on the inner diameter to protect the turbine from eroded ceramic material. A carbon steel outer liner strengthens these pipes structurally.

The fuel gas and vitiated air are oxidized in the topping combustor of the gas turbine. The nominal exit temperature of the combustor is $1977^{\circ} \mathrm{F}$. Combustion products expand through the expander section of the gas turbine, producing about $7 \mathrm{MW}$ (net) in the gas turbine unit.

Heat Recovery Steam Generator. The gas leaving the gas turbine flows through an HRSG, where it is cooled to $280^{\circ} \mathrm{F}$ by producing steam and heated feedwater. Gas exiting the HRSG is then ducted to the stack.

The HRSG and PFBC are closely tied in steam production. The HRSG provides all of the economizing and a small portion of the evaporating duty, and the PFBC provides the rest of the evaporating duty and any required superheat.

Together, the PFBC and HRSG provide about 99 percent of the required steam energy. The remaining 1 percent of steam cycle thermal input is provided by the ash screw coolers in the form of condensate heating. 
Back-Pressure Steam Turbine. The steam is expanded through a backpressure steam turbine before being released to process. The turbine is a 700-psig unit with a $750^{\circ} \mathrm{F}$ throttle inlet temperature. The turbine exhaust pressure is slightly above the required 150 psig process steam pressure.

Condensate System. Heating and deaeration of low-pressure condensate is provided primarily by extraction steam. The deaerator operates at $25 \mathrm{psia/}$ $240^{\circ} \mathrm{F}$. About 15 percent of the condensate is diverted around the feedwater heater to cool the ash screw coolers. The hot water leaving the screw coolers is discharged directly into the deaerator.

Water from the deaerator is pressurized by electrically driven booster pumps and feedwater pumps. Two 60-percent capacity pump trains are provided. The feedwater flow is heated by the HRSG economizer sections to $507^{\circ} \mathrm{F}$.

Feedwater leaving the HRSG economizer is split into two streams. The first stream feeds the high-pressure drum in the HRSG. The water is evaporated in the HRSG, piped over to the PFBC, and mixed with steam produced there. The rest of the feedwater is piped to the evaporator in the PFBC, where it is heated to steam. This dry, saturated steam is then sent to process.

\subsubsection{Plant Performance}

The second-generation PFBC cogeneration plant has an overall thermal efficiency of 78.5 percent, based on the HHV of coal. Table 33 summarizes the plant performance. Table 34 lists plant auxiliary power requirements.

Steam-generating heat exchangers are located in the PFBC, in the HRSG at the exhaust end of the gas turbine, and in the ash screw coolers. Thermal performance parameters for these exchangers are given in Table 35.

Table 36 lists the heat and material balance for the entire plant. 
Table 33 Plant Summary Performance Data--Case 4

\begin{tabular}{|c|c|c|c|c|c|}
\hline Description & $\begin{array}{l}\text { Flow } \\
(\mathrm{lb} / \mathrm{h})\end{array}$ & $\begin{array}{c}\text { Enthalphy } \\
(B t u / 1 b)\end{array}$ & $\begin{array}{l}\text { Power } \\
\text { (kW) }\end{array}$ & $\begin{array}{c}\text { Energy } \\
\left(10^{6} \mathrm{Btu} / \mathrm{h}\right)\end{array}$ & $\begin{array}{c}\text { Energy } \\
\text { Output }(\%)\end{array}$ \\
\hline Process Steam & 74,819 & $1,274.37$ & & 95.35 & \\
\hline (Returned Condensate) & $(48,632)$ & 128.30 & & $(6.24)$ & \\
\hline (Makeup Water) & $(27,518)$ & 23.10 & & $(0.64)$ & \\
\hline Steam Energy Output & & & & 88.47 & 75 \\
\hline Gas Turbine Power & & & 6,891 & & \\
\hline Steam Turbine Power & & & 2,076 & & \\
\hline Plant Auxiliaries & & & $(440)$ & & \\
\hline Electric Power Output & & & 8,529 & 29.11 & 25 \\
\hline Tota) Energy Output & & & & 117.58 & 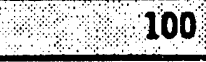 \\
\hline Coal Energy Input (HHV) & 12,038 & 12,452 & & 149.90 & \\
\hline Net Thermal Efficiency & & & & & 78.44 \\
\hline
\end{tabular}

Table 34 Auxiliary Summary--Case 4

\begin{tabular}{|l|r|}
\hline \multicolumn{1}{|c|}{ Item } & \multicolumn{1}{|c|}{$k W$} \\
\hline Transport Booster Compressor & 12 \\
\hline Carbonizer Booster Compressor & 76 \\
\hline Condensate Pumps & 2 \\
\hline Feedwater Pumps & 86 \\
\hline Boiler Forced-Circulation Pumps & 31 \\
\hline Circulating Water Pumps & 1 \\
\hline Gas Turbine Auxiliaries & 50 \\
\hline Steam Turbine Auxiliaries & 26 \\
\hline Unloading and Stacker/Reclaimer & 6 \\
\hline Coal Handling & 3 \\
\hline Dolomite Handling & 29 \\
\hline Coal and Sorbent Feed & 29 \\
\hline Ash Cool ing and Handling & 22 \\
\hline Slurry Preparation & 35 \\
\hline Service Water & 4 \\
\hline Miscellaneous & 27 \\
\hline Stepdown Transformer & 2 \\
\hline Total Auxiliaries & 440 \\
\hline
\end{tabular}


Table 35 Heat Exchanger Performance--Case 4

\begin{tabular}{|c|c|c|c|c|c|}
\hline \multirow{2}{*}{ Components } & \multirow{2}{*}{$\begin{array}{c}\text { Thermal } \\
\left(10^{8} \mathrm{Btu} / \mathrm{h}\right)\end{array}$} & \multirow{2}{*}{$\begin{array}{l}\text { Duty } \\
(\%)\end{array}$} & \multirow{2}{*}{$\begin{array}{l}\text { Flow } \\
(\mathrm{lb} / \mathrm{h})\end{array}$} & \multicolumn{2}{|c|}{$\begin{array}{l}\text { Temperature } \\
\left({ }^{\circ} \mathrm{F}\right)\end{array}$} \\
\hline & & & & Inlet & Outlet \\
\hline $\begin{array}{l}\text { PFBC Evaporator } \\
\text { Water/Steam } \\
\text { CPFBC }\end{array}$ & 29.73 & 29.0 & 40,512 & $\begin{array}{r}507.6 \\
1600.0\end{array}$ & $\begin{array}{r}517.6 \\
1600.0\end{array}$ \\
\hline $\begin{array}{l}\text { PFBC Superheater } \\
\text { Steam } \\
\text { CPFBC }\end{array}$ & 15.14 & 14.8 & 82,260 & $\begin{array}{r}517.6 \\
1600.0\end{array}$ & $\begin{array}{r}753.2 \\
1600.0\end{array}$ \\
\hline $\begin{array}{l}\text { HRSG Economizer } \\
\text { Water } \\
\text { HRSG Gas }\end{array}$ & 24.98 & 24.4 & $\begin{array}{r}83,091 \\
256,558\end{array}$ & $\begin{array}{l}571.6 \\
640.0\end{array}$ & $\begin{array}{l}507.6 \\
280.1 \\
\end{array}$ \\
\hline $\begin{array}{l}\text { HRSG Evaporator } \\
\text { Water/Steam } \\
\text { HRSG Gas }\end{array}$ & 31.24 & 30.5 & $\begin{array}{r}42,579 \\
256,558\end{array}$ & $\begin{array}{r}507.6 \\
1066.0\end{array}$ & $\begin{array}{l}517.6 \\
640.0\end{array}$ \\
\hline $\begin{array}{l}\text { Screw Cooler } \\
\text { Water } \\
\text { Ash }\end{array}$ & 1.37 & 1.3 & $\begin{array}{l}9,420 \\
3,851\end{array}$ & $\begin{array}{r}\vdots \\
55.1 \\
1132.4 \\
\end{array}$ & $\begin{array}{l}200.0 \\
300.0 \\
\end{array}$ \\
\hline Heat Exchanger Total & 102.45 & 100.0 & & & \\
\hline
\end{tabular}




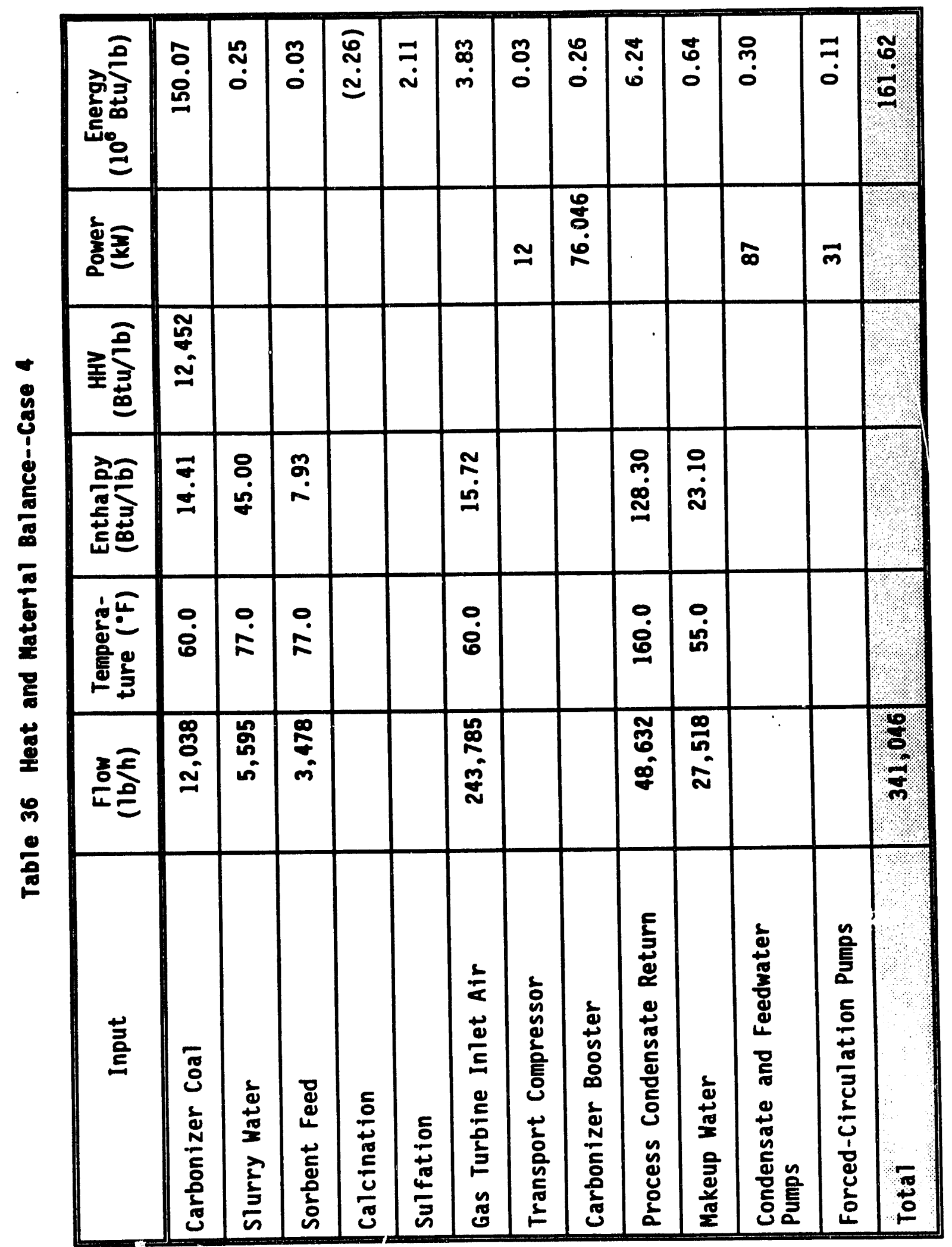




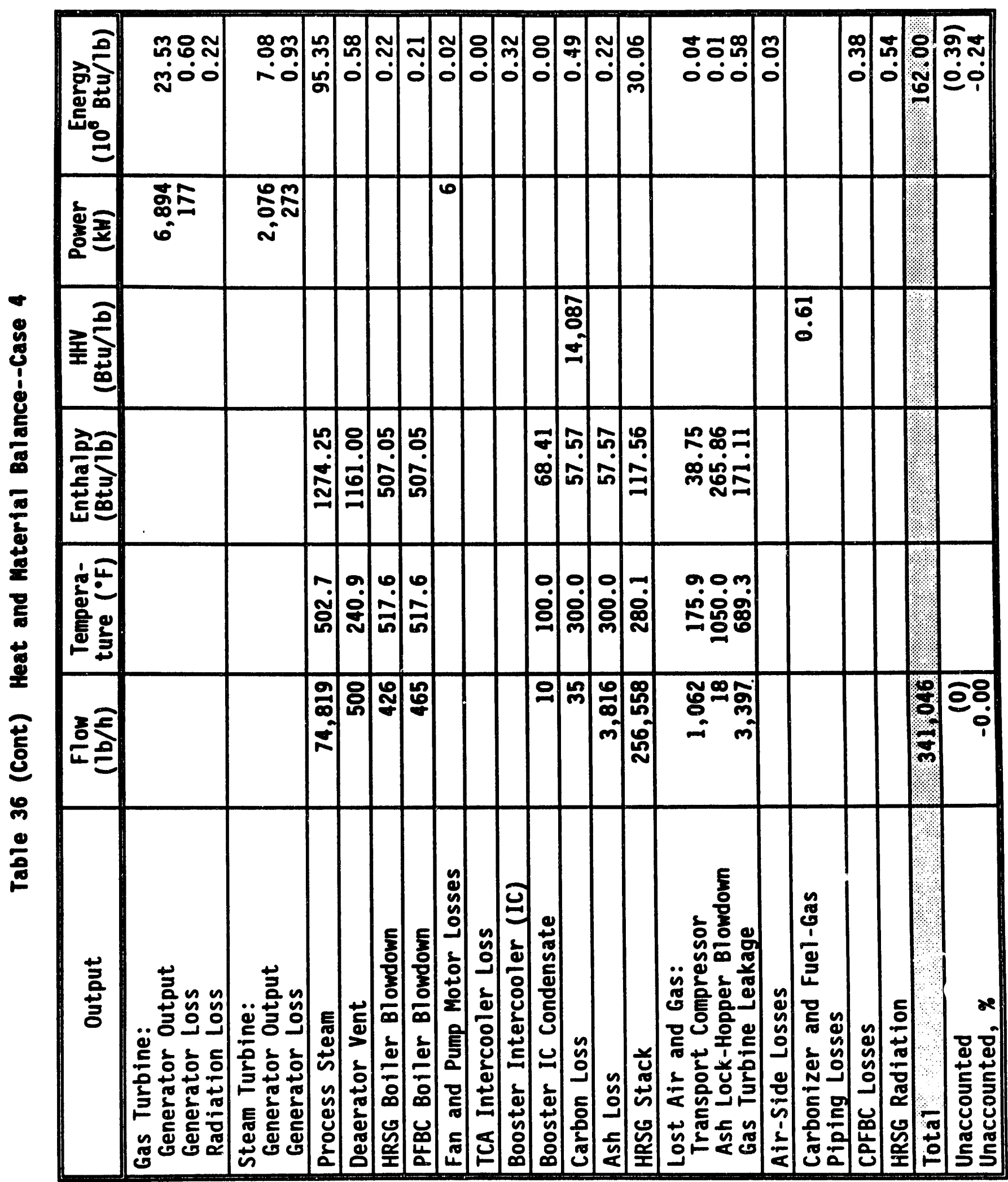




\subsubsection{Plant Capital Cost}

The capital requirements of the plant are tabulated in Table 37. The assumptions and methods used to estimate these costs are described in Section 6 .

\subsubsection{Plant Operating Costs}

Annual operating costs were estimated from the costs of fue?, feedstocks, plant labor, maintenance, and other items listed in Table 38.

The total annual operating cost and fixed costs associated with the total capital requirements are key components of the levelized cost of steam. The steam costs of all systems are compared in Section 6. 


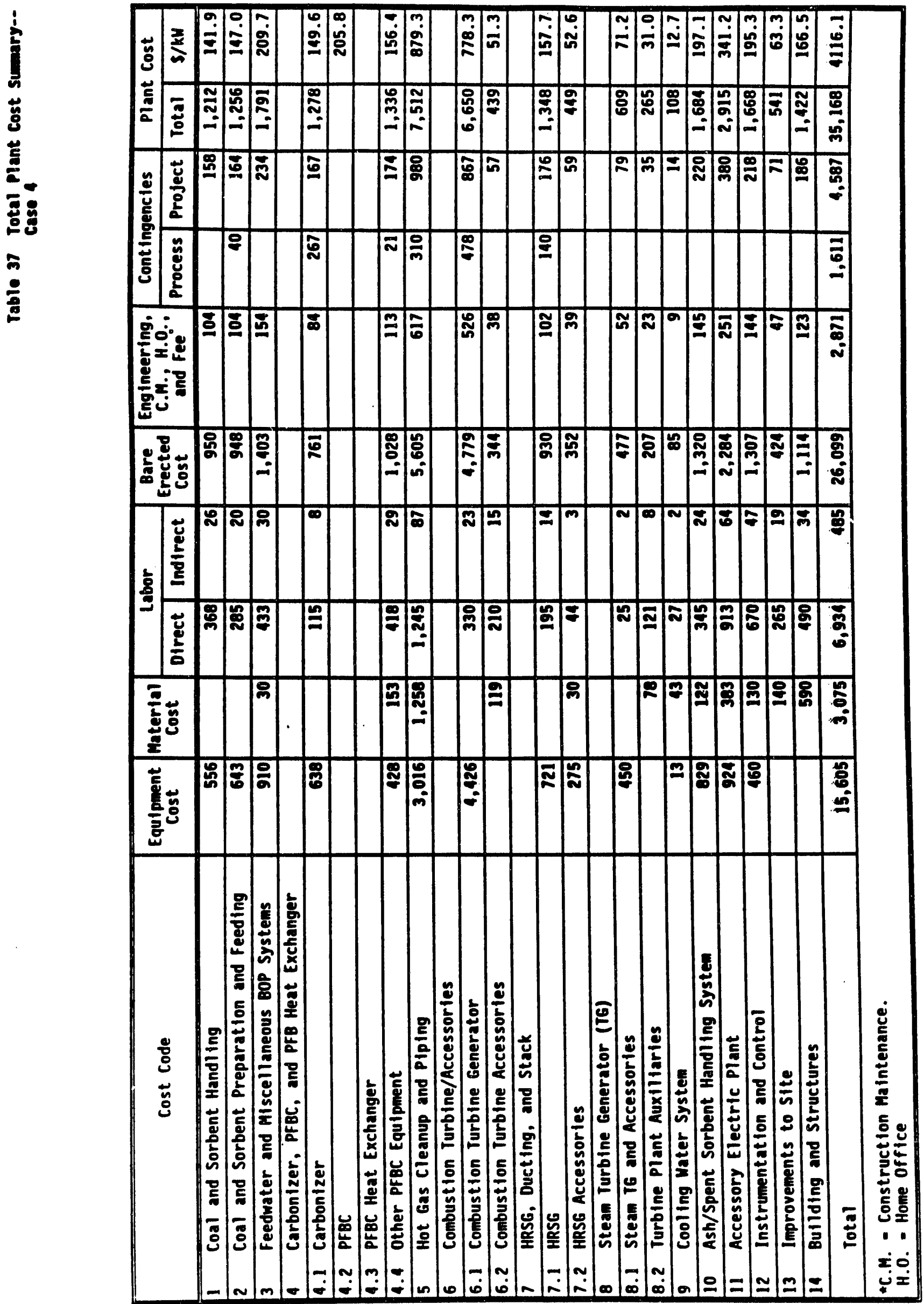


Table 38 Annual Operating Costs--Case 4 (Capacity Factor - 80\%)

\begin{tabular}{|c|c|c|c|}
\hline Cost Categories & Quantity & $\begin{array}{c}\text { Unit } \\
\text { Price, } s\end{array}$ & $\begin{array}{l}\text { Total } \\
\$ \times 10^{3}\end{array}$ \\
\hline Fuel: Pittsburgh No. 8 Coal & $\begin{array}{l}12,038 \mathrm{lb} / \mathrm{h} \\
149.910^{6} \mathrm{Btu} / \mathrm{h}\end{array}$ & $1.50 / 10^{\circ} \mathrm{Btu}$ & 1,566 \\
\hline $\begin{array}{l}\text { Consumable Materials: } \\
\text { Dolomite } \\
\text { Nitrogen } \\
\text { Raw Water } \\
\text { Water Treatment Chemicals } \\
\text { (40\% of water cost) }\end{array}$ & $\begin{array}{l}1.7 \mathrm{t} / \mathrm{h} \\
120 \mathrm{sft}^{3} / \mathrm{min} \\
62.5 \mathrm{gal} / \mathrm{min}\end{array}$ & $\begin{array}{l}18.80 / \mathrm{t} \\
0.29 / 100 \mathrm{sft}^{3} \\
0.75 / 1000 \mathrm{gal}\end{array}$ & $\begin{array}{r}229 \\
146 \\
20 \\
8\end{array}$ \\
\hline Ash Disposal Costs & $1.93 \mathrm{t} / \mathrm{h}$ & $9.75 / t$ & 132 \\
\hline $\begin{array}{l}\text { Plant Labor: } \\
\text { Operators } \\
\text { Supervision and Clerical } \\
\text { (20\% of O\&M) }\end{array}$ & $7 /$ shift & $24.65 / h$ & $\begin{array}{r}1,209 \\
432\end{array}$ \\
\hline Maintenance Costs & & & 950 \\
\hline Total Operating Costs. & & & 4,692 \\
\hline
\end{tabular}


Case 5 is a smaller plant without a steam turbine, similar in configuration to the larger Case 2 .

\subsubsection{Plant Description}

The second-generation PFBC cogeneration plant is designed to produce process steam as the main product and electric power as a byproduct. An airblown carbonizer converts coal/sorbent/water slurry into a low-Btu fuel gas for a gas turbine topping combustor. The char produced by the carbonizer is burned in a PFBC, preheating some of the topping combustor oxidant and also generating steam. The fuel gas from the carbonizer is burned in the topping combustor of a gas turbine.

Steam is generated by an HRSG at the gas turbine exit and by heat exchanger surface in the PFBC. The steam is sent to process.

Figure 65 is a process flow diagram of the plant, showing the functional arrangement of the major plant systems. The major systems are described in more detail below.

- Slurry Preparation System

- Carbonizer

- PFB Combustor

- Ash Cooling and Disposal
- Compressed Air System

- Topping Combustor and Combustion Turbine

- Heat Recovery Steam Generator

- Condensate System

Slurry Preparation System. Raw coal is fed by two Gravimetric feeders to a crusher, where it is crushed, screened, and dropped into slurry tanks with agitators. Sized dolomite sorbent is screened and added to the slurry tanks. Water is added to give a coal/water ratio of $70: 30$ by weight.

After leaving this holding tank, the coal/sorbent/water slurry is pumped to the carbonizer, where it is atomized by compressed air and injected into the vesse1.

Carbonizer. In this cogeneration arrangement, all of the slurry is used by the carbonizer to make fuel gas for the topping combustor. In the fluidized carbonizer, the coal and sorbent are converted into a low-Btu gas and a mixed solid containing char and spent sorbent. Both the carbonizer and the PFBC operate at $1600^{\circ} \mathrm{F}$.

Char and spent sorbent are separated from the carbonizer fuel gas at three locations. An overflow drain in the carbonizer allows solids to fall 10 a collecting hopper. This hopper also receives solids collected by cyclones and by ceramic cross-flow filters in the fuel gas cleanup system. Solids from the collecting hopper are fed to the CPFBC by " $N$ " valves, which are kept fluidized with a small flow of nitrogen. 


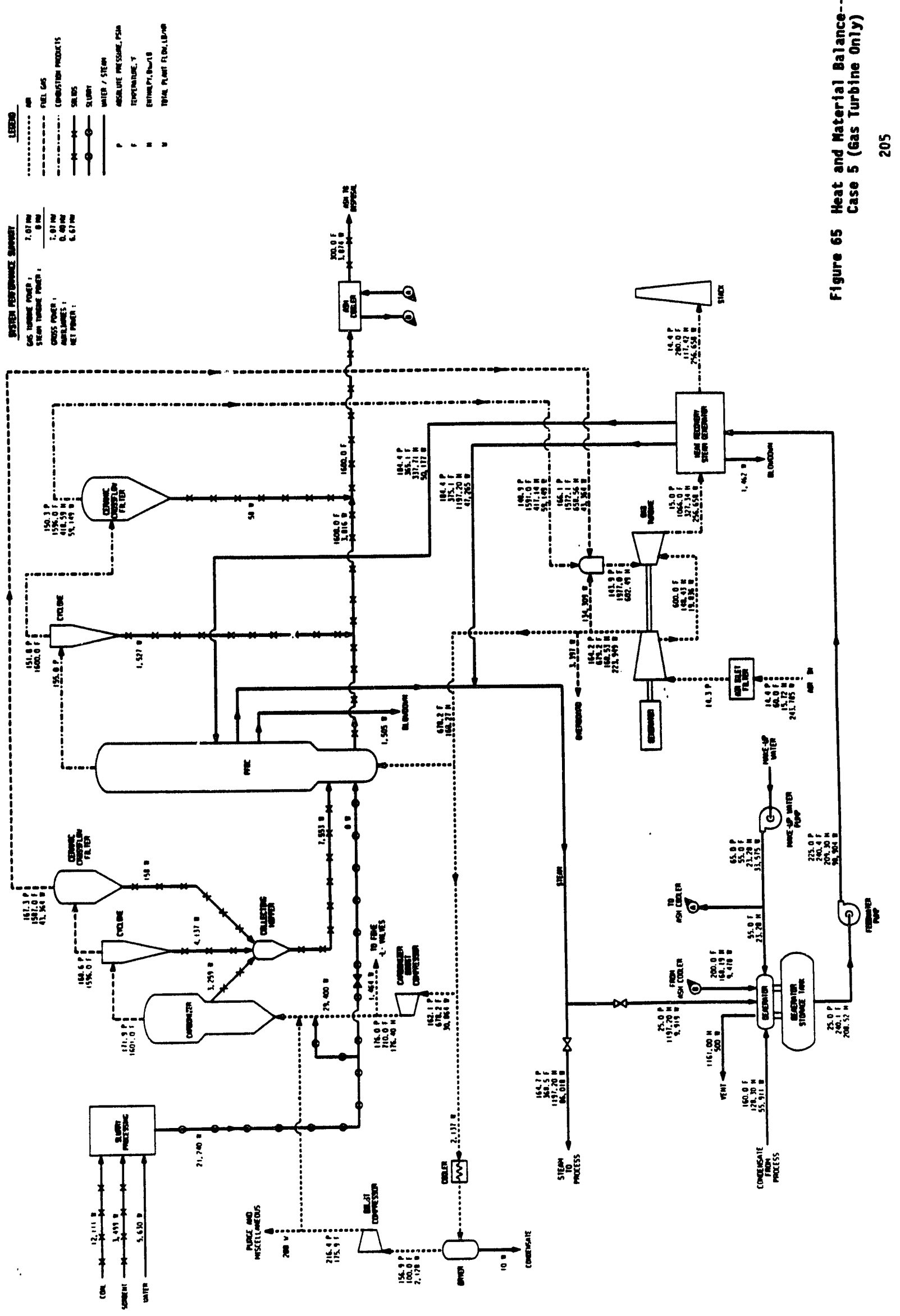


PFB Combustor. The PFBC receives all the char/sorbent mixture from the carbonizer. The PFBC is designed to operate with 40 -percent excess air at $1600^{\circ} \mathrm{F}$. The corresponding plant excess air is 110 percent. The air that does not go to the PFBC goes directly to the topping combustor. This type of process arrangement ensures the maximum steam production.

Heat-transfer surface in the PFBC generates 44 percent of the plant steam duty. The combustion products of the PFBC are cleaned by cyclones and ceramic cross-flow filters. The solids collected in the gas cleanup equipment and the solids drained from the bed go to the ash disposal system.

Ash Cooling and Disposal. Excess solids from the PFBC are extracted from the heat exchanger at $1600^{\circ} \mathrm{F}$ and depressured through an RPD vessel, then cooled in a screw cooler. Solids collected by the cross-flow filters are also depressurized in the RPD vessels, and then cooled in screw coolers.

Compressed Air system. Except for turbine cooling flows required by the gas turbine, all of the air produced by the gas turbine compressor is collected from the compressor discharge and ducted to the carbonizer/CPFBC area. This air, pressurized to 11 atm/689 $\mathrm{F}$, supplies three subsystems:

- Booster compressors, which provide pressurizing and atomizing air at 50 psi above the carbonizer entry pressure. The air is cooled and dried before being compressed by the boost compressors.

- Carbonizer booster compressors, which provide secondary air to the carbonizers. These compressors provide the carbonizer oxidant, and are needed to ensure that the fuel gas will have adequate pressure above the vitiated oxidant at the topping combustors. These compressors are not precooled.

- PFBC combustion air.

Topping Combustor and Combustion Turbine. Clean fuel gas from the carbonizers and the vitiated air product of the CPFBCs are conveyed to the gas turbine by ceramic-insulated hot gas piping. These pipes have metallic liners on the inner diameter to protect the turbine from eroded ceramic material. A carbon steel outer liner strengthens these pipes structurally.

The fuel gas and vitiated air are oxidized in the topping combustor of the gas turbine. The nominal exit temperature of the combustor is $1977^{\circ} \mathrm{F}$. Combustion products expand through the expander section of the gas turbine, producing about 7 MW (net) in the gas turbine unit.

Heat Recovery Steam Generator. The gas exiting the gas turbine flows through an HRSG, where it is cooled to $280^{\circ} \mathrm{F}$ by producing steam and heated feedwater. Gas from the HRSG is then ducted to the stack.

The HRSG and PFBC are closely tied in steam production. The HRSG provides all of the economizing and a small portion of the evaporating duty, and the PFBC provides the rest of the evaporating duty.

Together, the PFBC and HRSG provide about 99 percent of the required steam energy. The remaining 1 percent of steam thermal input is provided by the ash screw coolers in the form of condensate heating. 
Condensate system. Heating and deaeration of low-pressure condensate is provided primarily by extraction steam. The deaerator operates at 25 psia/ $240^{\circ} \mathrm{F}$. About 15 percent of the condensate is diverted around the feedwater heater to cool the ash screw coolers. The hot water leaving the screw coolers is discharged directly into the deaerator.

Water from the deaerator is pressurized by electrically driven booster pumps and feedwater pumps. Two 60-percent capacity pump trains are provided. The feedwater flow is heated by the HRSG economizer sections to $365^{\circ} \mathrm{F}$.

Feedwater leaving the HRSG economizer is split into two streams. The first stream feeds the high-pressure drum in the HRSG. The water is evaporated in the HRSG and piped over to the PFBC and mixed with steam produced there. The rest of the feedwater is piped to the evaporator in the PFBC, where it is heated to steam. This dry, saturated steam is then sent to process.

\subsubsection{Plant Performance}

The second-generation PFBC cogeneration plant has an overall thermal efficiency of 78.1 percent, based on the HHV of coal. Table 39 summarizes plant performance. Table 40 lists the plant auxiliary power requirements.

Steam-generating heat exchangers are located in the PFBC vessel of the fluidized bed combustor, in the HRSG at the exhaust end of the gas turbine, and in the ash screw coolers. Thermal performance parameters for these exchangers are tabulated in Table 41.

Table 42. lists the heat and material balance for the entire plant. 
Table 39 Plant Summary Performance Data--Case 5

\begin{tabular}{|l|r|r|r|r|r|}
\hline \multicolumn{1}{|c|}{ Description } & $\begin{array}{c}\text { Flow } \\
(1 \mathrm{~b} / \mathrm{h})\end{array}$ & $\begin{array}{c}\text { Enthalphy } \\
(\mathrm{Btu} / \mathrm{Ib})\end{array}$ & $\begin{array}{c}\text { Power } \\
(\mathrm{kW})\end{array}$ & $\begin{array}{c}\text { Energy } \\
\left(10^{6} \mathrm{Btu} / \mathrm{h}\right)\end{array}$ & $\begin{array}{c}\text { Energy } \\
\text { Output }(\%)\end{array}$ \\
\hline Process Steam & 86,018 & $1,197.20$ & & 102.98 & \\
\hline (Returned Condensate) & $(55,911)$ & 128.30 & & $(7.17)$ & \\
\hline (Makeup Water) & $(33,573)$ & 23.10 & & $(0.78)$ & 81 \\
\hline Steam Energy Output & & & & 95.03 & \\
\hline Gas Turbine Power & & & 7,073 & & \\
\hline Steam Turbine Power & & & 0 & & \\
\hline Plant Auxiliaries & & & $(398)$ & & 19 \\
\hline Electric Power Output & & & 6,675 & 22.78 & \\
\hline Total Energy Output & & & & 117.81 & 100 \\
\hline Coal Energy Input (HHV) & 12,111 & 12,452 & & 150.81 & \\
\hline $\begin{array}{l}\text { Natural Gas Energy } \\
\text { Input }\end{array}$ & 0 & 21,813 & & 0.00 & \\
\hline Total Energy Input & & & & 150.81 & \\
\hline Net Thermal Efficiency & & & & & 78.12 \\
\hline
\end{tabular}

Table 40 Auxiliary Summary--Case 5

\begin{tabular}{|l|r|}
\hline \multicolumn{1}{|c|}{ Item } & kH \\
\hline Transport Booster Compressor & 12 \\
\hline Carbonizer Booster Compressor & 76 \\
\hline Condensate Pumps & 2 \\
\hline Feedwater Pumps & 23 \\
\hline Boiler Forced-Circulation Pumps & 46 \\
\hline Circulating Hater Pumps & 1 \\
\hline Gas Turbine Auxiliaries & 50 \\
\hline Steam Turbine Auxiliaries & 31 \\
\hline Unloading and Stacker/Reclaimer & 6 \\
\hline Coal Handl ing & 3 \\
\hline Dolomite Handling & 29 \\
\hline Coal and Sorbent Feed & 30 \\
\hline Ash Cool ing and Handling & 22 \\
\hline Slurry Preparation & 35 \\
\hline Service Water & 4 \\
\hline Miscellaneous & 27 \\
\hline Stepdown Transformer & 2 \\
\hline Total Auxiliaries & 399 \\
\hline
\end{tabular}


Table 41 Heat Exchanger Performance--Case 5

\begin{tabular}{|c|c|c|c|c|c|}
\hline \multirow{2}{*}{ Components } & \multirow{2}{*}{$\begin{array}{c}\text { Thermal } \\
\left(10^{\circ} \mathrm{Btu} / \mathrm{h}\right)\end{array}$} & \multirow{2}{*}{$\begin{array}{l}\text { Duty } \\
(\%)\end{array}$} & \multirow{2}{*}{$\begin{array}{l}\text { Flow } \\
(1 \mathrm{~b} / \mathrm{h})\end{array}$} & \multicolumn{2}{|c|}{$\begin{array}{c}\text { Temperature } \\
\left({ }^{\circ} \mathrm{F}\right)\end{array}$} \\
\hline & & & & Inlet & Outlet \\
\hline $\begin{array}{l}\text { PFBC Evaporator } \\
\text { Water/Steam } \\
\text { PFBC }\end{array}$ & 44.14 & 43.4 & 50,177 & $\begin{array}{r}365.1 \\
1600.0\end{array}$ & $\begin{array}{r}375.1 \\
1600.0\end{array}$ \\
\hline $\begin{array}{l}\text { HRSG Economizer } \\
\text { Water } \\
\text { Gas }\end{array}$ & 13.40 & 13.2 & $\begin{array}{r}98,904 \\
256,658\end{array}$ & $\begin{array}{r}240.4 \\
1066.0\end{array}$ & $\begin{array}{l}365.1 \\
475.0\end{array}$ \\
\hline $\begin{array}{l}\text { HRSG Evaporator } \\
\text { Water/Steam } \\
\text { Gas }\end{array}$ & 42.87 & 42.1 & $\begin{array}{r}48,727 \\
256,658\end{array}$ & $\begin{array}{r}365.1 \\
1066.0\end{array}$ & $\begin{array}{l}375.1 \\
475.0\end{array}$ \\
\hline $\begin{array}{l}\text { Screw Cooler } \\
\text { Water } \\
\text { Ash }\end{array}$ & 1.37 & 1.3 & $\begin{array}{l}9,478 \\
3,874\end{array}$ & $\begin{array}{r}55.1 \\
1132.4\end{array}$ & $\begin{array}{l}200.0 \\
300.0\end{array}$ \\
\hline Heat Exchanger Iotal. & 101.78 & 100.0 & & & \\
\hline
\end{tabular}




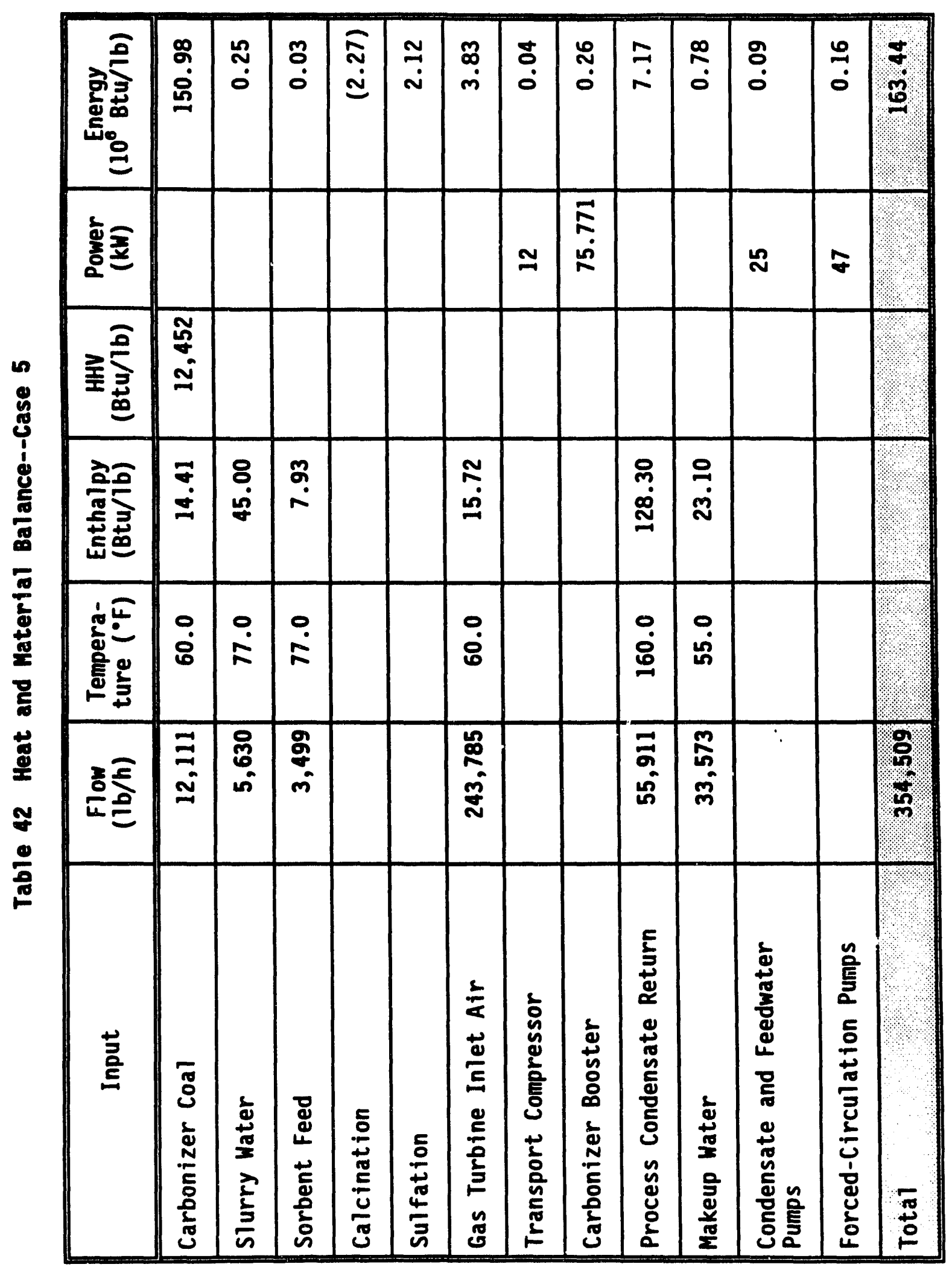




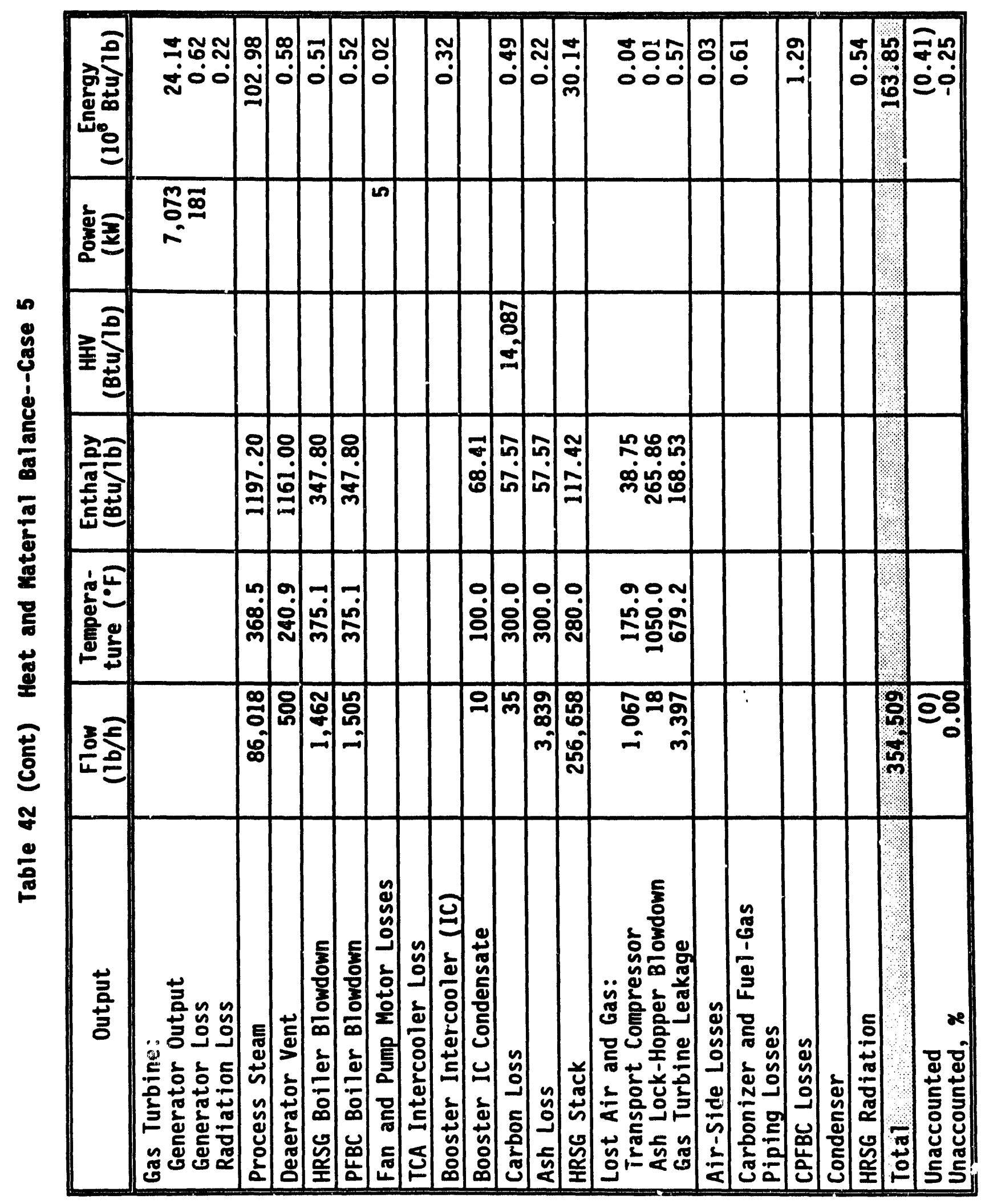




\subsubsection{Plant Capital Cost}

The capital requirements of the plant are given in Table 43 . The assumptions and methods used to estimate these costs are described in Section 6.

\subsubsection{Plant Operating Costs}

Annual operating costs were estimated from the costs of fuel, feedstocks, plant labor, maintenance, and other items as listed in Table 44.

The total annual operating cost and fixed costs associated with the total capital requirements are key components of the levelized cost of steam. The steam costs of all systems are compared in Section 6. 


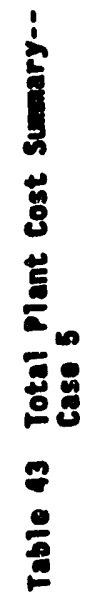

\begin{tabular}{|c|c|c|c|c|c|c|c|c|c|c|c|c|c|c|c|c|}
\hline 苟 & 趇 & 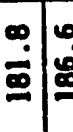 & 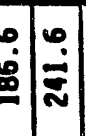 & $\left.\mid \begin{array}{l}0 \\
\vdots \\
\dot{\Xi} \\
\vdots\end{array}\right]$ & & 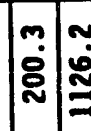 & | & ڤं & $\begin{array}{ll}0 \\
\vdots \\
\vdots \\
\vdots \\
\vdots\end{array}$ & \begin{tabular}{|l|l|l|} 
\\
$\dot{6}$
\end{tabular} & $=$ & $\overline{\mathrm{m}} \overrightarrow{\mathrm{N}}$ & $\overrightarrow{0}$ & & $\mid \begin{array}{l}\mid \\
0 \\
\dot{\omega} \\
\end{array}$ & 省 \\
\hline 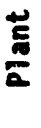 & ప్ & בְ: & & 拳: & & 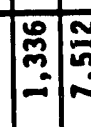 & & 屌 & & $=$ & 聪 & 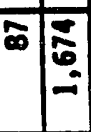 & $\begin{array}{l}2 \\
2 \\
\sim\end{array}$ & $=$ & : & $\begin{array}{l}\bar{m} \\
\bar{m} \\
\bar{m} \\
\bar{m}\end{array}$ \\
\hline$\frac{\Sigma}{u}$ & 总 & 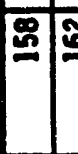 & & : & & $\equiv$ & 离 & 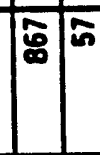 & $\underline{\Omega}$ & ब高 & 周: & $=\underset{\sim}{\infty}$ & 莌 & 28 & : & $\overline{\mathbf{m}}$ \\
\hline & 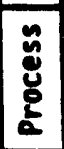 & & $\bar{p}$ & : & & $\approx$ & $\frac{9}{m}$ & \begin{tabular}{|l|}
$\mathscr{Q}$ \\
\end{tabular} & 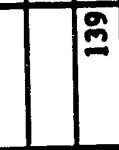 & a) & & & & & & 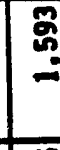 \\
\hline
\end{tabular}

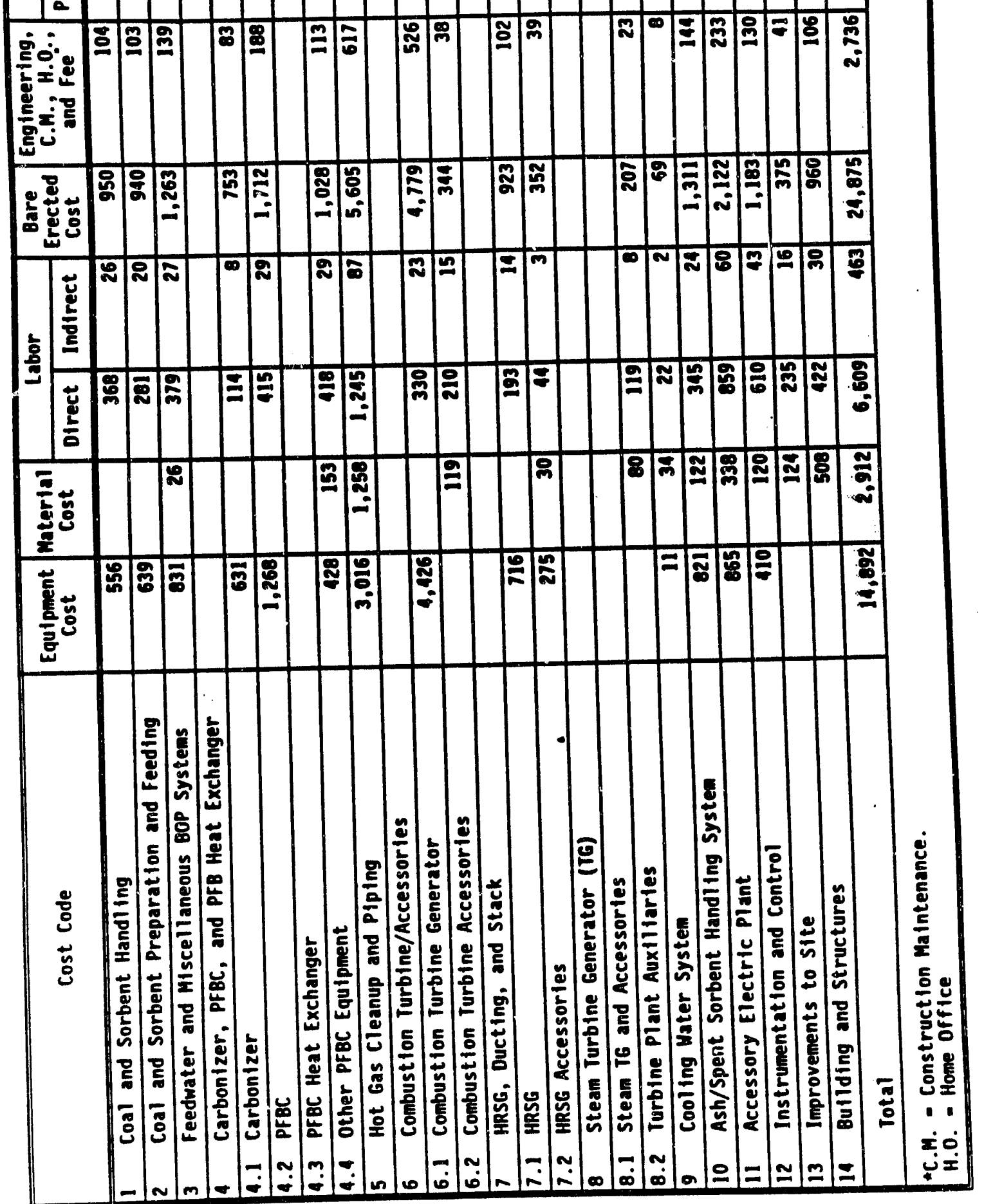


Table 44 Annual Operating Costs--Case 5 (Capacity Factor = 80\%)

\begin{tabular}{|c|c|c|c|}
\hline Cost Categories & Quantity & $\begin{array}{l}\text { Unit } \\
\text { Price, s }\end{array}$ & $\begin{array}{l}\text { Total } \\
5 \times 10^{3}\end{array}$ \\
\hline Fuel: Pittsburgh No. 8 Coal & $\begin{array}{l}12,111 \mathrm{lb} / \mathrm{h} \\
150.81 \\
10^{8}\end{array}$ & $1.50 / 10^{3} \mathrm{Btu}$ & 1,585 \\
\hline $\begin{array}{l}\text { Consumable Materials: } \\
\text { Dolomite } \\
\text { Nitrogen } \\
\text { Raw Water } \\
\text { Water Treatment Chemicals } \\
\text { (40\% of water cost) }\end{array}$ & $\begin{array}{l}1.94 \mathrm{t} / \mathrm{h} \\
120 \mathrm{sft}^{3} / \mathrm{min}^{2} \\
78 \mathrm{gal} / \mathrm{min}^{2}\end{array}$ & $\begin{array}{l}18.80 / \mathrm{t} \\
0.29 / 100 \mathrm{sft}^{3} \\
0.75 / 1000 \mathrm{gal}\end{array}$ & $\begin{array}{r}256 \\
146 \\
25 \\
10\end{array}$ \\
\hline Ash Disposal Costs & $1.94 \mathrm{t} / \mathrm{h}$ & $9.75 / t$ & 133 \\
\hline $\begin{array}{l}\text { Plant Labor: } \\
\text { Operators } \\
\text { Supervision and Clerical } \\
\text { (20\% of 0\&M) }\end{array}$ & $6 /$ shift & $24.65 / \mathrm{h}$ & $\begin{array}{r}1,036 \\
392\end{array}$ \\
\hline Maintenance Costs & & & 924 \\
\hline Total Operating costs & & & 4,507 \\
\hline
\end{tabular}


Case 6 is similar to Case 4, except that the topping combustor is fueled by natural gas instead of coal gas, eliminating the need for the carbonizer. Since this plant has a topping combustor (a "second-generation" feature) but does not have a carbonizer (a "first-generation" arrangement), Case 6 has been dubbed the "1-1/2 generation" case.

\subsubsection{Plant Description}

The 1-1/2 generation PFBC cogeneration plant is designed to produce process steam as the main product and electric power as a byproduct. Coal/ sorbent/water slurry is burned in a PFBC, preheating the topping combustor oxidant and generating steam. Natural gas is burned in the topping combustor of a gas turbine.

Steam is also generated by an HRSG at the gas turbine exit. This steam is sent to the PFBC. The steam leaving the PFBC is expanded through a back-pressure turbine and then sent to process.

Figure 66 is a process flow diagram of the plant, showing the functional arrangement of the major plant systems. The major systems are described in more detail below.

- Slurry Preparation System

- Circulating PFB Combustor

- Ash Cooling and Disposal

- Compressed Air System
- Topping Combustor and Combustion Turbine

- Heat Recovery Steam Generator

- Back-Pressure Steam Turbine

- Condensate System

Slurry Preparation System. Raw coal is fed by two gravimetric feeders to a crusher, where it is crushed, screened, and dropped into slurry tanks with agitators. Sized dolomite sorbent is screened and added to the slurry tanks. Water is added to give a coal/water ratio of $70: 30$ by weight.

After leaving this holding tank, the coal/sorbent/water slurry is pumped to both the carbonizer and the PFBC, where it is atomized by compressed air and injected into the vessels.

PFB Combustor. The PFBC receives all of the coal/sr,rbent slurry as fuel. The PFBC is designed to operate with 40-percent excess air at $1600^{\circ} \mathrm{F}$. The corresponding plant excess air is 90 percent. Most of the air that does not go to the PFBC goes directly to the topping combustor.

Heat-transfer surface in the PFBC is used to generate 51 percent of the steam duty. The combustion products of the PFBC are cleaned by cyclones and ceramic cross-flow filters. The solids collected in the gas cleanup equipment and the solids drained from the bed go to the ash disposal system. 


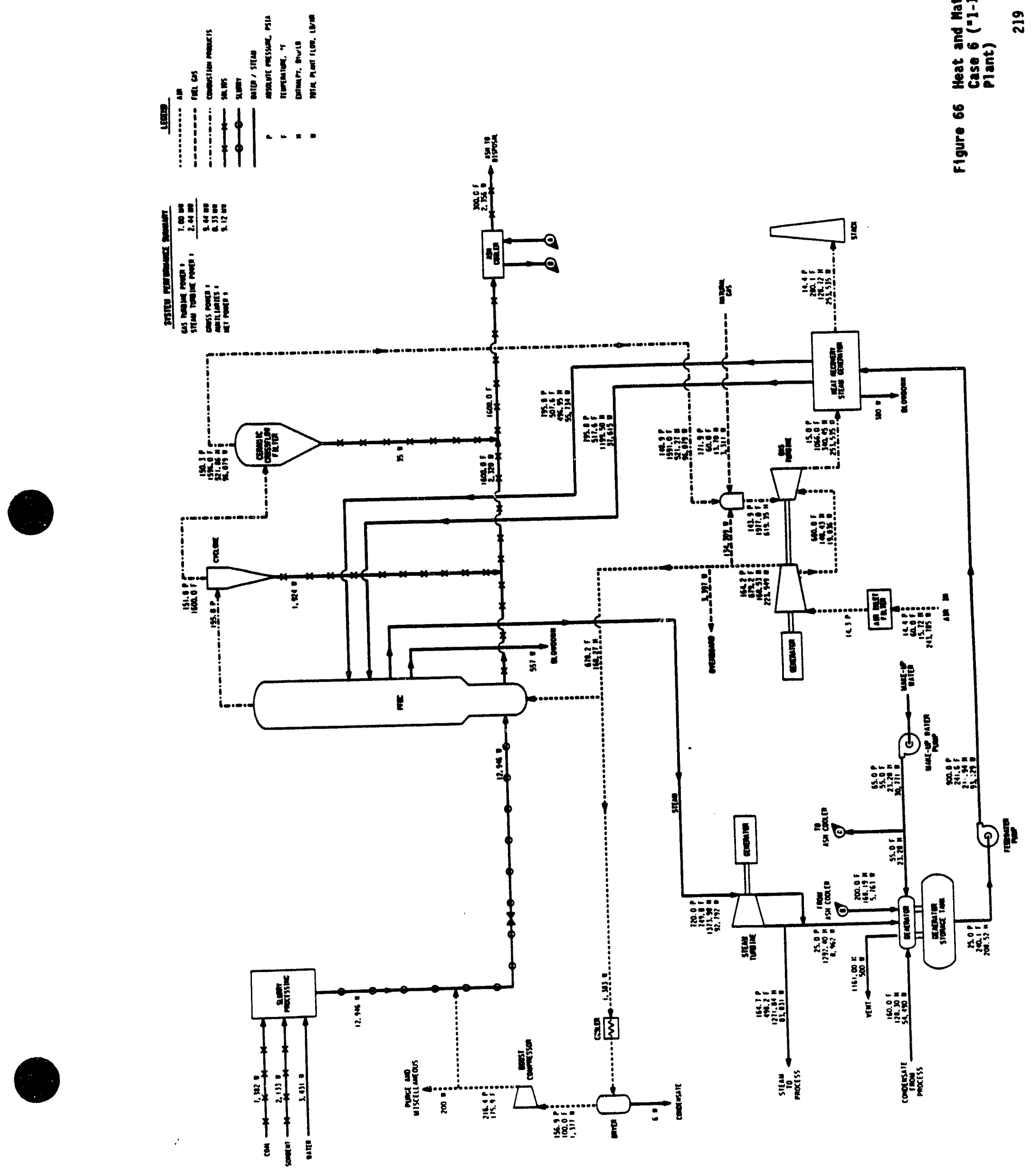


Ash Cooling and Disposal. Excess solids from the PFBC are extracted from the heat exchanger at $1600^{\circ} \mathrm{F}$, depressured through an RPD vessel and then cooled in a screw cooler. Solids collected by the cross-flow filters are also depressured in the RPD vessels and then cooled in screw coolers.

Compressed Air system. Except for turbine cooling flows and bypass flows required by the gas turbine, all of the air produced by the gas turbine compressor is collected from the compressor discharge and ducted to the PFBC area. This air, pressurized to 11 atm $/ 689^{\circ} \mathrm{F}$, supplies two subsystems:

- Booster compressors, which provide pressurizing and atomizing air at 50 psi above the carbonizer entry pressure. The air is cooled and dried before being compressed by the booster compressors.

- PFBC combustion air.

Topping Combustor and Combustion Turbine. The vitiated air product of the PFBC is conveyed to the gas turbine by ceramic-insulated hot gas piping. These pipes have metallic liners on the inner diameter to protect the turbine from eroded ceramic material. A carbon steel outer liner strengthens these pipes structurally.

Natural gas and vitiated air are oxidized in the topping combustor of the gas turbine. The nominal exit temperature of the combustor is $1977^{\circ} \mathrm{F}$. Combustion products expand through the expander section of the gas turbine, producing about $7 \mathrm{MW}$ (net) in the gas turbine unit.

Heat Recovery Steam Generator. The gas exiting the gas turbine flows through an HRSG, where it is cooled to $280^{\circ} \mathrm{F}$ by producing steam and heated feedwater. Gas exiting the HRSG is then ducted to the stack.

The HRSG and PFBC are closely tied in steam production. The HRSG provides all of the economizing and a small position of the evaporating duty, and the PFBC provides the rest of the evaporating duty and any required superheat.

Together, the PFBC and HRSG provide about 99 percent of the required steam energy. The remaining 1 percent of steam cycle thermal input is provided by the ash screw coolers in the form of condensate heating.

Back-Pressure Steam Turbine. The steam is expanded through a backpressure steam turbine before being released to process. The turbire is a 700-psig unit with a throttle inlet temperature of $750^{\circ} \mathrm{F}$. The turbine exhaust pressure is slightly above the required process steam pressure of 150 psig.

Condensate System. Heating and deaeration of low-pressure condensate is provided primarily by extraction steam. The deaerator operates at $25 \mathrm{psia/}$ $240^{\circ} \mathrm{F}$. About 15 percent of the condensate is diverted around the feedwater heater to cool the ash screw coolers. The hot water leaving the screw coolers is discharged directly into the deaerator.

Water from the deaerator is pressurized by electrically driven booster pumps and feedwater pumps. Two 60-percent capacity pump trains are provided. The feedwater flow is heated by the HRSG economizer sections to $507^{\circ} \mathrm{F}$.

Feedwater leaving the HRSG economizer is split into two streams. The first stream feeds the high-pressure drum in the HRSG. The water is evaporated in the HRSG, piped over to the PFBC, and mixed with steam produced 
there. The rest of the feedwater is piped to the evaporator in the PFBC, where it is heated to steam. The combined steam flow is superheated to $750^{\circ} \mathrm{F}$ for the steam turbine.

\subsubsection{Plant Performance}

The second-generation PFBC cogeneration plant has an overall thermal efficiency of 78.0 percent, based on the HHV of coal. Table 45 summarizes the performance of the plant. Table 46 lists the plant auxiliary power requirements.

Steam-generating heat exchangers are located in the PFBC, in the HRSG at the exhaust end of the gas turbine, and in the ash screw coolers. Thermal performance parameters for these exchangers are given in Table 47.

Table 48 lists the heat and material balance for the entire plant. 
Table 45 Plant Summary Performance Data--Case 6

\begin{tabular}{|l|r|r|r|r|r|r|}
\hline \multicolumn{1}{|c|}{ Description } & $\begin{array}{c}\text { Flow } \\
(\mathrm{ib} / \mathrm{h})\end{array}$ & $\begin{array}{c}\text { Enthalphy } \\
(\mathrm{Btu} / \mathrm{lb})\end{array}$ & $\begin{array}{c}\text { Power } \\
(\mathrm{KW})\end{array}$ & $\begin{array}{c}\text { Energy } \\
\left(10^{6} \mathrm{Btu} / \mathrm{h}\right)\end{array}$ & $\begin{array}{c}\text { Energy } \\
(\mathrm{MW})\end{array}$ & $\begin{array}{c}\text { Energy Out- } \\
\text { put }(\mathrm{x})\end{array}$ \\
\hline Process Steam & 72,863 & $1,274.80$ & & 92.89 & 27.22 & \\
\hline (Returned Condensate) & $(47,361)$ & 128.30 & & $(6.08)$ & $(1.78)$ & \\
\hline (Makeup Water) & $(26,818)$ & 23.10 & & $(0.62)$ & $(0.18)$ & \\
\hline Steam Energy Output & & & & 86.19 & 25.26 & 74.83 \\
\hline Gas Turbine Power & & & 6,752 & & 6.75 & \\
\hline Steam Turbine Power & & & 2,022 & & 2.02 & \\
\hline Plant Auxiliaries & & & $(278)$ & & $10.28)$ & \\
\hline Electric Power Output & & & 8,496 & 29.00 & 8.50 & 25.17 \\
\hline Total Energy Output & & & & 115.19 & 33.75 & 100.00 \\
\hline Coal Energy Input (HHV) & 6,092 & 12,452 & & 75.86 & 22.23 & 51.39 \\
\hline Natural Gas Energy Input & 3,289 & 21,813 & & 71.74 & 21.02 & 48.61 \\
\hline Total Energy Input & & & & 147.60 & 43.25 & 100.00 \\
\hline Net Thermal Efficiency & & & & & & 78.04 \\
\hline
\end{tabular}

Table 46 Auxiliary Summary--Case 6

\begin{tabular}{|l|r|}
\hline \multicolumn{1}{|c|}{ Item } & \multicolumn{1}{|c|}{ kW } \\
\hline Transport Booster Compressor & 6 \\
\hline Condensate Pumps & 2 \\
\hline Feedwater Pumps & 84 \\
\hline Boiler Forced-Circulation Pumps & 30 \\
\hline Gas Turbine Auxil laries & 50 \\
\hline Steam Turbine Auxil laries & 26 \\
\hline Rail Unloading and Stacker/Reclaimer & 3 \\
\hline Coal Handling & 1 \\
\hline Dolomite Handling & 15 \\
\hline Coal and Sorbent Feed & 15 \\
\hline Ash Cooling and Handling & 11 \\
\hline Slurry Preparation & 18 \\
\hline Service Water & 2 \\
\hline Misrellaneous & 14 \\
\hline Stepdown Transformer & 1 \\
\hline Total Auxiliaries & 278 \\
\hline
\end{tabular}


Table 47 Heat Exchanger Performance--Case 6

\begin{tabular}{|c|c|c|c|c|c|}
\hline \multirow{2}{*}{ Components } & \multirow{2}{*}{$\begin{array}{c}\text { Thermal } \\
\left(10^{6} \mathrm{Btu} / \mathrm{h}\right)\end{array}$} & \multirow{2}{*}{$\begin{array}{l}\text { Duty } \\
(\%)\end{array}$} & \multirow{2}{*}{$\begin{array}{l}\text { Flow } \\
(1 \mathrm{~b} / \mathrm{h})\end{array}$} & \multicolumn{2}{|c|}{$\begin{array}{c}\text { Temperature } \\
\left({ }^{\circ} \mathrm{F}\right)\end{array}$} \\
\hline & & & & Inlet & Outlet \\
\hline $\begin{array}{l}\text { PFBC Evaporator } \\
\text { Water/Steam } \\
\text { PFBC }\end{array}$ & 28.93 & 29.0 & 39,427 & $\begin{array}{r}507.6 \\
1600.0\end{array}$ & $\begin{array}{r}517.6 \\
1600.0\end{array}$ \\
\hline $\begin{array}{l}\text { PFBC Superheater } \\
\text { Steam } \\
\text { PFBC }\end{array}$ & 14.86 & 14.9 & 80,719 & $\begin{array}{r}517.6 \\
1600.0\end{array}$ & $\begin{array}{l}1002.0 \\
1600.0\end{array}$ \\
\hline $\begin{array}{l}\text { PFBC Reheater } \\
\text { Steam } \\
\text { PFBC }\end{array}$ & & & & 1600.0 & $\begin{array}{l}1002.0 \\
1600.0\end{array}$ \\
\hline $\begin{array}{l}\text { HRSG Economizer } \\
\text { Water } \\
\text { Gas }\end{array}$ & 24.51 & 24.5 & $\begin{array}{r}81,534 \\
251,757\end{array}$ & $\begin{array}{l}241.6 \\
638.2\end{array}$ & $\begin{array}{l}507.6 \\
280.0\end{array}$ \\
\hline $\begin{array}{l}\text { HRSG Evaporator } \\
\text { Water/Steam } \\
\text { Gas }\end{array}$ & 30.90 & 30.9 & $\begin{array}{r}42,107 \\
251,757\end{array}$ & $\begin{array}{r}507.6 \\
1066.0\end{array}$ & $\begin{array}{l}517.6 \\
638.2\end{array}$ \\
\hline $\begin{array}{l}\text { HRSG Superheater } \\
\text { Steam } \\
\text { Gas }\end{array}$ & & & 251,757 & $\begin{array}{r}517.6 \\
1066.0\end{array}$ & $\begin{array}{r}750.0 \\
1066.0\end{array}$ \\
\hline $\begin{array}{l}\text { Screw Cooler } \\
\text { Water } \\
\text { Ash }\end{array}$ & 0.69 & 0.7 & $\begin{array}{l}4,756 \\
1,944\end{array}$ & $\begin{array}{r}55.1 \\
1600.0\end{array}$ & $\begin{array}{l}200.0 \\
300.0\end{array}$ \\
\hline Heat Exchanger Tota1 & 99.88 & 100.0 & & & \\
\hline
\end{tabular}




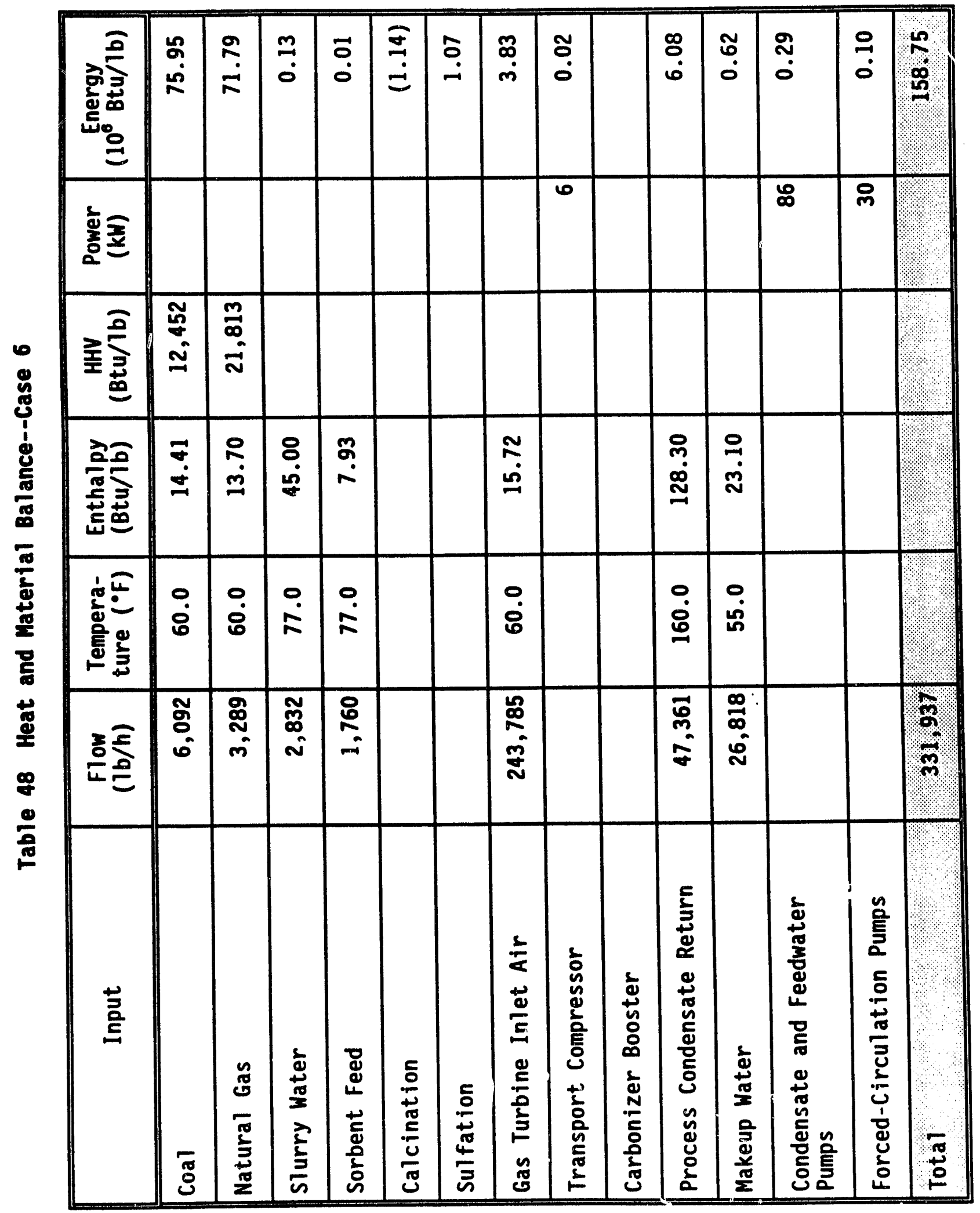




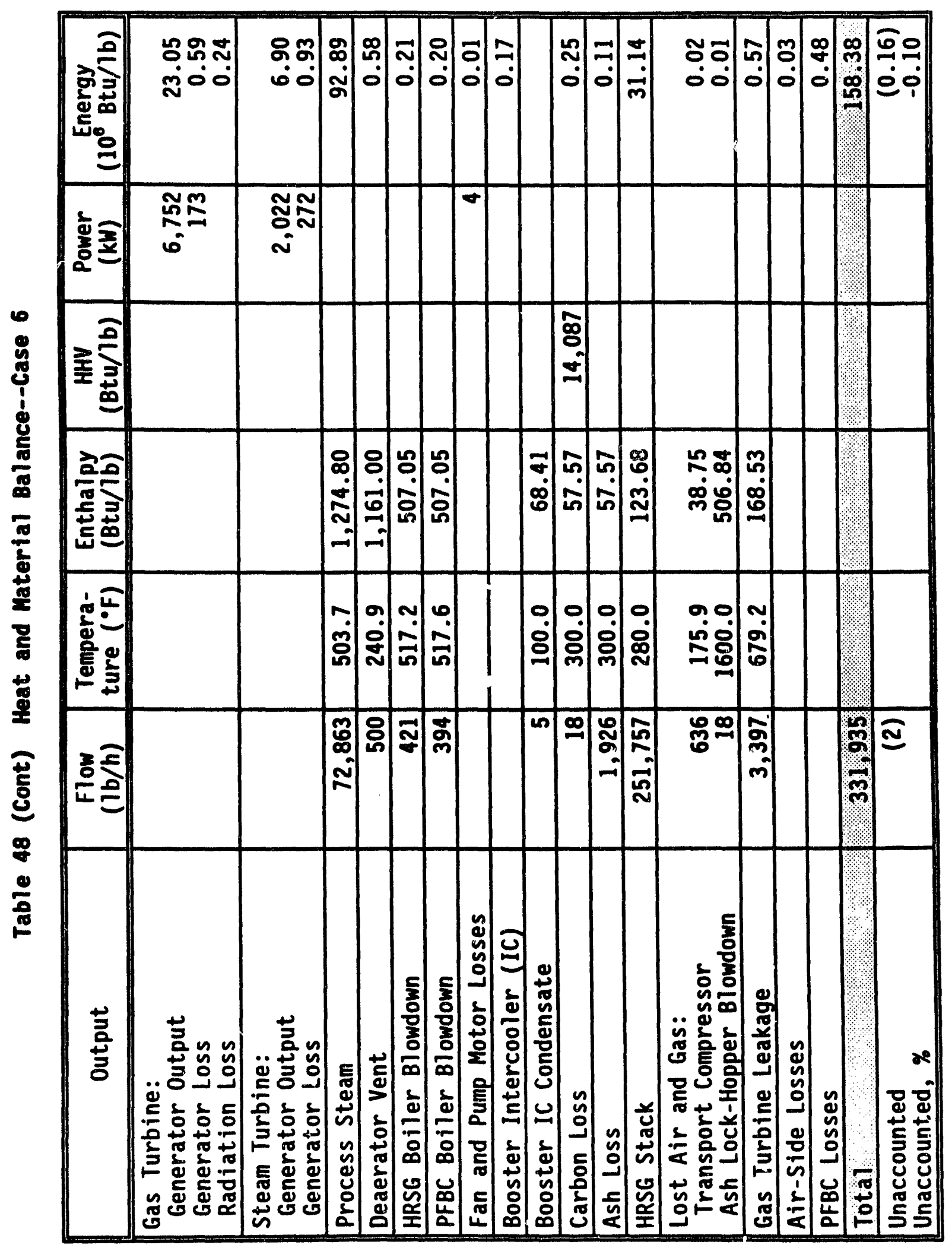




\subsubsection{Plant Capital Cost}

The capital requirements of the plant are listed in Table 49 . The assumptions and methods used to estimate these costs are described in Section 6.

\subsubsection{Plant Operating Costs}

Annual operating costs were estimated from the costs of fuel, feedstocks, plant labor, maintenance, and the other items listed in Table 50.

The total annual operating cost and the fixed costs associated with the total capital requirements, are key components of the levelized cost of steam. The steam costs of all systems are compared in Section 6 . 


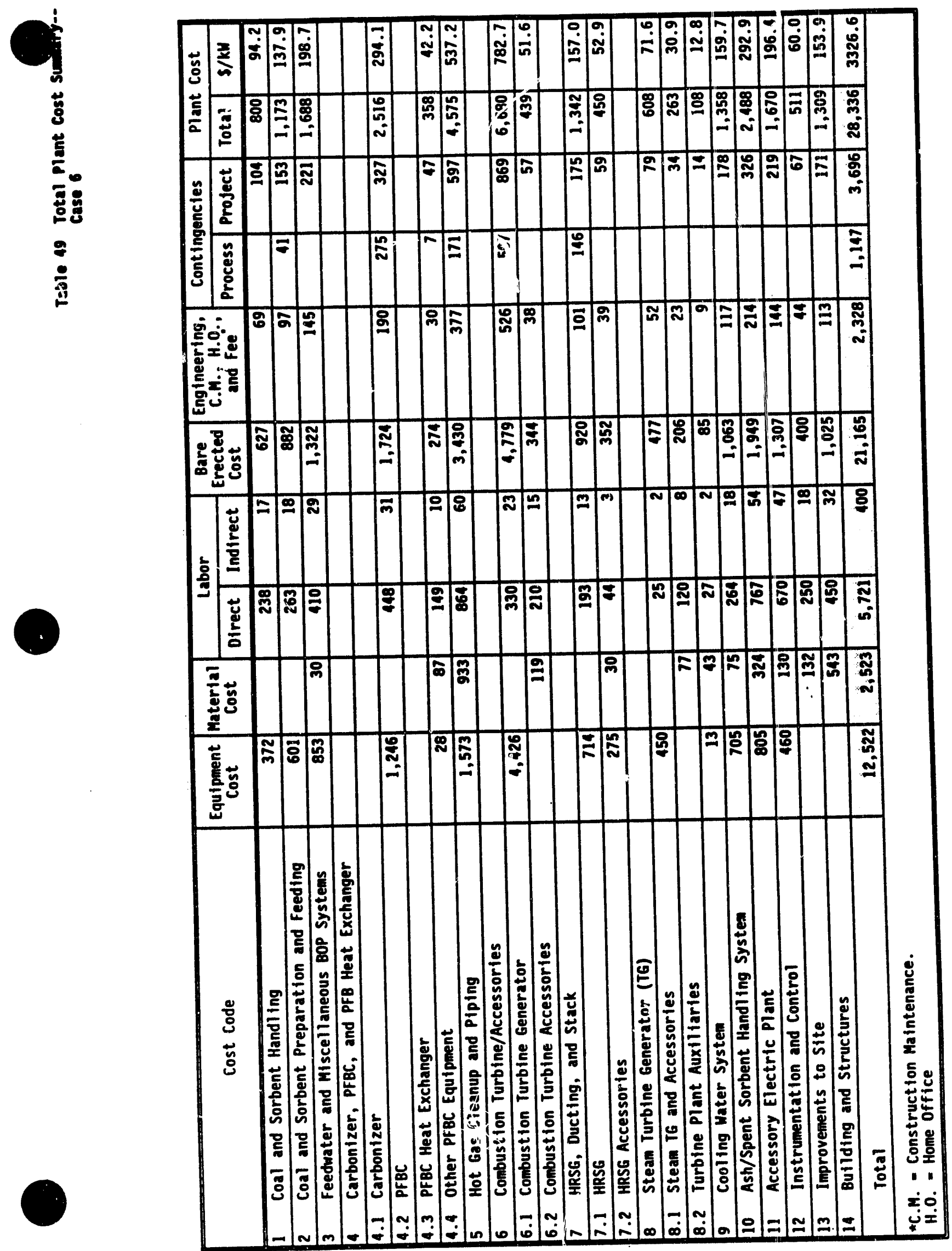


Table 50 Annual Operating Costs--Case 6 (Capacity Factor = 80\%)

\begin{tabular}{|c|c|c|c|}
\hline Cost Categories & Quantity & $\begin{array}{c}\text { Unit } \\
\text { Price, s }\end{array}$ & $\begin{array}{l}\text { Total } \\
\$ \times 10^{3}\end{array}$ \\
\hline 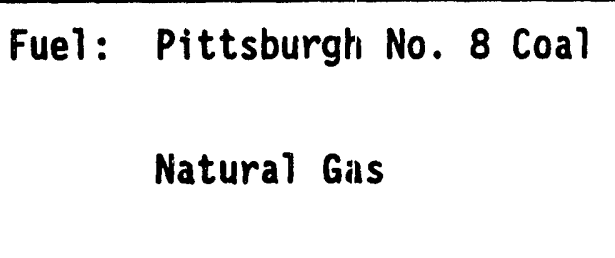 & $\begin{array}{l}6,029 \mathrm{lb} / \mathrm{h} \\
75.07 \mathrm{10} \mathrm{Btu} / \mathrm{h} \\
3,298 \mathrm{lb} / \mathrm{h} \\
71.7410^{6} \mathrm{Btu} / \mathrm{h}\end{array}$ & $\begin{array}{l}1.50 / 10^{3} \mathrm{Btu} \\
3.99 / 10^{3} \mathrm{Btu}\end{array}$ & $\begin{array}{r}966 \\
2,019\end{array}$ \\
\hline $\begin{array}{l}\text { Consumable Materials: } \\
\text { Dolomite } \\
\text { Nitrogen } \\
\text { Raw Water } \\
\text { Water Treatment Chemicals } \\
\text { (40\% of water cost) }\end{array}$ & $\begin{array}{l}0.88 \mathrm{t} / \mathrm{h} \\
58.0 \mathrm{gal} / \mathrm{min}\end{array}$ & $\begin{array}{l}18.80 / \mathrm{t} \\
0.75 / 1000 \mathrm{gal}\end{array}$ & $\begin{array}{r}116 \\
24 \\
18 \\
7\end{array}$ \\
\hline Ash Disposal Costs & $0.96 \mathrm{t} / \mathrm{h}$ & $9.75 / t$ & 66 \\
\hline $\begin{array}{l}\text { Plant Labor: } \\
\text { Operators } \\
\text { Supervision and Clerical } \\
\text { (20\% of O\&M) }\end{array}$ & $5.5 /$ shift & $24.65 / h$ & $\begin{array}{r}1,123 \\
365\end{array}$ \\
\hline Maintenance Costs & & & 704 \\
\hline Total Operating costs & & & 5,408 \\
\hline
\end{tabular}




\section{Section 5}

\section{COMPARISON CASES}

Alternatives to the Second-Generation PFEC industrial cogeneration systems are described in this section. The performance and cost of these alternatives are based on information in the open literature, adjusted as necessary to achieve size and performance consistency with the PFBC systems under study.

Table 51 summarizes the installed capital costs for each of the comparison cases and lists the sections in which they are discussed. Economic comparisons of the costs of steam $(\$ / 1 b)$ for all systems are discussed in section 6 .

Table 51 Installed Capital Costs--Comparison Cases

\begin{tabular}{|c|l|c|}
\hline Section & \multicolumn{1}{|c|}{ Comparison Plant } & $\begin{array}{c}\text { Installed Cost } \\
\left(\$ \times 10^{\circ}\right)\end{array}$ \\
\hline 5.1 & Large AFBC (boiler only) & 25.6 \\
\hline 5.2 & Large AFBC Cogeneration & 46.7 \\
\hline 5.3 & Large Gas Turbine Cogeneration & 31.1 \\
\hline 5.4 & Small AFBC (boiler only) & 9.0 \\
\hline 5.5 & Small AFBC Cogeneration & 16.1 \\
\hline 5.6 & Small Gas Turbine Cogeneration & 12.2 \\
\hline
\end{tabular}




\subsection{COMPARISON: LARGE AFBC (BOILER ONLY)}

\subsubsection{Plant Description}

This AFBC plant is designed to produce process steam only. Figure 67 is a process flow diagram of the plant, showing the functional arrangement of the major plant systems.

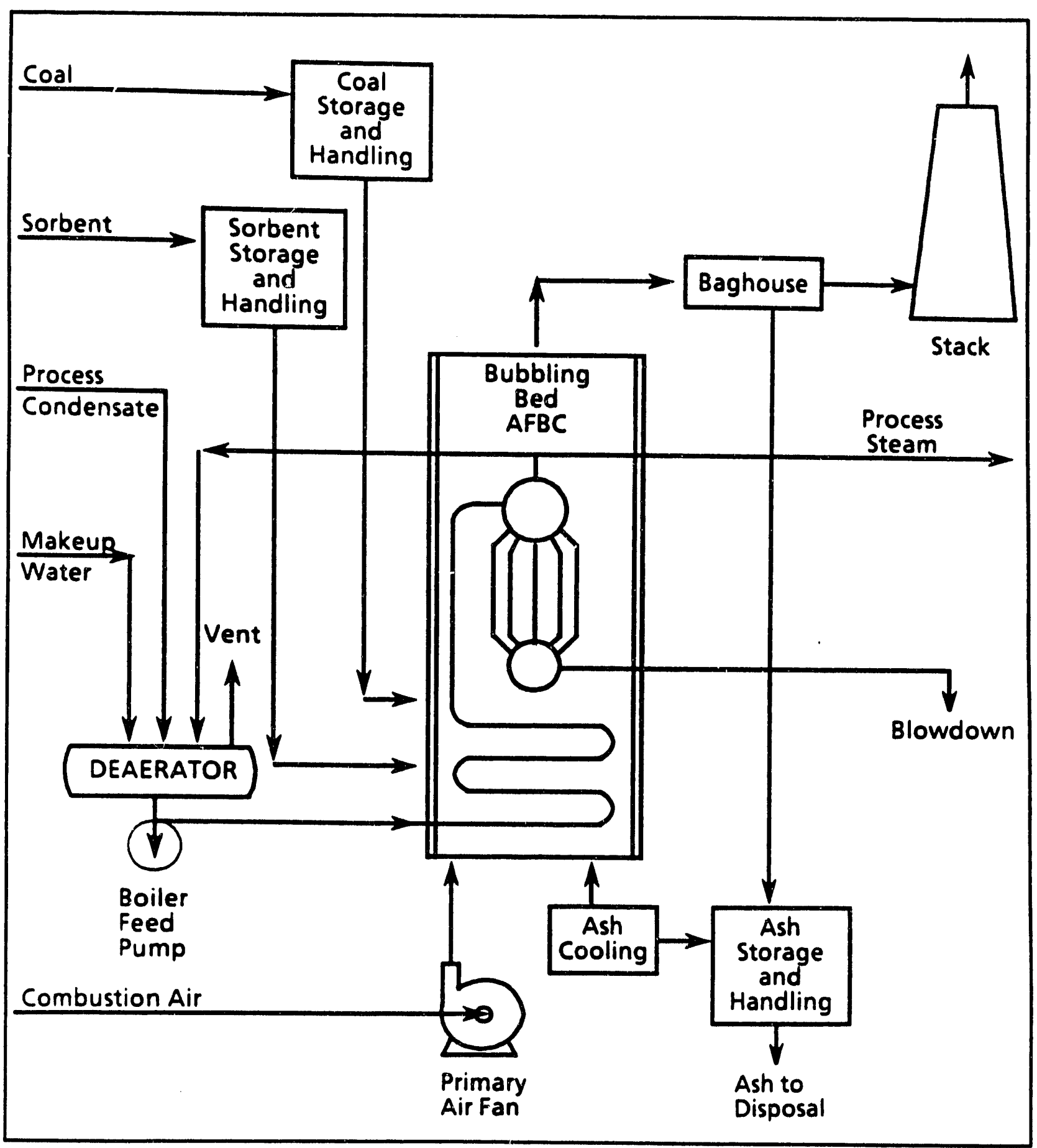

Figure 67 Process Flow Diagram--Large AFBC (Boiler Only) 
Pittsburgh No. 8 coal is burned in an AFBC, providing the energy to generate process steam. The primary air fan provides slightly pressurized air for fluidizing the bed and burning the coal. A limestone sorbent in the combustion process removes sulfur products before they leave the combustor. Coal ash and spent sorbent leaving the fluidized bed are cooled in an ash cooler.

A baghouse cleans the combustion products from the AFBr. Captured particulates are combined with cooled bed solids in an ash storage area before being sent to disposal.

About 65 percent of the process steam flow is returned as process water. The remaining mass flow is provided by makeup water. The process condensate is combined with makeup water in a deaerator. Heating and deaerating of low-pressure condensate are primarily by extraction steam. The deaerator operates at $10.6 \mathrm{psig} / 240^{\circ} \mathrm{F}$. Water from the deaerator is pressurized by an electrically driven feedwater pump. The feedwater is heated by the economizer section, then evaporated in the boiler. A small portion of the boiler steam is an energy source for the deaerator, with the rest going to process.

\subsubsection{Plant Performance}

The approach to estimating the performance of the AFBC plant was to use performance data from an existing report [1], adjusted to account for changes in steam generating capacity and coal type. The report contains costs for four coals ranging in sulfur content from 1 to 4 percent.

Based on the report, an empirical relationship was developed for estimating the coal feed rate as a strong function of steam generation rate and coal heating value and as a weak function of coal sulfur content. This relationship was calibrated to within 1 percent, using the coals in the report. The calibrated formula was then used for the Pittsburgh No. 8 coal, with its 2.99-percent sulfur content.

The limestone feed rate was estimated from the coal feed rate, the coal sulfur content, and the limestone-to-sulfur ratio in the report. The same limestone-to-sulfur ratio reported for the 2- to 4-percent sulfur coals was also used for the Pittsburgh No. $8 \mathrm{coal}$.

Ash from the plant was assumed to be the ash in the coal plus spent and inert material from the limestone. Therefore, the limestone contribution to solid waste is based on the limestone feed rate, based in turn on the coal feed rate and sulfur content.

The large AFBC plant has an overall thermal efficiency of 85.7 percent, based on the higher heating value of coal. Table 52 summarizes the plant performance, and Table 53 lists the auxiliary power requirements. 
Table 52 Summary Performance Data--Large AFBC (Boiler Only)

\begin{tabular}{|c|c|c|c|c|c|}
\hline Description & $\begin{array}{l}\text { Flow } \\
(1 \mathrm{~b} / \mathrm{h})\end{array}$ & $\begin{array}{l}\text { Enthalphy } \\
(\text { Btu/lb) }\end{array}$ & $\begin{array}{l}\text { Power } \\
(k W)\end{array}$ & $\underset{\left(10^{6} \mathrm{Btu} / \mathrm{h}\right)}{\text { Energy }}$ & $\begin{array}{c}\text { Energy } \\
\text { Output } \\
(\%)\end{array}$ \\
\hline Process Steam & 400,000 & $1,195.70$ & & 478.20 & \\
\hline (Returned Condensate) & $(260,000)$ & 128.30 & & $(33.36)$ & \\
\hline (Makeup Water) & $(148,000)$ & 23.10 & & $(3.42)$ & \\
\hline Steam Energy Output & & & & 441.42 & 101 \\
\hline (Plant Auxiliaries) & & & $(1,634)$ & (5.58) & \\
\hline Electric Power Output & & & & & (1) \\
\hline Total Energy Output & & & & 435.84 & 1.100 \\
\hline Coal Energy Input & 40,863 & 12,452 & & 508.83 & \\
\hline Limestone Feed & 19,119 & & & & \\
\hline Ash Production & 13,233 & & & & \\
\hline Net Thermal Efficiency & & & & & 85.65 \\
\hline
\end{tabular}

Table 53 Auxiliary Sumary--Large AFBC (Boilor Oniy)

\begin{tabular}{|l|r|}
\hline \multicolumn{1}{|c|}{ Item } & \multicolumn{1}{|c|}{ KW } \\
\hline Coal Handling & 8 \\
\hline Limestone Handling & 158 \\
\hline Coal Preparation and Feed & 78 \\
\hline Limestone Preparation and Feed & 36 \\
\hline Feedwater System & 170 \\
\hline Compressed Air System & 1049 \\
\hline Ash Handling & 75 \\
\hline Miscellaneous & 15 \\
\hline Total Auxiliaries & 1589 \\
\hline
\end{tabular}




\subsubsection{Plant Capital and Operating Costs}

Carital costs. The capital cost of each account item was estimated to equal its cost in the Stearns report [1] , adjusted to reflect any changes in cne or two performance parameters. For example, the cost of coal handiing equipment equals the cost in the report, adjusted to reflect changes in the coal feed rate. Table 54 lists the elements of the installed capital cost. Cost items were rearranged to fit into the same 14 categories as in this study. All costs in this report are expressed in $\$ 1989$.

Operating Costs. Annual operating costs were estimated from the costs of fuel, feedstocks, plant labor, maintenance, and other items as listed in Table 55 .

The total anaual operating cost, together with fixed costs associated with the total capital requirements, is a key component of the levelized cost of steam. The steani costs of all systems are compared in Section 6 . 
Table 54 Installed Capital Cost--Large AFBC (Boiler only) $\left(\$ \times 10^{3}\right)$

\begin{tabular}{|r|l|r||}
\hline 1 & Coal and Sorbent Handling & $2,356.8$ \\
2 & Coal and Sorbent Preparation and Feed & $2,179.1$ \\
3 & Feedwater and Miscellaneous Systems & $3,546.3$ \\
4 & Boiler and Accessories & $5,486.3$ \\
5 & Hot Gas Cleanup and Piping & --- \\
6 & Combustion Turbine and Accessories & --- \\
7 & Waste Heat Boiler, Duct, and Stack & 209.7 \\
8 & Steam Turbine and Accessories & --- \\
9 & Cooling Water System & 156.0 \\
10 & Ash and Spent Sorbent Handling & $1,981.0$ \\
11 & Accessory Electric--Plant & $1,215.1$ \\
12 & Instrumentation and Controls & $2,140.8$ \\
13 & Improvements to Site & 192.4 \\
14 & Bulldings and Structures & 787.2 \\
& Bare Erected Cost & $20,251.8$ \\
$10 \%$ & Indirect Costs & $2,025.2$ \\
0 & Process Contingency &.-- \\
$15 \%$ & Project Contingency & $3,341.5$ \\
\hline
\end{tabular}

\section{References and adjustments for estimating each cost account:}

1 Coal and Sorbent Handling: Equipment cost based on Case 1 cosl and sorbent handling equipment costs for Industrial CPFBC, adjusted to ref lect different coal and sorbent flows for this case.

2 Coal and Sorbent Prejaration and Feed: Equipment cost based on Case 2 coal and sorbent handling equipment costs for Industrial CPFBC, adjusted to reflect different coal and sorbent flows for this case.

3 Feeduater and Miscellaneous Syste-ns: Feedwater equipment cost based on Case 2 coal and sorbent handling equipment costs for Industrial CPFBC, adjusted to ref lect different feecwater flow and pressure for this case. Compressed air system cost a lso inc luded under this account, based on cost of a similar system in the Stearns Catalyt ic Report, adjusteu for different coal feed rate for this case and esca lated to $\$ 1989$.

4 Boiler and Accessories: Steam generat ing equipment cost based on cost of a siniliar system in the Stearns Catalyt ic Report, adjusted for different steam product ion rate for this case and escalated to $\$ 1989$. Stean piping cost also included under this account, based on cost of a similar system in the Stearns Catalytic Report, adjusted for the steam flow and pressure for this case and escalated to $\$ 1989$.

5 Hot Gas Cleanup and Piping: No equipment, no cost.

6 Combustion Iurbine and Accessories: No equipment, no cost.

7 Vaste Heat Boiler. Duct, and Stack: Air and flue gas system cost based on cost of a similar system in the Stearns Catalytic Report, adjusted for different coal feed rate for this case and escalated to $\$ 1989$.

8 Steam Turbine and Accessories: No equipment, no cost.

9 Cooling Water System: Equipment cost based on Case 2 cost for Industrial CPFBC, adjusted to reflect difference in thermal input to plant for this case.

10 Ash and Spent Sorbent Handling: Equipment cost based on Case 1 cost for Industrial CPFBC, adjusted to ref lect difference in ash production "or this case.

11 Accessory Electric--P lant: Equipment cost based on Case 1 cost for Industrial CPFBC, adjusted to ref lect difference in generated and auxiliary power for this case.

12 Instrumentation and Controls: Equipment cosit based on Case 1 cost for Industrial CPFBC, adjusted to ref lect difference in thermal input to plant for this case.

13 Improvements to Site: Equipment cost assumed the same fraction of equipment cost as in Case 1 for the Industrial CPFBC.

14 Buildings and Structures: Equipment cost assumed the same fraction of equipment cost as in Case 1 for the Industrial CPFBC. 
Table 55 Annual Operating Costs--Large AFBC (Boiler Only)

\begin{tabular}{|c|c|c|c|}
\hline Cost Categories & Quantity & $\begin{array}{c}\text { Unit } \\
\text { Price (\$) }\end{array}$ & $\begin{array}{c}\text { Total } \\
\left(\$ \times 10^{3}\right)\end{array}$ \\
\hline Fuel: Pittsburgh No. 8 Coal & $\begin{array}{l}40,863 \mathrm{lb} / \mathrm{h} \\
508.8310^{8} \mathrm{Btu} / \mathrm{h}\end{array}$ & $1.50 / 10^{3} \mathrm{Btu}$ & 5,352 \\
\hline $\begin{array}{l}\text { Consumable Materials: } \\
\text { Limestone } \\
\text { Raw Water } \\
\text { Water Treatment Chemicals } \\
\text { (40\% of water cost) }\end{array}$ & $\begin{array}{l}9.6 \mathrm{t} / \mathrm{h} \\
421 \mathrm{gal} / \mathrm{min}\end{array}$ & $\begin{array}{l}18.80 / \mathrm{t} \\
0.75 / 1000 \mathrm{gal}\end{array}$ & $\begin{array}{r}1,260 \\
91 \\
37\end{array}$ \\
\hline Ash Disposal Costs & $6.62 \mathrm{t} / \mathrm{h}$ & $9.75 / \mathrm{t}$ & 452 \\
\hline $\begin{array}{l}\text { Plant Labor: } \\
\text { Operators } \\
\text { Supervision and Clerical } \\
\text { (20\% of 08M) }\end{array}$ & $7 /$ shift & $24.65 / h$ & $\begin{array}{r}1,512 \\
423\end{array}$ \\
\hline Maintenance Costs & & & 605 \\
\hline Total Operating Costs & & & 9,732 \\
\hline
\end{tabular}




\subsection{COMPARISON: LARGE AFBC--COGENERATION}

\subsubsection{Plant Description}

The AFBC cogeneration plant is designed to produce process steam and electric power. Figure 68 is a process flow diagram of the plant, showing the functional arrangement of the major plant systems.

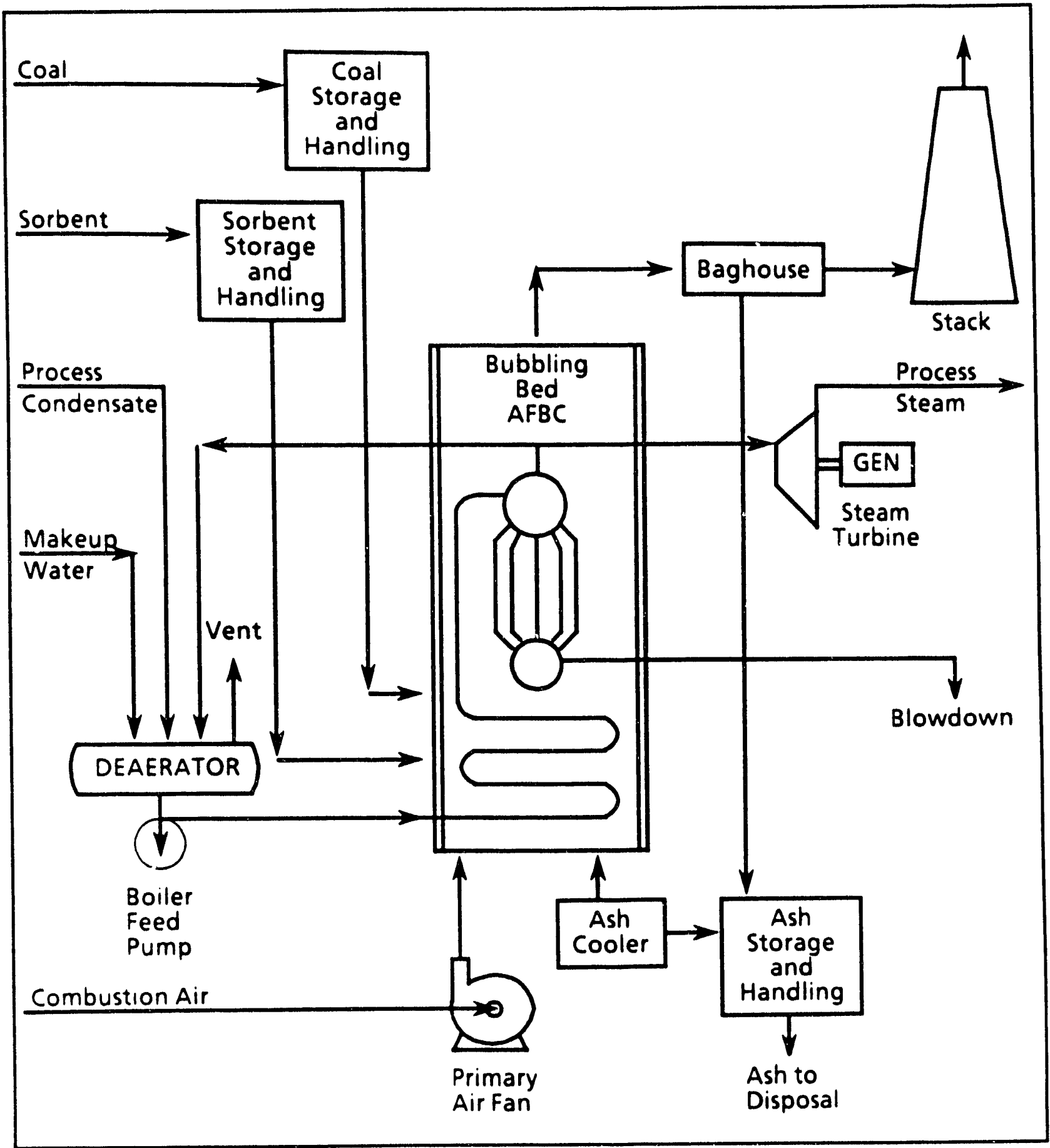

Figure 68 Process Flow Diagram--.Large AFB Cogeneration 
Pittsburgh No. 8 coal is burned in an AFB combustor, providing the energy to generate process steam. The primary air fan supplies slightly pressurized air for fluidizing the bed and burning the coal. A limestone sorbent is included in the combustion process to remove sulfur products before they leave the combustor. Coal ash and spent sorbent leaving the fluidized bed are cooled in an ash cooler.

A baghouse cleans the combustion products from the AFB combustor. Captured particulates are combined with cooled bed solids in an ash storage area before being sent to disposal.

About 65 nercent of the process steam flow is returned as process water. The remaining mass flow is provided by makeup water. The process condensate is combined with makeup water in a deaerator. Heating and deaerating of low-pressure condensate is primarily by extraction steam. The deaerator operates at $10.6 \mathrm{psig} / 240^{\circ} \mathrm{F}$. Water from the deaerator is pressurized by an electrically driven feedwater pump. The feedwater is heated by the economizer section, then evaporated in the boiler.

The steam is expanded through a back-pressure steam turbine before being released to process. The turbine is a 1200-psig unit with a throttle inlet temperature of $950^{\circ} \mathrm{F}$. The turbine exhaust pressure is slightly above the required process steam pressure of $150 \mathrm{psig.} \mathrm{A} \mathrm{small} \mathrm{portion} \mathrm{of} \mathrm{the} \mathrm{ex-}$ haust steam is used as an energy source for the deaerator, with the rest going to process.

\subsubsection{Plant Performance}

The approach to estimating the performance of the AFBC plant was to use performance data from an existing report [1], adjusted to account for changes in steam generating capacity and coal type.

The report contained costs for four coals ranging in sulfur content from 1 to 4 percent. An empirical relationship was developed, based on that report, for estimating the coal feed rate as a strong function of steam generation rate and coal heating value and a weak function of coal sulfur content. This relationship was calibrated to within 1 percent, using the coals listed in the report. The calibrated formula was then used for the Pittsburgh No. 8 coal, with its 2.99-percent sulfur content.

The limestone feed rate was estimated from the reported coal feed rate, the coal sulfur content, and the limestone-to-sulfur ratio [1]. The same limestone-to-sulfur ratio reported for the 2- to 4-percent sulfur coals was also used for the Pittsburgh No. 8 coal.

Ash from the plant was assumed to be the ash in the coal plus spent and inert material from the limestone. Therefore, the limestone contribution to solid waste is based on the limestone feed rate, based in turn on the coal feed rate and sulfur content.

The resultant large AFBC cogeneration plant has an overall thermal efficiency of 85.9 percent, based on the higher heating value of coal. Table 56 summarizes the performance of the plant, and Table $5 \prime$ lists the auxiliary power requirements. 
Table 56 Summary Performance Data--Large AFBC Cogeneration

\begin{tabular}{||l|r|r|r|r|r||}
\hline \multicolumn{1}{|c|}{ Description } & $\begin{array}{c}\text { Flow } \\
(\mathrm{lb} / \mathrm{h})\end{array}$ & $\begin{array}{c}\text { Enthalphy } \\
(\mathrm{Btu} / \mathrm{lb})\end{array}$ & $\begin{array}{c}\text { Power } \\
(\mathrm{kW})\end{array}$ & $\begin{array}{c}\text { Energy } \\
\left(10^{6} \mathrm{Btu} / \mathrm{h}\right)\end{array}$ & $\begin{array}{c}\text { Energy } \\
\text { Output } \\
(\mathrm{x})\end{array}$ \\
\hline Process Steam & 400,000 & $1,284.80$ & & 513.92 & \\
\hline (Returned Condensate) & $(260,000)$ & 128.30 & & $(33.36)$ & \\
\hline (Makeup Water) & $(148,000)$ & 23.10 & & $(3.42)$ & \\
\hline Steam Energy Output & & & & 477.14 & 87 \\
\hline Steam Turbine Power & & & 22,939 & 78.28 & \\
\hline (Plant Auxiliaries) & & & $(2,820)$ & $(9.62)$ & \\
\hline Electric Power Output & & & 20,119 & 68.66 & 13 \\
\hline Total Energy Output & & & & 614.46 & 100 \\
\hline Coal Energy Input & 51,017 & 12,452 & & 635.26 & \\
\hline Limestone Feed & 23,869 & & & & \\
\hline Ash Production & 16,521 & & & & \\
\hline Net Thermal Efficiency & & & & & 85.92 \\
\hline
\end{tabular}

Table 57 Auxiliary Summary--Large AFBC Cogeneration

\begin{tabular}{|l|r|}
\hline \multicolumn{1}{|c|}{ Item } & \multicolumn{1}{|c|}{ kW } \\
\hline Coal Handling & 10 \\
\hline Limestone Handling & 197 \\
\hline Coal Preparation and Feed & 97 \\
\hline Limestone Preparation and Feed & 45 \\
\hline Feedwater System & 854 \\
\hline Compressed Air System & 1366 \\
\hline Steam Turbine Auxiliarie: & 139 \\
\hline Ash Handling & 94 \\
\hline Miscellaneous & 17 \\
\hline Total Auxiliaries & 2819 \\
\hline
\end{tabular}




\subsubsection{Plant Capital and Operating Costs}

Capital Costs. The capital cost of each account item was estimated to equal its cost in the Stearns report [1], adjusted to reflect any changes in one or two performance parameters. For example, the cost of coal handi ing equipment equals the cost in the report, adjusted to reflect changes in the coal feed rate.

Table 58 lists the elements of the installed capital cost. Cost items were rearranged to fit into the same 14 categories as for this study. All costs in this report are expressed in $\$ 1989$.

Operating costs. Annual operating costs were estimated from the costs of fuel, feedstocks, plant labcr, maintenance, and the other items listed in Table 59.

The total annual operating cost, together with fixed costs associated with the total capital requirements, is a key component of the levelized cost of steam. The steam costs for all systems are compared in Section 6. 


\section{Table 58 Installed Capital Cost--Largs AFBC Cogeneration $\left(\$ \times 10^{3}\right)$}

\begin{tabular}{|c|l|r||}
\hline 1 & Coal and Sorbent Handling & $2,752.9$ \\
2 & Coal and Sorbent Preparation and Feed & $2,545.3$ \\
3 & Feedwater and Miscellaneous Systems & $4,269.9$ \\
4 & Boiler and Accessori ss & $11,045.8$ \\
5 & Hot Gas Cleanup and Piping &.-- \\
6 & Combustion Turbine and Accessories &.-- \\
7 & Waste Heat Boiler, Duct, and Stack & 245.0 \\
8 & Steam Turbine and Accessories & $5,558.3$ \\
9 & Cool ing Water System & 205.4 \\
10 & Ash and Spent Sorbent Handling & $2,314.0$ \\
11 & Accessory Electric--Plant & $3,527.4$ \\
12 & Instrumentation and Controls & $2,360.1$ \\
13 & Improvements to Site & 347.7 \\
14 & Buildings and Structures & $1,422.5$ \\
& Bare Erected Cost & $36,594.3$ \\
$10 \%$ & Indirect Costs & $4,025.4$ \\
0 & Process Contingency &.-- \\
$15 \%$ & Project Contingency & $6,092.9$ \\
\hline
\end{tabular}

\section{References and adjustments for estimating each cost account:}

1 Cosl and Sorbent Handling: Equipment cost based on Case 1 coal and sorbent handling equipment costs for Industrial CPFBC, adjusted to ref lect different coal and sorbent flows for this case.

2 Coal and Sorbent Preparation and Feed: Equipment cost based on Case 2 coal and sorbent handl ing equipment costs for Industrial CPFBC, adjusted to ref lect different coal and sorbent flows for this case.

3 Feeduter and Miscellanepus Systens: Feedwater equipment cost based on Case 2 coal and sorbent handling equipment costs for Industrial CPFBC, adjusted to ref lect different feectwater flow and pressure for this case. Compressed air system cost a lao included undar this account, based on cast of a similar system in the Stearns Catalyt ic Report, adjusted for different coal feed rate for this case and esca lated to \$1989.

4 Boiler and Accessories: Stean generating equipment cost based on cost of a simi lar system in the Stearns Catalyt ic Report, adjusted for different stean production rate for this case and eacalated to \$1989. Stean piping cost also included undar this account, based on cost of a similar system in the Stearns Catalytic Report, adjusted for the stean flow and pressure for this case and escalatud to \$1989.

5 Hot Gas Cleanup and Piping: No equipment, no cost.

6 Combustion Turbine and Accessories: Ho equipment, no cost.

7 Waste Heat Boiler. Duct, and Stack: Air and flue gas system cost based on cost of a similar system in the Stearns Cataiyt ic Report, adjusted for different coal feed rate for this case and escalated to $\$ 1989$.

8 Steam Turbine and Accessories: No equipment, no cost.

9 Cooling Hater System: Equipment cost based on Case 2 cost for Industrial CPFBC, adjusted to ref lect difference in thermal input to plant for this case.

10 Ash and Spent Sorbent Handling: Equipment, cost based on F-se 1 cost for Industrial CPFBC, adjusted to reflect difference in ash production for this case.

11 Accessory Electric--P lant: Equipment cost based on Case 1 cost for Industrial CPFBC, adjusted to ref lect difference in generated and auxiliary power for this case.

12 Instrumentation and Controls: Equipment cost based on Case 1 cost for Industrial CPFBC, adjusted to reflect difference in thermal input to plant for this case.

13 Improvements to Site: Equipment cost assumed the same fraction of equipment cost as in Case 1 for the Industrial CPFBC.

14 Bujldings and Structures: Equipment cost assumed the same fraction of equipment cost as in Case 1 for the Industrial CPFBC. 
Table 59 Annual Operating Costs--Large AFBC Cogeneration

\begin{tabular}{|c|c|c|c|}
\hline Cost Categories & Quantity & $\begin{array}{l}\text { Unit } \\
\text { Price (\$) }\end{array}$ & $\begin{array}{c}\text { Total } \\
\left(\$ \times 10^{3}\right)\end{array}$ \\
\hline Fuel: Pittsburgh No. 8 Coal & $\begin{array}{l}50,017 \mathrm{lb} / \mathrm{h} \\
635.2610^{6} \mathrm{Btu} / \mathrm{h}\end{array}$ & $1.50 / 10^{3} \mathrm{Btu}$ & 6,682 \\
\hline $\begin{array}{l}\text { Consumable Materials: } \\
\text { Limestone } \\
\text { Raw Water } \\
\text { Water Treatment Chemicals } \\
\text { (40\% of water cost) }\end{array}$ & $\begin{array}{l}11.9 \mathrm{t} / \mathrm{h} \\
290 \mathrm{gal} / \mathrm{min}\end{array}$ & $\begin{array}{l}18.80 / t \\
0.75 / 1000 \text { gal }\end{array}$ & $\begin{array}{r}1,573 \\
91 \\
37\end{array}$ \\
\hline Ash Disposal Costs & $8.26 \mathrm{t} / \mathrm{h}$ & $9.75 / t$ & 565 \\
\hline $\begin{array}{l}\text { Plant Labor: } \\
\text { Operators } \\
\text { Supervision and Clerical } \\
\text { (20\% of 08N) }\end{array}$ & $10 /$ shift & $24.65 / \mathrm{h}$ & $\begin{array}{r}2,159 \\
614\end{array}$ \\
\hline Maintenance Costs & & & 912 \\
\hline Total Operating Costs & & & 12,633 \\
\hline
\end{tabular}




\subsection{CONPARISON: LARGE GAS TURBINE COGENERATION}

\subsubsection{Plant Description}

The gas turbine cogeneration plant is designed to produce electric power and process steam. The major components are shown schematically in Figure 69.

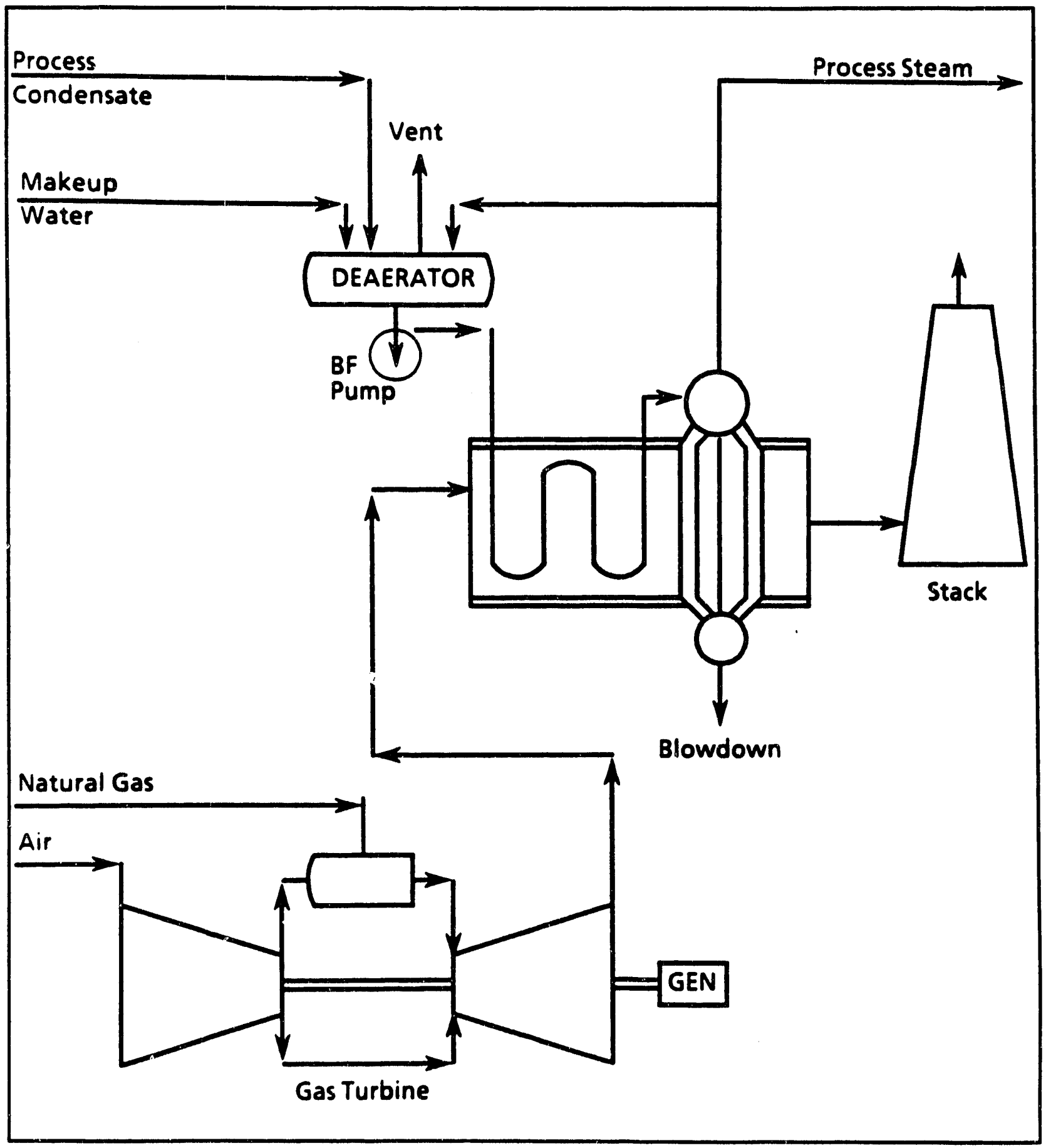

Figure 69 Process Flow Diagram--Large Gas Turbine Cogeneration 
Natural gas is burned in an industrial gas turbine to produce electric power and an exhaust stream at about $1000^{\circ} \mathrm{F}$. The exhaust stream is further heated with a duct burner fueled by natural gas. The energy in the exhaust stream produces process steam, cooling the exhaust to 250 to $300^{\circ} \mathrm{F}$ before it is released to the atmosphere.

About 65 percent of the process steam flow is returned as process water. The remaining mass flow is provided by makeup water. The process condensate is combined with makeup water in a deaerator. Heating and deaerating of low-pressure condensate is primarily by extraction steam. The deaerator operates at $10.6 \mathrm{psig} / 240^{\circ} \mathrm{F}$. Water from the deaerator is pressurized by an electrically driven feedwater pump. The feedwater is heated by the economizer section, then evaporated in the boiler. A small portion of the exhaust steam is an energy source for the deaerator, with the rest going to process.

\subsubsection{Plant Performance}

The approach to estimating the performance of the gas turbine cogeneration plant was to use performance data from an existing report [2], adjusted to account for changes in steam generating capacity and gas turbine efficiency.

The large gas turbine cogeneration plant has an overall thermal efficiency of 86 percent, based on the higher heating value of natural gas. Table 60 summarizes plant performance.

\subsubsection{Plant Capital and Operating Costs}

Capital Costs. The capital cost of each account item was estimated based on a reference cost, adjusted to reflect any changes in one or two performance parameters. The reference costs refer to either cases 1 and 2 in this report or to the Gas Turbine Horld 1990 Handbook [2], as indicated in the notes below Table 61. For example, the cost of the combustion turbine equals the cost in the Handbook, adjusted to reflect changes in power generation rating.

Table 61 lists the elements of the installed capital cost. Cost items were rearranged so they fit into the same 14 categories as for this study. A11 costs in this report are expressed in $\$ 1989$.

Operating Costs. Annual operating costs were estimated from the costs of fuel, feedstocks, plant labor, maintenance, and other items listed in Table 62 .

The total annual operating cost, together with fixed costs associated with the total capital requirements, are key components of the levelized cost of steam. The steam costs for all systems are compared in Section 6. 
Table 60 Sumary Performance Data--Large Gas Turbine Cogeneration

\begin{tabular}{|c|c|c|c|c|c|}
\hline Description & $\begin{array}{l}\text { Flow } \\
(1 \mathrm{~b} / \mathrm{h})\end{array}$ & $\begin{array}{c}\text { Enthalphy } \\
(B t u / 1 b)\end{array}$ & $\begin{array}{l}\text { Power } \\
\text { (kW) }\end{array}$ & $\begin{array}{c}\text { Energy } \\
\left(10^{6} \mathrm{Btu} / \mathrm{h}\right)\end{array}$ & $\begin{array}{c}\text { Energy } \\
\text { Output } \\
\text { (\%) }\end{array}$ \\
\hline Process Steam & 400,000 & $1,195.67$ & & 478.27 & \\
\hline $2 \%$ Boiler Blowdown & 8,163 & 338.46 & & 2.76 & \\
\hline (Returned Condensate) & $(260,000)$ & 128.30 & & $(33.36)$ & \\
\hline (Makeup Water) & $(148,000)$ & 23.10 & & $(3.42)$ & \\
\hline Steam Energy output. & & & & 444.25 & 80 \\
\hline Gas Turbine Power & & & 32,278 & 110.16 & \\
\hline (Plant Auxiliaries) & & & (289) & $(0.99)$ & \\
\hline Electric Power Output & & & $(31,989)$ & $(109.17)$ & 20 \\
\hline Total Energy output & & & & 19.553 .42 & 100 \\
\hline Gas Turbine Fuel & 16,583 & 21,813 & & 361.72 & 56 \\
\hline Duct Burner Fuel & 12,922 & 21,813 & & 281.86 & 44 \\
\hline Fuel Energy Input & 29,505 & & & 643.58 & 100 \\
\hline Net Thernal E St K ency) & & & & & $85 \% 9$ \\
\hline
\end{tabular}


Table 61 Installed Capital Cost--Large Gas Turbine Cogeneration $\left(\$ \times 10^{3}\right)$

\begin{tabular}{|r|l|r|}
\hline 1 & Coal and Sorbent Handling &.-- \\
2 & Coal and Sorbent Preparation and Feed & -- \\
3 & Feedwater and Miscellaneous Systems & $3,098.9$ \\
4 & Boiler and Accessories & --- \\
5 & Hot Gas Cleanup and Piping & -- \\
6 & Combustion Turbine and Accessories & $15,263.1$ \\
7 & Waste Heat Boiler, Duct, and Stack & $2,484.3$ \\
8 & Steam Turbine and Accessories &.-- \\
9 & Cooling Water System &.-- \\
10 & Ash and Spent Sorbent Handling & $2,294.0$ \\
11 & Accessory Electric--Plant & 159.7 \\
12 & Instrumentation and Controls & 232.7 \\
13 & Improvements to Site & 827.3 \\
14 & Buildings and Structures & $24,360.0$ \\
& Bare Erected Cost & $2,679.6$ \\
$11 \%$ & Indirect Costs &.-- \\
0 & Process Contingency & $4,055.9$ \\
$15 \%$ & Project Contingency & $31,095.5$ \\
\hline
\end{tabular}

References and adjustments for estimating each cost account:

1 Coal and Sorbent Handling: No equipment, no cost.

2 Coal and Sorbent Preparation and Feed: No equipment, no cost.

3 Feedwater and Miscellianeous Systens:- Feedwater equipment cost based on Case 2 coal and sorbent handling equipment costs for Industrial CPFBC, adjusted to ref lect different feedwater flow and pressure for this case.

4 Boiler and Accessories: No equipment, no cost. (The cost of steam generat ing equipment is inc luded under Account 7.)

5 Hot Gas Cleanup and Piping: No equipment, no cost.

6 Combustion Turbine and Accessories: The cost of the combustion turbine system was based on the cost of a similar system in the 1990 Gas Turbine Horld Handbook, adjusted for the different power generat ion rat ing for this case.

7 Haste Heat Boiler. Duct. and Stack: Air and flue gas system cost based on cost of a similar system in the Stearns Catalytic Report, adjusted for different coal feed rate for this case and escalated to $\$ 1989$.

8 Steam Turbine and Accessories: No equipment, no cost.

9 Cooling Yater System: No equipment, no cost.

10 Ash and Spent Sorbent Handling: No equipment, no cost.

11 Accessory Electric--Plant: The cost of this equipment was based on the cost of a similar system in the 1990 Gas Turbine World Handbook, adjusted for the different power generation rating for this case.

12 Instrumentation and Controls: The cost of this equipment was based on the cost of a similar system in the 1990 Gas Turbine Horld Handbook, adjusted for the different power generation rat ing for this case.

13 Improvements to site: Equipment cost assumed the same fraction of equipment cost as in Case 1 for the Industrial CPFBC.

14 Buildings and Structures: Equipment cost assumed the same fraction of equipment cost as in Case 1 for the Industrial CPFBC. 
Table 62 Annual Operating Costs--Large Gas Turbine Cogeneration

\begin{tabular}{|c|c|c|c|}
\hline Cost Categories & Quantity & $\begin{array}{l}\text { Unit } \\
\text { Price (\$) }\end{array}$ & $\begin{array}{c}\text { Total } \\
\left(5 \times 10^{3}\right)\end{array}$ \\
\hline Fuel: Natural Gas & $\begin{array}{l}29,505 \mathrm{jb} / \mathrm{h} \\
643.59 \mathrm{jo}{ }^{6} \mathrm{Btu} / \mathrm{h}\end{array}$ & $3.99 / 10^{3} \mathrm{Btu}$ & 18,008 \\
\hline $\begin{array}{l}\text { Consumable Materials: } \\
\text { Raw Water } \\
\text { Water Treatment Chemicals } \\
\text { ( } 40 \% \text { of water cost) }\end{array}$ & $290 \mathrm{gal} / \mathrm{min}$ & $0.75 / 1000 \mathrm{gal}$ & $\begin{array}{l}91 \\
37\end{array}$ \\
\hline $\begin{array}{l}\text { Plant Labor: } \\
\text { Operators } \\
\text { Supervision and Clerical } \\
\text { (20\% of O\&M) }\end{array}$ & $5 /$ shift & $24.65 / h$ & $\begin{array}{r}1,080 \\
338\end{array}$ \\
\hline Maintenance Costs & & & 609 \\
\hline Total Operating Costs & & & 20,163 \\
\hline
\end{tabular}




\subsection{COMPARISON: SMALL AFBC (BOILER ONLY)}

\subsubsection{Plant Description}

This AFBC boiler plant is designed to produce process steam only. The plant arrangement is identical to that of the large AFBC boiler plant described previously and is as shown in Figure 68. The major components are:

- Coal and sorbent storage and handling facilities

- An AFB combustor burning Pittsburgh No. 8 coal with limestone

- A primary air fan to pressurize the air for fluidizing the bed and burning the coal

- An ash cooler to cool the coal ash and spent sorbent

- A baghouse to clean the combustion products from the AFBC

- An ash storage area

- A steam generation system, including a deaerator, a boiler feed pump, an economizer section, and a boiler.

Pittsburgh No. 8 coal is burned in an AFB combustor, providing the energy to generate process steam. The primary air fan supplies slightly pressurized air for fluidizing the bed and burning the coal. A limestone sorbent is included in the combustion process to remove sulfur products before they leave the combustor. Coal ash and spent sorbent leaving the fluidized bed are cooled in an ash cooler.

A baghouse cleans the combustion products from the AFB combustor. Captured particulates are combined with cooled bed solids in an ash storage area before being sent to disposal.

About 65 percent of the process steam flow is returned as process water. The remaining mass flow is provided by makeup water. The process condensate is combined with makeup water in a deaerator. Heating and deaerating of low-pressure condensate is provided primarily by extraction steam. The deaerator operates at $10.6 \mathrm{psig} / 240^{\circ} \mathrm{F}$. Water from the deaerator is pressurized by an electrically driven feedwater pump. The feedwater is heated by the economizer section, then evaporated in the boiler. A small portion of the boiler steam is an energy source for the deaerator, with the rest going to process.

\subsubsection{Plant Performance}

The approach to estimating the performance of the AFBC plant was to use performance data from an existing report [1], adjusted to account for changes in steam generating capacity and coal type.

The small AFBC boiler plant has an overall thermal efficiency of 85.65 percent, based on the higher heating value of coal. Table 63 summarizes the performance of the plant, and Table 64 lists the auxiliary power requirements. 
Table 63 Summary Performance Data--Small AFBC (Boiler Only)

\begin{tabular}{|c|c|c|c|c|c|}
\hline Description & $\begin{array}{l}\text { Flow } \\
(1 \mathrm{~b} / \mathrm{h})\end{array}$ & $\begin{array}{c}\text { Enthalphy } \\
\text { (Btu/lb) }\end{array}$ & $\begin{array}{c}\text { Power } \\
(k W)\end{array}$ & $\underset{\left(10^{\circ} \mathrm{Btu} / \mathrm{h}\right)}{\text { Energy }}$ & $\begin{array}{c}\text { Energy } \\
\text { Output } \\
(\%)\end{array}$ \\
\hline Process Steam & 80,000 & $1,195.50$ & & 95.64 & \\
\hline (Returned Condensate) & $(52,000)$ & 128.30 & & $(6.67)$ & \\
\hline (Makeup Water) & $(29,600)$ & 23.10 & & $(0.68)$ & \\
\hline Steam Energy Output & & & & 8.88 .29 & 101 \\
\hline (Plant Auxiliaries) & & & (329) & $(1.12)$ & \\
\hline Electric Power Output & & & & & (1) \\
\hline Total Energy Output & & & & $8.86,05$ & 100 \\
\hline Coal Energy Input & 8,173 & 12,452 & & 101.77 & \\
\hline Limestone Feed & 3,824 & & & & \\
\hline Ash Production & 2,647 & & & & \\
\hline Net Thermal Efficfency & & & & & 85.65 \\
\hline
\end{tabular}

Table 64 Auxiliary Sumary--Small AFBC (Boiler Only)

\begin{tabular}{|l|r|}
\hline \multicolumn{1}{|c|}{ Item } & \multicolumn{1}{|c|}{$k W$} \\
\hline Coal Handling & 2 \\
\hline Limestone Handling & 32 \\
\hline Coal Preparation and Feed & 16 \\
\hline Limestone Preparation and Feed & 7 \\
\hline Feedwater System & 34 \\
\hline Compressed Air System & 219 \\
\hline Ash Handling & 15 \\
\hline Miscellaneous & 5 \\
\hline Total Auxiltaries & 330 \\
\hline
\end{tabular}




\subsubsection{Plant Capital and Operating Costs}

Capital Costs. The capital cost of each account item was estimated to equal its cost in the report [1], adjusted to reflect any changes in one or two performance parameters. For example, the cost of coal handling equipment equals the cost in the report, adjusted to reflect changes in the coal feed rate.

Table 65 lists the elements of the installed capital cost. Cost items were rearranged to fit into the same 14 categories as for this study. All costs in this report are expressed in $\$ 1989$.

Operating Costs. Annual operating costs were estimated from the costs of fuel, feedstocks, plant labor, maintenance, and other items as listed in Table 66 .

The total annual operating cost and fixed costs associated with the total capital requirements are key components of the levelized cost of steam. The steam costs of all systems are compared in Section 6. 


\section{Table 65 Installed Capital Cost--Small AFBC (Boiler Oniy) $\left(\$ \times 10^{3}\right)$}

\begin{tabular}{|r|l|r|}
\hline 1 & Coal and Sorbent Handling & 763.9 \\
2 & Coal and Sorbent Preparation and Feed & 706.3 \\
3 & Feedwater and Miscellaneous Systems & $1,151.5$ \\
4 & Boiler and Accessories & $1,620.8$ \\
5 & Hot Gas Cleanup and Piping &.-- \\
6 & Combustion Turbine and Accessories \\
7 & Waste Heat Boiler, Duct, and Stack &.- \\
8 & Steam Turbine and Accessories & 68.0 \\
9 & Cooling Water System & -- \\
10 & Ash and Spent Sorbent Handling & 54.8 \\
11 & Accessory Electric--Plant & 642.1 \\
12 & Instrumentation and Controls & 640.3 \\
13 & Improvements to Site & $1,124.6$ \\
14 & Buildings and Structures & 67.6 \\
& Bare Erected Cost & 276.6 \\
$10 \%$ & Indirect Costs & $7,116.5$ \\
$0 \%$ & Process Contingency & 711.7 \\
$15 \%$ & Project Contingency &.-- \\
\hline
\end{tabular}

\section{References and adjustments for estimating each cost account:}

1 Cosl and Sorbent Handling: Equipment cost based on Case 1 cosl and sorbent handling equipment costs for Industrial CPFBC, adjusted to ref lect different coal and sorbent flows for this case.

2 Coal and Sorbent Preparation and Feed: Equipment cost based on Case 2 coal and sorbent handling equipurent costs for Industrial CPFBC, adjusted to ref lect different coal and sorbent flows for this case.

3 Feedwater and Miscellaneous Systens: Feedwater equipment cost based on Case 2 coal and sorbent handling equipment costs for Industrial CPFBC. adjusted to ref lect different feedwater flow and pressure for this case. Compressed air system cost a lso included undar this account, based on cost of a similar system in the Stearns Catalyt ic Report, adjusted for different coal feed rate for this case and escalated to \$1989.

4 Boiler and Accessories: Stean generating equipment cost based on cost of a simi lar system in the Stearns Catalytic Report, adjusted for different steam production rate for this case and escalated to \$1989. Stean piping cost also included under this account, based on cost of a simi lar system in the Stearns Catalytic Report, adjusted for the steam flow and pressure for this case and escalated to $\$ 1989$.

5 Hot Gas Cleanup and Piping: No equipment, no cost.

6 Combustion Turbine and Accessories: No equipment, no cost.

7 Waste Heat Bojler. Duct and Stack: Air and flue gas system cost based on cost of a similar system in the Stearns Catalytic Report, adjusted for different coal feed rate for this case and escalated to \$1989.

8 Steam Turbine and Accessories: No equipment, no cost.

9 Cooling Vater System: Equipment cost based on Case 2 cost for Industrial CPFBC, adjusted to ref lect difference in thermal input to plant for this case.

10 Ash and Spent Sorbent Handling: Equipment cost based on Case 1 cost for Industrial CPFE: adjusted to reflect difference in ash production for this case.

11 Accessory Electric--P lant: Equipment cost based on Case 1 cost for Industrial CPFBC, adjusted to ref lect difference in generated and auxiliary power for this case.

12 Instrumentation and Controls: Equipment cost based on Case 1 cost for Industrial CPFBC, adjusted to reflect difference in thermal input to plant for this case.

13 Imorovements to Site: Equipment cost assumed the same fraction of equipment cost as in Case 1 for the Industrial CPFBC.

14 Buildings and Structures: Equipment cost assumed the same fraction of equipment cost as in Case 1 for the Industrial CPFBC. 
Table 66 Annual Operating Costs--Small AFBC Boiler

\begin{tabular}{|c|c|c|c|}
\hline Cost Categories & Quantity & $\begin{array}{c}\text { Unit } \\
\text { Price (\$) }\end{array}$ & $\begin{array}{c}\text { Total } \\
\left(5 \times 10^{3}\right)\end{array}$ \\
\hline $\begin{aligned} & \text { Fuel: } \text { Pittsburgh No. } 8 \\
& \text { Coal }\end{aligned}$ & $\begin{array}{l}8,1731 \mathrm{~b} / \mathrm{h} \\
101.7710^{6} \mathrm{Btu} / \mathrm{h}\end{array}$ & $1.50 / 10^{3} \mathrm{Btu}$ & 1,071 \\
\hline $\begin{array}{l}\text { Consumable Materials: } \\
\text { Limestone } \\
\text { Raw Water } \\
\text { Water Treatment Chemicals } \\
\text { (40\% of water cost) }\end{array}$ & $\begin{array}{l}1.9 \mathrm{t} / \mathrm{h} \\
58 \mathrm{gal} / \mathrm{min}\end{array}$ & $\begin{array}{l}\$ 18.80 / \mathrm{t} \\
0.75 / 1000 \mathrm{gal}\end{array}$ & $\begin{array}{r}252 \\
18 \\
7\end{array}$ \\
\hline Ash Disposal Costs, & $1.32 \mathrm{t} / \mathrm{h}$ & $\$ 9.75 / t$ & 90 \\
\hline $\begin{array}{l}\text { Plant Labor: } \\
\text { Operators } \\
\text { Supervision and Clerical } \\
\text { (20\% of O8M) }\end{array}$ & $4.5 /$ shift & $24.65 / h$ & $\begin{array}{l}972 \\
237\end{array}$ \\
\hline Maintenance Costs & & & 214 \\
\hline Total Operating Costs & & & 2,861 \\
\hline
\end{tabular}




\subsection{COMPARISON: SMALL AFBC COGENERATION}

\subsubsection{Plant Description}

The AFBC cogeneration plant is designed to produce process steam and electric power. The plant arrangement is identical to that of the large AFBC cogeneration plant described previously and is as shown in Figure 68 . The major components are:

- Coal and sorbent storage and handling facilities

- An AFB combustor burning Pittsburgh No. 8 coal with limestone

- A primary air fan to pressurize the air for fluidizing the bed and burning the coal

- An ash cooler to cool the coal ash and spent sorbent

- A baghouse to clean the combustion products from the AFBC

- An ash storage area

- A steam generation system including a deaerator, a boiler feed pump, an economizer section, and a boiler

- A back-pressure steam turbine

\subsubsection{Plant Performance}

The approach to estimating the performance of the AFBC plant was to use performance data from an existing report [1], adjusted to account for changes in steam generating capacity and coal type.

The small AFBC cogeneration plant has an overall thermal efficiency of 85.9 percent, based on the higher heating value of coal. Table 67 summarizes the performance of the plant, and Table 68 lists the auxiliary power requirements.

\subsubsection{Plant Capital and Operating Costs}

Capital costs. The capital cost of each account item was estimated to equal its cost in the report [1], adjusted to reflect any changes ir. one or two performance parameters. For example, the cost of coal handling equipment equals the cost in the report, adjusted to reflect changes in the coal feed rate.

Table 69 lists the elements of the installed capital cost. Cost items were rearranged so they fit into the same 14 categories as for this study. All costs in this report are expressed in $\$ 1989$.

Operating Costs. Annual operating costs were estimated from the costs of fuel, feedstocks, plant labor, maintenance, and other items as listed in Table 70 .

The total annual operating cost and fixed costs associated with the total capital requirements are key components of the levelized cost of steam. The steam costs of all systems are compared in Section 6 . 
Table 67 Summary Performance Data--Small AFBC Cogeneration

\begin{tabular}{|l|r|r|r|r|c|}
\hline \multicolumn{1}{|c|}{ Description } & $\begin{array}{c}\text { Flow } \\
(\mathrm{lb} / \mathrm{h})\end{array}$ & $\begin{array}{c}\text { Enthalphy } \\
(\mathrm{Btu} / \mathrm{lb})\end{array}$ & $\begin{array}{c}\text { Power } \\
(\mathrm{KW})\end{array}$ & $\begin{array}{c}\text { Energy } \\
\left(10^{6} \mathrm{~B}-\right. \\
\mathrm{tu} / \mathrm{h})\end{array}$ & $\begin{array}{c}\text { Energy } \\
\text { Output } \\
(\%)\end{array}$ \\
\hline Process Steam & 80,000 & $1,284.80$ & & 102.78 & \\
\hline (Returned Condensate) & $(52,000)$ & 128.30 & & $(6.67)$ & \\
\hline (Makeup Water) & $(29,600)$ & 23.10 & & $(0.68)$ & \\
\hline Steam Energy Output & & & & 95.43 & 87 \\
\hline Steam Turbine Power & 4,588 & 15.66 & & & \\
\hline (Plant Auxiliaries) & $(566)$ & $(1.93)$ & & & \\
\hline Electric Power Output & & & 4,022 & 13.73 & 13 \\
\hline Total Energy Output & & & & 109.16 & 100 \\
\hline Coal Energy Input & 10,203 & 12,452 & & 127.05 & \\
\hline Ash Production & 3,304 & & & & \\
\hline Net Thermal Efficlency & & & & & 85.91 \\
\hline
\end{tabular}

Table 68 Auxiliary Summary--Small AFBC Cogeneration

\begin{tabular}{|l|r|}
\hline \multicolumn{1}{|c|}{ Item } & \multicolumn{1}{|c|}{ kW } \\
\hline Coal Handling & 2 \\
\hline Limestone Handling & 39 \\
\hline Coal Preparation and Feed & 19 \\
\hline Limestone Preparation and Feed & 9 \\
\hline Feedwater System & 171 \\
\hline Compressed Air System & 273 \\
\hline Steam Turbine Auxiliaries & 28 \\
\hline Ash Handling & 19 \\
\hline Miscellaneous & 6 \\
\hline Total Auxiliaries & 566 \\
\hline
\end{tabular}




\begin{tabular}{|r|l|r|}
\hline 1 & Coal and Sorbent Handling & 892.3 \\
2 & Coal and Sorbent Preparation and Feed & 825.0 \\
3 & Feedwater and Miscellaneous Systems & $1,386.3$ \\
4 & Boiler and Accessories & $3,260.3$ \\
5 & Hot Gas Cleanup and Piping &.-- \\
6 & Combustion Turbine and Accessories & -7.4 \\
7 & Waste Heat Boiler, Duct, and Stack & 79.4 \\
8 & Steam Turbine and Accessories & $1,662.3$ \\
9 & Cooling Water System & 72.1 \\
10 & Ash and Spent Sorbent Handling & 750.0 \\
11 & Accessory Electric--Plant & $1,853.3$ \\
12 & Instrumentation and Controls & $1,239.8$ \\
13 & Improvements to Site & 120.0 \\
14 & Buildings and Structures & 491.0 \\
& Bare Erected Cost & $12,631.8$ \\
$10 \%$ & Indirect Costs & $1,389.7$ \\
$0 \%$ & Process Contingency &.-- \\
$15 \%$ & Project Cont ingency & 2.103 .2 \\
\hline
\end{tabular}

\section{References and adjustments for estimating each cost account:}

1 Coal and Sorbent Handling: Equipenent cost based on Case 1 cosl and sorbent handling equipment costs for Industrial CPFBC, adjusted to ref lect different coal and sorbent flows for this case.

2 Coal and Sorbent Preparation and Feed: Equipwent cost based on Case 2 cos 1 and sorbent handling equipment costs for Industrial CPFBC, adjusted to ref lect different coal and sorbent flows for this case.

3 Feedwater and Miscell lanepus Systeas: Feedwater equipment cost based on Case 2 coal and sorbent handling equipment costs for Industrial CPFBC, adjusted to ref lect different feedwater flow and pressure for this case. Compressed air system cost a lso included under this account. based on cost of a simi lar system in the Stearns Catalytic Rmport, adjusted for different coel feed rate for this case and escalated to \$1989.

4 Botler and Accessories: Stcam generating equipment cost based on cost of a simi lar system in the Stearns Catalytic Report, adjusted for different steam product ion rate for this case and eaca lated to \$1989. Staam piping cost a 130 included under this account, based on cost of a sint lar system in the Stearns Catalytic Report, adjusted for the steam flow and pressure for this case and escalated to \$1989.

5 Hot Gas Cleanup and Piping: No equipment, no cost.

6 Conbustion Turbine and Accessories: Ho equipment, no cost.

7 Haste Heat Boiler. Duct, and Stack: Air and flue gas system cost based on cost of a similar system in the Stearns Catalytic Report, adjusted for different coal feed rate for this case and esca lated to $\$ 1989$.

8 Steam Turbine and Accessories: Backpressure Stean Turbine and its accessory costs was based on the stean turbine cost in Case 1 for the Industrial CPFBC, adjusted to ref lect difference in power generation for this case.

9 Coolina Vater System: Equipment cost based on Case 2 cost for Industrial CPFBC, adjusced to ref lect difference in thermal input to plant for this case.

10 Ash and Spent Sorbent Handling: Equipment cost based on Case 1 cost for Industrial CPFBC, adjusted to reflect difference in ash production for this case.

11 Accessory Electric--Plant: Equipment cost based on Case 1 cost for Industrial CPFBC, adjusted to ref lect difference in generated and auxiliary power for this case.

12 Instrumentation and Controls: Equipment cost based on Case 1 cost for Industrial CPFBC, adjusted to reflect difference in thermal input to plant for this case.

13 Improvements to Site: Equipment cost assumed the same fraction of equipment cost as in Case 1 for the Industrial CPFBC.

14 Buildings and Structures: Equipment cost assumed the same fraction of equipnent cost as in Case 1 for the Industríal CPFBC. 
Table 70 Annual Operating Costs--Small AFBC Cogeneration

\begin{tabular}{|c|c|c|c|}
\hline Cost Categories & Quantity & $\begin{array}{c}\text { Unit } \\
\text { Price (\$) }\end{array}$ & $\left(5 \times 10^{3}\right)$ \\
\hline $\begin{array}{l}\text { Fuel: } \begin{array}{l}\text { Pittsburgh No. } 8 \\
\text { Coal }\end{array}\end{array}$ & $\begin{array}{l}10,2031 \mathrm{~b} / \mathrm{h} \\
127.0510^{8} \mathrm{Btu} / \mathrm{h}\end{array}$ & $1.50 / 10^{6} \mathrm{Btu}$ & 1,336 \\
\hline $\begin{array}{l}\text { Consumable Materials: } \\
\text { Limestone } \\
\text { Raw Water } \\
\text { Water Treatment Chemicals } \\
\text { (40\% of water cost) }\end{array}$ & $\begin{array}{l}2.4 \mathrm{t} / \mathrm{h} \\
58 \mathrm{gal} / \mathrm{min}\end{array}$ & $\begin{array}{l}\$ 18.80 / \mathrm{t} \\
0.75 / 1000 \mathrm{gal}\end{array}$ & $\begin{array}{r}315 \\
18 \\
7\end{array}$ \\
\hline Ash Disposal Costs & $1.65 \mathrm{t} / \mathrm{h}$ & $\$ 9.75 / t$ & 113 \\
\hline $\begin{array}{l}\text { Plant Labor: } \\
\text { Operators } \\
\text { Supervision and Clerical } \\
\text { (20\% of 0\&M) }\end{array}$ & $5.5 /$ shift & $24.65 / \mathrm{h}$ & $\begin{array}{r}1,188 \\
301\end{array}$ \\
\hline Maintenance Costs & & & 316 \\
\hline Total Operating Costs & & & 3,594 \\
\hline
\end{tabular}




\subsection{COMPARISON: SMALL GAS TURBINE COGENERATION}

\subsubsection{Plant Description}

The small gas turbine cogeneration plant is designed to produce process steam and electric power. The plant arrangement identical to that of the large gas turbine cogeneration plant and is shown in Figure 69.

The major components are:

- Natural-gas-fired gas turbine.

- A steam generation system, including a deaerator, a boiler feed pump, an economizer section, and a boiler.

\subsubsection{Plant Parformance}

The approach to estimating the performance of the gas turbine cogeneration plant was to use performance data from an existing report [2], adjusted to accourt. for changes in steam generating capacity and gas turbine efficiency.

The small gas turbine cogeneration plant has an overall thermal efficiency of 81.18 percent, based on the higher heating value of natural gas. Table 71 summarizes plant performance.

\subsubsection{Plant Capital and Operating Costs}

Capital Costs. The capital cost of each account item was estimated based on a reference cost [2], adjusted to reflect any changes in one or two performance parameters. The reference costs refer to either Cases 1 and 2 of this report or to the Gas Turbine Morld 1990 Handbook [2], as indicated in the notes below Table 72. For example, the cost of the combustion turbine equals the cost in the report, adjusted to reflect changes in power generation rating.

Table 72 lists the elements of the installed capital cost. Cost items were rearranged to fit into the same 14 categories as for this study. All costs in this report are expressed in $\$ 1989$.

Operating Costs. Annual operating costs were estimated from the costs of fuel, feedstocks, plant labor, maintenance, and other items as listed in Table 73.

The total annual operating cost and fixed costs associated with the total capital requirements are key components of the levelized cost of steam. The steam costs of all systems are compared in Section 6. 
Table 71 Summary Performance Data--Small Gas Turbine Cogeneration

\begin{tabular}{|l|r|r|r|r|c|}
\hline \multicolumn{1}{|c|}{ Description } & $\begin{array}{c}\text { Flow } \\
(\mathrm{lb} / \mathrm{h})\end{array}$ & $\begin{array}{c}\text { Enthalphy } \\
(\mathrm{Btu} / \mathrm{lb})\end{array}$ & $\begin{array}{c}\text { Power } \\
(\mathrm{KW})\end{array}$ & $\begin{array}{c}\text { Energy } \\
\left(10^{6} \mathrm{Btu} / \mathrm{h}\right)\end{array}$ & $\begin{array}{c}\text { Energy } \\
\text { Output } \\
(\%)\end{array}$ \\
\hline Process Steam & 80,000 & $1,195.67$ & & 95.65 & \\
\hline $2 \%$ Boiler Blowdown & 1,633 & 338.46 & & 0.55 & \\
\hline (Returned Condensate) & $(52,000)$ & 128.30 & & $(6.67)$ & \\
\hline (Makeup Water) & $(29,633)$ & 23.10 & & $(0.68)$ & $:$ \\
\hline Steam Energy Output & & & & 88.85 & 75 \\
\hline Gas Turbine Power & & & 8,623 & 29.43 & \\
\hline (Plant Auxiliaries) & & & $(100)$ & $10.34)$ & \\
\hline Electric Power output & & & 8,523 & 29.09 & 25 \\
\hline Total Energy Output & & & & 117.94 & 100 \\
\hline Gas Turbine Fuel & 4,938 & 21,813 & 107.71 & & 74 \\
\hline Duct Burner Fuel & 1,723 & 21,813 & 37.58 & & 26 \\
\hline Net Thermal Efficiency & & & & & 81.18 \\
\hline
\end{tabular}




\begin{tabular}{|c|c|c|}
\hline $\begin{array}{r}1 \\
2 \\
3 \\
4 \\
5 \\
6 \\
7 \\
8 \\
9 \\
10 \\
11 \\
12 \\
13 \\
14\end{array}$ & $\begin{array}{l}\text { Coal and Sorbent Handling } \\
\text { Coal and Sorbent Preparation and Feed } \\
\text { Feedwater and Miscellaneous Systems } \\
\text { Boiler and Accessories } \\
\text { Hot Gas Cleanup and Piping } \\
\text { Combustion Turbine and Accessories } \\
\text { Waste Heat Boiler, Duct, and Stack } \\
\text { Steam Turbine and Accessories } \\
\text { Cooling Water System } \\
\text { Ash and Spent Sorbent Handling } \\
\text { Accessory Electric--Plant } \\
\text { Instrumentation and Controls } \\
\text { Improvements to Site } \\
\text { Buildings and Structures } \\
\text { Bare Erected Cost }\end{array}$ & $\begin{array}{r}\ldots \\
1,004.4 \\
\ldots \\
5,924.2 \\
755.1 \\
\ldots \\
\ldots \\
1,351.6 \\
94.1 \\
91.2 \\
324.2 \\
9,544.8\end{array}$ \\
\hline $\begin{array}{r}11 \% \\
0 \% \\
15 \%\end{array}$ & $\begin{array}{l}\text { Indirect Costs } \\
\text { Process Contingency } \\
\text { Project Cont ingency } \\
\text { Total Plant Cost }\end{array}$ & $\begin{array}{r}1,049.9 \\
\cdots \\
1,589.2 \\
12,183.9\end{array}$ \\
\hline
\end{tabular}

\section{References and adjustments for estimating each cost account:}

1 Coal and Sorbent Handling: No equipment, no cost.

2 Coal and Sorbent Preparation and Feed: No equipment, no cost.

3 Feedwater and Miscellaneous Systems: The cost of the feedwater equipment was based on the coal and sorbent handling equipment costs in Case 2 for the Industrial CPFBC. The Case 2 costs were adjusted to ref lect the different feedwater flow and pressure for this case.

4 Boiler and Accessories: No equipment, no cost. (The cost of stean generat ing equipment is inc luded under Account 7.)

5 Hot Gas Cleanup and Piping: No equipment, no cost.

6 Conbustion Turbine and Accessories: The cost of the combustion turbine system was based on the cost of a similar system in the 1990 Gas Turbine Morld Mandbook, adjusted for the different power generation rating for this case.

7 Haste Heat Bofler. Duct, and Stack: The cost of the waste heat bol ler systen was based on the cost of a similar system in Case 2 for the Industrial CPFBC. adjusted for the different stean generation rate and gas volumetric flow rate for this case.

8 Steam Turbine and Accessories: No equipment, no cost.

9 Cooling Hater System: No equipment, no cost.

10 Ash and Spent Sorbent Handling: Ho equipment, no cost.

11 Accessory Electric--Plant: The cost of this equipment was based on the cost of a similar system in the 1990 Gas Turbine World Handbook, adjusted for the different power generation rat ing for this case.

12 Instrumentation and Controls: The cost of this equipment was based on the cost of a simi'ar system in the 1990 Gas Turbine World Handbook, adjusted for the different power generation rat ing for this case.

13 Improvements to Site: The cost of this equipment was assumed to be the same fraction of equipment cost as in Case 1 for the Industrial CPFBC.

14 Buildings and Structures: The cost of this equipment was assumed to be the same fraction of equipment cost as in Case 1 for the Industrial CPFBC. 
Table 73 Annual Operating Costs--Small Gas Turbine Cogeneration

\begin{tabular}{|c|c|c|c|}
\hline Cost Categories & Quantity & $\begin{array}{l}\text { Unit } \\
\text { Price (\$) }\end{array}$ & $\begin{array}{l}\text { Total } \\
\left(\$ \times 10^{3}\right)\end{array}$ \\
\hline Fuel: Natural Gas & $\begin{array}{l}6,660 \mathrm{lb} / \mathrm{h} \\
145.27 \mathrm{10} \mathrm{Btu} / \mathrm{h}\end{array}$ & $3.99 / 10^{6} \mathrm{Btu}$ & 4,065 \\
\hline $\begin{array}{l}\text { Consumable Materials: } \\
\text { Raw Water } \\
\text { Water Treatment Chemicals } \\
\text { ( } 40 \% \text { of water cost) }\end{array}$ & $58 \mathrm{gal} / \mathrm{min}$ & $0.75 / 1000 \mathrm{gal}$ & $\begin{array}{r}18 \\
7\end{array}$ \\
\hline $\begin{array}{l}\text { Plant Labor: } \\
\text { Operators } \\
\text { Supervision and Clerical } \\
\text { (20\% of 0\&M) }\end{array}$ & 3/shift & $24.65 / \mathrm{h}$ & $\begin{array}{l}648 \\
177\end{array}$ \\
\hline Maintenance Costs & & & 239 \\
\hline Total Operating Costs & & & 5,154 \\
\hline
\end{tabular}




\subsection{REFERENCES}

1. B. N. Gaglia and R. L. Clausen, "Fluidized Bed Combustion Final Report," DOE/METC Report DOE/MC/22024-2339, Vol. 1 (DE87006478), Appendix B and Appendix F, Stearns Catalytic Corporation, Denver, May 1986.

2. "Industrial Cogeneration and Independent Power," Gas Turbine World 1990 Handbook, Pequot Publishing, Inc., Fairfield, Connecticut, 1990, p. 1-27. 
The relative economics of each industrial second-generation PFBC $p l a n t$ configuration were established by comparing selected alternative technologies within each of the two general size ranges evaluated.

Cases 1 and 2 , as defined in Subsections 4.1 and 4.2, are compared with those alternatives described in Subsections 5.1, 5.2, and 5.3. Cases 3, 4, and 5 are measured against the remaining alternatives for which performance and other criteria are developed in Section 5.

In each case the comparison between alternatives is accomplished in terms $\delta$ the levelized unit cost of steam, established after adjustment for the vilue of electricity produced, purchased, or both. In other respects, underlying assumptions and other analysis criteria are defined in the following paragraphs.

\subsection{GENERAL ASSUMPTIONS}

Financial and related criteria uniformly applied in all analyses reflect the baseline assumptions given in Table 74 .

Table 74 Baseline Assumptions

\begin{tabular}{|c|c|c|c|}
\hline Item & $\begin{array}{l}\text { Cost of } \\
\text { Money }\end{array}$ & $\begin{array}{l}\% \text { of } \\
\text { Total }\end{array}$ & $\begin{array}{c}\text { Weighted } \\
\text { Cost }\end{array}$ \\
\hline Equity & $15 \%$ & 50 & $7.5 \%$ \\
\hline Debt & $11 \%$ & 50 & $5.5 \%$ \\
\hline \multicolumn{2}{|c|}{ Composite (Discount Rate) } & & $13.0 \%$ \\
\hline \multicolumn{2}{|c|}{$\begin{array}{l}\text { Construction Interest Rate } \\
\text { Average Service Life } \\
\text { Construction Escalation Rate } \\
\text { In-Service Date } \\
\text { Construction Periods } \\
\text { General Inflation Rate } \\
\text { Real Escalation Rate-Coal } \\
\text { Real Escalation Rate-Gas } \\
\text { Property Taxes } \\
\text { Plant Insurance } \\
\text { Composite Income Tax Rate } \\
\text { Tax Life }\end{array}$} & \multicolumn{2}{|c|}{$\begin{array}{l}11.25 \% \\
20 \text { Years } \\
4.0 \% \\
\text { January } 1993 \\
\text { Various } \\
5.0 \% \\
-1.0 \% \\
0.0 \\
1.0 \% \text { of Plant } \\
1.0 \% \text { of Plant } \\
36.0 \% \\
20 \text { Years }\end{array}$} \\
\hline
\end{tabular}

Other underlying assumptions are defined under the topical headings in the sections that follow. 


\subsection{CAPITAL COSTS}

Direct capital costs, indirect costs, and contingencies included for each relevant option are developed in Section 4 for the technologies being studied and in Section 5 for the alternatives used for comparison. For reference, costs for the respective Study Cases are restated in Table 75.

Table 75 Summary of Capital Costs for Study Cases $\left(\$ \times 10^{3}\right)$

\begin{tabular}{||c|c|c|c|c|c||}
\hline $\begin{array}{c}\text { Study } \\
\text { Case }\end{array}$ & $\begin{array}{c}\text { Direct } \\
\text { Costs }\end{array}$ & $\begin{array}{c}\text { Indirect } \\
\text { Costs }\end{array}$ & $\begin{array}{c}\text { Contingency } \\
\text { Process }\end{array}$ & $\begin{array}{c}\text { Contingency } \\
\text { Project }\end{array}$ & $\begin{array}{c}\text { Total } \\
\text { Cost }\end{array}$ \\
\hline 1 & 64,521 & 7,097 & 4,290 & 11,386 & 87,294 \\
\hline 2 & 57,008 & 6,271 & 4,069 & 10,102 & 77,450 \\
\hline 3 & 23,151 & 2,599 & 1,492 & 4,086 & 31,328 \\
\hline 4 & 26,098 & 2,871 & 1,572 & 4,581 & 34,123 \\
\hline 5 & 24,716 & 2,719 & 1,593 & 4,354 & 33,382 \\
\hline 6 & 21,165 & 2,328 & 1,147 & 3,696 & 28,336 \\
\hline
\end{tabular}

\subsection{OPERATING EXPENSES}

\subsubsection{Operating and Maintenance Expenses}

Specific operating characteristics unique to each Study Case and their alternatives are discussed in Sections 4 and 5 . With respect to fuel costs and other generalized assumptions, the criteria applied are given in Table 76.

Table 76 Operating Expense Criteria

\begin{tabular}{||l|l|}
\hline Operating Labor Cost & $\$ 24.65 / \mathrm{h}$ \\
\hline Maintenance Cost & $\%$ of Plant (or est.) \\
\hline Administration and Overhead & $20 \%$ of Labor and Maintenance \\
\hline Fuel Cost--Coal & $\$ 1.36 / 10^{\circ} \mathrm{Btu}$ \\
\hline Coal Transport & $10 \%$ of Coal Cost \\
\hline Delivered Coal Cost & $\$ 1.50 / 10^{\circ} \mathrm{Btu}$ \\
\hline Fuel Cost--Gas & $\$ 3.99 / 10^{\circ} \mathrm{Btu}$ \\
\hline Sorbent & $\$ 18.80 /$ ton \\
\hline Raw Water & $\$ 0.75 / 1000 \mathrm{gal}$ \\
\hline Water Treating Chemicals & $\$ 0.30 / 1000 \mathrm{gal}$ \\
\hline Ash Removal & $\$ 9.75 /$ ton \\
\hline
\end{tabular}


In each case, the assumptions reflect mid-1989 cost levels, which are escalated to the in-service date (1993) levels through the application of appropriate general inflation and real escalation rates.

\subsubsection{Purchased Power Costs}

A basic assumption of this analysis is that the electrical requirements in the generic industrial environment represented are equivalent to the electrical output of the maximum kilowatt rated alternative. In the respective size categories, electrical requirements are dictated by Case 1 (with a net capacity of $39,460 \mathrm{~kW})$ and Case 4 with $(8529 \mathrm{~kW})$. For all other alternatives, it is then necessary to meet at least some portion of total electrical requirements through assumed power purchases. In the case of the base reference cases (AFBC boiler only), power purchases are necessary to meet total requirements.

To represent the dynamics of purchased power cost calculations as realistically as possible, the actual tariff schedule for a randomily selected investor-owned utility operating within the assumed generic study area (Ohio Valley) was applied. The specific components of the applicable rate schedules are presented in Table 77.

Table 77 Components of Typical Rate Schedules (Ohio Valley)

\begin{tabular}{|c|c|}
\hline \multicolumn{2}{|c|}{ Large Power Service (Over $5000 \mathrm{~kW}$ Demand) } \\
\hline $\begin{array}{l}\text { Capacity Charge: } \\
\text { First } 5000 \mathrm{~kW} \text { or less per month } \\
\text { Next } 10,000 \mathrm{~kW} \\
\text { Next } 25,000 \mathrm{~kW} \\
\text { Over } 40,000 \mathrm{~kW}\end{array}$ & $\begin{array}{l}\$ 72,017 \\
\$ 11.60 \text { per } \mathrm{kW} \\
11.27 \\
10.95\end{array}$ \\
\hline $\begin{array}{l}\text { Energy Charge: } \\
\text { First } 750 \mathrm{mWh}+\$ 400 \text { per month } \\
\text { Next } 150 \mathrm{kWh} / \mathrm{kW} \\
\text { Additional kWh }\end{array}$ & $\begin{array}{l}\text { \$0.0381 per } \cdot \text { kWh } \\
0.0257 \\
0.0233\end{array}$ \\
\hline \multicolumn{2}{|c|}{ General Service--Large $(300$ to $5000 \mathrm{~kW})$} \\
\hline $\begin{array}{l}\text { Capacity Charge: } \\
\text { First } 300 \mathrm{~kW} \text { or less } \\
\text { Additional kW }\end{array}$ & $\begin{array}{l}\$ 5,591 \\
\$ 14.14 \text { per } \mathrm{kW} \\
\end{array}$ \\
\hline $\begin{array}{l}\text { Energy Charge: } \\
\text { Al1 kWh }\end{array}$ & 0.0381 \\
\hline
\end{tabular}

In addition to the information presented in Table 77 , it is particularly relevant to recognize that a substantial charge is applicable for firm backup power supporting the capacity normally available from on-site facilities. In general accord with the representative supplier's rates for such service, a charge of $\$ 3,500 / \mathrm{MW}$ has been incorporated in the analysis. As a consequence, even the maximum capacity alternative upon which overall electrical requirements are based is not free from purchased power costs. 
Obviously, the selection of another utility's tariff schedule would. almost invariably result in expense levels different from those represented on the basis of the rates used in the study. In recognition of this factor, the effect of alternative purchased power cost structures is addressed later as a sensitivity analysis criteria.

\subsubsection{Income Tax Effects}

In our opinion, the inclusion of income tax considerations as a component of operating expenses is essential to analyses that truly reflect actual circumstances, particularly in the case of industrial, and therefore nonregulated, applications.

It is obviously impossible to address all of the specifics of income tax calculations, particularly from the generic perspective of this evaluation. However, it is significant to recognize the incremental (or decremental) effect on income taxes of variations in tax-sensitive items between each of the study and alternative cases and the respective reference cases.

To the extent that operation and maintenance, purchased power costs, and other expenses differ in total from reference levels, income tax bases are affected (i.e., a reduction in operating expenses has the effect of increasing taxable income under the not-unreasonable assumption that overall revenue levels will not be adjusted proportionately). Relative income tax levels are similarly affected by variations in deductible interest charges and tax depreciation related to increments in capital costs.

Income taxes represented in the following analyses were developed by applying the assumed composite Federal and State income tax rate (36 percent) to the net of incremental expenses (excluding income taxes) and deductions for interest charges and tax depreciation established under the assumption of a 20-year tax life. For comparison, results are also developed without consideration for the effects of income tax.

\subsection{EVALUATIONS, COMPARISONS, AND SENSITIVITY ANALYSIS}

\subsubsection{Evaluations and Comparisons}

Although finally combined, the analysis was actually accomplished in two segments representing the large (Cases 1 and 2) and small (Cases 3, 4, 5, and 6) study cases and their respective alternatives, one of which (AFBC boiler-only case) has been designated the reference case for comparison (both large and small cases).

Underlying assumptions, most of which have already been referenced, and other essential parameters (including the development of first-year operating expenses for the several cases) are summarized in Tables 78 (7arge plants) and 79 (small plants).

Comparative costing results are developed in Tables 80 and 81 . Total capital costs include escalation (related to a uniform cash flow over the assumed construction period) and interest during construction. Annual equivalent (levelized) capital costs are determined as fixed charges incorporating return, depreciation, assumed property taxes, and plant insurance costs. 


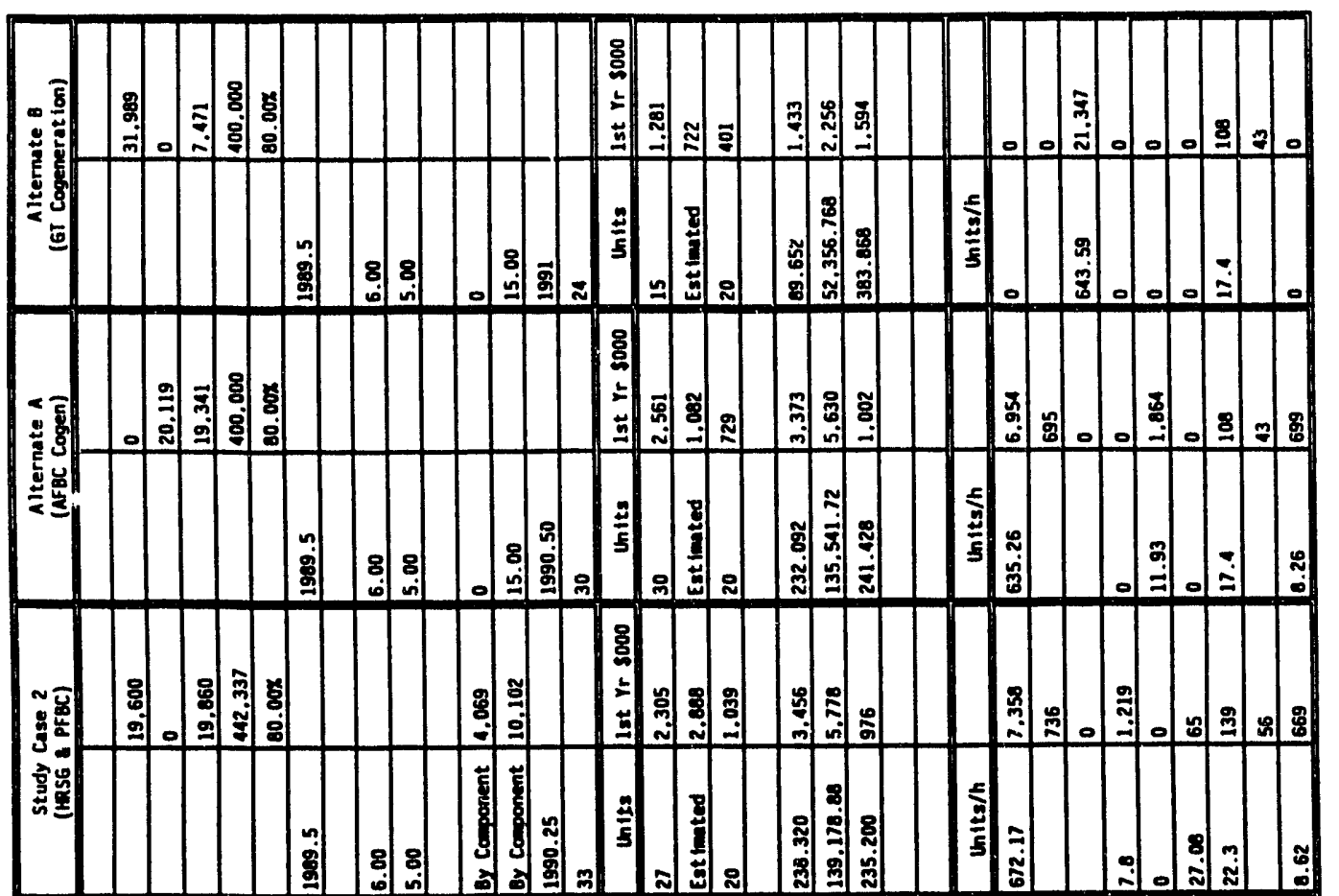

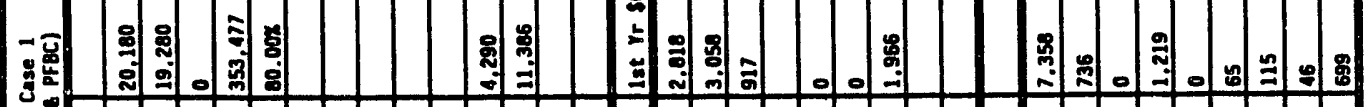

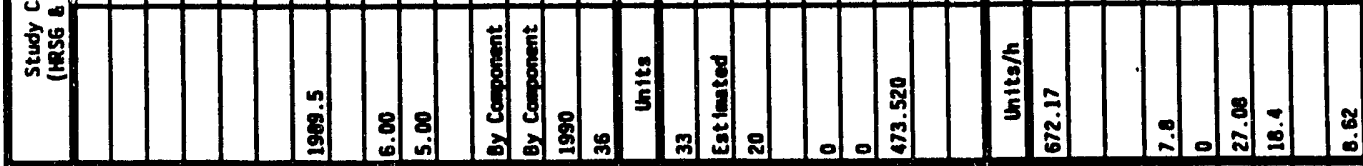

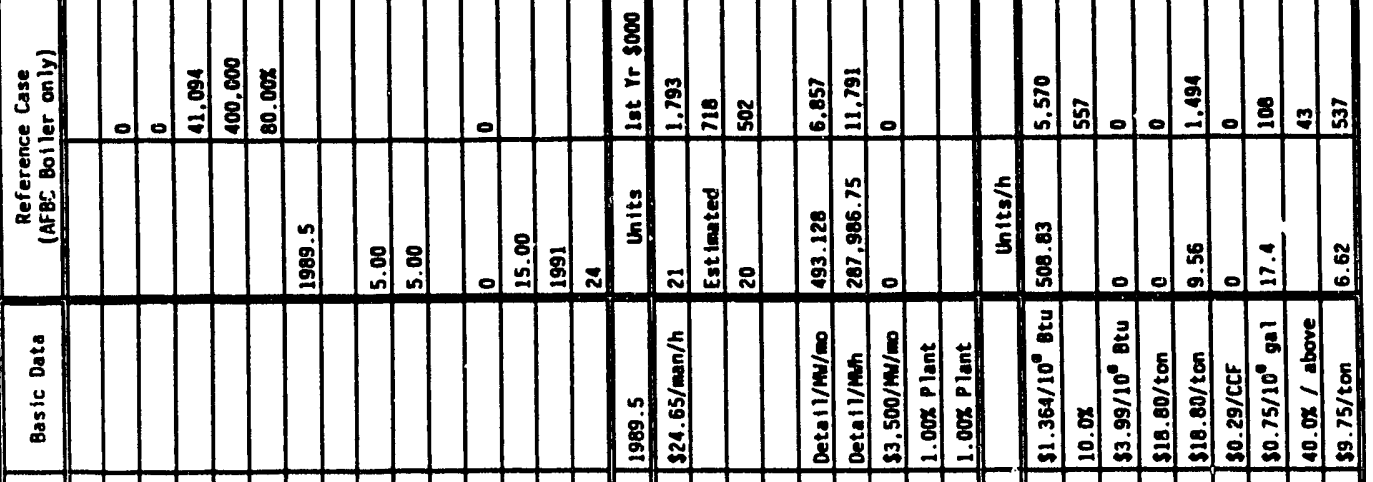

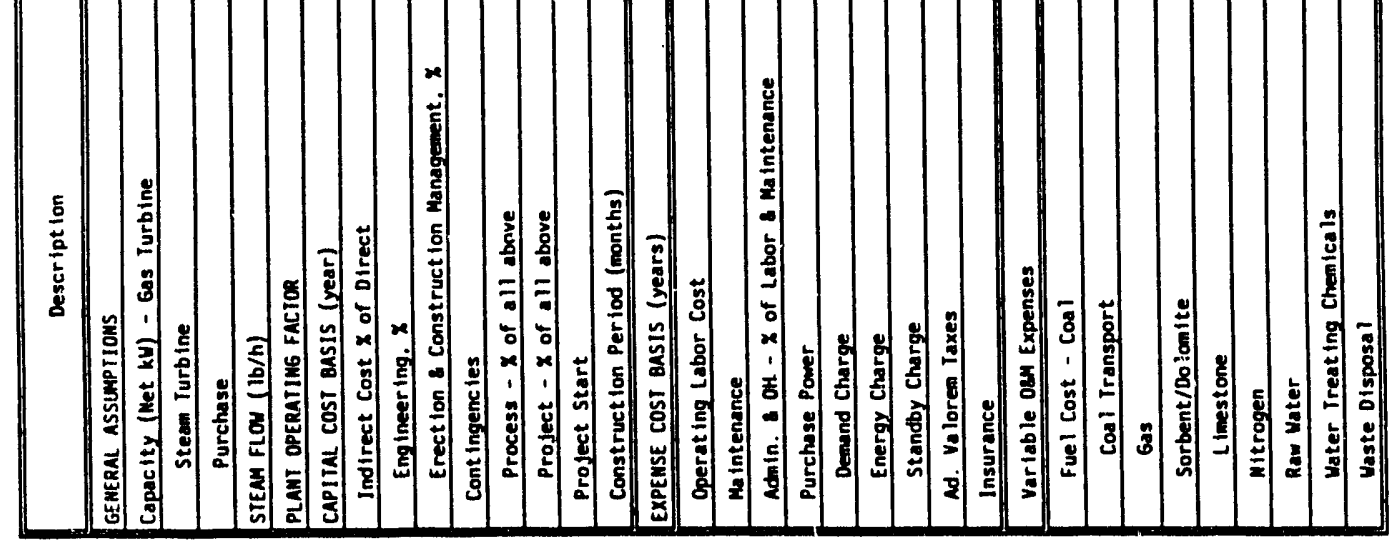



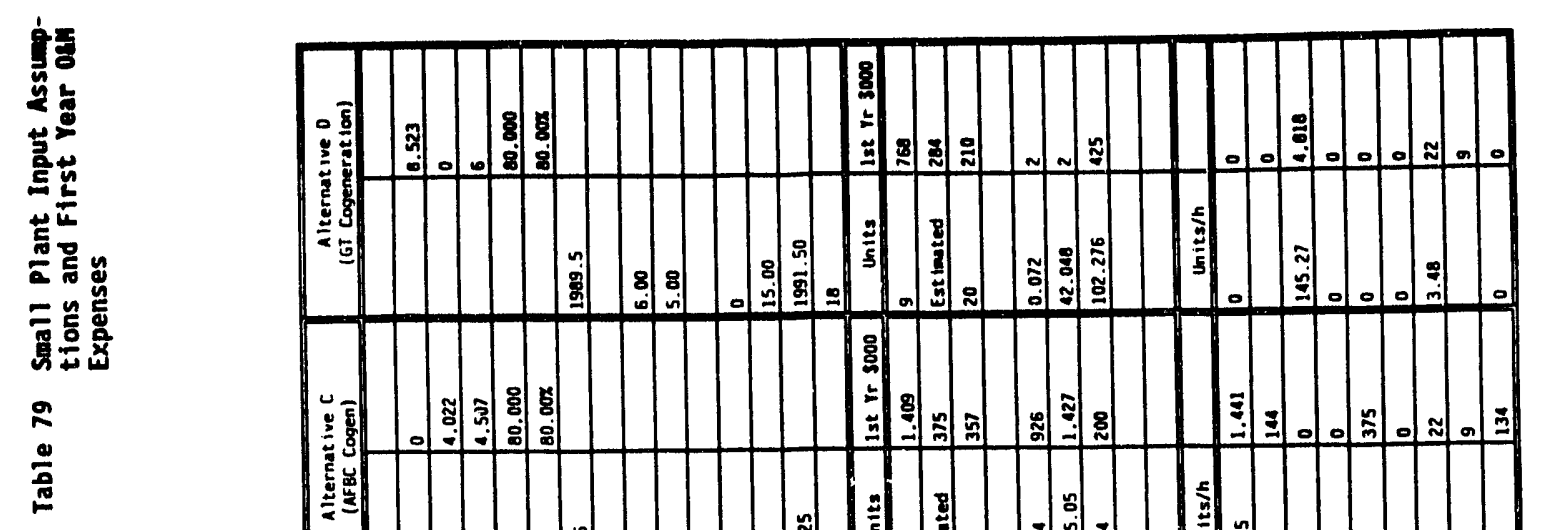
:

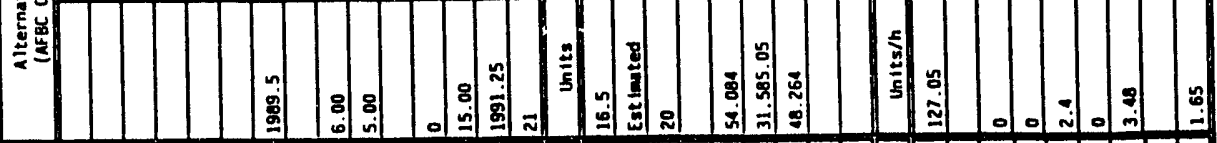

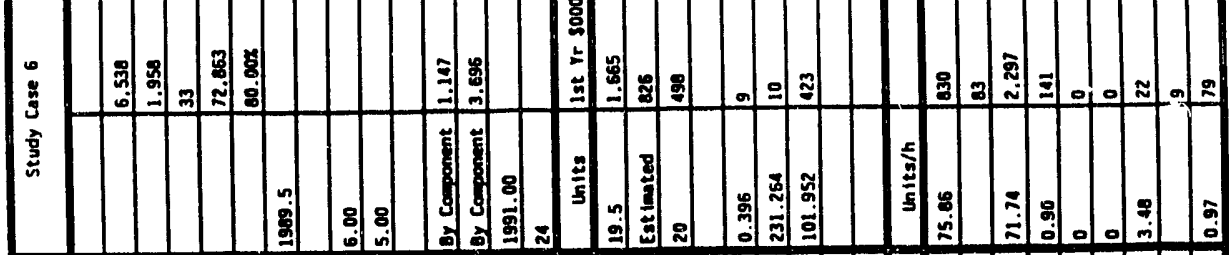

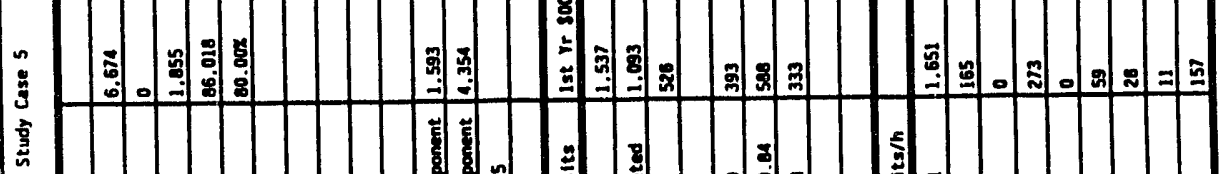

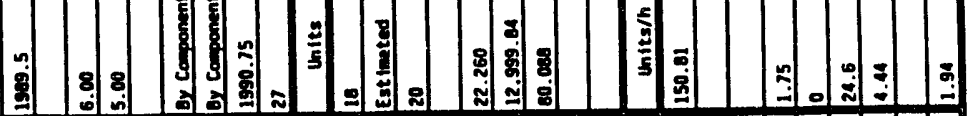

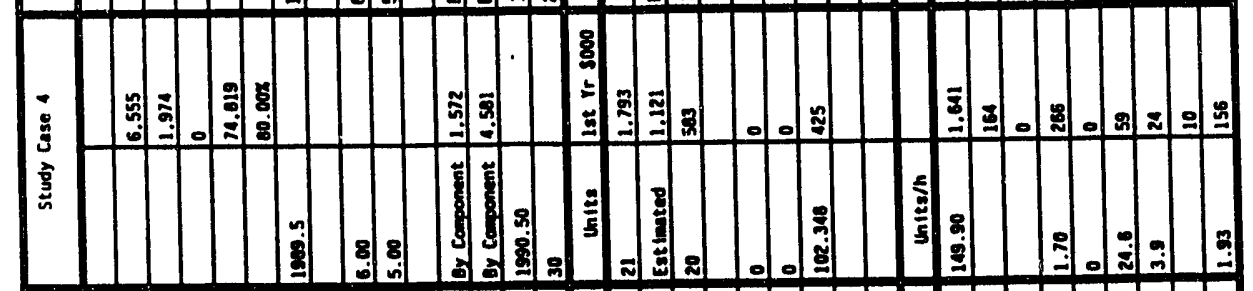

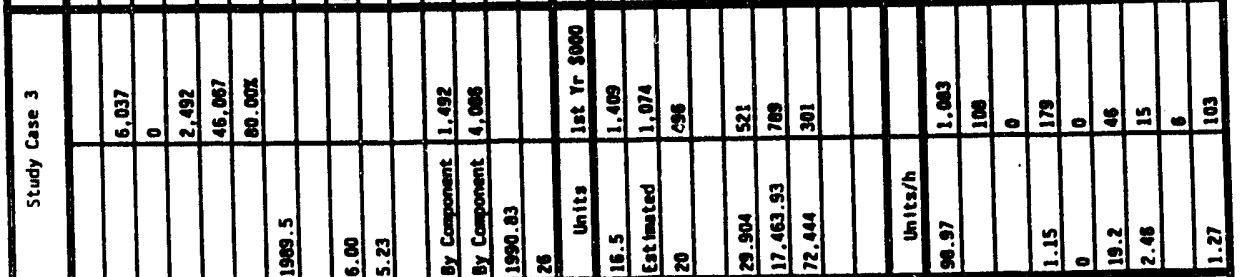
D.

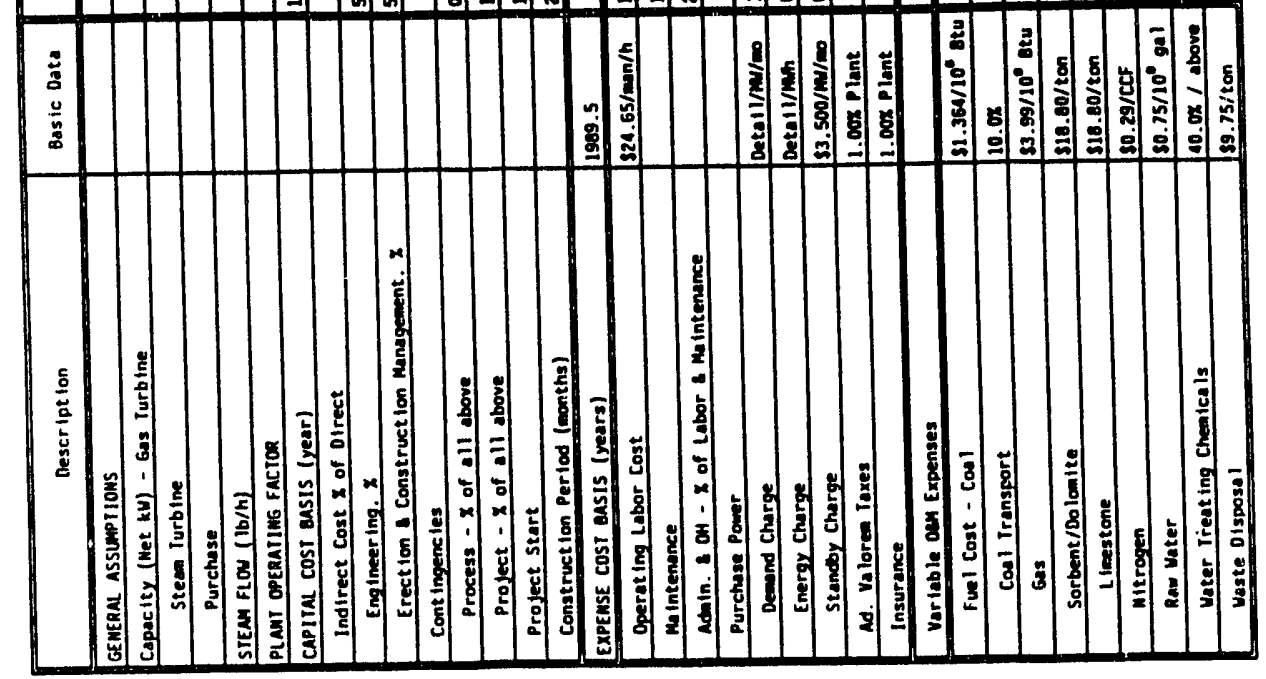




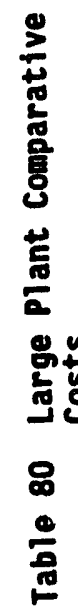

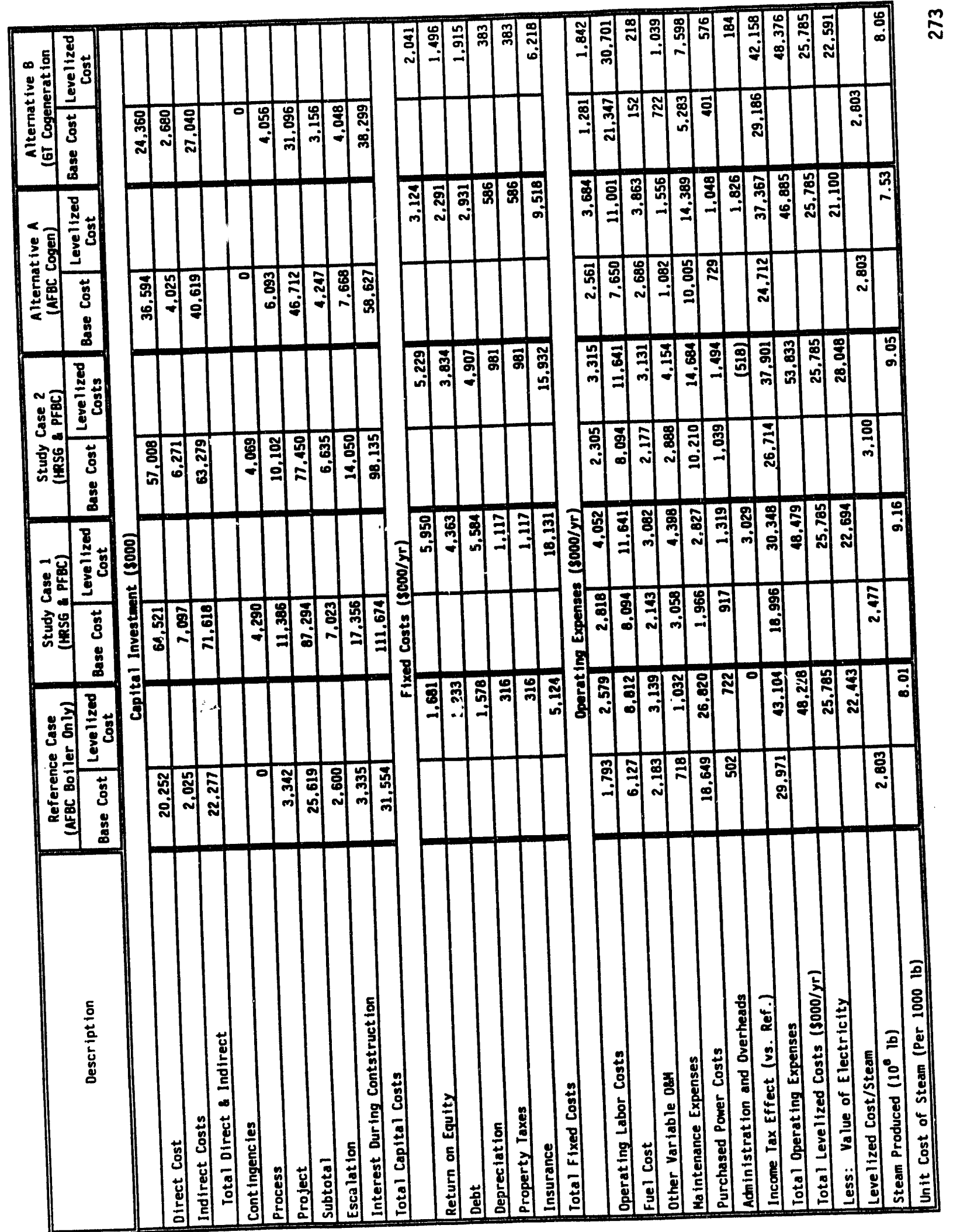




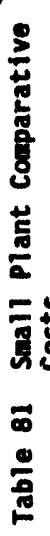

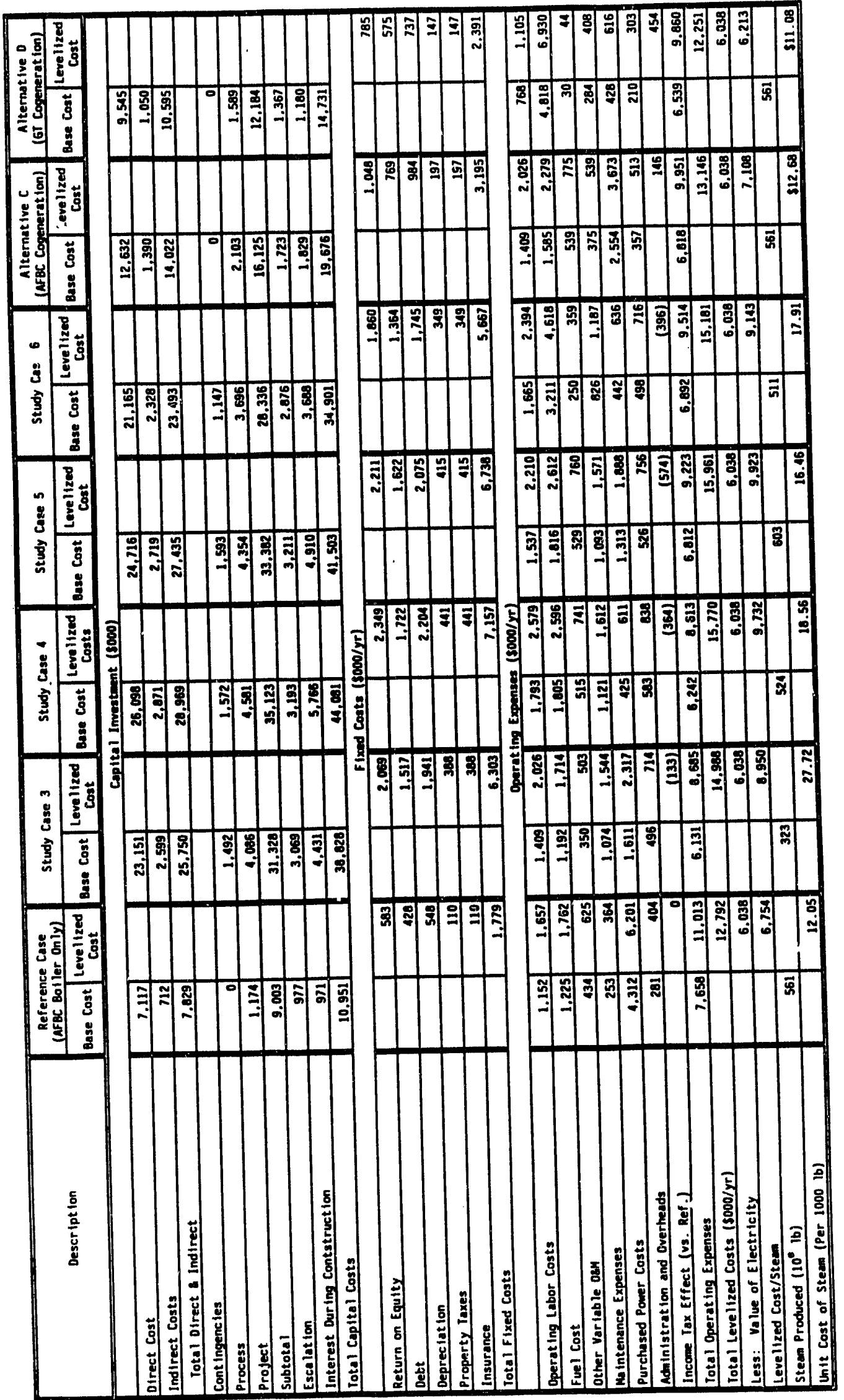

ล 
Similarly, Operating and Maintenance Expenses are represented as levelized annual costs developed from first-year cost levels summarized in Tables 78 and 79 and reflect the composite effect of escalation and discounting at the indicated discount rate. Unit costs in the Basic Data column of Table 78 match the unit prices in the Annual Operating Cost tables in Section 5, expressed in mid-1989 dollars. First-year cost (1st year \$000), however, are expressed in 1993 dollars; they have been escalated at 5 percent from mid-1989 to the in-service date of 1993.

Finally, to isolate costs associated with steam production, the value of electricity is credited to total costs, including fixed charges and levelized operating expenses. The value of electricity is equated in all cases to the avoided cost of total electrical requirements which would otherwise have to be purchased. This value is essentially that represented for the respective reference AFBC boiler-only cases, except that an adjustment is made to exclude purchased power costs related to direct plant auxiliaries.

The unit cost of steam produced is then derived as the basis for evaluation of the economic consequences of adopting any of the study cases posed rather than the reference case or one of the other alternatives against which the study case technologies are measured. Developed in Tables 80 and 81 and summarized in Table 82 , the results obtained are presented in Table 83.

As these data show, the unit cost of steam for all study cases in both size categories is greater than that for the respective reference cases and for all other alternatives represented.

\subsubsection{Sensitivity Analyses}

The conclusions derived are obviously affected by the underlying assumptions incorporated in the analysis. To investigate the effect of variations in certain basic parameters, corresponding results were determined under alternative criteria.

Initially, since some question was raised as to the propriety of including the effect of income taxes, the relative costs of steam were reestabiished in the absence of this factor with all other conditions unchanged. On this basis, the unit costs of steam are derived (Table 84 ).

Significantly, under this basis, the cost of steam for Study Case 1 falls below that for the reference case and the gas turbine cogeneration alternative, but remains higher than that for the AFBC Cogeneration case. For the small study cases, the cost is actually higher than previously since the cumulative effect of interest charges and tax depreciation offset decremental operating expenses to the extent that they initially resulted in a reduction in income taxes compared with the reference case.

Secondly, while the assumption of an 80-percent Plant Operating Factor is considered a reasonable reflection of actual operating circumstances in an industrial environment, variations in the level of operations apparently have a direct effect on unit costs of steam. Figures 70 and 71 illustrate the effect of varying Plant Operating Factor over the range from 25 to 95 percent. Although, as might be expected, the absolute level of steam costs is reduced as the distribution of fixed churges is diluted with ascending levels of steam production, the basic relationship between alternatives (although converging) remains essentially unchanged except for the previously noted emergence of Case 1 in the absence of income tax effects. 


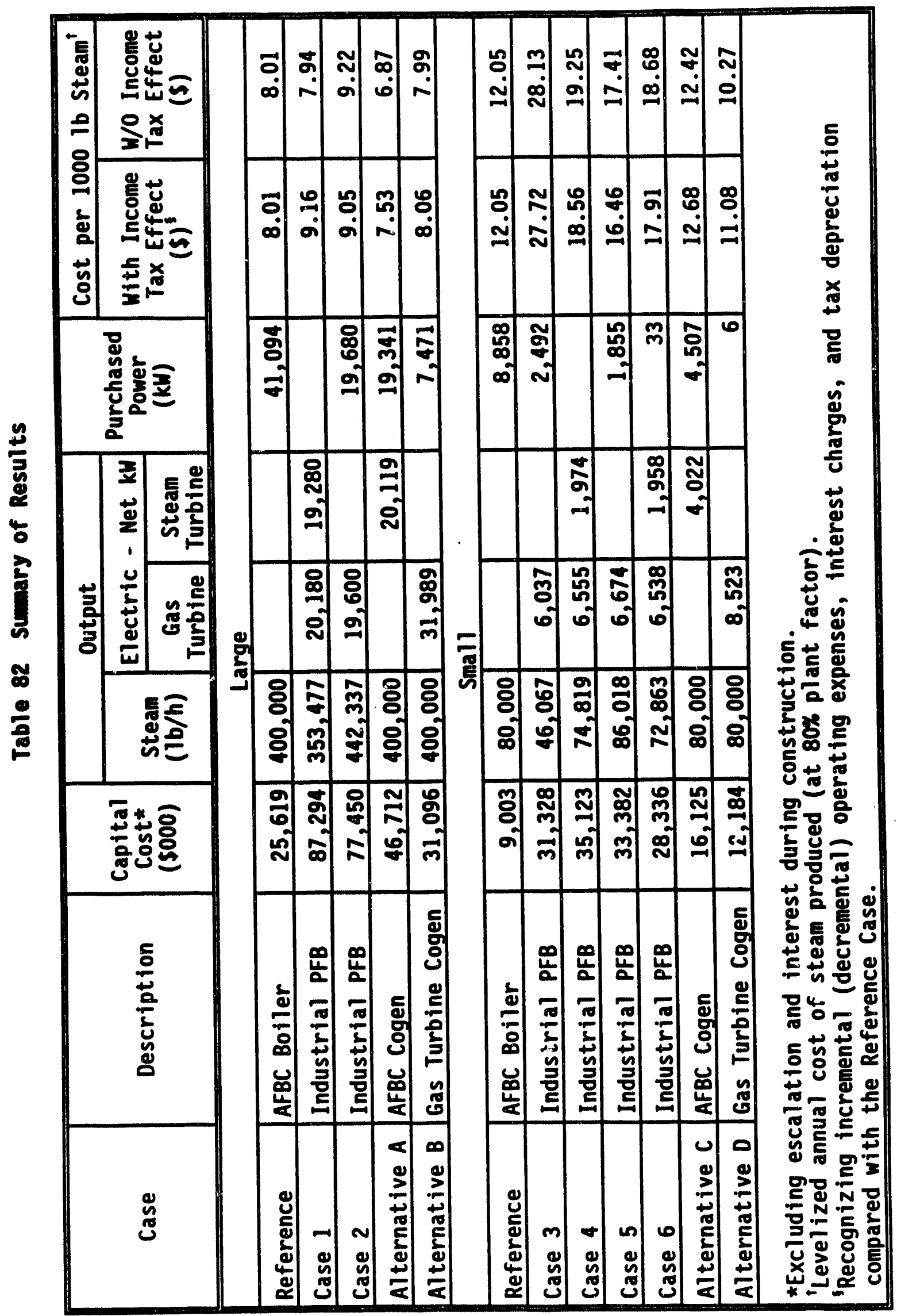


Table 83 Unit Cost of Steam With Income Tax Effect (Based on Tables 80 through 82)

\begin{tabular}{|l|r|r|r||}
\hline \multicolumn{1}{|c|}{ Case } & $\begin{array}{c}\text { Level ized Cost } \\
\text { of Steam } \\
\left(5 \times 10^{3} / \mathrm{yr}\right)\end{array}$ & $\begin{array}{c}\text { Steam } \\
\text { Produced } \\
\left(10^{6} 1 \mathrm{~b}\right)\end{array}$ & $\begin{array}{c}\text { Unit Cost of } \\
\left(\$ \times 10^{3}\right. \\
\text { Steam })\end{array}$ \\
\hline Reference & \multicolumn{3}{|c|}{ Large } \\
\hline Study Case 1 & 22,443 & 2,803 & 8.01 \\
\hline Study Case 2 & 22,694 & 2,477 & 9.16 \\
\hline Alternative A & 28,048 & 3,100 & 9.05 \\
\hline Alternative B & 21,100 & 2,803 & 7.53 \\
\hline & 22,591 & 2,803 & 8.06 \\
\hline Reference & $5 m 11$ & & 12.05 \\
\hline Study Case 3 & 6,754 & 561 & 27.72 \\
\hline Study Case 4 & 8,950 & 323 & 18.56 \\
\hline Study Case 5 & 9,732 & 524 & 16.46 \\
\hline Study Case 6 & 9,923 & 603 & 17.91 \\
\hline Alternative C & 9,143 & 511 & 12.68 \\
\hline Alternative D & 7,108 & 561 & 11.08 \\
\hline
\end{tabular}


Table 84 Unit Cost of Steam Without Income Tax Effect

\begin{tabular}{|l|l|}
\hline \multicolumn{1}{|c|}{ Case } & \multicolumn{1}{|c|}{$\begin{array}{l}\text { Levelized Cost of } \\
\text { Steam }(\mathrm{S} / 1000 \mathrm{Ob})\end{array}$} \\
\hline \multicolumn{2}{|c|}{ Large } \\
\hline Refereñce & 8.01 (unchanged) \\
\hline Study Case 1 & 7.94 \\
\hline Study Case 2 & 9.22 \\
\hline Alternative A & 6.87 \\
\hline Alternative B & 7.99 \\
\hline & Smal1 \\
\hline Reference & 12.05 (unchanged) \\
\hline Study Case 3 & 28.13 \\
\hline Study Case 4 & 19.25 \\
\hline Study Case 5 & 17.41 \\
\hline Study Case 6 & 18.68 \\
\hline Alternative C & 12.42 \\
\hline Alternative D & 10.27 \\
\hline
\end{tabular}




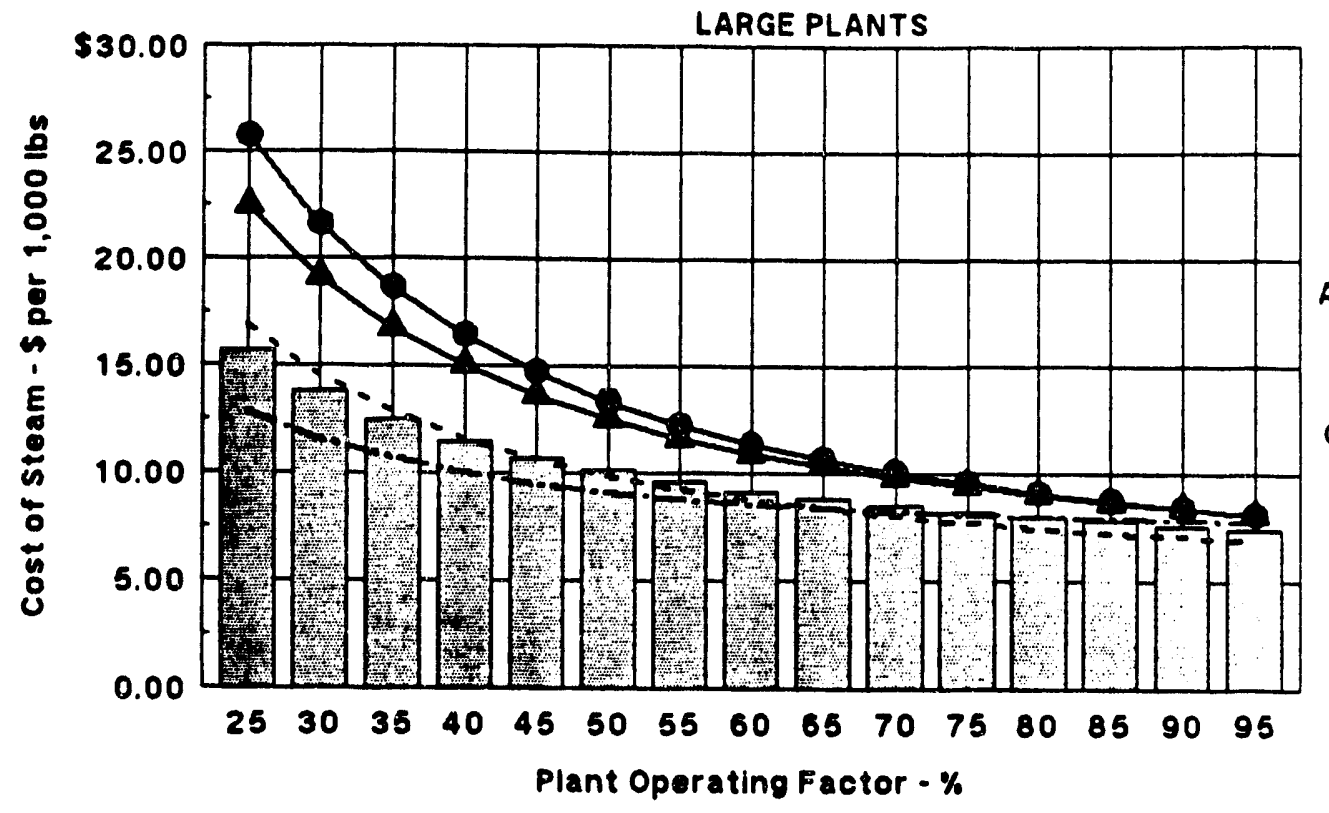

Study Case 1

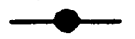

study Case 2

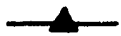

Alternative A

AFBC Cogeneration

-....

Alternative B Gas Turbine Cogen -....

Reference Case AFBC Boiler Only
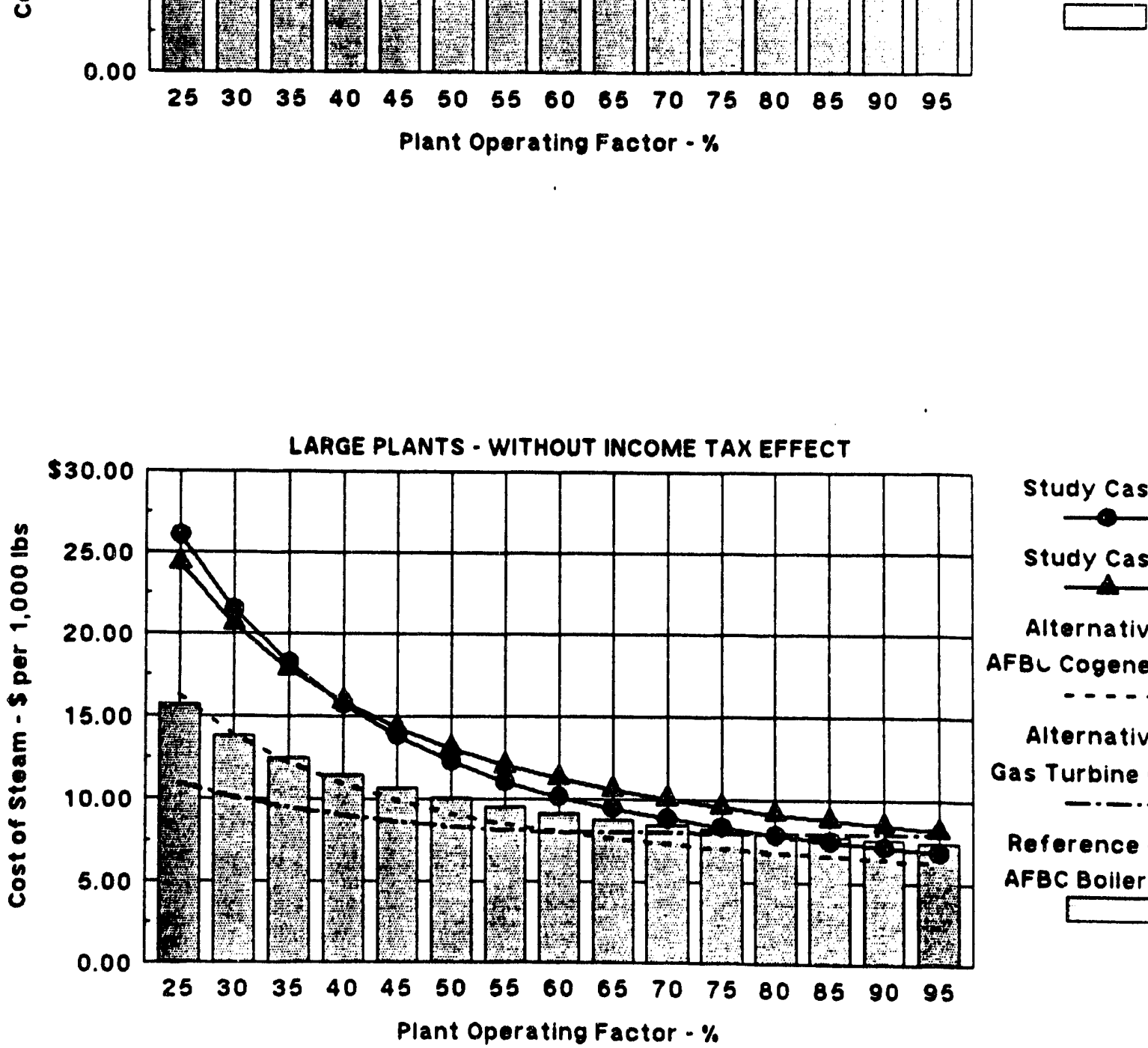

Study Case 1

$\longrightarrow$

Study Case 2

$\longrightarrow$

Alternative A

AFBL Cogeneration

.....

Alternative $B$

Gas Turbine Cogen

-.....

Reference Case

AFBC Boiler Only

Figure 70 Cost of Steam From Alternative Sources at Various Plant Operating Factors--Large Plants 


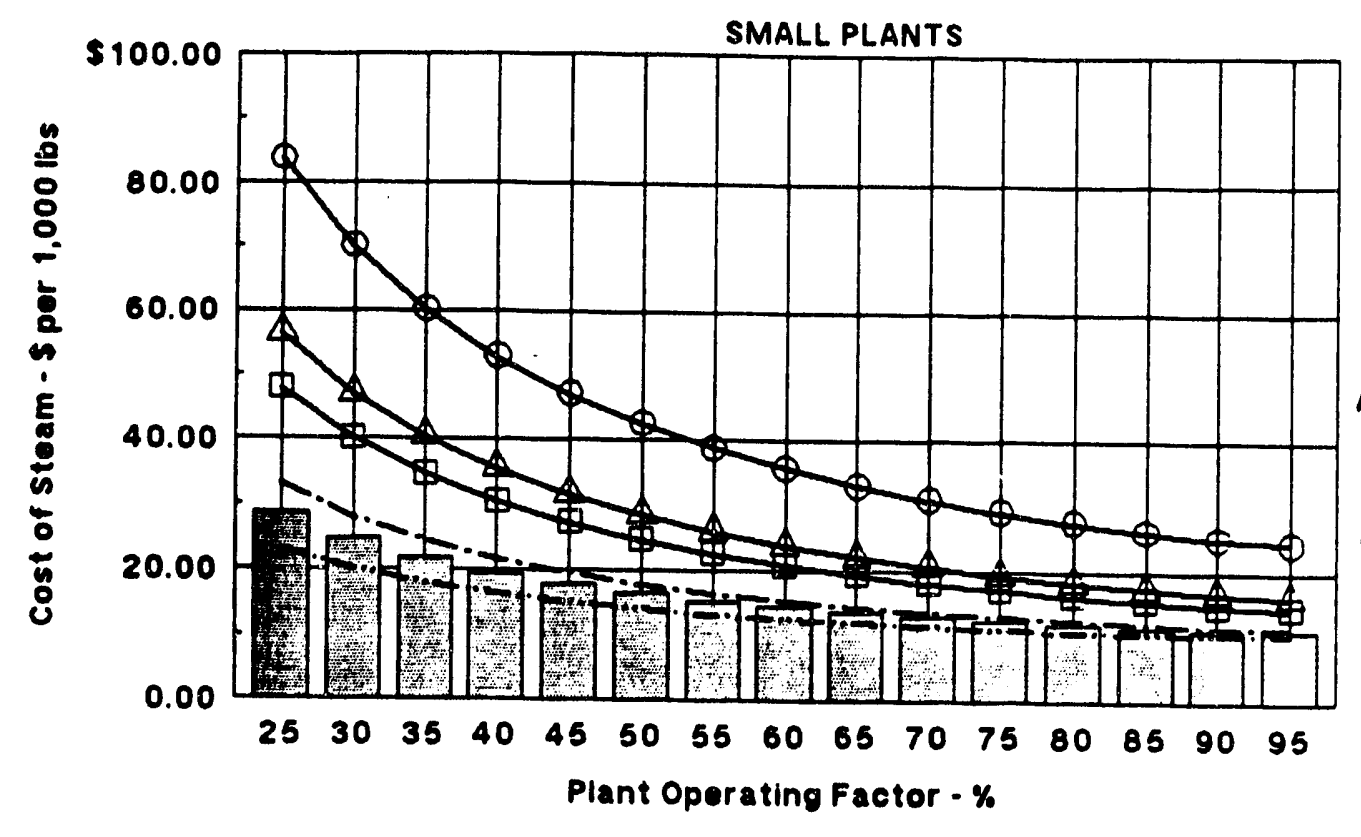

Study Case 3

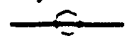

Study Case 4

$\hat{\imath}$

Study Case 5

$\square$

Alternative $C$ AFBC Cogeneration

-.-..

Alternative $D$ Gas Turbine Cogen $-\cdots-\cdots$

Reference Case AFBC Boiler Only
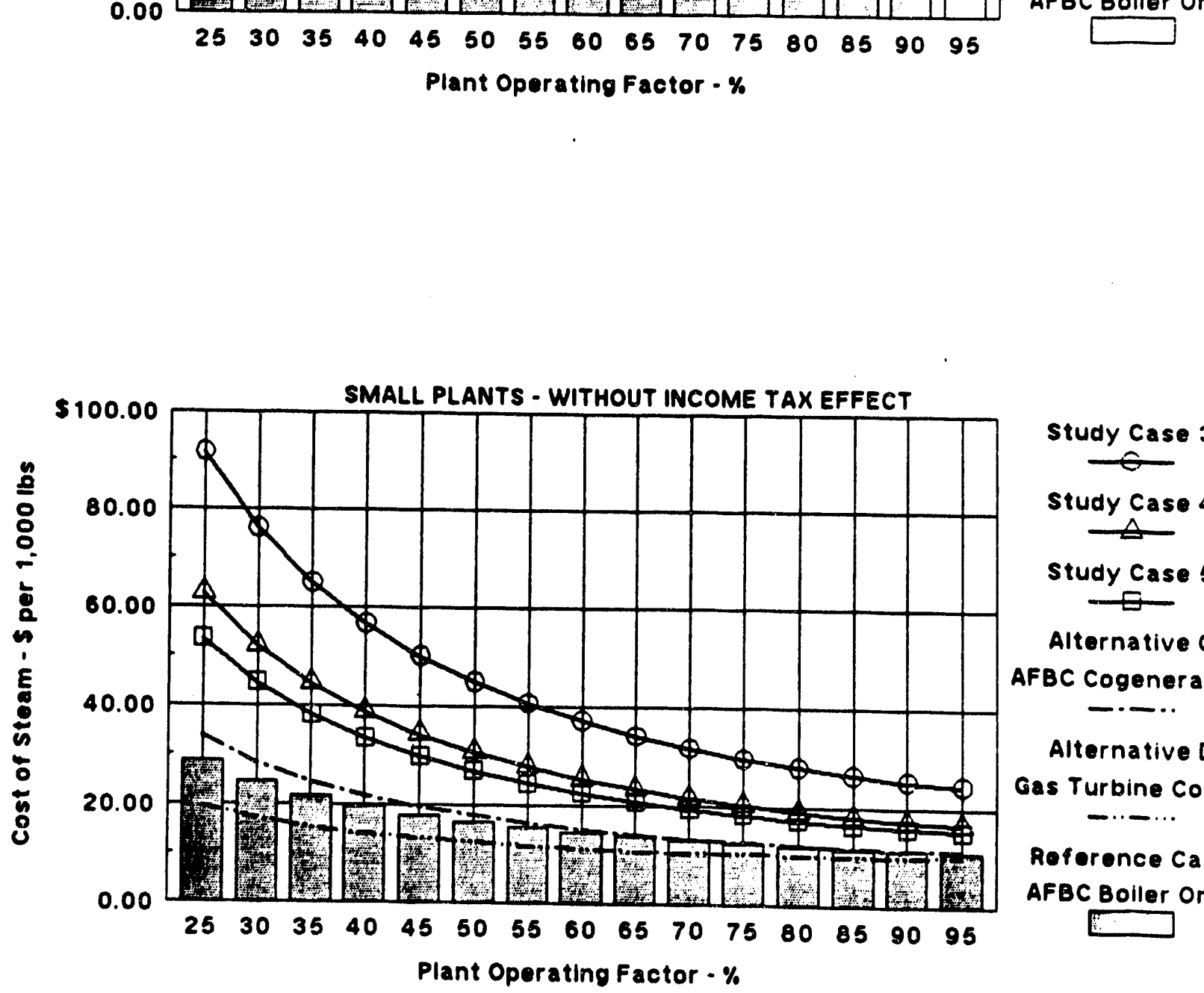

Study Case 3 द्रि

Study Case 4 $\triangle$

Study Case 5 $\square$

Alternative C AFBC Cogeneration -....

Alternative $D$ Gas Turbine Cogen $-\cdots-\cdots$

Reforence Case AFBC Boller Only

Figure 71 Cost of Steam From Alternative Sources at Various Plant Operating
Factors--Small Plants 
A third sensitivity analysis deals with the effect of alternative purchased power cost levels. As indicated, basic analyses have been performed by applying the actual relevant rate tariff for a randomly selected ohio Valley utility. To establish whether study cases might appear more promising in jurisdictions with higher purchased power cost levels, alternative analyses were performed utilizing the rate structures applicable for two other electric utilities within the same general geographic region. These alternative analyses were completed for the large cases only, since those study case results were much closer to their alternatives in the base study and because the substantially larger electrical requirements provide a much greater opportunity for purchased power cost levels to affect the results of the analysis.

Comparative results are summarized in Table 85 and are shown graphically in Figure 72 by plotting the cost of steam for each analys is case at the respective average reference purchased power cost level. Linear representations are linear regressions of the three-point determinations. In each instance, results are developed:

- Under the base conditions indicated

- Without the income tax effect

- Excluding standby (firm backup) power charges

- Excluding both income tax effects and standby charges.

As the data show, variations in the assumed cost of purchased power affect the study, reference, and alternative cases in substantially different ways. Since all electrical power is purchased in the reference case, the cost and value of electricity is (except for plant auxiliary use) a direct offset at any purchased power cost level, and the cost of steam is only minimally affected by variations in that parameter. However, as the cost of purchased power increases, the value (avoided cost) of electricity produced increases proportionately, causing a reduction in the residual cost of steam in all other cases--most dramatically in those cases with the greatest levels of electrical output.

As a result, at higher purchased power cost levels, Study Case 1 steam cost drops below that for Study Case 2, but both remain higher than all alternatives under base conditions. In the absence of income taxes, Case 1 costs are below Reference Case costs at all Purchased Power cost levels. Where both income taxes and standby charges are eliminated, Case 1 becomes the least-cost option when the highest of the three purchased power cost structures is applied, since standby charges are the only external power costs associated with Case 1 . Case 2 remains the highest-cost option under all conditions.

The effect of variations in the price of coal is explored for all coal-fired cases in Figures 73 and 74 . As these data show, coal cost variances have virtually no effect on related rankings.

Finally, the capital costs for Study Cases 1 and 2 would have to be reduced by approximately 20 and 26 percent respectively to yield steam costs comparable to the reference case--with all other factors remaining unchanged. Further reductions of 8 to 9 percent would be required to compete with Alternative $A$. In the smaller sizes, only at capital costs approximately 60 percent lower for Study Case 4,50 percent lower for Study Case 5, and 66 percent lower for Study Case 6 are they competitive with that reference case. In each 


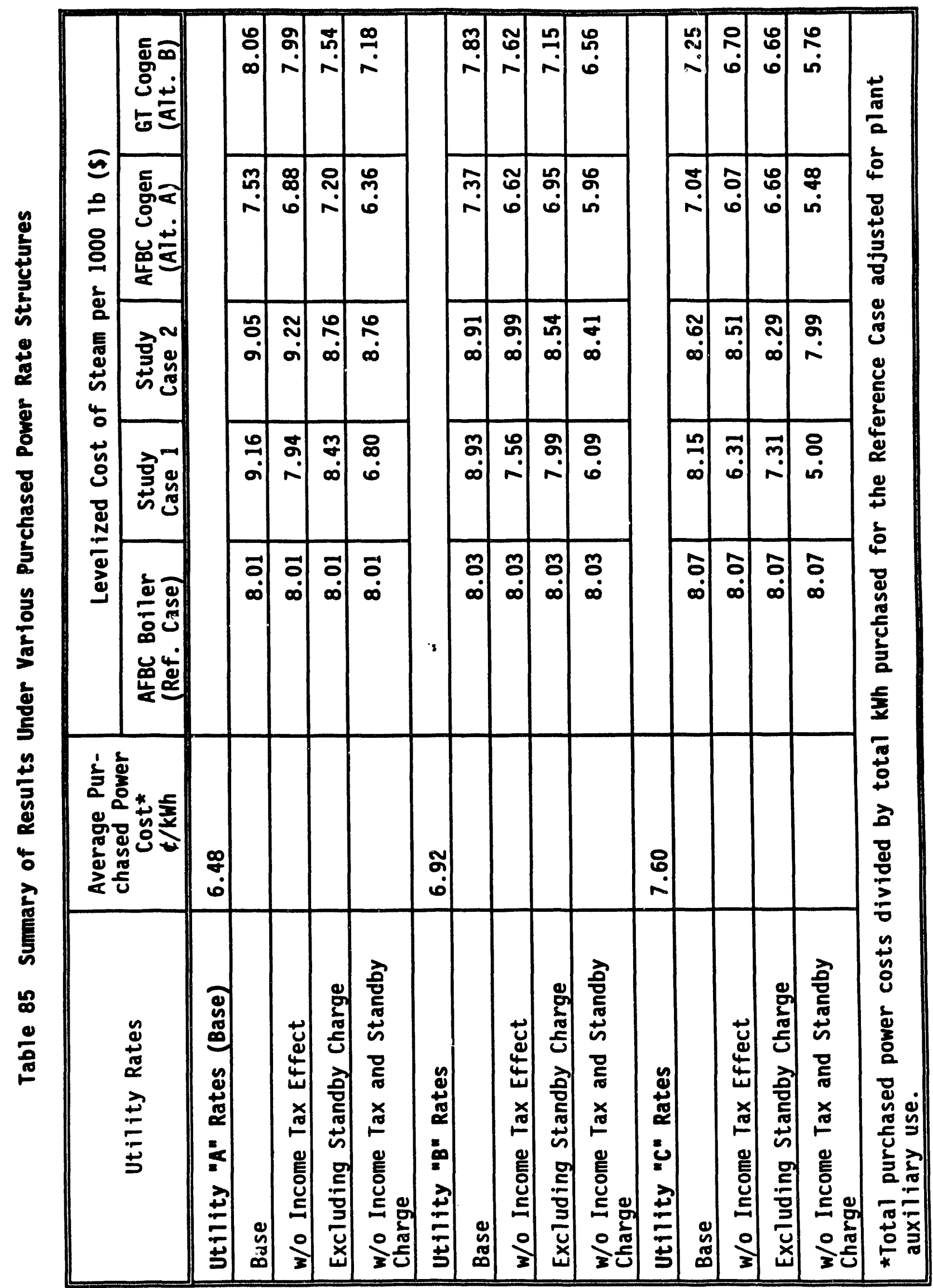



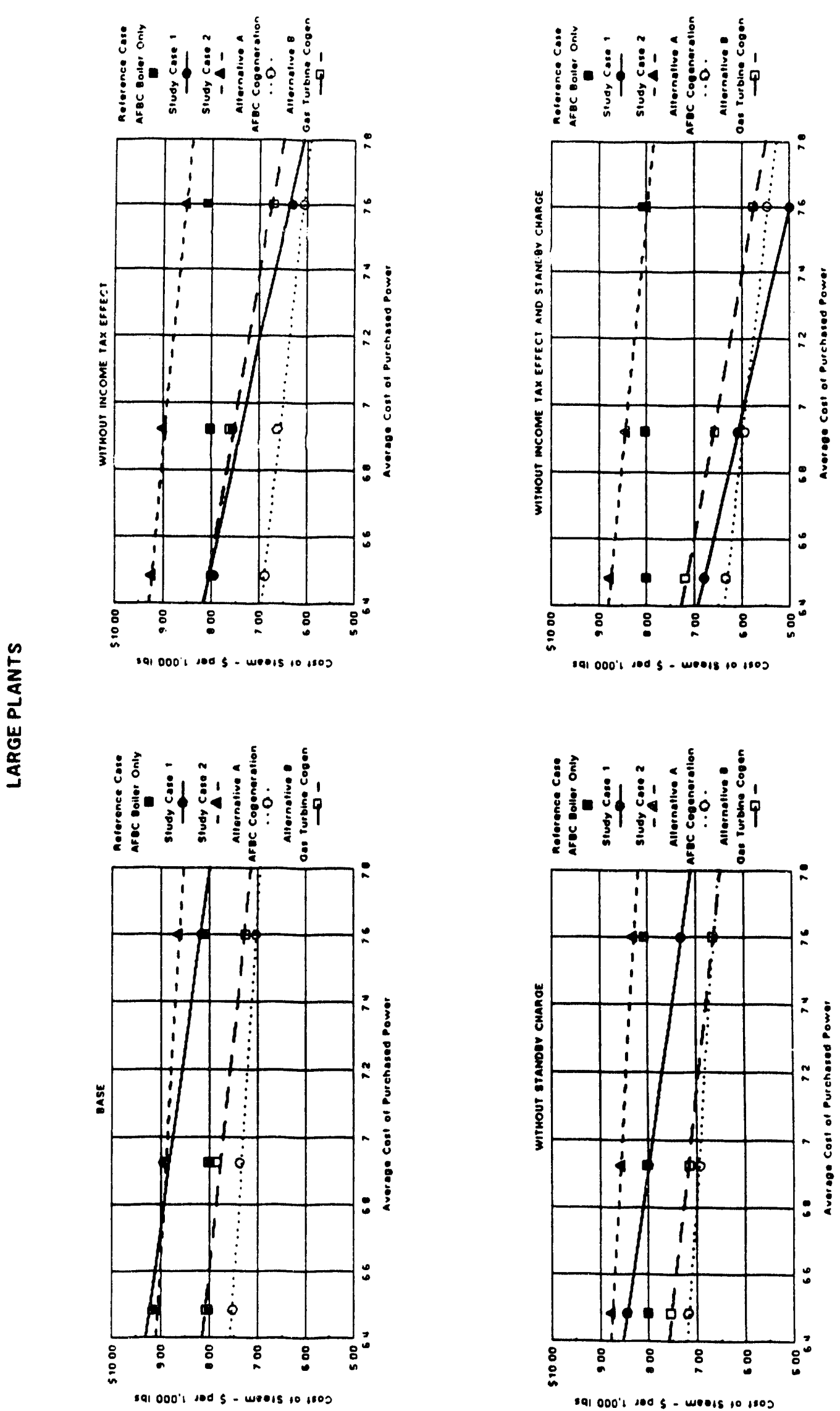

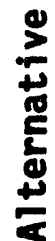

ญ

$\frac{5}{8}$

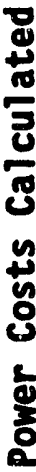

0
0
0
$\frac{0}{2}$
2

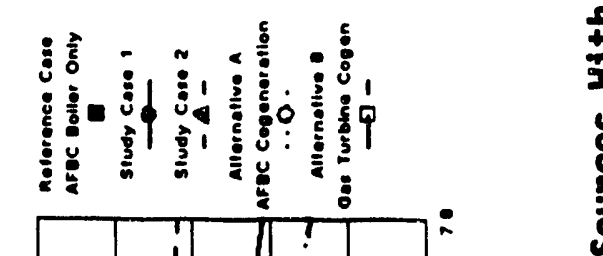

$\pm$

y

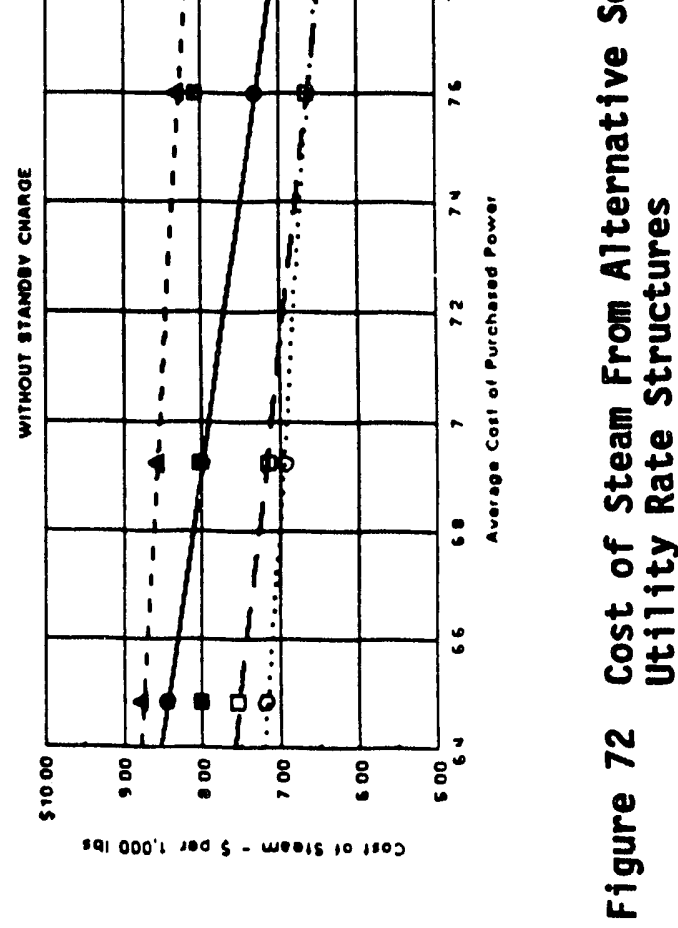




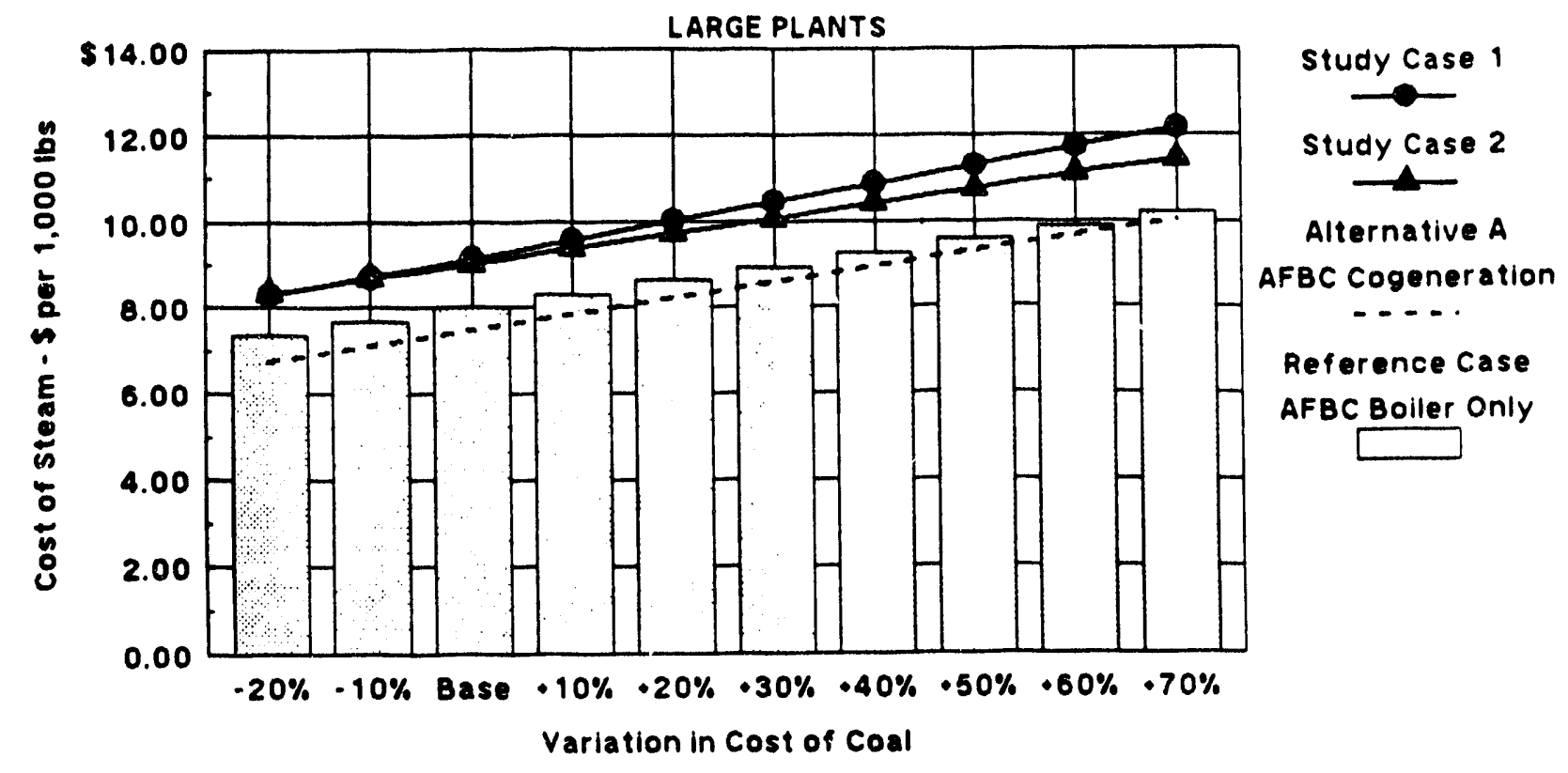

Plant Operating Factor at $80 \%$ for all Cases.

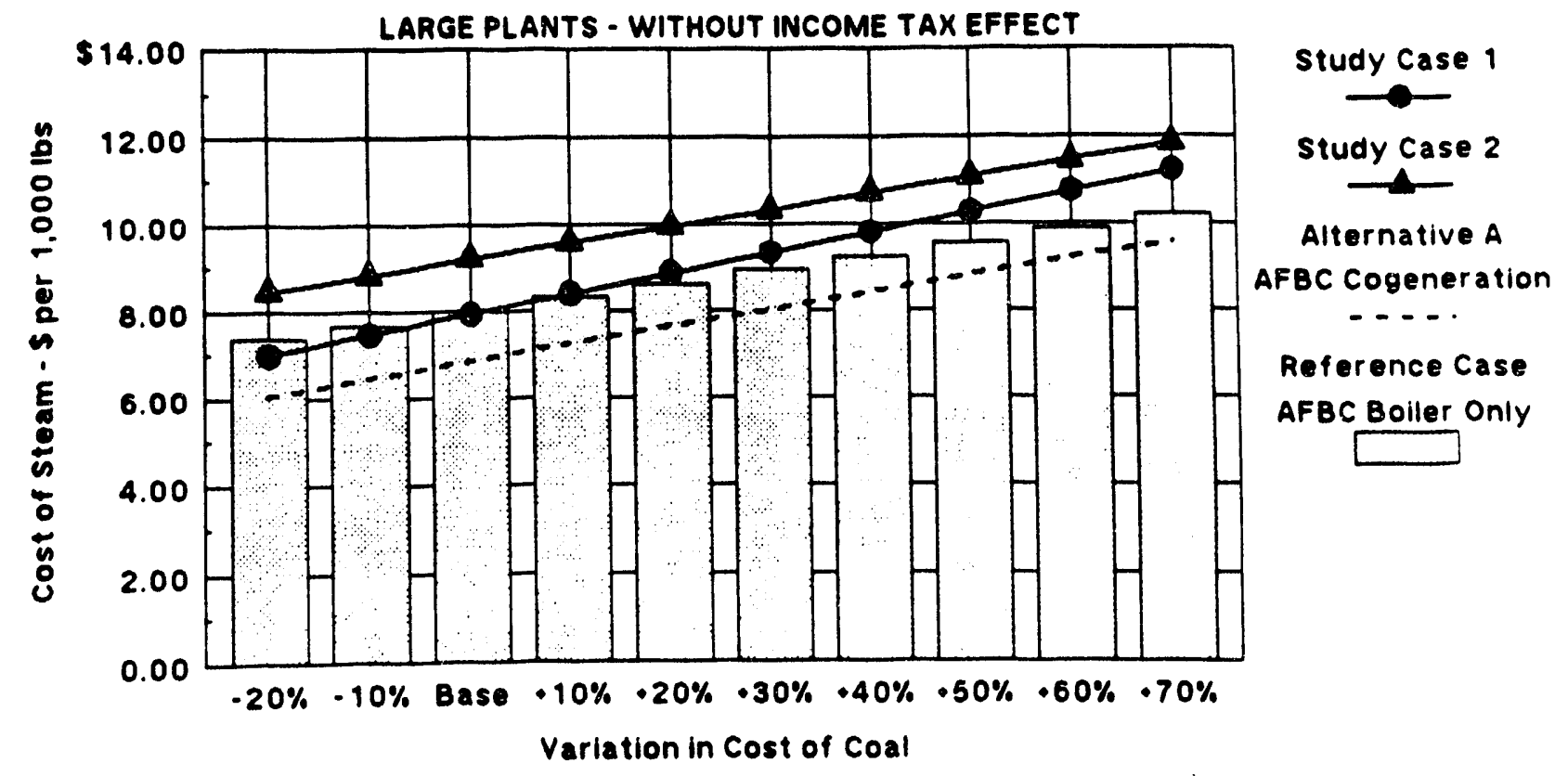

Figure 73 Cost of Steam From Alternative Sources at Various Coal Cost Levels--Large Plants 


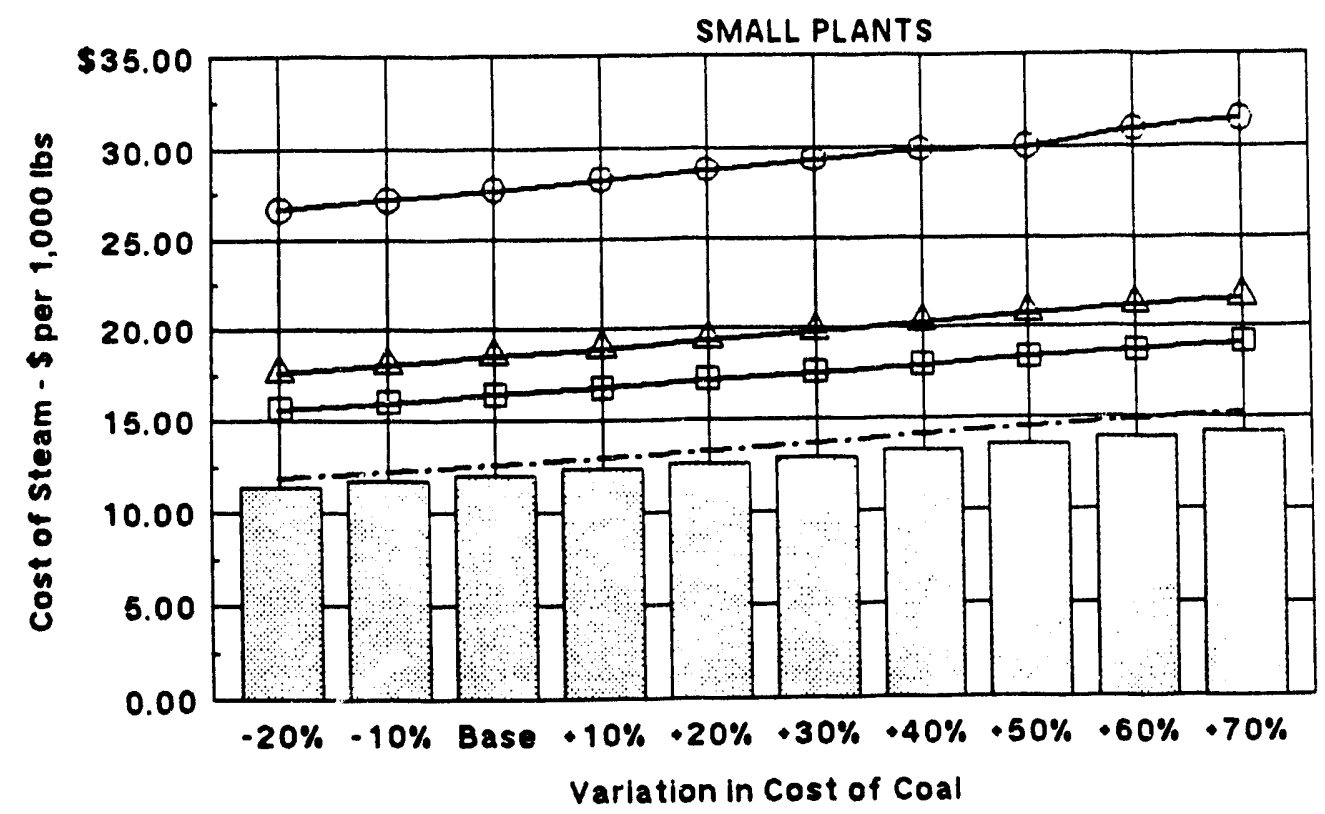

Study Case 3

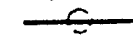

Study Case 4

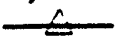

Study Case 5

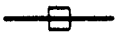

Alternative $\mathrm{C}$ AFBC Cogeneration

-. - .

Reference Case

AFBC Boiler Only

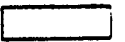

Plant Operating Factor at $80 \%$ for all Cases.

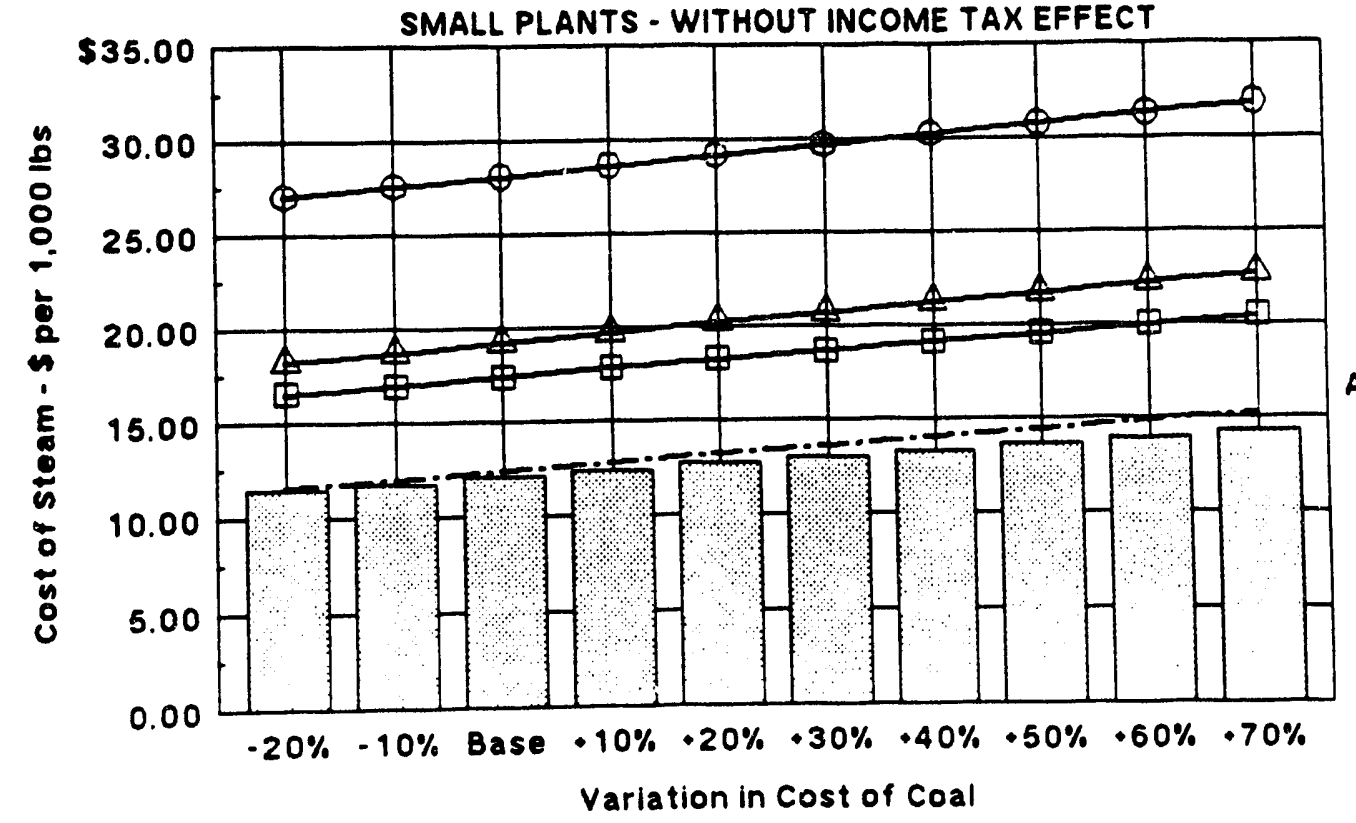

Study Case 3

-

Study Case 4

$\hat{A}$

Study Case 5 ?

Alternative $\mathrm{C}$ AFBC Cogeneration

-.-.

Reference Case

AFBC Boiler Only

Plant Operating Factor at $80 \%$ for all Cases.

Figure 74 Cost of Steam From Alternative Sources at Various Coal cost Levels--Smal1 Plants 
case, the necessary reduction in cost is greater than the entire cost of the Hot Gas Clean-Up (HGCU) System and related piping--the single largest component of estimated study case costs. Case 3 produces much less steam than the other small cases; its capital cost would have to be virtually eliminated for it to compete. Required capital cost reductions under base case conditions are summarized in Table 86.

Table 86 Capital Cost Reductions Required To Achieve Equivalent Steam Costs (\%)

\begin{tabular}{||c|c|c|c||}
\hline \multirow{2}{*}{$\begin{array}{c}\text { Study } \\
\text { Case }\end{array}$} & $\begin{array}{c}\text { Reference } \\
\text { Case }\end{array}$ & \multicolumn{2}{|c|}{ Cogeneration } \\
\cline { 3 - 4 } & AFBC & Gas \\
\hline Case 1 & 20 & 28 & 19 \\
\hline Case 2 & 26 & 37 & 24 \\
\hline Case 3 & N/A & 97 & N/A \\
\hline Case 4 & 60 & 54 & 69 \\
\hline Case 5 & 50 & 43 & 61 \\
\hline Case 6 & 66 & 59 & 78 \\
\hline
\end{tabular}


The research and development needs for the utility size second-generation PFBC plant were identified [1]. Ranked and tabulated in Table 87, they address basic process unknowns and areas of the mechanical design that need to be proved. A research program to investigate each of these areas at pilot plant scale is currently in progress as part of DOE Contract DE-AC21-86MC21023. Phase 2 of this project consists of separate testing of the topping combustor, carbonizer with HGCU (cross-flow filter) equipment, and CPFBC with HGCU equipment. These Phase 2 tests will provide information on the operation and performance of each of these systems. Process information, such as the composition of the various flow streams, will also be determined.

Following the Phase 2 test program, the pilot plant will be modified to test an integrated carbonizer/CPFBC system. This part of the program is designated Phase $3 A$. It will demonstrate the transfer of hot solids from the carbonizer to the CPFBC and provide information on the operating and load-following characteristics of the integrated system.

The research and development needs for utility-size plants also apply to the industrial-size plants, and the planned research is sufficient to ensure the technical success of an industrial-size second-generation PFBC plant. However, there are some additional concerns and some differences in emphasis that would apply to the industrial market. These issues primarily affect cost and operation. For example:

- Industrial users would be less likely than utilities to have long-term fuel contracts; therefore, the effects of coal variation on plant operation are important and would require research beyond that currently planned in this area.

- The smailer plants in the present study were designed with bubbling bed PFB combustors instead of the circulating beds used in the larger plants and in the utility study. This choice was made to lower costs and reduce plant height requirements. Research would be desirable to determine certain design parameters for a char-fired bubbling bed. The parameters would include the number of feed points and the bed geometry required for complete combustion of the char.

- Slurry feed systems for the coal and sorbent have the potential for reducing capital and operating costs. Although the feasibility of feeding coal and sorbent to a PFB combustor has been demonstrated, long-term reliability of this feeding method needs demonstration.

- Turndown in industrial plants has an added dimension over utility plants in that demand varies for both electricity and process steam. The investigation of various turndown schemes would be of interest to industrial users. The process parameters for different modes of operation would have to be determined, and the practical range of operation of the different system components and the system as a whole would also have to be determined. This work would probably best be accomplished with a comprehensive computer model of the system that would include important operating characteristics of the various components. 


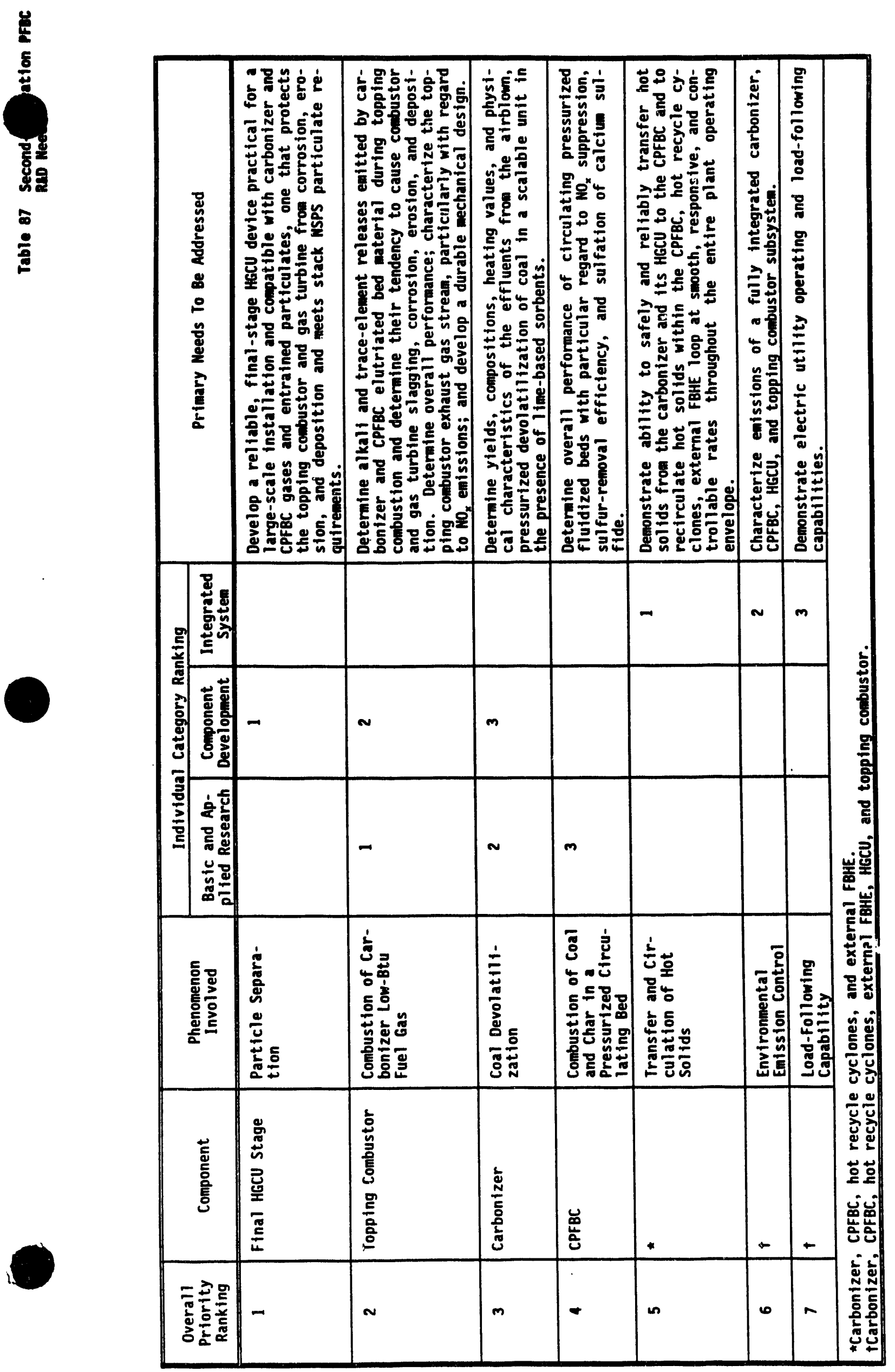


Even if they were not critical to the design of an industrial system, research in these areas would probably be required to gain acceptance from potential users.

\section{REFERENCES}

1. Robertson, et a1., "Second-Generation Pressurized Fluidized Bed Combustion Plant Research and Development Needs," Phase 1 Task 2 report to the DOE (Contract DE-AC21-86MC21023), March 1989. 
The results of this study show that it is technically feasible to incorporate a second-generation PFB combustion system into a cogeneration plant as small as 7 MWe. The process of conceptually designing the various plant arrangements did not reveal any major technological gaps that are not being addressed in the current second-generation PFBC research program. In fact, the process of choosing the plant parameters and designing the plants in the study brought to light how much flexibility the second-generation system has in terms of plant equipment design and the range of outputs that can be achieved.

The industrial market is quite diverse in its needs, and the second-generation PFB combustion system can be configured to cover a wide range of industrial requirements. It can be designed to operate with higher electric-to-thermal output ratios than conventional coal-fired cogeneration systems. The secondgeneration systems also have a greater capability for shifting the plant output between steam duty and gas turbine duty. This inherent flexibility will be of great benefit in industrial applications where the electric power and steam needs can be quite variable.

The multiple needs of the industrial market also affect the economic evaluation of the process. Diverse industries in different locations will have varied costs and output requirements, and these differences will affect the economics for the particular user. To design and evaluate plants in a wide variety of industries and locations was impossible within the scope of this study. Instead, "generic" industrial plants were assumed. These plants were assumed to have the facilities and requirements that are most often found in industrial plants. The operating and maintenance costs were for a plant in Ohio or the surrounding states.

The results for the base-case assumptions of this study were summarized in Table 82. As the table shows, the lowest cost of steam in the nominal $400,000 \mathrm{lb} / \mathrm{h}$ category is the AFBC cogeneration plant. In the nominal $80,000 \mathrm{lb} / \mathrm{h}$ category, the lowest cost of steam would be supplied by a naturalgas-fired gas turbine cogeneration plant. Although the second-generation PFB combustion plants do not have the lowest cost of steam under the base-case assumptions, they are close for the nominal $400,000 \mathrm{lb} / \mathrm{h}$ steam flow plants.

Capital costs for these second-generation plants are higher than for the comparison conventional cogeneration systems; however, the operating costs are lower in all but one of the second-generation cases. The main reason for the lower operating costs with second-generation systems is that the increased electrical output reduces the purchased power costs. Major factors in the economic comparisons of the second-generation PFB combustion cases and the conventional cogeneration cases are, therefore, plant capital costs, the rate structure of the local utility, and the income tax effects of capital vs. operating costs.

The income tax effect is a combination of the relative effects of interest charges, capital equipment depreciation, and increased profits as a result of lower operating costs. Since a corporation pays taxes on its total operations, the income tax effect would depend on the situation in a particular company. For this reason the economic analysis was also done without considering taxes, and these results are shown in the last column of Table 82 as the 
cost per pound of steam without income tax effect. This type of analysis lowers the steam cost for the large second-generation PFB combustion plants, but increases the steam cost for the small plants.

The effect of the purchased cost of electricity on the steam cost is shown in Table 83 for the large plants. The three electric rates shown are the average electric rates based on the rate structures of three major utilities in the Ohio area. As the table shows, increases in electric rate improve the relationship position of the second-generation PFB combustion plants. At the $7.60 \$ / k W h$ rate, the Case 1 second-generation plant has the lowest cost of steam if the income tax effect and any possible standby charges from the electric utility are excluded. There are many areas of the country where electric rates are higher and the relative economic position of the second-generation PFB combustion plants would be improved.

of course, any reductions in second-generation PFB combustion plant capital costs would improve the economics relative to the conventional cogeneration plants. A decrease in capital cost of approximately 20 percent would bring the cost of steam for the Case 1 plant down to the levels of the comparison plants under the base-case assumptions. Although the second-generation plant capital costs were estimated for an $n^{\text {th }}$ plant, there were contingencies placed on the costs in certain areas. Capital cost estimates could probably be lowered as research is done to advance the technology. Also, the relative economic position of the second-generation plants would improve for larger plants. As plant size increases, the capital costs al so increase--but not as much as the output of electricity and steam. This effect will work in favor of the second-generation plants because the capital cost of systems such as coal handling and slurry feeding drop on a pound-of-coal basis.

In general, this study indicates that at 7 Me the plant designs in this study do not look economically attractive. Uniess a way is found to simplify the equipment at this small scale, it does not appear that these small plants will be viable. A 4l-MWe cogeneration plant is a borderline size for the viability of second-generation plants. Depending on the specific costs and requirements of the user, it may or may not be the best option. At larger sizes the conditions under which the second-generation PFB combustion would be preferred would be more numerous. 


\section{Appendix A}

\section{EMISSIONS}

The expected emissions of a various components of a second-generation plant are discussed in the Phase 1 report [1]. The actual emissions characteristics of the carbonizer, CPFBC, and topping combustor are being determined in the Phase 2 test program. The emissions from these components should be similar for the utility-size plants and the industrial-size plants; however, differences in the split of the flow streams between the system components require some adjustment in overall plant emissions. These differences exist between the industrial plant system arrangements and between the industrial and utility plants as well.

\section{A.1 SULFUR}

Estimates of sulfur-removal efficiency (SRE) for similar carbonizer and CPFBC conditions in the Phase 1 study were 84 and 94 percent respectively. These efficiencies are based on a $\mathrm{Ca} / \mathrm{S}$ ratio of 1.75 . Under the utility plant arrangement, these efficiencies resulted in an overall plant SRE of 90 percent. Based on the Phase 1 carbonizer and CPFBC efficiencies, the overall industrial plant SREs are listed in Table A.1, along with the sulfur emissions (in $1 \mathrm{~b} / 10^{\circ} \mathrm{Btu}$ ).

With the Phase 1 removal estimates, Cases 1 and 2 have a better overall plant SRE than in the utility plant because some coal is fired in the CPFBC, where sulfur capture is better. The overall plant SRE for Cases 3, 4, and 5 is slightly lower than in the utility plant because of differences in the cycle conditions. Case 6 has the best SRE because there is no carbonizer. Under these assumed conditions, Cases 3, 4, and 5 have SREs of 89.2 percent, slightly below the target efficiency of 90 percent. This small difference could be eliminated with a change in the $\mathrm{Ca} / \mathrm{S}$ ratio.

Table A.l Plant Sulfur Emissions*

\begin{tabular}{|c|c|c|}
\hline Case & Plant SRE (\%) & $\begin{array}{c}\text { SuIfur Emissions } \\
\left(1 \mathrm{~b} / 10^{\circ} \text { Btu }\right)\end{array}$ \\
\hline 1 & 92.6 & 0.17 \\
\hline 2 & 92.6 & 0.17 \\
\hline 3 & 89.2 & 0.25 \\
\hline 4 & 89.2 & 0.25 \\
\hline 5 & 89.2 & 0.25 \\
\hline 6 & 94.0 & 0.08 \\
\hline $\begin{array}{c}\text { *Based on a carbonizer SRE of } 84 \text { per- } \\
\text { cent and a PFBC efficiency of } 94 \text { per- } \\
\text { cent of sulfur released. }\end{array}$ \\
\hline
\end{tabular}




\section{A.2 $\mathrm{NO}_{\mathrm{x}}$}

Equations have been developed for the estimation of the $\mathrm{NO}_{\mathrm{x}}$ produced in fluidized bed combustors [1]. These equations are based on correlation of available data from bubbling bed AFB and PFB combustors and from atmospheric circulating bed combustors.

Cases 1 and 2 have staged combustion in the CPFBC. The lower portion of the bed would be run at conditions of 50 to 70 percent of stoichiometry. With this type of operation, the following equation is proposed:

$$
N O_{x}(\mathrm{ppm})=\left[(6.40)\left(10^{-2}\right) \exp \left[\frac{9604}{T+406}\right)\right]\left(\mathrm{Fs}^{0.79}\right)\left(U^{0.72}\right)\left(\mathrm{Xn}^{0.05}\right)\left(\mathrm{Hb}^{-0.38}\right)\left(Y_{s 0_{2}}{ }^{-0.18}\right)
$$

where:

$T$ = Temperature (1339 to $1690^{\circ} \mathrm{F}$ )

$U=$ Superficial gas velocity $(3$ to $20 \mathrm{ft} / \mathrm{s}$ )

$\mathrm{Hb}=$ Expanded bed depth $(2.7 \mathrm{to} 20 \mathrm{ft})$

$\mathrm{Y}_{\mathrm{SO}_{2}}=\mathrm{SO}_{2}$ content $[19$ to $845 \mathrm{ppm}(v)]$

$X_{n}=$ Fuel nitrogen content (1 to 1.9 wt\%)

Fs = Staged combustion factor (45- to 100-percent stoichiometric)

Cases 3, 4, 5, and 6 use bubbling bed combustors. In these combustors, the combustion wili not be staged. The following equation applies to these conditions:

$$
N O_{x}=\left[2.25 \exp \left[\frac{5088}{T+460}\right)\right]\left(Y_{O_{2}}^{0.24}\right)\left(X n^{0.44}\right)\left(Y_{s O_{2}}{ }^{-0.1}\right)
$$

where:

$$
\begin{aligned}
\mathrm{T} & \left.=\text { Temperature (1339 to } 1690^{\circ} \mathrm{F}\right) \\
\mathrm{Y}_{\mathrm{O}_{2}} & =\text { Oxygen content }(2.5 \text { to } 11.4 \text { vol\%) } \\
\mathrm{Y}_{\mathrm{SO}_{2}} & =\mathrm{SO}_{2} \text { content }[19 \text { to } 845 \mathrm{ppm}(\mathrm{V})] \\
\mathrm{X}_{\mathrm{n}} & =\text { Fuel nitrogen content ( } 1 \text { to } 1.9 \mathrm{wt \%})
\end{aligned}
$$

The resultant $\mathrm{NO}_{\mathrm{x}}$ emissions from the study case PFB combustors are listed in Table A.2 on a basis of $1 \mathrm{~b} / 10^{6}$ Btu of plant heat input. 
Table A.2 PFB Combustor $\mathrm{NO}_{\mathrm{x}}$ Emissions

\begin{tabular}{|c|c|c|c|}
\hline Case & $\begin{array}{c}\text { Type of } \\
\text { Bed }\end{array}$ & $\begin{array}{c}\text { Combustor } \\
\text { Fuel }\end{array}$ & $\begin{array}{c}\text { NO } \\
\left(1 \mathrm{~b} / 10^{6} \text { Btu }\right)\end{array}$ \\
\hline 1 & CPFB & Coal/Char & 0.16 \\
\hline 2 & CPFB & Coal/Char & 0.16 \\
\hline 3 & PFB & Char & $\star$ \\
\hline 4 & PFB & Char & 0.08 \\
\hline 5 & PFB & Char & 0.08 \\
\hline 6 & PFB & Coal & 0.14 \\
\hline $\begin{array}{c}\text { *0utside range of correlation because of high } \\
\text { excess-air level. }\end{array}$ \\
\hline
\end{tabular}

Another source of $\mathrm{NO}_{\mathrm{x}}$ from the plant is the topping combustor. The Allison topping combustor used in Cases $3,4,5$, and 6 is expected to have $\mathrm{NO}_{\mathrm{x}}$ emissions of $40 \mathrm{ppm}(v)$ for Cases 3,4 , and 5 and $15 \mathrm{ppm}(v)$ for Case 6.

Cases 1 and 2 use a Westinghouse topping combustor with anticipated $\mathrm{NO}_{\mathrm{x}}$ emissions of $50 \mathrm{ppm}(\mathrm{v})$. Table A.3 lists the topping combustor $\mathrm{NO}_{\mathrm{x}}$ emissions on a $1 \mathrm{~b} / 10^{\circ}$ Btu basis for each case study plant.

Table A.3 Topping Combustor $\mathrm{NO}_{\mathrm{x}}$ Enissions

\begin{tabular}{|c|c|}
\hline Case & $\begin{array}{c}\mathrm{NO}_{\mathrm{x}} \text { Emissions } \\
\left(1 \mathrm{~b} / 10^{\circ} \mathrm{Btu}\right)\end{array}$ \\
\hline 1 & 0.06 \\
\hline 2 & 0.06 \\
\hline 3 & 0.11 \\
\hline 4 & 0.10 \\
\hline 5 & 0.10 \\
\hline 6 & 0.04 \\
\hline
\end{tabular}

The barrier filters used to clean the fuel gas and flue gas streams are 99.99 percent efficient. Particulate emissions for all of the plant arrangements are less than $0.00041 \mathrm{~b} / 10^{\circ}$ Btu--well below NSPS levels.

\section{A.3 REFERENCES}

1. A. Robertson, et a1., "Second-Generation Pressurized Fluidized Bed Combustion Plant-Conceptual Design and Optimization of a Second-Generation PFB Combustion Plant," Plase 1 Report, Appendix C, to the Department of Energy under Contract DE-AC21-86MC21023, September 1989. 

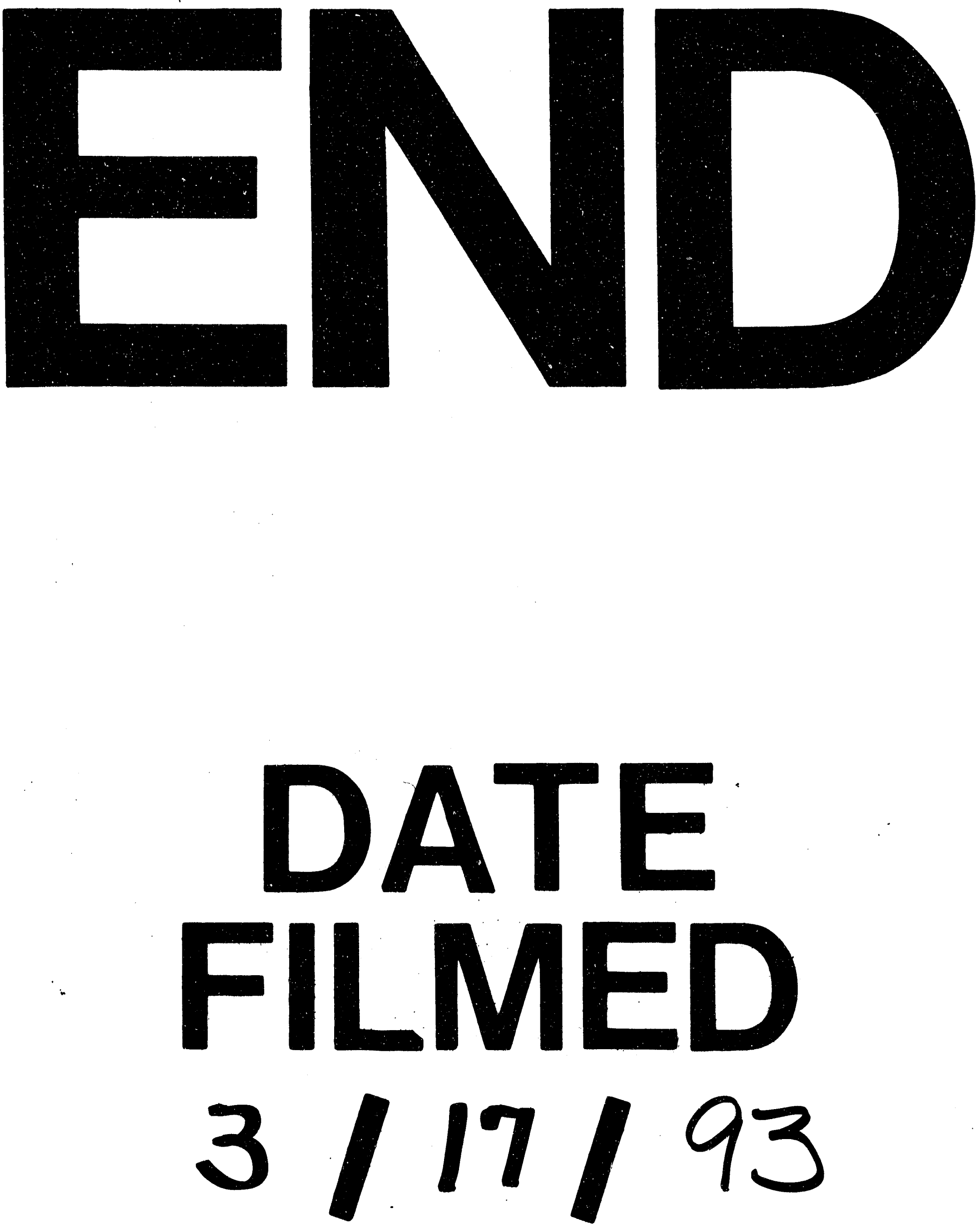

I 
